\title{
Bioactive Compounds from Marine Heterobranchs
}

\author{
Conxita Avila 1,*(i) and Carlos Angulo-Preckler 1,2 (-) \\ 1 Department of Evolutionary Biology, Ecology, Environmental Sciences, \\ and Biodiversity Research Institute (IrBIO), Faculty of Biology, University of Barcelona, Av. Diagonal 643, \\ 08028 Barcelona, Catalonia, Spain; carlos.a.preckler@uit.no \\ 2 Norwegian College of Fishery Science, UiT The Arctic University of Norway, Hansine Hansens veg 18, \\ 9019 Tromsø, Norway \\ * Correspondence: conxita.avila@ub.edu
}

Received: 21 November 2020; Accepted: 7 December 2020; Published: 21 December 2020

check for updates

\begin{abstract}
The natural products of heterobranch molluscs display a huge variability both in structure and in their bioactivity. Despite the considerable lack of information, it can be observed from the recent literature that this group of animals possesses an astonishing arsenal of molecules from different origins that provide the molluscs with potent chemicals that are ecologically and pharmacologically relevant. In this review, we analyze the bioactivity of more than 450 compounds from ca. 400 species of heterobranch molluscs that are useful for the snails to protect themselves in different ways and/or that may be useful to us because of their pharmacological activities. Their ecological activities include predator avoidance, toxicity, antimicrobials, antifouling, trail-following and alarm pheromones, sunscreens and UV protection, tissue regeneration, and others. The most studied ecological activity is predation avoidance, followed by toxicity. Their pharmacological activities consist of cytotoxicity and antitumoral activity; antibiotic, antiparasitic, antiviral, and anti-inflammatory activity; and activity against neurodegenerative diseases and others. The most studied pharmacological activities are cytotoxicity and anticancer activities, followed by antibiotic activity. Overall, it can be observed that heterobranch molluscs are extremely interesting in regard to the study of marine natural products in terms of both chemical ecology and biotechnology studies, providing many leads for further detailed research in these fields in the near future.
\end{abstract}

Keywords: marine natural products; Mollusca; Gastropoda; chemical ecology

\section{Background}

Marine heterobranch molluscs are a well-known source of marine natural products (MNPs) that have been studied in depth over the years [1-3]. MNPs from heterobranchs show an amazing structural diversity and display a wide variety of biological activities, as reported in previous reviews [1-4]. In general, MNPs have been demonstrated to be crucial in many ecological interactions among marine organisms, regulating several aspects of reproduction, development, settlement, growth, defense, and others [2,5-7]. Some general reviews have reported a significant amount of detailed information on the structure of MNPs, marine chemical ecology, and marine chemistry, or have analyzed some particular mollusc compounds [4,8-18]. The yearly reports by Blunt and collaborators [5,6] have provided very accurate information on new marine natural products. Previous reviews have also dealt with the different chemical structures found in heterobranchs, the origin and anatomical allocation of their compounds, their biosynthesis, biogeography, and their evolutionary patterns [1,2,19-29]. Therefore, all of these topics will not be considered again here.

Furthermore, MNPs have been described to be potentially useful as drugs, and some of them are already available on the market [7,8,10,12,30-33]. Remarkably, many MNPs possess unique 
chemical structures that are totally absent in terrestrial or freshwater environments [32,34-37]. Five drugs, at least, have been isolated from marine invertebrates and are approved for different (mostly anticancer) purposes, including cytarabine (Ara-C), eribulin mesylate, ziconotide, brentuximab vedotin, and trabectedin, obtained from two sponges, two molluscs, and a tunicate, respectively [31,33,38]. These molecules include very different chemical structures, from nucleosides to peptides, alkaloids, macrolides, and antibody-drug conjugates (ADCs). Many other compounds are currently in phase III, phase II, and phase I clinical trials, including several heterobranch compounds, and could soon be on the market [31]. Moreover, many studies deal with MNPs bioactivity, mechanisms of action, virtual screening, synthesis, derivatives, ADMET (absorption, distribution, metabolism, excretion, and toxicity), and others in an attempt to increase the chances of finding new useful drugs [31-43]. Some databases are also very good tools to search the details of MNPs described to date, such as MarinLit (http://pubs.rsc.org/marinlit/). In cancer research, for example, NPs are considered very relevant as potential drug leads, and approximately $80 \%$ of the approved chemotherapeutic drugs and more than $50 \%$ of all drugs are based on bioactive natural products, while almost $90 \%$ of human diseases are treated with natural products or their derivatives [39-43]. Thus, many MNPs are being tested as antitumor agents because of their potent growth inhibition against human tumor cells, both in vitro and in vivo in murine models (and others), as well as in cancer clinical trials $[39,42,43]$.

In fact, marine organisms are still considered an underexplored source of NPs, displaying specific biological activities, with biomedically interesting applications to be potentially used as drugs $[2,5,6,8,10,29-31,44]$. Many compounds found in heterobranchs are also promising drugs and are being tested under clinical trials $[36,43,45,46]$. However, as far as we know, there has not yet been a comprehensive published review on the bioactivity of MNPs from heterobranch molluscs, despite the fact that this is one of the most chemodiverse invertebrate groups [2,4]. For this reason, we summarize here all the ecological and pharmacological activities reported in heterobranch molluscs, trying to emphasize in the assays carried out, whether they are or not ecologically and biomedically significant, and their potential interest, since it seemed timely and necessary now. As previously mentioned, this review does not cover other ecological or evolutionary aspects that are already covered in previous reviews [1,2], nor the chemical synthesis of the MNPs. The aim of this review is, therefore, to showcase the main ecological and pharmacological bioactivities of the chemical compounds found in heterobranch molluscs, describing in which groups they are found and their particular bioactivities with all of the information we have been able to compile up to June 2020.

Heterobranch molluscs are soft-bodied and mostly shell-less animals that live all around the planet at all latitudes and depths [2]. These animals are often protected by chemical strategies, although they may also present behavioral and/or morphological strategies to combine them with [1]. As a result of the most recent evolutionary, phylogenetic, and taxonomical studies on the group, heterobranch gastropods now comprise the classical "Opisthobranchia" and the marine "Pulmonata" together with several other groups, reaching a total of more than 33,000 species, although the most well-known groups account for only ca. 9000 species [47-51]. Among these, only about 400 species have been chemically analyzed, and, therefore, a lot of compounds remain to be potentially discovered [1,2,5,6,52]. Among the chemically studied heterobranch species, a wide variety of compounds has been described, many of them being bioactive at the ecological and/or pharmacological level $[2,8]$. At the ecological level, some NPs are used for protection against potential predators and competitors, enhancing their ecological performance, while others may have a role in their reproduction, development, growth, and feeding behavior $[1,2,8]$. In heterobranch molluscs, NPs may be de novo biosynthesized by the animals, obtained from their diet (biotransformed or not), or perhaps even produced by symbionts [1,2]. In any case, all of them are considered in this review because they are found in and used by the molluscs.

This review analyzes the bioactive compounds by activity (ecological and pharmacological, and different subtopics within them) and by taxonomical groups. Heterobranchs classically include eight major taxa: Nudibranchia, Pleurobranchoidea (or Pleurobranchida), Tylodinoidea (or Umbraculida), Cephalaspidea, Anaspidea (or Aplysiida), Pteropoda, Sacoglossa, and Pulmonata (Table 1) [47-50]. 
All of these taxa have different morphological and anatomical characteristics; different diet, behavioral, and ecological traits; and different chemical strategies [1,2]. Nudibranchs (sea slugs) are carnivorous and comprise Doridacea, Dendronotida, Euarminida, and Aeolidida, and are considered the most diverse group, with Doridacea feeding on porifera (sponges), bryozoans, tunicates, or other "opisthobranchs", Dendronotids prey on cnidarians (usually octocorals or hydrozoans) or some small animals (crustaceans or turbellarians), Euarminida feed on octocoral cnidarians or bryozoans, and Aeolidida are mainly cnidarian feeders [1]. All of them lack a shell in adult stage, and they possess interesting chemistry that may be de novo biosynthesized or obtained from their diet of the above-mentioned prey $[1,2]$. Pleurobranchoidea (side-gill slugs) are usually ascidian feeders or generalist scavengers, while Tylodinoidea (false limpets) feed on sponges, and Cephalaspidea (head-shielded slugs and snails) may be algal feeders or voracious predators of other animals (other "opisthobranchs", including other cephalaspideans), sponges, annelids, and others [1]. Anaspideans (sea hares) are herbivorous, feeding on different kinds of algae, but also on sea grasses, or even cyanobacteria. On the other hand, pelagic Pteropods (sea angels) are planktonic and feed on phytoplankton or other pteropods, while Sacoglossans and Pulmonates are herbivorous that feed on different types of algae [1,2].

Table 1. Species number and natural products numbers (NPs) for the different heterobranch groups [2,49,50]. * Accepted species number obtained from WoRMs (www.marinespecies.org), accessed on 11 November 2020). ${ }^{* *}$ Natural products' number, main types of molecules, and diet according to Avila et al. [2]. *** Only marine pulmonata are considered here. \# Number.

\begin{tabular}{|c|c|c|c|c|}
\hline $\begin{array}{l}\text { Phylum Mollusca Class } \\
\text { Gastropoda Subclass } \\
\text { Heterobranchia }\end{array}$ & $\begin{array}{l}\text { Species \#* } \\
8054833193\end{array}$ & NPs \#** & Main Types of Molecules ** & Main Diet ** \\
\hline Nudibranchia & 2462 & $\sim 250$ & $\begin{array}{l}\text { Terpenoids, alkaloids, macrolides, } \\
\text { peptides, acidic secretions, etc. }\end{array}$ & $\begin{array}{c}\text { Porifera, bryozoa, tunicata, } \\
\text { cnidaria, } \\
\text { other heterobranchs, } \\
\text { crustacea, turbellaria }\end{array}$ \\
\hline Pleurobranchoidea & 96 & 25 & $\begin{array}{l}\text { Terpenoids, alkaloids, peptides, } \\
\text { acidic secretions, etc. }\end{array}$ & Tunicates, other animals \\
\hline Tylodinoidea & 12 & 6 & Alkaloids, diacylglycerols, etc. & Porifera \\
\hline Cephalaspidea & 875 & 40 & $\begin{array}{l}\text { Polyketides, polypropionates, } \\
\text { polyacetates, ethers, acidic } \\
\text { secretions, etc. }\end{array}$ & $\begin{array}{l}\text { Algae, other } \\
\text { heterobranchs, porifera, } \\
\text { other animals }\end{array}$ \\
\hline Anaspidea & 94 & $\sim 200$ & $\begin{array}{l}\text { Polyketides, terpenoids, } \\
\text { peptides, etc. }\end{array}$ & $\begin{array}{l}\text { Algae, sea grasses, } \\
\text { cyanobacteria }\end{array}$ \\
\hline Pteropoda & 409 & 5 & Polypropionates, etc. & $\begin{array}{l}\text { Phytoplankton, } \\
\text { other pteropods }\end{array}$ \\
\hline Sacoglossa & 362 & $\sim 120$ & Terpenoids, polypropionates, etc. & Algae \\
\hline Pulmonata & $500^{* * *}$ & $\sim 75$ & $\begin{array}{l}\text { Polypropionates, terpenoids, } \\
\text { peptides, etc. }\end{array}$ & Algae \\
\hline
\end{tabular}

\section{Ecological Activity}

\subsection{Predation}

Heterobranch mollusc are protected against predation by a vast array of defensive strategies, many of which are combined with or include the use of natural products (Figures 1-5) [2]. These chemical strategies may, in fact, be useful against many different kinds of predators, which can usually be grouped into three main types: fish, crabs, and sea stars, although other potential predators, such as anemones, sea spiders, etc., have also been reported (Table 2) [1,2]. Whether defensive strategies used against one predator are also effective against another potential predator is seldom reported in the literature. Furthermore, when laboratory assays are carried out using non-sympatric potential predators, the presumed ecological roles become highly speculative, because laboratory results cannot and should not be directly extrapolated to the field. The possibility that chemical compounds are used in the field against a wider range of 
predators than those usually tested in the laboratory remains to be proven in most cases [1,2]. In general, as reported below, very few studies have been conducted in the field against sympatric predators, and, thus, the ecological role of NPs in the field should be carefully considered.<smiles>CC(=O)OC1CC2(C)C(CC1C(C)=O)C(C(C)=O)CCC2(C)C</smiles>

1 Hodgsonal

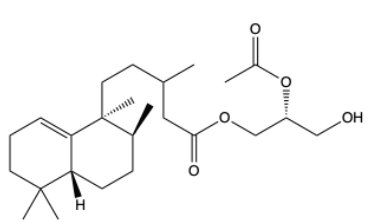

2 Diterpenoid diacylglycerol

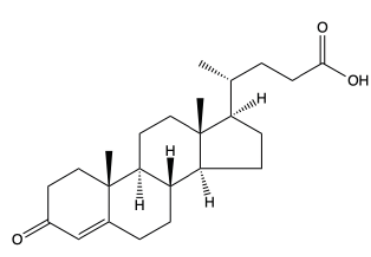

3 3-oxo-chol-4-ene-24-oic acid

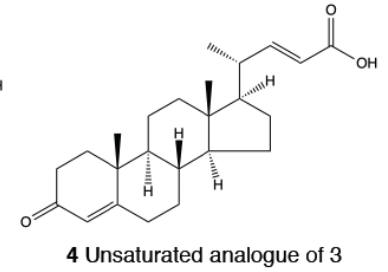

4 Unsaturated analogue of 3<smiles>Oc1ccc(-c2cnc(-c3[nH]c(Cl)c(Cl)c3Cl)o2)cc1</smiles>

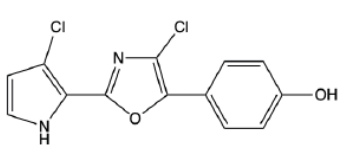

5 9-Chloro-phorbazole D<smiles>Oc1ccc(-c2cnc(-c3[nH]ccc3Cl)o2)cc1</smiles>

9 Phorbazole D

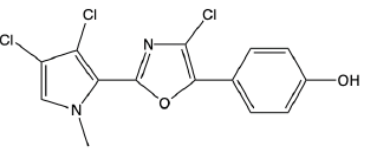

6 N1-Methyl-phorbazole A<smiles>CC1=C(CC/C(C)=C/C(=O)O[C@H](CO)CO[Na])C(C)(C)CCC1</smiles>

10 Tanyolide $A$<smiles>O=C(O)OC(=O)OCc1nc(-c2[nH]cc(Cl)c2Cl)oc1-c1ccc(O)cc1</smiles>

7 Phorbazole A<smiles>CC(=CC(=O)OC(CO)CO)CCC1C(C)CCCC1(C)C</smiles>

11 Tanyolide B<smiles>CC(=CCCc1ccoc1)CCC[C@@H](C)C=C1OC(=O)C(C)=C1O</smiles><smiles>CC1(C)CCCC2(C)C3COC(=O)C3=CCC12</smiles>

17 Cinnamolide

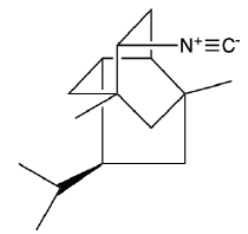
pupukeanane

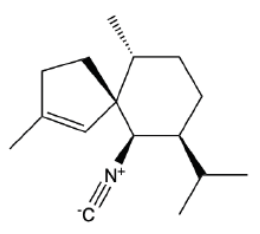

25 Axisonitrile-3<smiles>[C-]#[N+][C@]12C=C(C(C)C)CC[C@]1(C)CCC[C@@H]2C</smiles>

29 ent-Stylotelline

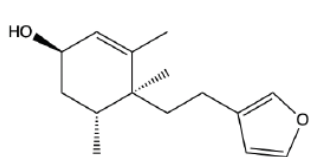

18 Pelseneeriol-1

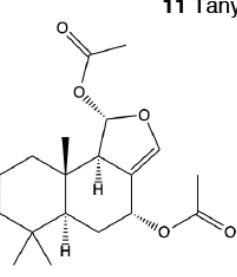

14 Olepupuane<smiles>COC(C)=O</smiles>

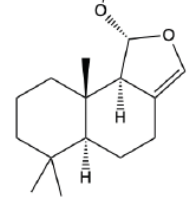

15 7-Deacetoxyolepupuane<smiles>CC1(C)CCC[C@]2(C)[C@H](C=O)C(C=O)=CC[C@]12C</smiles>

13 Polygodial<smiles>CC1(C)CCC[C@@]2(C)[C@H]1CC=C1C(=O)O[C@@H](O)[C@]12C</smiles>

16 Dendocarbin A<smiles>CC(=O)OC[C@]1(C)CCC[C@]2(C)c3occc3CC[C@@]21C</smiles>

20 15-Acetoxy-ent-pallescensin<smiles>C#[N+][C@]1(C)CC[C@H](C(C)C)C2=C[C@](C)(O)CC[C@H]21</smiles>

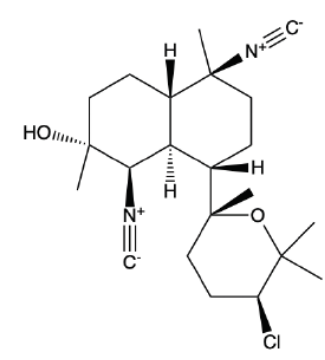

27 Kalihinol-A
24 Xidaoisocyanate $A$

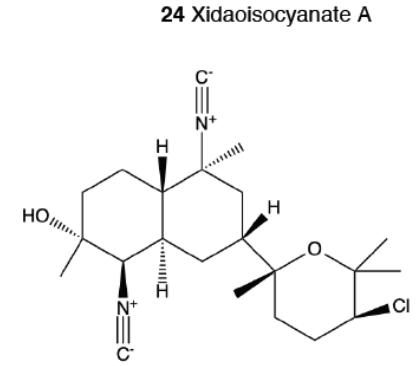

28 Kalihinol-E

Figure 1. Structures of selected compounds used against predation in some Doridacea. These molecules may also display other activities, as reported in the text. 


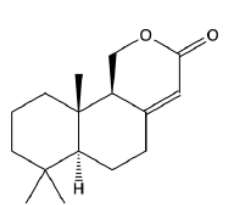

31 Albicanyl acetate

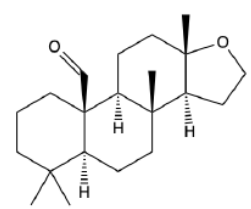

32 Cadlinaldehyde

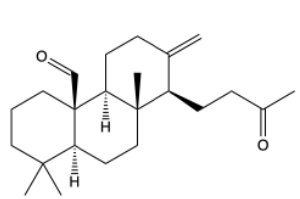

33 Luteone

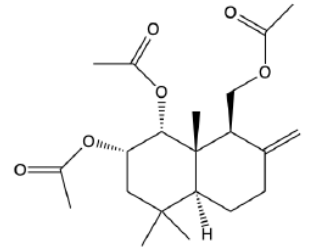

34 1a,2a-diacetoxyalbicanyl acetate<smiles>C[C@]12CC[C@H]3[C@@](C)(CO)[C@@H](O)C(=O)C[C@]3(C)[C@@H]1CCc1cocc12</smiles>

35 Spongiadiol<smiles>C=C(CC)CCCC1CC=CC(C/C=C\C(=O)O[C@H](C[C@H]2O[C@H]2C(O)CC(C)(C)C)[C@H](O)/C=C/C2CC(C)=CCO2)O1</smiles><smiles>C=C(C)C(C)CCC1(C)C(Cl)C(O)CC2(C)C3C(=O)OCC3=CCC21</smiles>

41 Hamiltonin<smiles>C[C@]12CCC[C@@]3(C)C1CC[C@H]1[C@@H]3CC=C(C=O)[C@@H](C=O)[C@]1(C)[C@H]2O</smiles><smiles>CC(=CCCc1ccoc1)CC1C=C(CC=Cc2ccoc2)C(=O)O1</smiles>

36 Kurospongin<smiles>C=C(CC(C)C)CC(C)CC1CC=CC(C/C=C\C(=O)O[C@@H]2C[C@H]([C@H](O)C(O)CC(=O)O[Na])O[C@@H]2/C=C/C2CC(C)=CCO2)O1</smiles>

40 Isolaulimalide

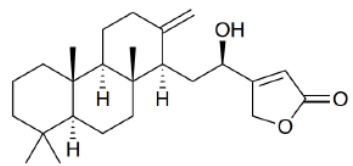
42 Hamiltonin E

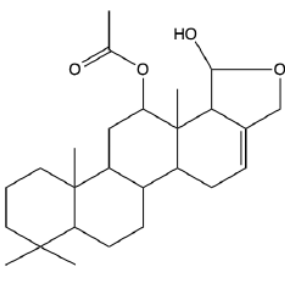

46 Deoxoscalarin

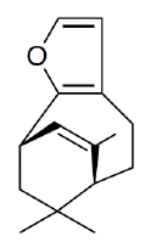

47 Pallescensin B

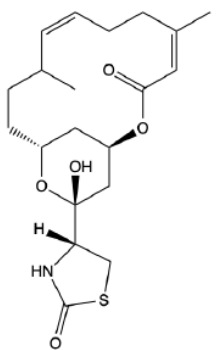

37 Latrunculin B

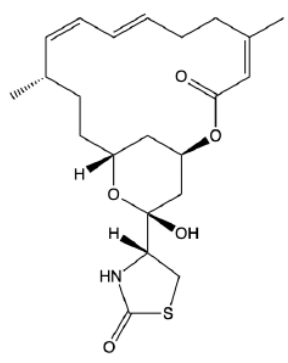

38 Latrunculin A<smiles>C[C@]12C(=O)C[C@@H]3[C@](C)(CCC[C@]4(C)CC[C@]34C)C1CC=C(C=O)[C@@H]2C=O</smiles>

43 12-deacetoxy-12oxoscalaradial

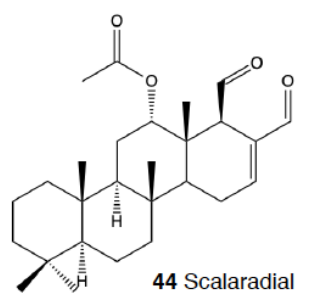

44 Scalaradial

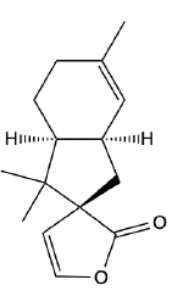

49 Dehydroherbadysidolide

45 Deacetylscalaradial<smiles>CC1=C[C@H]2C[C@@]3(CCOC3=O)C(C)(C)[C@H]2CC1</smiles>

50 Herbadysidolide<smiles>CC(C)=CCC/C=C\CCc1ccoc1</smiles><smiles>C=C1CCCC(C)(C)C1CC(=O)c1ccoc1</smiles>

60 Pallescensone

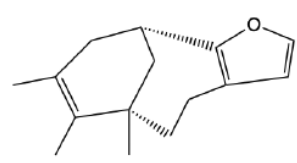

51 Nakafuran-9

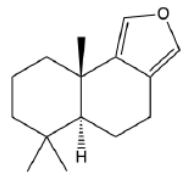

56 Euryfuran
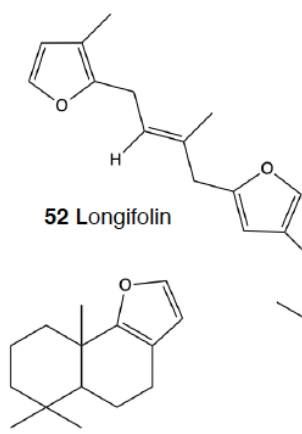

57 Pallescensin A<smiles>CC1=C[C@H]2Cc3occc3C(C)(C)[C@H]2CC1</smiles>

48 Furodysinin

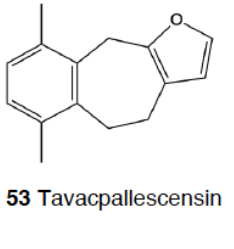

$C_{1}^{C}$

58 Furodysin

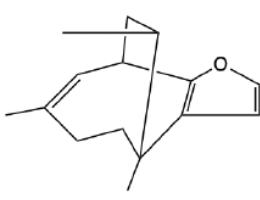

54 Nakafuran-8
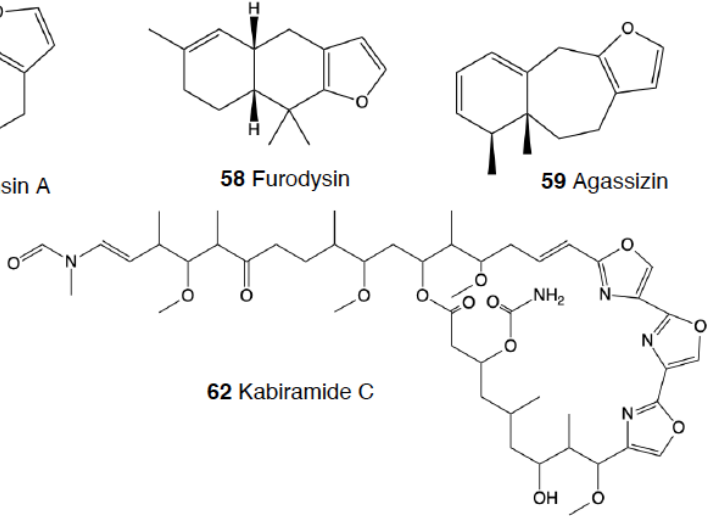

Figure 2. Structures of selected compounds used against predation in some Doridacea. These molecules may also display other activities, as reported in the text. 

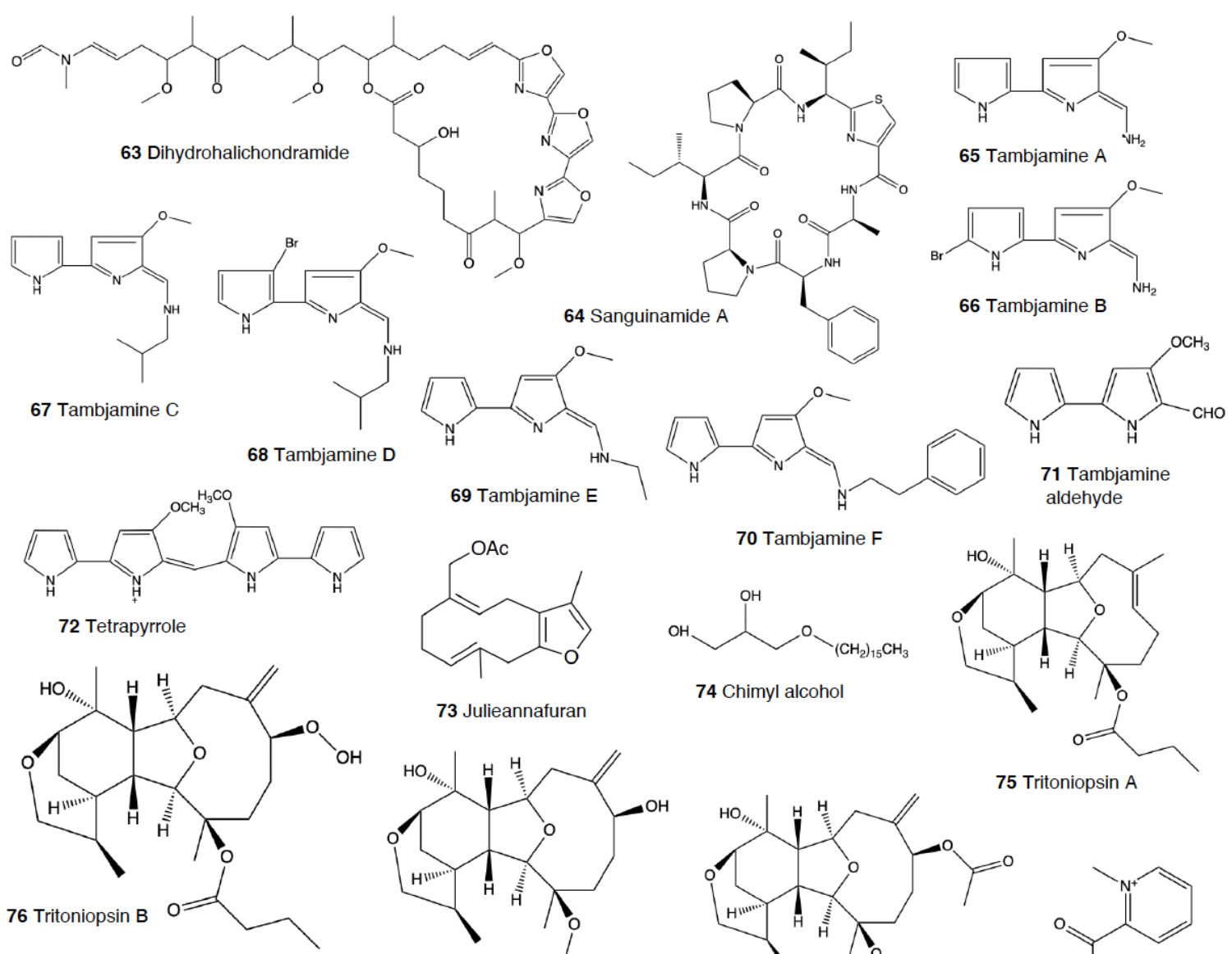<smiles></smiles>

$80 \mathrm{PGE}_{2}$-1,15-lactone

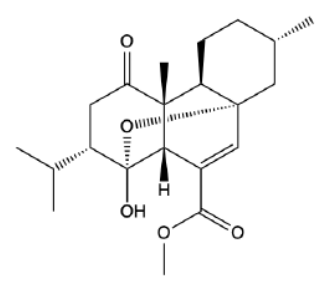

85 4-Oxochatancin<smiles>NC(Cc1cc(Br)c(O)c(Br)c1)C(=O)O</smiles>

87 3,5-Dibromotyrosine

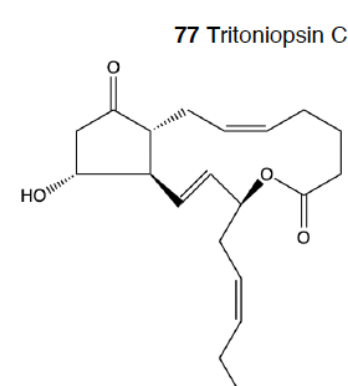

$81 \mathrm{PGE}_{3}$-1,15-lactone

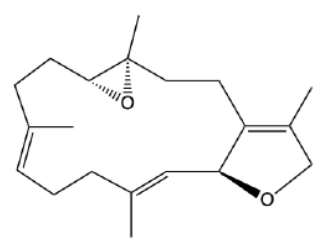

86 (2S)-Iso-sarcophytoxide

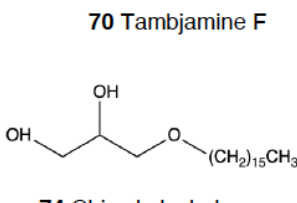

74 Chimyl alcohol

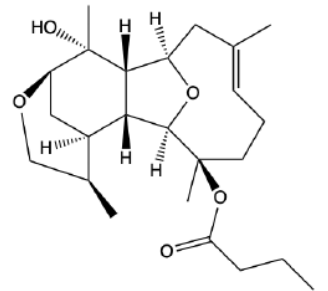

75 Tritoniopsin A
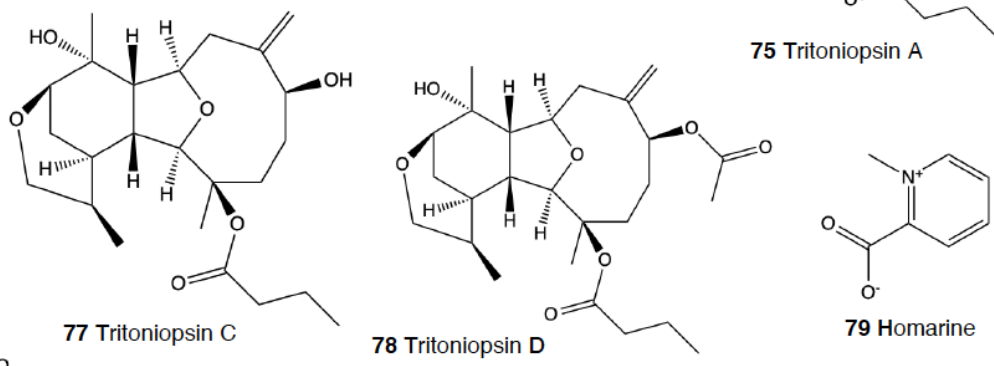

79 Homarine

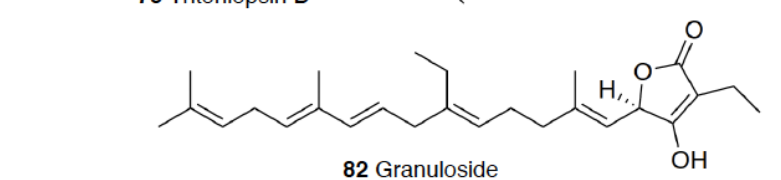

82 Granuloside

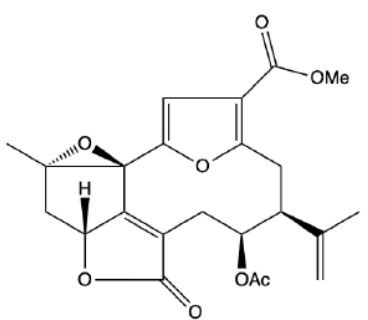<smiles></smiles>

84 Trocheliophorol

$8311 \beta$-Acetoxypukalide<smiles>CC/C=C(\C)C(=O)/C(C)=C/C(C)/C=C(C)/C=C(\C)C(=O)C(C)C(=O)CC</smiles><smiles>CC[C@H](C)C[C@@H](C)C(=O)/C(C)=C/C(C)/C=C(C)/C=C(\C)c1oc(=O)c(C)c(O)c1C</smiles>

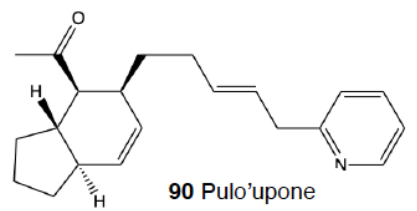

Figure 3. Structures of selected compounds used against predation in some Doridacea, Dendronotida, Euarminida, Aeolidida, Pleurobranchoidea, Tylodinoidea, and some Cephalaspidea. These molecules may also display other activities, as reported in the text. 

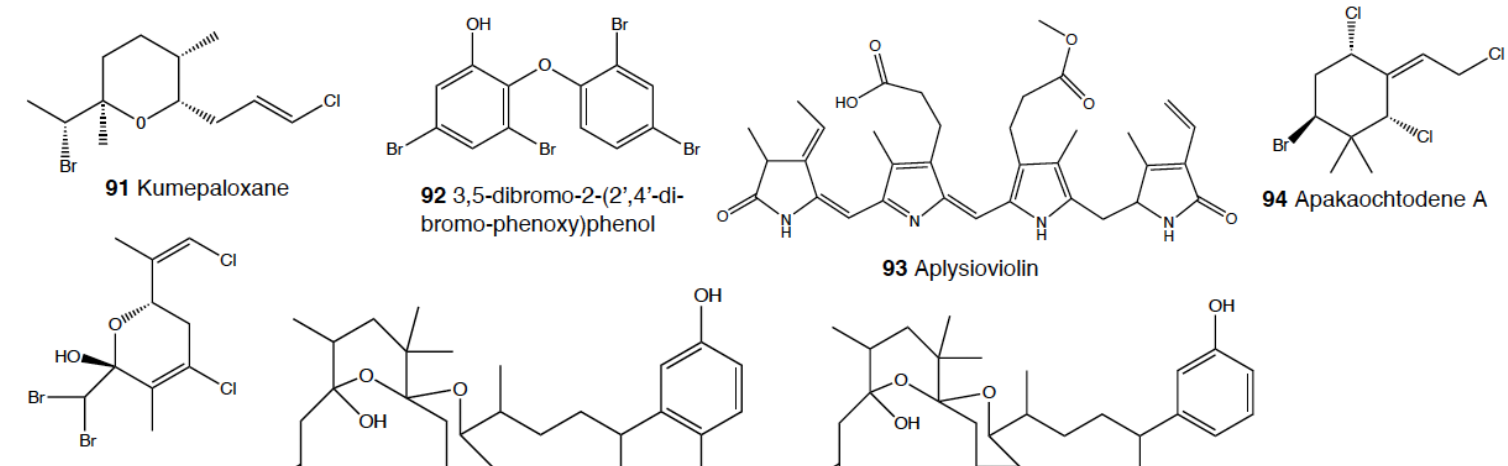
bromo-phenoxy)phenol

95 Costatone

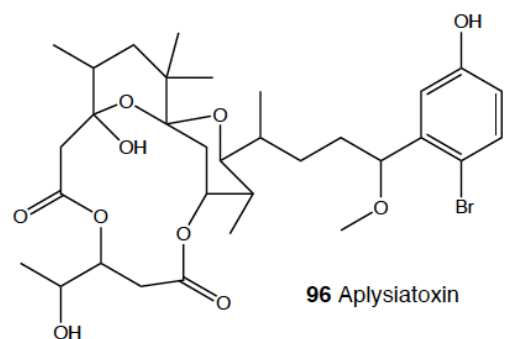

93 Aplysioviolin

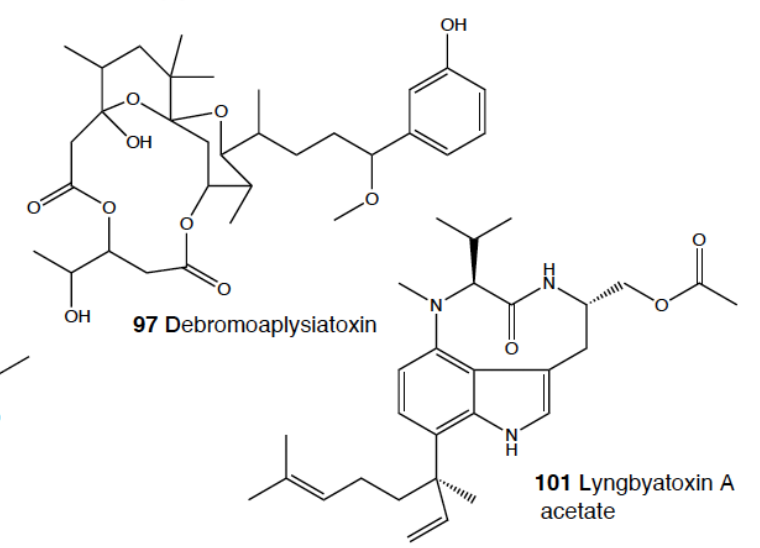
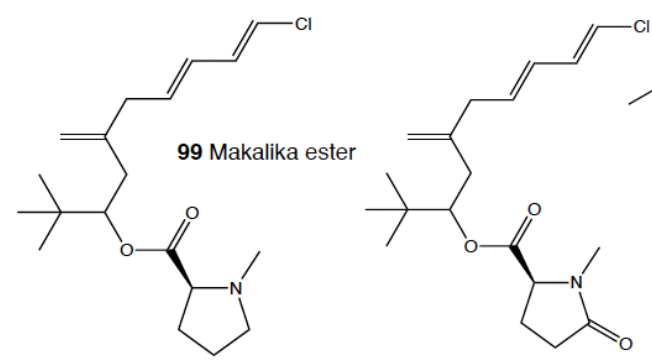

100 Makalikone ester<smiles>CCCCCCC[C@@H](C/C=C/CCC(=O)N(C)C/C(=C\Cl)CC(=O)CC(=O)OC)OC</smiles>

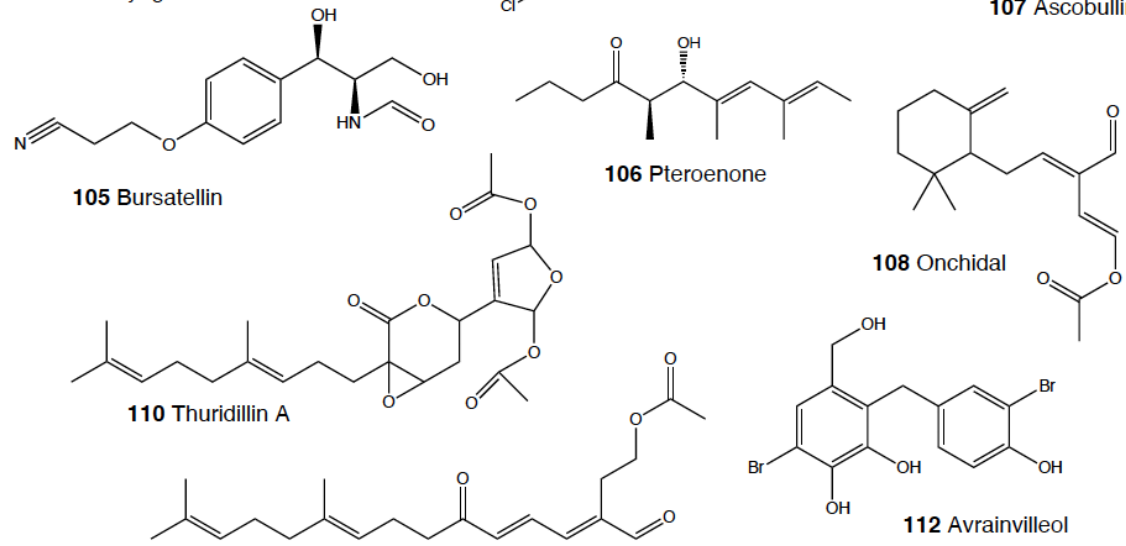<smiles>CCCCC</smiles><smiles>CCCCC(CC=CCCC(=O)NC)OC</smiles><smiles>C=C(CC(=CCl)CN(C)CCC/C=C/CCCCCCCCC)OC</smiles>

104 Malyngamide $A$

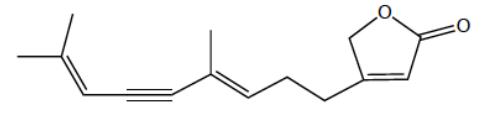

107 Ascobullin A<smiles>C=C1CCCC(C)(C)C1C/C=C(/C=O)CC=O</smiles>

109 Ancistrodial<smiles>CC/C=C(C)/C=C(\C)c1oc(=O)cc(OC)c1C</smiles><smiles>CCOCCOCCOC(C)=O</smiles><smiles>C=C1CC[C@H](Br)C(C)(C)[C@H]1Cc1cc(O)c(Br)cc1O</smiles><smiles>CC/C=C(C)\C=C(/C)c1oc(OC)c(C)c(=O)c1C</smiles>

Figure 4. Structures of selected compounds used against predation in some Cephalaspidea, Anaspidea, Pteropoda, and Sacoglossa. These molecules may also display other activities, as reported in the text. 
<smiles>CC(=O)O[C@H]1C=C(CC/C(C)=C\CO)[C@]2(C)CCCC(C)(C)[C@@]2(C)[C@H]1OC(C)=O</smiles>

117 6ß,7a-diacetoxylab-8,13-dien-15-ol<smiles>CCC[C@H](C)C[C@@H](C)C[C@H](C)/C=C(\C)[C@@H](O)[C@@H](C)C(=O)CC</smiles>
119 Siphonarienolone

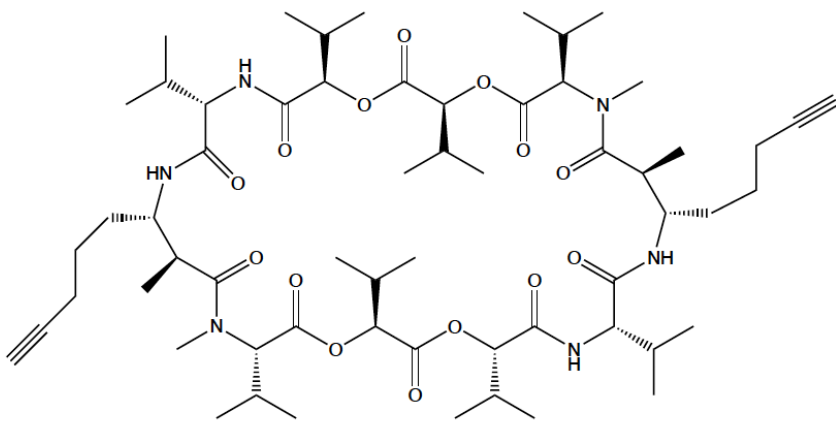

121 Onchidin<smiles>CC(=O)O[C@H]1C(C)=C(CC/C(C)=C/CO)[C@]2(C)C[C@H](OC(C)=O)CC(C)(C)[C@@]2(C)[C@H]1OC(C)=O</smiles>

118 2a,6ß,7a-triacetoxylabda-8,13-dien-15-ol<smiles>CCC(=O)[C@H](C)[C@H]1O[C@@]2(O[C@@](O)([C@@H](C)c3oc(C)c(C)c(=O)c3C)[C@H](C)[C@H](O)[C@@H]2C)[C@H](C)C(=O)[C@@H]1C</smiles><smiles>[2H][C@]12O[C@](O)([C@H](C)c3oc(CC)c(C)c(=O)c3C)[C@@H](C)[C@@H](OC(=O)CC(C)C)[C@@H]1Cc1c(oc([C@@H](C)C(=O)CC)c(C)c1=O)[C@@H]2C</smiles>

Figure 5. Structures of selected compounds used against predation in Pulmonata. These molecules may also display other activities, as reported in the text.

\subsubsection{Nudibranchia}

\section{Doridacea}

This is the most studied group of heterobranchs regarding compounds against predation (Figures 1-3). Even the most basal species are protected against potential predators, such as the Antarctic Bathydoris hodgsoni $[53,54]$. This large slug presents the drimane sesquiterpene hodgsonal (1), which is located in its mantle and dorsal papillae, and which is suggested to be de novo biosynthesized. Hodgsonal (1) was the first described 2-substituted drimane sesquiterpene from a marine organism $[55,56]$. While $B$. hodgsoni is chemically protected against sympatric predators, such as the sea star Odontaster validus and the anemone Epiactis sp., its egg masses seem to rely only on physical defenses [54,57]. The related Antarctic species, Prodoris (Bathydoris) clavigera also possesses chemical defenses against $O$. validus, but the compounds behind this activity have not been yet described (C Avila and K Iken, unpublished results; [2]).

The most studied group within Doridacea are the Doridoidei, comprising the well-known dorids, phyllids, and chromodorids, among others. The Antarctic Doris (Austrodoris) kerguelenensis possesses a series of diterpene diacylglycerides (2) along with monoacylglycerides, and monoacylglycerides of regular fatty acids, which are located in the mantle and deter sympatric predators, such as sea stars (O. validus) and anemones (Epiactis sp.) [1,58-61]. This slug possesses many other molecules that may 
not be involved in defense against predators, including additional diterpene glycerides with different skeletons, such as ent-labdane, labdane, halimane, clerodane, and isocopalane diterpenes, as well as norsesquiterpenes $[18,58,59,62-67]$. Cryptic speciation has been reported in D. kerguelenensis, and this could be behind their chemical variability, even at the intrapopulation level, as well as perhaps the presence of different terpene synthase variants involved in their de novo biosynthesis [61,67-70]. Since these compounds occur in complex mixtures in the slug, it seems difficult to trace the bioactivity to the individual compounds. Doris (Archidoris) species also present similar glycerid compounds [1,71].

Several species have been reported to use steroids against potential predators. This is the case of Aldisa sanguinea, and perhaps also the Brazilian Doris aff. verrucosa [1,72]. The steroidal acids, 3-oxo-chol-4-ene-24-oic acid (3) and its unsaturated analogue (4) were reported from Aldisa sanguinea (A. cooperi), probably originated from some related inactive compounds from its diet of the sponge Anthoarcuata graceae [73]. The 3-oxo-chol-4-ene-24-oic acid (3) deterred feeding in the common freshwater goldfish (Carassius auratus) in laboratory assays [73]. Similarly, a progesterone homologue was found in the mantle of Aldisa smaragdina from Spain [74]. Another species, A. andersoni from India, is protected against predators by two phorboxazoles, 9-chloro-phorbazole D (5) and N1-methyl-phorbazole A (6), and the phorbazoles A (7), B (8), and D (9) located in their mantle and viscera $[55,75,76]$. The phorbazoles are chlorinated phenyl-pyrrolyloxazoles that were previously found in the sponge Phorbas aff. clathrata, and, therefore, a dietary origin from a sponge has been suggested $[55,56,75,76]$. The two phorboxazoles $(\mathbf{5 , 6})$ and phorbazole A $(\mathbf{7})$ were tested in the laboratory at $1 \mathrm{mg} / \mathrm{mL}$ against the shrimp Palaemon elegans and showed to be deterrent, although they were not in their natural concentration $[75,77]$.

The Pacific slug Sclerodoris tanya presents the sesquiterpene glyceride esters tanyolides A (10) and B (11) in its mantle, reported to be effective deterrents against sympatric fish predators, such as Gibbonsia elegans and Paraclinus integrippinis at $1 \mathrm{mg} /$ pellet [78]. The Mediterranean Paradoris (Discodoris) indecora incorporates furanosesterterpenes, including variabilin (12), from its sponge preys Ircinia variabilis and I. fasciculata [79] as deterrents against fish predation [79]. Variabilin (12) was tested in the laboratory at $300 \mu \mathrm{g} / \mathrm{cm}^{2}$ against freshwater and marine fishes [79].

Dendrodoris species are well studied, with polygodial (13) from $D$. limbata being the first example of de novo biosynthesis in nudibranchs [80,81]. Polygodial (13), a drimane sesquiterpene, was first described in plants, where it is a deterrent against herbivores [82], and it is a deterrent in the slug against predation by marine and freshwater fish [80]. Polygodial (13) was found to be transformed from olepupuane (14) once secreted from the mantle cells, since it is not present in vivo in the slug tissues $[80,83,84]$. Furthermore, some fatty acid-esterified sesquiterpenoids were also found in D. limbata, and later in other species, generally found in the reproductive organs and egg masses and possibly with other functions, or perhaps just being stored as putative precursors of polygodial (13) [85]. Further studies with many other Dendrodoris species around the planet have yielded similar drimane sesquiterpenes located in the mantle, such as in D. arborescens, D. carbunculosa, D. denisoni, D. grandiflora, D. carbunculosa, D. krebsii, D. nigra, and D. tuberculosa, which are suggested to be used as feeding deterrents against predators [1,2,81,86-94]. In particular, D. arborescens presents 7-deacetoxyolepupuane (15) [87], D. carbunculosa possesses dendrocarbins A-N (16) [86], D. krebsi also has drimane sesquiterpenes and esters [89,90], and D. denisoni has cinnamolide (17), olepupuane (14), and polygodial (13) in its mantle [88].

Doriopsilla species also present similar metabolites to the related genus Dendrodoris. The Atlantic Doriopsilla pelseneeri presents the furanosesquiterpene alcohols pelseneeriols-1 and -2 (18) in the mantle $[81,85,95-97]$. D. albopunctata and D. areolata also have drimane sesquiterpenes and ent-pallescensin A (19) [89]. Other Doriopsilla species studied possess also drimane sesquiterpenoids and sesquiterpenoids with the ent-pallescensin A (19) skeleton in the mantle, including D. janaina and $D$. pharpa $[81,89,95-98]$. These natural products are de novo biosynthesized by the slugs, such as 15-acetoxy-ent-pallescensin (20) via the mevalonic pathway in D. areolata and Doriopsilla sp. [81,96,97,99]. It has been suggested that these compounds are used for defense against predators, but very few 
assays have been reported $[81,96]$. These include only the extracts of $D$. pharpa presenting polygodial (13), which deter feeding of the blenny fish Chasmodes bosquianus and the mummichog fish Fundulus heteroclitus, which even learned to avoid food items with extracts of slugs, and also deter the crabs Callinectes similus and Panopeus herbstii in the field [98].

The group of phyllidids has also been well studied over the last years [1,4]. These are usually brightly colored tropical animals, very specious, and quite similar in their external morphology, which has often resulted in some misidentifications [2,4,100]. These slugs are characterized by presenting isocyanate compounds that display a wide array of activities, apart from avoiding predation (see below) [1,101-105]. The first species studied was Phyllidia varicosa from Hawai'i, where a toxic compound, 9-isocyanopupukeanane (21), and a tricyclic sesquiterpene isocyanide were described almost 50 years ago [106]. The compound was also found in its prey, the sponge Ciocalypta (Hymeniacidon) sp. [106], and a related compound was subsequently reported in the slug, 2-isocyanopupukeanane (22) [107]. The extracts of Palauan P. varicosa deterred feeding by sympatric reef fish at natural concentration [108]. Similarly, the extracts from other species from Guam of the related genus Phyllidia, Phyllidiella, Phyllidiopsis, and Fryeria are deterrent to the sympatric crabs Leptodius sp., the mantle extracts being more deterrent than the viscera extracts [2]. A fast transformation of the secreted compounds was reported and was related to the loss of the deterrent activity [2]. The analysis of the sesquiterpene isocyanides that these slugs present suggests a broad diet of different demosponges, indicating a wide feeding variability [22]. Some experiments with agar-based food combined with different color patterns were also conducted, and the results showed that phyllidiids were defended against fish predators [109]. P. varicosa also possesses two 9-thiocyanatopupukeanane sesquiterpenes found in epimeric mixture; these were traced to its prey, the demosponge Axinyssa aculeata [110]. One of them is located in the mantle and is probably related to defense, but both compounds are found in the viscera, indicating their dietary origin. Phyllidia coelestis from Thailand also contains two pupukeanane sesquiterpenoids suggested to be used as for defense against predators $[2,109,111]$. Phyllidia elegans from Guam was a deterrent against reef fish, although the natural products have not been yet identified [109]. Other Phyllidia species contain related compounds, such as Phyllidia picta from Bali yielding two axane sesquiterpenoids, pictaisonitrile-1 (23) and pictaisonitrile-2, and Phyllidia sp. From Sri Lanka presenting the sponge-related 3-isocyano-theonellin (similar to a cyanide from Axinyssa), together with some nitrogenous bisabolene sesquiterpenes [112-115].

Phyllidia varicosa, P. ocellata, Phyllidiella pustulosa, and Phillidiopsis krempfi from Australia also present three more sesquiterpene isonitriles, 10-epi-axisonitrile-3, 10-isocyano-4-cadinene, and 2-isocyanotrachyopsane, and the peroxide 1,7-epidioxy-5-cadinene, together with some more sesquiterpene isonitriles [102,116]. Moreover, Phyllidia ocellata and Phyllidiella pustulosa contain stereoisomers of 10-isocyano-4-amorphene and of 4-isocyano-9-amorphene, respectively $[102,116]$. Phyllidia coelestis and Phyllidiella pustulosa from South China and their potential prey Acanthella cavernosa contain a nitrogenous cadinane-type sesquiterpenoid, xidaoisocyanate A (24), together with other sesquiterpenoids and diterpenoids [117]. P. pustulosa from Fiji possesses axisonitrile-3 (25), an isothiocyanate, and some minor related sesquiterpenes [118]. In China and Vietnam, P. pustulosa also presents sesquiterpene isocyanides, isothiocyanate, as well as some sterols, some of them also reported in Acanthella sponges, while in Japan, a sesquiterpene isonitrile is reported [103,119-122]. Samples from Hainan island present diterpenes together with sesquiterpenes, with the diterpenes amphilectene (26), kalihinol-A (27), and kalihinol-E (28) being previously found in sponges, and the sesquiterpene ent-stylotelline (29) being the enantiomer of the sponge compound stylotellin $[120,123]$. Amphilectene (26), kalihinol-A (27), and kalihinol-E (28) display deterrence in the laboratory against the allopatric goldfish C. auratus at $50 \mu \mathrm{g} / \mathrm{cm}^{2}$ [120]. P. pustulosa is therefore a chemically rich species, containing a wide variety of compounds, perhaps related to its unrestricted sponge diet, or to the presence of unknown cryptic species, but only a few of their metabolites have been tested against predation. Moreover, in field experiments, living Phyllidiella granulatus were offered to fish but were never consumed, while crude lipophilic extracts of three species of phyllidiids were shown to be 
effective against fish predation [109]. These were Phyllidia varicosa from Palau, P. elegans from Guam, and Phyllidiella pustulosa from Palau, where crude extracts at natural concentrations deterred feeding by sympatric reef fish, such as Abudefduf sexfasciatus, A. vaigiensis, Cheilinus fasciatus, Thalassoma lutescens, T. hardwickii, Naso vlamingii, and Bodianus axillaris, although P. pustulosa extracts from Guam did not [109]. In this study, the authors reported that visual and chemical cues are more effective against fish when used together than either of them alone [109].

Another exhaustively studied group is that of "chromodoridids", which possess a huge diversity of compounds from their diet of demosponges, often accumulating them in mantle dermal formations (MDFs) $[1,4,124]$. This group was recently the subject of important taxonomical revisions that resulted in changes in several genus names [125]. One of the first species studied was Cadlina luteomarginata, where natural mixtures of three isocyanides and three isothiocyanates from its sponge prey were found, with the isocyanides (30) being deterrent in laboratory assays against goldfish at $10 \mu \mathrm{g} / \mathrm{mL}$ and both mixtures being deterrent against the woolly sculpin Clinocottus analis $[126,127]$. Some terpenoids from C. luteomarginata are de novo biosynthesized, while others are obtained from its sponge diet [128]. Specimens from British Columbia present de novo produced albicanyl acetate (31), cadlinaldehyde (32) and luteone (33) [128]. Albicanyl acetate (31), which is concentrated in mantle and mucus, was shown to be deterrent [129]. The related 1a,2a-diacetoxyalbicanyl acetate (34) was found in their egg masses and was suggested to be involved in defense against predators based on structural similarity $[128,130]$.

Chromodoris is among the most studied heterobranch genus, although many studies were published using different names [76,131-165]. These slugs accumulate mostly terpenoids from their diet sponges, and many different structures have been reported, including sesquiterpenes, diterpenes and nor-diterpenes, sesterterpenes, macrolides, and bromophenols [131-133,135-165]. Previous studies analyzed the chemistry in the Mediterranean species C. luterorosea, C. purpurea, C. krohni, and C. britoi $[1,2,4]$, containing diterpenoids from Spongilla sponges, while tropical species such as C. mandapamensis from India contain spongiadiol (35), previously found in sponges from Australia, within a mixture of related spongiane compounds [166]. In the Red Sea, C. africana presents the furanoterpene kurospongin (36), as well as a 14-membered macrolide with an attached 2-thiazolidinone unit, latrunculin B (37) [167-170]. Kurospongin (36) was obtained also from a Spongia sp. in Okinawa and reported to be deterrent [167-169]. Latrunculin B (37) was also found in C. (Glossodoris) quadricolor [171] and in the sponge Latrunculia magnifica [169,170]. In fact, also latrunculin A (38) is a sponge compound initially found in L. magnifica and reported in the MDFs of several Chromodoris species $[136,141,153,164,169]$. Other macrolides, such as laulimalide (39) and isolaulimalide (40), were reported in C. lochi and its sponge prey, Hyattella sp. [142,172-174]. C. hamiltoni from South Africa presents hamiltonins $\mathrm{A}-\mathrm{D}(\mathbf{4 1}, \mathbf{4 2})$, atypical chlorinated homoditerpenes, as well as the sesterterpene hamiltonin E (42) and latrunculins A and B $(37,38)$, while specimens from Mozambique possess two spongian diterpene lactones in addition to latrunculin B (37) [153,155]. Many other compounds have been described in this genus, often located in the MDFs and suggesting a defensive role, but unfortunately very few tests for deterrence have been carried out [1,4].

In the genus Glossodoris, G. vespa and G. averni from Australia, as well as G. pallida from China, contain 12-deacetoxy-12-oxoscalaradial (43), while G. pallida from Guam contains some sesquiterpenes, such as scalaradial (44), deacetylscalaradial (45), and deoxoscalarin (46) [175-177]. The sesquiterpenes from G. pallida from Guam, located in their MDFs, have been proven to act as deterrents against sympatric reef fish (Abudefduf sexfasciatus, among others) and crabs (Leptodius sp.) at natural concentrations [176,177]. Further studies with G. vespa showed high concentrations of sesquiterpenes in mantle rim tissues that were more unpalatable to the allopatric palaemonid shrimp Palaemon serenus than metabolites from the viscera, suggesting selective accumulation of dietary compounds or perhaps even biotransformation to more potent defenses [178].

As taxonomical studies progress, many Chromodoris and Glossodoris species have been renamed, such as Goniobranchus, Ardeadoris, Doriprismatica, Felimare, and Felimida, respectively [171,175,179-185]. Goniobranchus collingwoodi presents six spongian-16-one diterpenes in the mantle, and the extract of the 
whole body displayed deterrence against the allopatric palaemonid shrimp P. serenus [185]. G. reticulatus from Australia contains a dialdehyde sesquiterpene and its ring-closed acetal, also reported in G. sinensis from China, where they are described to be deterrents against Palaemon elegans [186]. Specimens of G. splendidus from different localities in east Australia were described to present different abundances, types, and richness of natural products in addition to high individual variation between specimens from the same population [187]. These variations resulted in different potencies when deterring feeding in the allopatric, generalist rock-pool shrimp P. serenus, but in all cases, the specimens showed deterrent activity $[187,188]$. Other Goniobranchus species, such as G. albonarus, present diterpenes and nor-diterpenes obtained from their sponge prey, but they have not been tested for feeding deterrence [189-192].

Another interesting genus within this chromodorid group is Ceratosoma, because these species present a dorsal protuberance containing MDFs loaded with furanosesquiterpenoids. Although a defensive role has been suggested and it seems highly probable, it still remains to be demonstrated using sympatric predators [22,193]. These species include C. trilobatum and C. gracillimum from China, which possess pallescensin-B (47), (-)-furodysinin (48), (-)-dehydroherbadysidolide (49), and (-)-herbadysidolide (50) previously reported for Dysidea sponges [22,193-197]. From them, (-)-furodysinin (48) shows deterrent activity against the goldfish Carassius auratus in the laboratory [194]. Another compound, nakafuran-9 (51), present in C. gracillimum specimens from Hainan, was also reported as a deterrent [131]. In Australia, C. trilobatum possesses furodysinin (48), furodysin (58), and dendrolasin (55) in the viscera and, additionally, agassizin (59) and dehydroherbadysidolide (49) in the mantle, while $C$. brevicaudatum presents mixtures of the same compounds along with some unidentified metabolites [178].

Hypselodoris is another well-studied genus, although some species are now named Felimare or even Risbecia [125,131,165,198-208]. All of these species possess diet-derived furanosesquiterpenes, among other terpenoids, located in their MDFs [131,165,198-209]. Longifolin (52) is one of the main furanosesquiterpenes found in these groups, is located in MDFs, and is a deterrent in the lab against the goldfish Carassius auratus, like several other compounds of theirs [131,198,201,208]. Many of these molecules are obtained from Dysidea sponge species $[165,200,206,207]$. Some of the studied species include the Mediterranean F. picta webbi, F. villafranca, F. cantabrica, F. tricolor, F. fontandraui, and others, presenting longifolin (52) and some related compounds [2,124]. In the laboratory, the crude extracts of F. cantabrica displayed stronger deterrence against the allopatric shrimp Palaemon elegans than extracts from their prey sponge, Dysidea fragilis, suggesting a selective accumulation of compounds [206]. The main chemical behind the deterrence was nakafuran-9 (51). The Mediterranean and North Atlantic species mentioned above have aposematic colorations and conform Müllerian mimicry groups $[1,210]$. F. fontandraui, however, does not present MDFs and presents tavacpallescensin (53) in its mantle rim $[6,205,210,211]$. Tavacpallescensin (53) is a deterrent against the allopatric shrimp Palaemon elegans at $1 \mathrm{mg} / \mathrm{mL}$ in the laboratory, a very low concentration compared to that reported in its mantle $(25.98 \pm 1.41 \mathrm{mg} / \mathrm{mL})$ [205]. In the Atlantic, F. picta webbi presents longifolin (52) and tavacfuran, while F. picta azorica also presents microcionin-1 [212]. Hypselodoris capensis presents the feeding deterrents nakafuran-8 (54) and -9 (51), which are active against the reef fishes Chaetodon spp., together with the sesterterpene 22-deoxy-23-hydroxymethyl-variabilin and other sesquiterpenes and sesterterpenes from its presumed prey, the sponges Fasciospongia sp. and Dysidea sp. [213]. The Australian H. obscura contains dendrolasin (55), (-)-euryfuran (56), and (+)-pallescensin A (57), while $H$. whitei presents (-)-euryfuran (56), (-)-furodysin (58), (-)-furosydinin (48), and dendrolasin (55), some of which are deterrents against the shrimp P. elegans, as previously mentioned [186]. H. infucata from Hawai'i also possesses nakafuran-8 (54) and -9 (51), probably obtained from Dysidea fragilis [157]. In Bali, H. infucata presents (-)-furodysinin (48), and its crude extract is repellent against the sympatric shrimp Penaeus vannamei at natural concentration [214]. In Hawai'i, H. infucata (Chromodoris maridadilus) contains a 3:1 mixture of nakafuran-8 (54) and nakafuran-9 (51), like its sponge prey Dysidea fragilis, both reported to be deterrent [165]. H. bennetti and H. obscura from Australia contain euryfuran (56), but $H$. obscura also 
has furodysinin (48), furodysin (58), and dendrolasin (55), while H. bennetti presents agassizin (59), dehydroherbadysidolide (49), and pallescensone (60) [178]. In addition, in Australia, H. tryoni presents dehydroherbadysidolide (49), furodysinin (48), nakafuran-9 (51), and dendrolasin (55) [178]. In India, H. kanga and its prey sponge Dysidea sp. also present furodysinin (48) [166]. In Brazil, H. lajensis presents furodysinin lactone (61), also originated from Dysidea species [207]. Other Hypselodoris species such as $H$. jacksoni contain similar or related compounds, but no activity against potential predators has been shown [209]. Similarly, the related Mexichromis festiva has euryfuran (56) and dendrolasin (55), while M. mariei presents only euryfuran (56) [178]. Other chromodoridid genera like Tyrinna contain interesting compounds, but none of them have been demonstrated to be used against predation to date $[131,179,215,216]$.

The genus Hexabranchus mainly contains macrolides. In several locations around the Pacific and the Indo-Pacific, H. sanguineus presents several macrocyclic lactones, but only kabiramides and halichondramide derivatives have been proved to be deterrents against the sympatric fish Thalassoma lunare and the crab Dardanus megistos [217-220]. Active compounds consist mainly of kabiramide C (62) and halichondramide derivatives, such as dihydrohalichondramide (63) $[217,218,220,221]$. These macrolides are found in the slugs and even at higher concentrations in their spawn, suggesting a defensive role [218,222]. Since these compounds are found in mantle and viscera, they are suggested to be obtained and biotransformed from their diet of Halichondria sponges [218,221]. H. sanguineus from Fiji contains also macrolides along with two thiazole cyclic peptides, sanguinamides A (64) and B [219].

Finally, within the group of nembrothids, the tambjamines (65-71) are alkaloids obtained from their diet of several species [223]. Tambja abdere and T. eliora in the east Pacific accumulate tambjamines (65-71) from the bryozoan Sessibugula translucens, and they are in turn preyed on by another nembrothid slug, Roboastra tigris $[61,224,225]$. In Micronesia, Nembrotha species present tambjamines (65-71) from their ascidian prey, Atapozoa sp. $[157,226,227]$. These compounds include mixtures of tambjamine A (65), B (66), C (67), D (68), E (69), and F (70); a tambjamine aldehyde (71); and a blue tetrapyrrol (72) [226]. Crude extracts and mixtures containing tambjamine $C(67)$ and $F(70)$ and the tetrapyrrol (72) are reported to be deterrents against fish at (or below) natural concentrations, while tambjamines A (65) and $\mathrm{E}(69)$ are not deterrents [61,226]. R. tigris feeds on T. abdere and T. eliora, accumulating tambjamines A-D (65-68) [223]. Both Tambja species and R. tigris are able to detect the tambjamines released into the mucus by chemoreception and thus chemically locate their prey $[61,223]$. When the concentration of tambjamines is very high, $R$. tigris may reject its prey $[61,223]$. Similarly, tambjamines have also been reported in T. ceutae and T. stegosauriformis and their bryozoan prey, Bugula dentata [207,228].

\section{Dendronotida}

In Florida, Tritonia hamnerorum presents julieannafuran (73), a furano-germacrene obtained from its diet, the sea fan Gorgonia ventalina [229]. Julieannafuran (73) has been shown in reliable field assays to be a deterrent at natural concentrations against sympatric reef fish, such as Thalassoma bifasciatum, as well as in the laboratory [229]. The Antarctic Tritonia challengeriana, instead, has been proved to be chemically protected against feeding by the sympatric sea stars Odontaster validus, but no compounds have been identified from it to date ([2], Avila and K Iken, unpublished results). Furthermore, in Antarctica, Tritoniella belli sequesters 1-O-hexadecyl glycerol (chimyl alcohol) (74) from its diet, the stoloniferan coral Clavularia frankliniana [230-232]. This compound provides protection against the potential sympatric predator, the sea star O. validus, which is also deterred by the mantle tissue of the slug ([2,230-232], Avila and Iken, unpublished results). The spawn of T. belli is also chemically defended against predators [232,233].

Tritoniopsis elegans presents the sesquiterpenes tritoniopsins A-D (75-78) in the mantle, which are obtained from its diet of the soft coral Cladiella krempfi [234]. Tritoniopsins A (75) and B (76) are the major compounds, with tritoniopsin A (75) more abundant in the slug and tritoniopsin B (76) in the soft coral, thus suggesting a selective accumulation by the slug, which incorporates it in its mantle possibly for protection against potential predators [234]. 
The Mediterranean Marionia blainvillea presents homarine (79), a widespread zwitterionic natural product described to be a feeding deterrent, but it has not been tested against sympatric predators of the slug [235]. Homarine (79) has been suggested to derive from its cnidarian diet and could be the only defense of this slug that has no nematocysts [235]. Furthermore, homarine (79) has been found in other molluscs, for example, in Antarctica (Marseniopsis mollis), where it was described to deter feeding in the seastar Odontaster validus [235,236].

The colorful Tethys fimbria was described to de novo biosynthesize a series of prostaglandins (PG) and PG-lactones [1,237-240]. These compounds are well known in many organisms as promotors of hormonal responses [28]. Different PGEs, such as $\mathrm{PGE}_{2}-1,15$-lactone (80) and $\mathrm{PGE}_{3}-1,15-$ lactone (81) are found in T. fimbria cerata [237], while PGFs are present in the reproductive system of the slugs [239]. Since cerata are detached when the animal is disturbed, together with a copious amount of mucus and a strong antero-posterior waving movement, PGEs are suggested to be involved somehow in defense, autotomy, and/or tissue protection, as well as further regeneration of cerata, while PGE-lactones $(\mathbf{8 0 , 8 1 )}$ are converted to the free acid forms $\mathrm{PGE}_{2}$ and $\mathrm{PGE}_{3}$, respectively [237]. Similarly, Melibe viridis contains one of these prostaglandin lactones (80) in its mucus and cerata, suggested to be used for defense against predators [77].

\section{Euarminida}

Only one species has been suggested to use defensive compounds in this group [1,2], the Antarctic Charcotia granulosa [241,242], although no experiments have proved this yet. This species possesses a unique linear homosesterterpene lactone, granuloside (82), probably stored in its MDF-like structures [242]. Granuloside (82) was isolated from the lipophilic extract of the mantle of the slug, while it was absent in the gut and digestive gland as well as in the prey of the nudibranch, the bryozoan Beania erecta, strongly supporting its de novo biosynthetic origin. Sesterterpenes are known in nudibranchs [4], but, to date, granuloside (82) is the only known linear homosesterterpene in nature.

\section{Aeolidida}

Homarine (79), previously mentioned above, has been also found in the Atlantic aeolidids Cratena pilata and Cuthona gymnota, the Pacific Hermissenda crassicornis, the Australian Phestilla lugubris, and the Mediterranean Cuthona coerulea [2,92,235]. It has been suggested that the slugs obtain homarine (79) from their diet of hydrozoans or other cnidarians [235]. Flabellina exoptata, F. ischitana, F. pedate, and F. affinis also contain homarine (79) [235,243]. Despite the fact that homarine (79) has not been tested specifically for these species, its potential deterrent role cannot be overruled (see above) and may complement their cnidocyst defenses.

Phyllodesmium species do not to present functional cnidocysts, and, thus, their chemical defenses become their only protective shield, together with their cryptic behavior [244-248]. P. magnum from China presents an uncommon asteriscane sesquiterpene related to $11 \beta$-acetoxypukalide (83), as well as some other sesquiterpenes [249]. 11 $\beta$-acetoxypukalide (83) was previously reported to be the chemical defense of P. guamensis from Guam, which accumulate it in their cerata, and it was suggested to be obtained from feeding on Sinularia soft corals [246]. 11ß-Acetoxypukalide (83) was shown to deter feeding by the sympatric omnivorous pufferfish Canthigaster solandri at concentrations at least an order of magnitude lower than those found in their cerata (0.5\% of dry mass in artificial food) [246]. Previously, trocheliophorol (84) was also found to be accumulated in the cerata of the Australian P. longicirrum and in its prey, the soft coral Sarcophyton trocheliophorum [245]. Four more polycyclic diterpenes and other compounds were described from P. longicirrum, some of them (for example, 4-oxochatancin (85), (2S)-isosarcophytoxide (86), and cembranoid bisepoxide 12) being deterrent also to the pufferfish $C$. solandri $[250,251]$. The 4-oxochatancin (85) is probably obtained from a diet of Sarcophyton corals $[28,250,251]$. P. longicirrum also possesses many other compounds, including steroids, cembranoid diterpenes, biscembranoids, and the above-mentioned chatancin diterpenes [251]. 
Other Phyllodesmium species have been reported to contain other interesting natural products, but its role in deterring potential predators has not been proved to date [244,248].

\subsubsection{Pleurobranchoidea}

This group is well known for presenting acidic secretions that may deter putative predators [1,2]. Examples, with $\mathrm{pHs}$ as low as 1-2 include Pleurobranchaea californica, Berthellina citrina, and Pleurobranchus strongi from the Pacific, as well as Berthella plumula and Pleurobranchus membranaceus from the North Atlantic. In addition, Berthella sp. 1 from the Mediterranean and Berthella sp. 2 from Antarctica display $\mathrm{pH} \sim 1$ [2]. P. californica and P. membranaceus have also been described to possess buccal acid glands [124,252]. Both Berthella and Berthellina are usually consumers of demosponges and occasionally of calcareous sponges and corals [253], and no chemical defenses have been described for them besides the acid secretions mentioned above. Similarly, the Antarctic Bathyberthella antarctica presents defensive acid secretions in its mantle [254,255].

\subsubsection{Tylodinoidea}

Tylodina species seem to be protected from predation by using sponge compounds and crypsis. Tylodina fungina from the Pacific contains an ester derivative of the brominated isoxazoline alkaloid 3,5-dibromotyrosine (87), which is a known feeding deterrent in sponges of the genus Aplysina [256]. T. perversa from the Mediterranean possesses similar metabolites from the sponge Aplysina aerophoba [257]. Finally, T. corticalis from Australia selectively accumulates several bromotyrosine-derived alkaloids from its sponge diet, Pseudoceratina purpurea, which contains a larger variety of these compounds [258]. In all cases, the natural products are sequestered by the molluscs and can then be found in the mantle, mucus, reproductive organs, and egg masses [259,260]. In the case of T. perversa, they feed preferentially on the symbiotic tissues of sponge prey loaded with cyanobacteria [261]. Furthermore, the slugs combine chemical defense with crypsis, while their mimetic yellow color (as well as that of their egg masses) on Aplysina species is due to uranidine, a phenolic pigment that becomes dark by oxidation when exposed to air, and it is also derived from the sponge [262,263].

\subsubsection{Cephalaspidea}

Species of the genus Philine often secrete sulfuric acid from subepithelial notal glands, and this is supposed to be a defense against predators, similarly to acid-secreting nudibranchs and pleurobranchoids [124,264]. P. quadripartita from the Mediterranean, Atlantic, South Africa, and Indo-Pacific is an example, possessing sulfuric and hydrochloric acid in acidic glands [265,266]. Some other cephalaspideans are able to de novo biosynthesize their own chemical defenses, such as Bulla striata, a generalist algal feeder found in the Atlantic and the Mediterranean [267,268]. Remarkably, cephalaspideans, such as the voracious predator Philinopsis depicta, are able to prey on B. striata, thus obtaining chemical defenses from them-in this case, the polypropionates aglajnes 1-3 (88), using them for their own defense, with aglajne-1 being the most deterrent [269-271]. Similarly, the Pacific species $P$. speciosa contains the polypropionates niuhinones $A$ and $B(\mathbf{8 9})$, as well as a pyridine derivate pulo'upone (90) reported to be deterrent, and although their origin is not yet known, P. speciosa probably also relies on other cephalaspideans [272,273]. In fact, niuhinones A and B (89) have also been found in the Atlantic species B. occidentalis, along with the acyclic polypropionate, niuhinone C (89) [274]. P. speciosa also presents other compounds, such as the depsipeptide kulolide-1, a linear tetrapeptide (see below), pupukeamide, additional peptides, and the macrolide tolytoxin-23-acetate [275-277]. Similarly, Bulla gouldiana possesses an isomer of pulo'upone (90) which is further found in its cephalaspidean predator, Navanax inermis, and suggested to be used for its own protection [278]. Moreover, Nakamigawaia spiralis from Guam has been reported to chemically deter sympatric reef fish, but the active compounds have not been identified to date [279]. 
Homarine (79), again, could be used against predators in this group of heterobranchs, since it has been found in the Mediterranean Aglaja tricolorata, probably from its diet of sea slugs, such as dendronotaceans and/or aeolidids [235].

Another interesting group is that of Haminoea species. In Guam, H. cymbalum uses a halogenated polyacetate, kumepaloxane (91), which it secretes when it is disturbed and which deters porcupine fish [280]. Similarly, a chemically related brominated tetrahydropyran has been found in the same species from India, as well as in $H$. cyanomarginata from the Mediterranean, strongly deterring predation by the generalist crustacean Palaemon elegans $[77,166]$. Moreover, the spawn of $H$. virescens from the Pacific has been shown to deter feeding in decapod crustaceans, although the compound(s) has not yet been identified [281].

In Guam, Sagaminopteron species concentrate polybrominated diphenyl ethers, probably for defense against potential predators, although this has not yet been demonstrated. S. nigropunctatum and S. psychedelicum both feed on the sponge Dysidea granulosa and sequester the sponge-polybrominated diphenyl ethers, concentrating them in their mantle and parapodia [282]. One of the compounds, 3,5 dibromo-2-( $2^{\prime}, 4^{\prime}$-dibromo-phenoxy)phenol (92), is found at higher concentrations in the slug's parapodia $(8-10 \%)$ than in the sponge or the rest of tissues of the slug $(2-4 \%)$, thus supporting a potential defensive role [282].

\subsubsection{Anaspidea}

Although sea hares are among the most studied heterobranch groups and many compounds have been described, not so many studies have focused on metabolites used to avoid predation $[1,4,283]$. Usually, sea hares obtain natural products from their red algal food and are often able to biotransform them [284-286]. Surprising reports on sea hares include specimens of Aplysia fasciata (A. brasiliana) being rejected by sharks, even when hidden in fish fillets [287]. The sharks avoided all of the pieces, except for the buccal mass, presumably containing no defensive metabolites [287]. In fact, it is well known that sea hares present glandular structures containing deterring compounds, which may be secreted or stored in their external tissues. A. juliana is known to use opaline and ink secretions to deter crabs, while A. californica, A. dactylomela, and A. parvula present aplysioviolin (93) and phycoerythrobilin, biotransformed from their algal food in the ink gland and used to avoid blue crabs' predation [288-290]. Enzymatic interactions between opaline and ink secretions in A. californica involving escapin result in hydrogen peroxide production, and this induces deterrence against crabs, spiny lobsters, fishes, and anemones, as widely described in the literature [2,291-297]. Significant deterrence was also described when A. californica was fed on Ulva (green algae) and on Plocamium (red algae) and given to kelp bass (Paralabrax clathratus), and the effect proved to be stronger when the sea hare had fed on Plocamium (richer in natural products) [298]. A. parvula from Guam accumulates apakaochtodenes A (94) and B, two halogenated monoterpenes, from their red algal food Portieria hornemanii, using them as repellents against potential sympatric reef fish predators at natural concentrations [299]. In New Zealand, the same species contains several brominated and chlorinated terpenoids from the red algae Plocamium costatum, among which costatone (95) is found 14 times more concentrated in the slug than in the algae, supporting a potential defensive role [88,300].

Stylocheilus feeds on cyanobacteria using compounds from their diet to deter predators [301]. In Hawai'i, S. longicauda presents aplysiatoxin (96), debromoaplysiatoxin (97), stylocheilamide (98) and some complex proline esters (makalika ester (99) and makalikone ester (100)) together with lyngbyatoxin A acetate (101) [302-305]. Stylocheilamide (98) was later considered to be identical to acetyl malyngamide I, previously described from the Hawaiian cyanobacteria Lyngbya majuscula [306]. Moreover, the alkaloids malyngamides $\mathrm{O}(\mathbf{1 0 2})$ and $\mathrm{P}(\mathbf{1 0 3})$ were also found in the sea hare, being also structurally related to L. majuscula compounds [307]. Malyngamides A (104) and B were first found in Microcoleus lyngbyaceus (probably L. majuscula) [308]. In Guam, S. longicauda contains malyngamydes from the cyanobacteria and biotransforms malyngamyde B into an acetate. It has been proved that $S$. longicauda compounds are deterrents against sympatric fish (such as the pufferfish 
Canthigaster solandri), amphipods, crabs (Leptodius spp.), and even the herbivorous cephalaspidean Diniatys dentifer [309,310].

Bursatella leachii plei from Puerto Rico presents bursatellin (105), a diol nitrile alkaloid, structurally related to chloramphenicol, while B. leachii from the Mediterranean possesses the $(+)$ and $(-)$ isomers of bursatellin (105), in their external extracts, but no deterrent activity has been reported to date [311,312].

\subsubsection{Pteropoda}

The amazing case of the Antarctic pelagic slug Clione limacina is worth mentioning here. C. limacina possesses a polypropionate-derived compound, pteroenone (106), which is a strong feeding deterrent against fish predators, such as Pagothenia borchgrevincki and Pseudotrematomas bernachii [313]. Pteroenone seems to be de novo biosynthesized, since it is not found in the prey of $C$. limacina, the thecosomate Limacina helicina [314]. The pelagic hyperiid crustacean Hyperiella dilatata captures and carries the chemically protected pteropods on its dorsum, thus increasing its chances of survival [315].

\subsubsection{Sacoglossa}

Despite the fact that the variety of compounds described in sacoglossa is huge [2], very few studies have tested deterrence at natural concentrations and against sympatric predators. The shelled sacoglossa Ascobulla ulla presents ascobullin A (107) and B, structurally related to oxytoxins (see below), but with less reactive molecules [316]. Elysia crispata from Venezuela contains, among other compounds, crispatenine and onchidal (108), the latter also found in the pulmonate Onchidella (see below) where it is presumably used to deter potential predators in its active form, ancistrodial (109) [316-319]. Elysia translucens contains udoteal as a main component from the green algae Udotea petiolata, which induces significant avoidance in the fish Pomacentrus coeruleus at $800 \mathrm{ppm}$ [320].

Among the shell-less sacoglossans, the Mediterranean Thuridilla hopei contains the diterpenoids thuridillins (110), possessing a central $\alpha, \beta$-epoxy- $\delta$-lactone ring which is substituted by an uncyclized or cyclized isoprenoid chain and a 2,5-diacetoxy-2,5-dihydrofuran unit [321,322]. T. hopei also possesses nor-thuridillonal (111), the epoxylactone from the algae Pseudochlorodesmis furcellata [323], considered the putative precursor of thuridillins (110), and which is active in laboratory feeding deterrence tests against the shrimp Palaemon elegans at a concentration of $5.0 \mathrm{mg} / \mathrm{mL}$ [322]. Thuridilla splendens from Australia also presents thuridillins (110), but contrastingly, these thuridillins did not deter feeding by the sympatric shrimp Palaemon serenus in the laboratory [186,324].

The Caribbean Costasiella ocellifera (C. lilianae) contains avrainvilleol (112), a brominated diphenylmethane dietary algal derivative, from feeding on the algae Avrainvillea longicaulis [316,325]. Avrainvilleol (112) possesses deterrent properties against the tropical damselfish Pomatocentrus coeruleus at $100 \mathrm{ppm}[316,325]$.

The Mediterranean Cyerce cristallina presents cyercene polypropionates (113) [326]. This slug has unknown feeding habits and may autotomize its cerata [326,327]. Cyercenes (113) are also found in the Australian C. nigricans, which feeds on Chlorodesmis algae and presents the algal diterpenoid chlorodesmin (114) [328]. The Atlantic Mourgona germaineae secrets a toxic mucus when disturbed and may also autotomize the cerata [329]. M. germaineae retains active chloroplasts form its algal diet, the calcareous green alga Cymopolia barbata, from which it also accumulates prenylated bromohydroquinones, such as cyclocymopol (115) [330]. Cyclocymopol (115) is similar to the deterrent avrainvilleol (112) mentioned above [325]. Caliphylla mediterranea, instead, seems to rely only on a defensive cryptic behavior to avoid predators, lacking propionates or other defensive chemistry [331]. This species captures chloroplasts from the algae Bryopsis plumula for camouflage and does not autotomize [331]. Contrastingly, Placida dendritica possesses polypropionate $\gamma$-pyrones such as iso-placidene A (116) that are probably used for deterrence; this species also uses crypsis as a defensive mechanism but does not autotomize [332]. 


\subsubsection{Pulmonata}

While many different compounds have been described in pulmonates, very few have been appropriately tested using natural concentrations and against sympatric predators [2]. Trimusculus costatus from South Africa presents the diterpenoid labdanes 6 $\beta$,7a-diacetoxylab-8,13-dien-15-ol (117) and 2 $\alpha, 6 \beta, 7 a-t r i a c e t o x y l a b d a-8,13-d i e n-15-o l$ (118), which produce feeding deterrence against the predatory fish Pomadasys commersonnii [333]. T. reticulatus from New Zealand, instead, possesses some deterrent diterpenes, such as $6 \beta$-isovaleroxylabda-8,13-dien-7 $\alpha, 15$-diol and $2 \alpha, 7 \alpha$-diacetoxy-6/3-isovaleroxylabda-8,13-dien-15-ol, which are located in the mantle and foot are effective against sea star predators [334]. Other species of this genus also display antifeeding activities, such as T. costatus from Chile and T. peruvianus from South Africa [333,335-337].

Contrastingly, species of the genus Siphonaria present two different classes of polypropionates, some of which are found in the mucus and mantle border, thus indicating some sort of deterrent role, and are considered to be de novo biosynthesized [338,339]. The first type of polypropionates is represented by acyclic compounds with a 2-pyrone and furanone rings, such as siphonarienolone (119), structurally related to the polypropionates of the cephalaspideans (see above). This type of polypropionate is found in some species from Australia, Atlantic Ocean, and South Africa [340-346]. The second type possesses variable lengths in the alkyl chain, producing a polyoxygenated network that often cyclizes, for example siphonarin A (120), similar to polypropionates from actinomycetes, and found in Siphonaria from Australia, New Zealand, Pacific Ocean, and South Africa [347-352]. The species that have been analyzed to date include S. capensis, S. concinna, S. cristatus, and S. serrata, and some of their polypropionates are deterrents against fish [353].

The Onchidiidae possess repugnatorial glands which may contain sesquiterpenoids, depsipeptide acetates, or propionates. Onchidella binneyi presents onchidal (108), which is secreted as ancistrodial (109), its active form, to deter potential predators [319]. Many species of Onchidella present variable amounts of natural products at different geographical locations, all of them being deterrent for sea stars, such as the sympatric Leptasterias hexactis for Onchidella borealis [354,355]. Peronia peronii and several Onchidium species present polypropionates similar to those of Siphonaria mentioned above [356,357], as well as some depsipeptides, such as onchidin (121) [358,359]. Finally, Onchidium sp. From China presents onchidione (122) in the mucus and mantle [360], with a potential defensive role, as well as onchidiol and 4-epi-onchidiol (see below) [361,362].

Table 2. Natural products used against predation in the different heterobranch groups. In brackets: number of species with antipredatory compounds, number of the compounds in figures, and reference numbers. \# Number.

\begin{tabular}{|c|c|c|c|}
\hline Species (\#) & Compounds (\#) & Predator(s) Tested & References (\#) \\
\hline \multicolumn{4}{|c|}{ Nudibranchia (68) } \\
\hline Bathydoris hodgsoni & Hodgsonal (1) & $\begin{array}{l}\text { Sea star Odontaster validus, } \\
\text { anemone Epiactis sp. }\end{array}$ & [54-56] \\
\hline Doris (Austrodoris) kerguelenensis & Diterpene diacylglycerides (2) & $\begin{array}{l}\text { Sea star Odontaster validus, } \\
\text { anemone Epiactis sp. }\end{array}$ & [58-60] \\
\hline Aldisa sanguinea & $\begin{array}{l}\text { 3-Oxo-chol-4-ene-24-oic acid (3), } \\
\text { unsaturated analogue (4) }\end{array}$ & Goldfish (Carassius auratus) & [73] \\
\hline Aldisa andersoni & $\begin{array}{c}\text { 9-Chloro-phorbazole D (5), } \\
\text { N1-methyl-phorbazole A (6), } \\
\text { phorbazoles A (7), B (8), and D (9) }\end{array}$ & Shrimp & {$[54,56,75-77]$} \\
\hline Sclerodoris tanya & Tanyolides A (10) and B (11) & $\begin{array}{l}\text { Fishes (Gibbonsia elegans and } \\
\text { Paraclinus integrippinis) }\end{array}$ & [78] \\
\hline Paradoris (Discodoris) indecora & Variabilin (12) & Marine and freshwater fishes & [79] \\
\hline Dendrodoris limbata & Polygodial (13), olepupuane (14) & Marine and freshwater fishes & {$[80,81,83,84]$} \\
\hline Dendrodoris arborescens & 7-Deacetoxyolepupuane (15) & Feeding deterrence & [87] \\
\hline
\end{tabular}


Table 2. Cont

\begin{tabular}{|c|c|c|c|}
\hline Species (\#) & Compounds (\#) & Predator(s) Tested & References (\#) \\
\hline Dendrodoris carbunculosa & Dendrocarbins A-N (16) & Feeding deterrence & [86] \\
\hline Dendrodoris denisoni & $\begin{array}{l}\text { Cinnamolide (17), olepupuane (14), } \\
\text { polygodial (13) }\end{array}$ & Fish & [88] \\
\hline Doriopsilla pelseneeri & $\begin{array}{l}\text { Pelseneeriols } 1 \text { (18) and 2, polygodial } \\
\text { (13) }\end{array}$ & Feeding deterrence & {$[95,99]$} \\
\hline $\begin{array}{c}\text { Doriopsilla albopunctata, } \\
\text { D. areolata, D. janaina, D. pharpa }\end{array}$ & $\begin{array}{c}\text { ent-pallescensin A (19), } \\
\text { 15-acetoxy-ent-pallescensin (20) }\end{array}$ & Feeding deterrence & {$[96,97,99]$} \\
\hline Doriopsilla pharpa & Polygodial (13) & $\begin{array}{c}\text { Fishes (Chasmodes bosquianus, } \\
\text { Fundulus heteroclitus), crabs } \\
\text { (Callinectes similus, Panopeus } \\
\text { herbstii) }\end{array}$ & [98] \\
\hline Phyllidia varicosa & $\begin{array}{l}\text { 9-Isocyanopupukeanane (21), } \\
\text { 2-isocyanopupukeanane (22) }\end{array}$ & Fish & [106-108] \\
\hline $\begin{array}{l}\text { Phyllidia coelestis, Phyllidiella } \\
\text { pustulosa }\end{array}$ & Xidaoisocyanate A (24) & Fish & [117] \\
\hline P. pustulosa & $\begin{array}{c}\text { Axisonitrile-3 (25), amphilectene (26), } \\
\text { kalihinol A (27), kalihinol E (28), } \\
\text { ent-stylotelline (29) }\end{array}$ & Goldfish (C. auratus) & {$[118,120,123]$} \\
\hline Cadlina luteomarginata & $\begin{array}{l}\text { Isocyanides (30), albicanyl acetate (31), } \\
\text { cadlinaldehyde (32), luteone (33), } \\
\text { 1a,2a-diacetoxyalbicanyl acetate (34) }\end{array}$ & $\begin{array}{l}\text { Fishes (Carassius auratura, } \\
\text { Clinocottus analis) }\end{array}$ & [126-130] \\
\hline $\begin{array}{l}\text { Chromodoris africana, } \\
\text { C. (Glossodoris) quadricolor }\end{array}$ & Kurospongin (36), latrunculin B (37) & Fish (Tilapia mosambica) & {$[167,168,170,171]$} \\
\hline Chromodoris hamiltoni & $\begin{array}{l}\text { Latrunculins A (38) and B (37), } \\
\text { hamiltonins A-E }(\mathbf{4 1}, \mathbf{4 2})\end{array}$ & Feeding deterrence & {$[153,155]$} \\
\hline $\begin{array}{l}\text { Glossodoris vespa, G. averni, } \\
\text { G. pallida }\end{array}$ & 12-Deacetoxy-12-oxoscalaradial (43) & Shrimp (Palaemon serenus) & [175-177] \\
\hline Glossodoris pallida & $\begin{array}{l}\text { Scalaradial (44), deacetylscalaradial } \\
(45), \text { deoxoscalarin }(46)\end{array}$ & $\begin{array}{l}\text { Crabs (Leptodius sp.), fish } \\
\text { (Abudefduf sexfasciatus) }\end{array}$ & [176-178] \\
\hline $\begin{array}{l}\text { Ceratosoma trilobatum, } \\
\text { C. gracillimum }\end{array}$ & $\begin{array}{c}\text { Pallescensin B (47), (-)-furodysinin } \\
\text { (48), (-)-dehydroherbadysidolide (49), } \\
\text { (-)-herbadysidolide (50), nakafuran-9 } \\
\text { (51), dendrolasin (55), furodysin (58), } \\
\text { agassizin (59) }\end{array}$ & Goldfish (C. auratus) & {$[131,193-196]$} \\
\hline $\begin{array}{l}\text { Felimare (Hypselodoris) picta } \\
\text { webbi, F. (Hypselodoris) villafranca, } \\
\text { F. (Hypselodoris) cantabrica, } \\
\text { F. (Hypselodoris) tricolor, } \\
\text { F. (Hypselodoris) fontandraui }\end{array}$ & Longifolin (52) & Shrimp (P. elegans) & {$[124,165]$} \\
\hline $\begin{array}{l}\text { Felimare (Hypselodoris) } \\
\text { fontandraui }\end{array}$ & Tavacpallescensin (53) & Shrimp (P. elegans) & {$[205,211]$} \\
\hline Hypselodoris capensis & Nakafuran-8 and $-9(\mathbf{5 4 , 5 1 )}$ & Feeding deterrence & [213] \\
\hline Hypselodoris obscura & $\begin{array}{l}\text { Dendrolasin (55), (-)-euryfuran (56), } \\
(+) \text {-pallescensin A (57), } \\
\text { (-)-furodysinin (48), (-)-furodysin (58) }\end{array}$ & Feeding deterrence & [186] \\
\hline Hypselodoris whitei & $\begin{array}{l}\text { (-)-Euryfuran (56), (-)-furodysin (58), } \\
(-) \text {-furosydinin (48), dendrolasin (55) }\end{array}$ & Feeding deterrence & [186] \\
\hline Hypselodoris infucata & $\begin{array}{c}\text { Nakafuran-8 and }-9(\mathbf{5 4 , 5 1 )} \\
(-) \text {-furodysinin }(\mathbf{4 8})\end{array}$ & Shrimp (Penaeus vannamei) & {$[157,165,186]$} \\
\hline Hypselodoris benneti & $\begin{array}{l}\text { Euryfuran (56), agassizin (59), } \\
\text { dehydroherbadysidolide (49), } \\
\text { pallescensone (60) }\end{array}$ & Feeding deterrence & [178] \\
\hline Hypselodoris (Risbecia) tryoni & $\begin{array}{l}\text { Dehydroherbadysidolide (49), } \\
\text { furodysinin (48), nakafuran-9 (51), } \\
\text { dendrolasin (55) }\end{array}$ & Feeding deterrence & [178] \\
\hline Hypselodoris kanga & Furodysinin (48) & Feeding deterrence & [166] \\
\hline Hypselodoris lajensis & Furodysinin lactone (61) & Feeding deterrence & [207] \\
\hline Mexichromis festiva & Euryfuran (56), dendrolasin (55) & Feeding deterrence & {$[178]$} \\
\hline Mexichromis marieri & Euryfuran (56) & Feeding deterrence & [178] \\
\hline Hexabranchus sanguineus & $\begin{array}{c}\text { Kabiramide C (62), } \\
\text { dihydrohalichondramide (63), } \\
\text { sanguinamides A (64) and B }\end{array}$ & $\begin{array}{l}\text { Fish (Thalassoma lunare), crab } \\
\text { (Dardanus megistos) }\end{array}$ & [217-222] \\
\hline
\end{tabular}


Table 2. Cont

\begin{tabular}{|c|c|c|c|}
\hline Species (\#) & Compounds (\#) & Predator(s) Tested & References (\#) \\
\hline Tambja abdere, T. eliora & $\begin{array}{l}\text { Tambjamines A-F (65-70), } \\
\text { tambjamine aldehyde (71) }\end{array}$ & Fish & {$[160,224,225]$} \\
\hline Roboastra tigris, Nembrotha spp. & $\begin{array}{c}\text { Tambjamines A-F (65-70), } \\
\text { tambjamine aldehyde (71), tetrapyrrol } \\
(\mathbf{7 2})\end{array}$ & Fish & {$[137,157,223,226,227]$} \\
\hline Tritonia hamnerorum & Julieannafuran (73) & Fish & [229] \\
\hline Tritoniella belli & 1-O-hexadecyl glycerol (74) & Seastar (O. validus) & [230] \\
\hline Tritoniopsis elegans & Tritoniopsins A-D (75-78) & Feeding deterrent & [234] \\
\hline Marionia blainvillea & Homarine (79) & Feeding deterrent & [235] \\
\hline Tethys fimbria, Melibe viridis & $\begin{array}{l}\text { PGE }_{2}-1,15 \text {-lactone }(\mathbf{8 0}), \\
\text { PGE }_{3}-1,15 \text {-lactone }(\mathbf{8 1})\end{array}$ & Feeding deterrent & {$[237,238]$} \\
\hline Charcotia granulosa & Granuloside (82) & Seastar (O. validus) & {$[241,242]$} \\
\hline $\begin{array}{c}\text { Cratena pilata, Cuthona gymnota, } \\
\text { Hermissenda crassicornis, Phestilla } \\
\text { lugubris, Cuthona coerulea, } \\
\text { Flabellina exoptata, F. ischitana, } \\
\text { F. pedata, F. affinis }\end{array}$ & Homarine (79) & Feeding deterrent & [235] \\
\hline $\begin{array}{l}\text { Phyllodesmium magnum, } \\
\text { Phyllodesmium guamensis }\end{array}$ & 11ß-Acetoxypukalide (83) & Pufferfish (Canthigaster solandri) & {$[236,249]$} \\
\hline Phyllodesmium longicirrum & $\begin{array}{l}\text { Trocheliophorol (84), 4-oxochatancin } \\
\text { (85), (2S)-isosarcophytoxide (86), } \\
\text { cembranoid bisepoxide } 12\end{array}$ & Pufferfish (Canthigaster solandri) & {$[245,250,251]$} \\
\hline \multicolumn{4}{|c|}{ Tylodinoidea (3) } \\
\hline Tylodina fungina, T. perversa & 3,5-Dibromotyrosine (87) & Feeding deterrent & {$[256,257]$} \\
\hline Tylodina corticalis & Bromotyrosine-derived alkaloids & Feeding deterrent & [258] \\
\hline \multicolumn{4}{|c|}{ Cephalaspidea (9) } \\
\hline Bulla striata, Philinopsis depicta & Aglajnes 1-3 (88) & Fish (C. auratus) & [269] \\
\hline Bulla gouldiana, Navanax inermis & Pulo'upone (90) & Feeding deterrent & {$[278]$} \\
\hline Aglaja tricolorata & Homarine (79) & Reef fish & [235] \\
\hline Haminoea cymbalum & Kumepaloxane (91), tetrahydropyran & Porcupine fish & [280] \\
\hline Haminoea cyanomarginata & Tetrahydropyran & Shrimp (P. elegans) & [77] \\
\hline $\begin{array}{l}\text { Sagaminopteron nigropunctatum, } \\
\text { S. psychedelicum }\end{array}$ & $\begin{array}{c}3,5 \\
\text { Dibromo-2-(2', } 4^{\prime} \text {-dibromo-phenoxy)phenol } \\
(\mathbf{9 2})\end{array}$ & Feeding deterrent & [282] \\
\hline \multicolumn{4}{|c|}{ Anaspidea (5) } \\
\hline $\begin{array}{c}\text { Aplysia californica, A. dactylomela, } \\
\text { A. parvula }\end{array}$ & Aplysioviolin (93), phycoerythrobilin & Blue crabs, lobsters & {$[289,290,292]$} \\
\hline Aplysia parvula & $\begin{array}{c}\text { Apakaochtodene A (94) and B, } \\
\text { costatone (95) }\end{array}$ & Fish & {$[88,299,300]$} \\
\hline Stylocheilus longicauda & $\begin{array}{c}\text { Aplysiatoxin (96), } \\
\text { debromoaplysiatoxin (97), } \\
\text { stylocheilamide (98), makalika ester } \\
\text { (99), makalikone ester (100), } \\
\text { lyngbyatoxin A acetate (101), } \\
\text { malyngamide A (104), malyngamide } \\
\text { B, malyngamide O (102), and } \\
\text { malyngamide P (103) }\end{array}$ & $\begin{array}{l}\text { Fish, amphipods, crabs, } \\
\text { cephalaspidean }\end{array}$ & {$[302,303]$} \\
\hline Bursatella leachii & Bursatellin (105) & $\begin{array}{l}\text { Fish (Oreochromis mossambicus } \\
\text { and Caffragobius gilchristi) }\end{array}$ & {$[311,312]$} \\
\hline \multicolumn{4}{|c|}{ Pteropoda (1) } \\
\hline Clione limacina & Pteroenone (106) & Fish & [314] \\
\hline \multicolumn{4}{|c|}{ Sacoglossa (9) } \\
\hline Ascobulla ulla & Ascobullin A (107) and B & Feeding deterrent & [316] \\
\hline Elysia crispata & Crispatenine, onchidal (108) & Feeding deterrent & [131] \\
\hline Elysia translucens & Udoteal & Fish (Pomacentrus coeruleus) & {$[320]$} \\
\hline Thuridilla hopei & $\begin{array}{l}\text { Thuridillins (110), nor-thuridillonal } \\
\text { (111), epoxylactone }\end{array}$ & Shrimp (P. elegans) & {$[123,321,322]$} \\
\hline Costasiella ocellifera & Avrainvilleol (112) & Fish & {$[316,325]$} \\
\hline Cyerce cristallina, C. nigricans & Cyercenes (113), chlorodesmin (114) & Mosquito fish (Gambusia affinis) & [326-328] \\
\hline Mourgona germaineae & Cyclocymopol (115) & Fish & [330] \\
\hline
\end{tabular}


Table 2. Cont.

\begin{tabular}{|c|c|c|c|}
\hline Species (\#) & Compounds (\#) & Predator(s) Tested & References (\#) \\
\hline Placida dendritica & Polypropionate $\gamma$-pyrones (116) & Feeding deterrent & [332] \\
\hline \multicolumn{4}{|c|}{ Pulmonata (11) } \\
\hline Onchidella binneyi & Onchidal (108), ancistrodial (109) & Fish and crabs & [319] \\
\hline Peronia peronii, Onchidium ssp. & $\begin{array}{l}\text { Onchidin (121), onchidione (122), onchidiol, } \\
\text { 4-epi-onchidiol }\end{array}$ & Sea stars & {$[343,358,359,361,362]$} \\
\hline Trimusculus costatus & $\begin{array}{l}\text { Labdanes } 6 \beta, 7 \text { a-diacetoxylab-8,13-dien-15-ol } \\
\text { (117), } 2 \alpha, 6 \beta, 7 \text { a-triacetoxylabda-8,13-dien-15-ol } \\
\text { (118) }\end{array}$ & $\begin{array}{l}\text { Fish (Pomadasys } \\
\text { commersonnii) }\end{array}$ & {$[333]$} \\
\hline $\begin{array}{l}\text { Trimusculus reticulatus, } \\
\text { T. costatus, T. peruvianus }\end{array}$ & $\begin{array}{c}\text { 6 } \beta \text {-isovaleroxylabda-8,13-dien-7 } \alpha, 15 \text {-diol, } \\
2 \alpha, 7 \alpha \text {-diacetoxy-6/3-isovaleroxylabda-8,13-dien- } \\
\text { 15-ol }\end{array}$ & Sea stars & [334-337] \\
\hline $\begin{array}{l}\text { Siphonaria capensis, S. concinna, } \\
\text { S. cristatus, S. serrata }\end{array}$ & $\begin{array}{c}\text { Siphonarienolone (119), siphonarin A (120), } \\
\text { diemenensins A and B }\end{array}$ & Fish & {$[341,342,344,347,350]$} \\
\hline
\end{tabular}

\subsection{Toxicity}

Toxicity was the first described activity in heterobranch molluscs, when the mucus secretion of Phyllidia varicosa was reported to be toxic to fish and crustaceans [106,109]. All nudibranchs except aeolidids, and all the other groups except pleurobranchoideans and pteropods, have been described to use toxic compounds for protection and survival (Figures 6 and 7). Toxicity may affect putative macropredators, such as fish, crabs, or others; small micropredators, such as amphipods or other crustaceans; and even gametes and early embryos of potential competitors or predators (Table 3). As mentioned above, the problem of assays that use species that are not sympatric puts in question the ecological validity of some of the results.

\subsubsection{Nudibranchia}

Doridacea

Species of the genus Archidoris present de novo biosynthesized ichthyotoxic diterpene glycerides (123) [71,363-367]. In the Atlantic, A. pseudoargus locates them in the mantle and egg masses [363]. Their compounds include a wide variety of terpenoids and related compounds (sesquiterpenoic and diterpenoic acid glycerides and glyceryl ether), although not all of them have been tested for ichthyotoxicity [367-373]. Doris verrucosa also presents ichthyotoxic diterpenoid acid glycerides, the verrucosins (124), active in the laboratory against Gambusia affinis, and most probably biosynthesized [370-372].

Phyllidia varicosa accumulates sponge compounds and secretes them in the mucus, producing toxicity in fish and crustaceans [106,109]. Among several other bioactive compounds, 9-isocyanopupukeanane (21) and 2-isocyanopupukeanane (22) are obtained from the demosponge Ciocalypta (Hymeniacidon) [106,107]. When 9-isocyanopupukanane (21) was tested using the killifish Oryzias latipes, it was more toxic than its 9-epi-isomer, while 2-isocyanoallopupukeanane (125) was toxic at $10 \mu \mathrm{g} / \mathrm{mL}[101,185]$. In Indonesia, P. varicosa feeds on Axinyssa aculeata sequestering two epimeric 9-thiocyanatopupekeanane sesquiterpenes (126), which, together with 9-isocyanopupukeanane (21), are mildly toxic to brine shrimp $\left(\mathrm{LC}_{50} 5 \mathrm{ppm}\right)$ in the laboratory [110]. P. pulitzeri and its sponge food, Axinella cannabina, possess axisonitrile-1 (127), which was toxic against the marine fish Chromis chromis and the freshwater fish Carassius carassius [184]. Many other phyllidid species (P. rosans (P. bourguini), P. coelestis, P. ocellata, Phyllidia sp, Phyllidiella pustulosa, Phyllidiopsis krempfi, etc.) contain a wide variety of these and other nitrogenated compounds, but these have not been tested for toxicity [101-103,111,114,118-120,122,373-377]. 
<smiles>CC1=CC[C@]2(C)[C@@]3(C)CCCC(C)(C)[C@@]3(C)CC[C@]2(C)[C@H]1C(=O)OC[C@@H](O)CO</smiles><smiles>CC1CC2CC(C(C)C)C(C1)CC2C#N</smiles>

126 9-thiocyanatopupukeanane<smiles>C=C(C1C(OC(C)=O)OC2OC(=O)C[C@@H]21)C1CCC2C(C)(C)CCCC12C</smiles>

130 Norrisolide<smiles>C#[N+][C@H]1[C@H](C(C)C)CC[C@]2(C)CCCC(=C)[C@]12C</smiles>

127 Axisonitrile-1<smiles>CC(=O)OC[C@@H](O)COC(=O)[C@H]1[C@@H](C)CC[C@]2(C)[C@@H]3CCCC(C)(C)C3=CC[C@]12C</smiles><smiles>CC(C)[C@H]1CC2CC3CC1CC(C)(C)C(C3)C2</smiles>

125 2-isocyanoallopupukeanan<smiles>C=CC/C=C\Cc1csc(C(C)(C)C(O)C/C=C/C(=C)CCNC(=O)OC)n1</smiles><smiles>CC1C2C3[C@@H](C)CCC[C@H]3CCC2C1(C)C</smiles>

128 Isothiocyanate
C$$
129 \mathrm{Mycothizzote}
$$<smiles>CC(=O)O[C@H]1OC(=O)c2ccc([C@@]3(C)CCCC(C)(C)C3)c(C(C)=O)c21</smiles>

134 Macfarlandin A

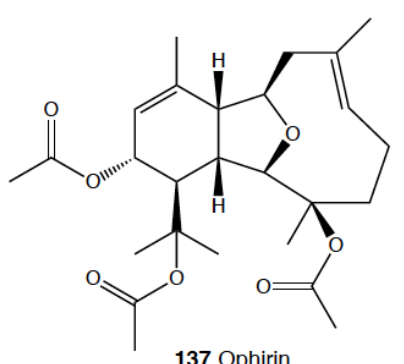

137 Ophirin<smiles>CC(=O)[C@H]1[C@@H](CCC/C=C/c2ccccn2)C=C[C@H]2CCC[C@@H]21</smiles>
35 12-deacetyl-23-acetoxy-

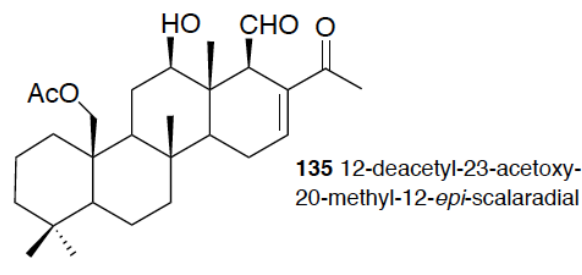<smiles>CN[C@@H](C)C(=O)N[C@@H](C)[C@@H](O)[C@@H](C)C(=O)N1C(=O)C(C)(C)C(=O)[C@H]1C(C)C</smiles><smiles>CC1(C)CCCC2(C)C1CCC1(C)C2CC(=O)[C@@]2(C)C1CC=C1CO[C@H](O)[C@H]12</smiles><smiles>C/C=C/CCCCC/C=C/C=C\C(=O)OCC(CO)OC(=O)/C=C/SC</smiles><smiles>CCC(C)/C=C(\C)C(=O)/C(C)=C/C(C)/C=C(C)/C=C(\C)c1oc(=O)c(C)c(O)c1C</smiles><smiles>C=C/C=C/C[C@H]1O[C@](C)([C@@H](C)Br)CC[C@@H]1C</smiles>

Figure 6. Structures of selected compounds displaying toxicity in Doridacea, Dendronotida, Euarminida, Tylodinoidea, and Cephalaspidea. These molecules may also display other activities, as reported in the text. 

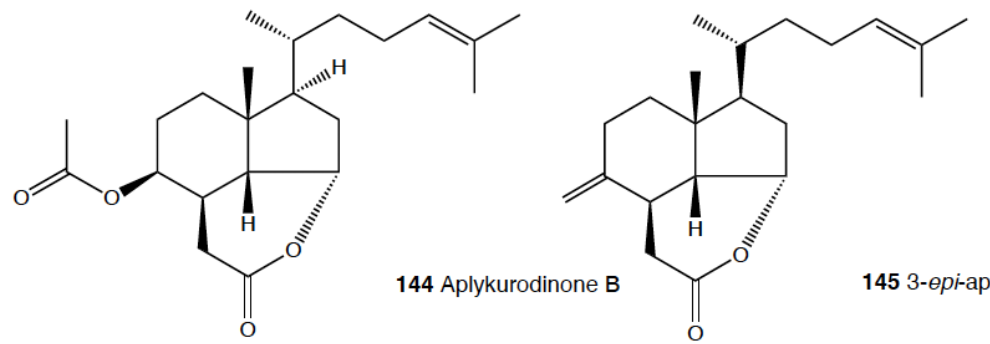

145 3-epi-aplykurodinone
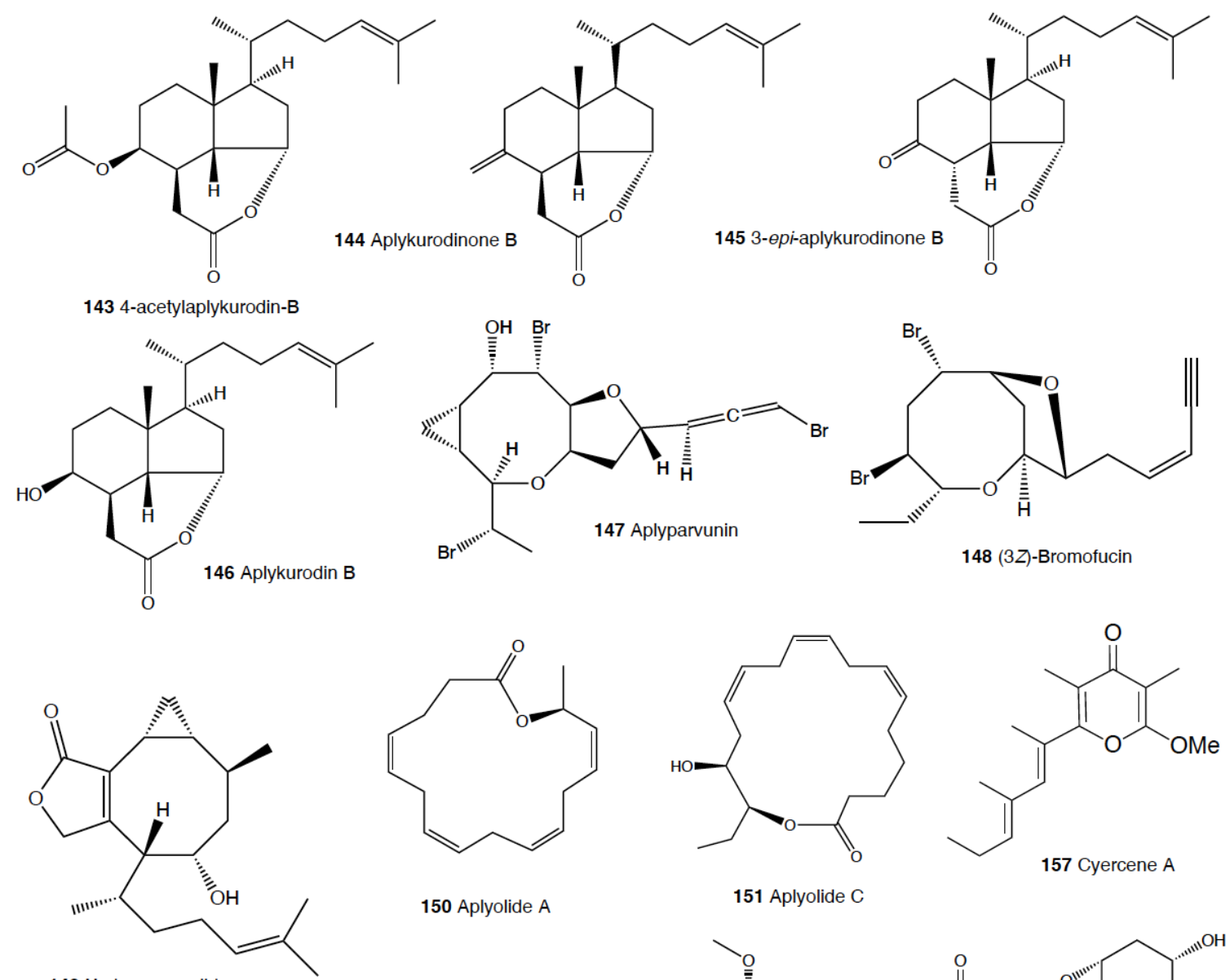

150 Aplyolide A

151 Aplyolide C

149 Hydroxycrenulide
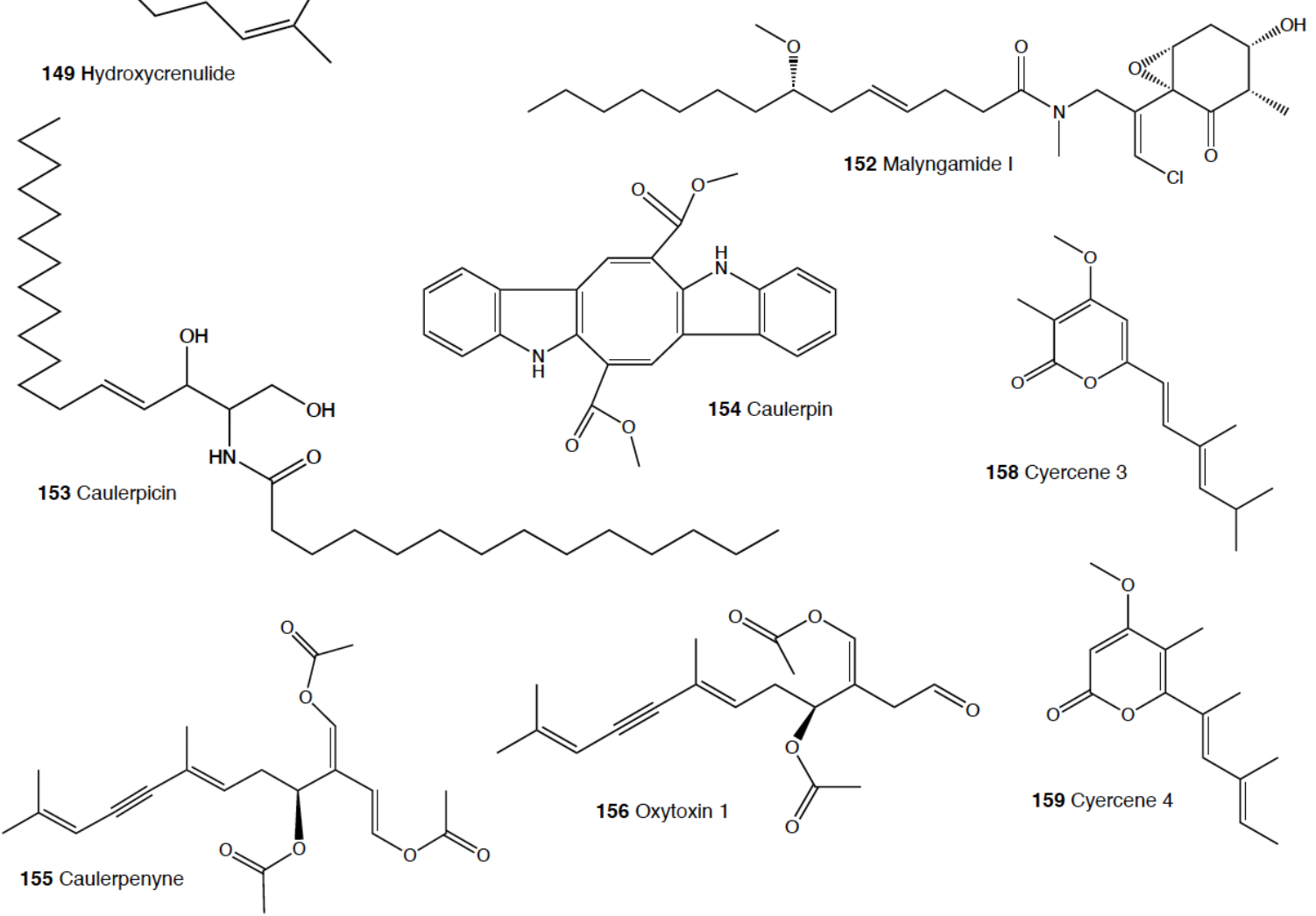

Figure 7. Structures of selected compounds displaying toxicity in Anaspidea, Sacoglossa, and Pulmonata. These molecules may also display other activities, as reported in the text. 
Within chromodoridids, Cadlina luteomarginata presents three isocyanides (30) and three isothiocyanates (128) obtained from its sponge diet [126,127]. These metabolites resulted toxic in laboratory at $100 \mu \mathrm{g} / \mathrm{mL}$, but no studies at natural concentrations and sympatric species are reported [126,127]. Further, as previously mentioned, the well-studied genus Chromodoris possess toxic compounds [1,6]. Kurospongin (36), a furanoterpene found in C. africana from the Red Sea, was obtained from an Okinawan Spongia sp. and reported to be strongly ichthyotoxic to the freshwater goldfish (C. auratus) at $5 \mu \mathrm{g} / \mathrm{mL}$ [167]. C. hamiltoni from South Africa and Mozambique presents one or both latrunculins A and B $(38,37)$, among other compounds, as does C. africana from the Red Sea, and C. quadricolor (Glossodoris quadricolor) [153,168-171]. Latrunculin B (37) has been reported to be ichthyotoxic and was described from the sponge Latrunculia magnifica $[168,169]$. The Mediterranean Felimida (Chromodoris) luteorosea contains many ichthyotoxic sponge-derived diterpenes tested in the laboratory, including norrisolide (130), polyrhaphin C (131), chelonaplysin C (132), luteorosin (133), macfarlandin A (134), and closely related compounds [149]. Although many other Chromodoris species possess interesting chemicals, they have not been tested for toxicity.

Among the scalarane sesterterpenes described in Doriprismatica (Glossodoris) sedna from Costa Rica, 12-deacetyl-23-acetoxy-20-methyl-12-epi-scalaradial (135) was ichthyotoxic to the allopatric fish Gambusia affinis at $0.1 \mathrm{ppm}$ [183]. Goniobranchus splendidus from Australia contains many sponge compounds, mainly spongian diterpenes, rearranged diterpenes, and nor-diterpenes [187]. Its chemical extracts have been proven to be toxic to brine shrimp (Artemia sp.) at natural concentrations, with potency depending on the mixture of chemicals present in each population analyzed, from no activity to toxicity [187]. Doriprismatica (Glossodoris) atromarginata presents furanoditerpenoids and scalarane sesterterpenes from its dietary sponges Spongia (Hyatella) sp. and Hyrtios spp., and these compounds display ichthyotoxicity against the mosquito fish, G. affinis-particularly, the activity of 12-deacetoxy-12-oxodeoxoscalarin (136) is noticeable [92,175,180,378-386]. Other NPs from chromodoridids were analyzed for ichthyotoxicity against G. affinis, including homoscalarane and scalarane compounds from Felimida (Glossodoris) dalli, Glossodoris rufomarginata, Glossodoris pallida, Glossodoris vespa, and Ardeadoris (Glossodoris) averni, and 12-deacetyl-23-acetoxy-20-methyl-12-epi-scalaradial (135) was the most potent of them $[175,183,383]$.

Ceratosoma trilobatum and C. gracillimum from China contain the furanosesquiterpenes pallescensin B (47), (-)-furodysinin (48), (-)-dehydroherbadysidolide (49), and (-)-herbadysidolide (50), previously found in Dysidea sponges. These were tested for toxicity in the laboratory against mosquito fish and were all observed to be non-toxic except (-)-furodysinin (48) [22,131,193].

\section{Dendronotida}

The Mediterranean species Tethys fimbria contains a variety of de novo synthesized prostaglandins with diverse functions $[1,240]$, among which is a prostaglandin lactone, $\mathrm{PGE}_{2}-1,15$-lactone (80), later also found in Melibe viridis [77]. This prostaglandin lactone (80) is located in the mucus and cerata of T. fimbria and is ichthyotoxic in the laboratory against the mosquito fish [77].

\section{Euarminida}

Two euarminid species are reported to present toxic compounds. In China, Dermatobranchus ornatus has been reported to possess compounds inhibiting cell division in fertilized starfish eggs [9]. D. ornatus possesses four diterpenoids of the eunicellin class in the mantle, ophirin (137), calicophirin B, 13-deacetoxyl calicophirin B, and 13-deacetoxyl-3-deacetyl calicophirin B, two of them probably from its diet on the gorgonian Muricella sinensis, and another one previously found in an unidentified soft coral from the Pacific Ocean [22,387]. Among them, ophirin (137) is reported to induce brine shrimp (Artemia sp.) lethality. The second case is that of Janolus cristatus, which possesses janolusimide (138), a toxic tripeptide which is toxic to mice at LD $5 \mathrm{mg} / \mathrm{kg}[388,389]$. The $\mathrm{N}$-methyl analogue, janolusimide $\mathrm{B}$, has been further isolated from Bugula flabellata, a bryozoan from New Zealand, thus suggesting a putative dietary origin for janolusimide (138) [390]. 


\subsubsection{Tylodinoidea}

The Mediterranean Umbraculum mediterraneum contains diacylglycerid fatty acid esters that are ichthyotoxic to the mosquito fish in the laboratory [391-393]. These natural products, umbraculumins A, B, and C (139), are suggested to be obtained from their sponge prey [263].

\subsubsection{Cephalaspidea}

Several compounds from Bulla species, such as niuhinone-B, isopulo'upone (140), and 5,6-dehydroaglajne-3 (141), are polypronionates described to be toxic to fish and shrimp [274,278]. Niuhinone-B is found in the Pacific B. gouldiana and the Mexican B. occidentalis [274,278]. In the Pacific Ocean, Navanax inermis also uses these compounds after ingesting B. gouldiana specimens, while in Hawai'i, Philinopsis depicta probably obtains niuhinone-B from other cephalaspideans [272,273,278]. $N$. inermis also contains isopulo'upone (140), which is reported to be a strong ichthyotoxin that significantly affects the mosquito fish Gambusia affinis at $10 \mathrm{ppm}$ and Artemia salina at $2 \mathrm{ppm}$ in the laboratory [271,394]. The Mediterranean P. depicta contains aglajne-3 (88), a polypropionate toxic to Artemia salina $\left(\mathrm{LD}_{50}<35 \mathrm{ppm}\right)$ and Gambusia affinis [270].

Haminoea species also possess some toxic compounds. In the Mediterranean, $H$. cyanomarginata presents a brominated tetrahydropyran (142) reported to be highly toxic to the mosquito fish G. affinis at $1 \mathrm{ppm}$ in the laboratory [77]. This tetrahydropyran (142) was also found in the Indian H. cymbalum, where it could play the same role, and it is structurally similar to kumepaloxane (91) from conspecifics of Guam [280].

\subsubsection{Anaspidea}

Several sea hares are reported to use toxic compounds. In the Mediterranean, Aplysia fasciata presents different compounds in different locations, with polyhalogenated monoterpenes similar to those of Plocamium red algae in some places [395], but some degraded sterols in other localities, such as 4-acetylaplykurodin-B (143), aplykurodinone B (144), and 3-epi-aplykurodinone B (145), which are located in the mantle and are described to be ichthyotoxic to the mosquito fish G. affinis in the laboratory [396]. These compounds are also related to the steroids found in the Atlantic A. fasciata [397] and to aplykurodin B (146) from the Pacific A. kurodai [398]. In Japan, instead, $A$. parvula possesses the ichthyotoxic brominated acetogenin dicyclic ether, aplyparvunin (147), which possesses strong activity ( $\mathrm{LC}_{100} 3 \mathrm{ppm}$ in 24h) against G. affinis in the laboratory [399], while specimens from South East Africa present (3Z)-bromofucin (148), a halogenated cyclic acetogenin obtained from its red algal food, Laurencia implicata [400]. A. vaccaria from the Pacific Ocean presents also ichthyotoxic compounds, in this case, the crenulides (149), non-halogenated diterpenoids obtained from its brown algal food, Dictyota crenulata, and located in their digestive gland [401,402]. Crenulides (149) are toxic to the reef-dwelling fish Eupomacentrus leucosticus at $10 \mu \mathrm{g} / \mathrm{mL}$ [401,402]. A. depilans also possesses ichthyotoxic fatty acid lactones, the aplyolides A-E $(\mathbf{1 5 0 , 1 5 1 ) , ~ w h i c h ~ a r e ~ t o x i c ~ i n ~ t h e ~ l a b o r a t o r y ~}$ to the mosquito fish G. affinis at $10 \mathrm{ppm}$ [403]. In the Caribbean, A. argus presents ichthyotoxic biotransformed compounds from its diet, the brown algae Stypopodium zonale, but it possesses the bioactive diphenyl ether 2-( $2^{\prime}, 4^{\prime}$ dibromophenoxy)-dibromoanisole from the green alga Cladophora vagabunda in the digestive gland when it feeds on it [404,405].

Several bioactive compounds have also been isolated from Stylocheilus, mostly related to cyanobacterial metabolites [301-310]. However, only the related acetyl malyngamide I (152) from the Hawaiian Lyngbya majuscula was found to be ichthyotoxic [306], being structurally similar to stylocheilamide (98), a non-toxic amide from the Hawaiian S. longicauda [304].

\subsubsection{Sacoglossa}

The first toxic species reported in this group was Oxynoe panamensis from California, containing caulerpicin (153) and caulerpin (154) from its green algal food, Caulerpa sertularioides [406]. 
Later, in the Mediterranean, the shelled sacoglossans Oxynoe olivacea and Ascobulla (Cylindrobulla) fragilis were described to biotransform the sesquiterpenoid caulerpenyne (155) from its green algal food (Caulerpa prolifera) into the more potent ichthyotoxic aldehydes, oxytoxin-1 (156) and oxytoxin-2 [316,407]. In particular, oxytoxin-1 (156) is toxic to the mosquito fish G. affinis at $>10 \mu \mathrm{g} / \mathrm{mL}$ in the laboratory, while oxytoxin- 2 is toxic at $1 \mu \mathrm{g} / \mathrm{mL}$. These animals are able to transport the compounds from the digestive gland to the mantle and secrete them into toxic whitish mucus [407]. Similarly, Lobiger serradifalci, also feeding on C. prolifera, presents only oxytoxin-1 (156) in its parapodial lobes and defensive secretion $[407,408]$. In the Caribbean species Ascobulla ulla (eating Caulerpa fastigiata), Oxynoe antillarum (eating Caulerpa sp.), and Lobiger souberveii (eating Caulerpa racemosa), also caulerpenyne (155) is also found [316]. In fact, only caulerpenyne (155) is detected in L. souberveii, while the rest of species modify it to oxytoxins (156) [316]. Caulerpenyne (155) is also found in Volvatella sp. in India [409].

Some shell-less species use the same system, transforming caulerpenyne (155) from Caulerpa species into oxytoxins (156) [410]. The Caribbean Elysia subornata feeds on Caulerpa prolifera, while E. patina and E. nisbeti feed on Caulerpa sp., and they all present caulerpenyne (155) and oxytoxin-1 (156) [316]. In India, E. cf. expansa also contains caulerpenyne (155), along with dihydrocaulerpenyne and expansinol, some minor reduced derivatives, similar to Ascobulla ulla compounds (see above) [411]. In A. ulla, ascobullin A (107) and ascobullin B have replaced oxytoxins, being structurally related but less reactive compounds detoxification process [316,411].

Avrainvilleol (112) from Costasiella ocellifera (C. lilianae) from the Caribbean is toxic to sympatric reef fishes at $10 \mu \mathrm{g} / \mathrm{mL}$ [325].

Cyercenes (113) are pyrone compounds found in several shell-less sacoglossans, displaying a very strong ichthyotoxicity against the mosquito fish, G. affinis in the laboratory [326,327]. The Mediterranean Cyerce cristallina de novo biosynthesizes the $\alpha$ - and $\gamma$-pyrones cyercene $\mathrm{A}(\mathbf{1 5 7})$ and $\mathrm{B}$, as well as cyercenes $1-5(\mathbf{1 5 8 , 1 5 9 )}[326,327]$. In the toxicity assays, the most active compounds were cyercene A (157), cyercene-3 (158), and cyercene-4 (159), all at $10 \mu \mathrm{g} / \mathrm{mL}[326,327]$. Although many other compounds of interest have been described in this group [19,412-419], they have not been proven to be toxic against sympatric species.

Table 3. Number of toxic compounds in the different heterobranch groups. In brackets: number of species with toxic compounds, number of the compounds in figures, and reference numbers. \# NumberSpecies (\#).

\begin{tabular}{|c|c|c|c|}
\hline & Compounds (\#) & Activity & References (\#) \\
\hline \multicolumn{4}{|c|}{ Nudibranchia (22) } \\
\hline Archidoris pseudoargus & Diterpenoic acid glycerides (123) & Ichthyotoxicity & {$[363,366]$} \\
\hline Doris verrucosa & Verrucosins A (124) and B & $\begin{array}{l}\text { Ichthyotoxicity, potent activators } \\
\text { of PKC, and promotion of tentacle } \\
\text { regeneration in the freshwater } \\
\text { hydrozoan Hydra vulgaris }\end{array}$ & {$[371,420]$} \\
\hline Phyllidia varicosa & $\begin{array}{l}\text { 2-Isocyanopupukeanane (22), 9-isocyanopupukeanane } \\
\text { (21), 2-isocyanoallopupukeanane (125), } \\
\text { 9-Thiocyanatopupekeanane (126) }\end{array}$ & $\begin{array}{l}\text { Toxic to brine shrimp, killifish } \\
\text { (Oryzias latipes), and crustaceans }\end{array}$ & {$[106,110,123]$} \\
\hline Phyllidia pulitzeri & Axisonitrile-1 (127) & $\begin{array}{c}\text { Toxic to fish (Chromis chromis and } \\
\text { Carassius carassius) }\end{array}$ & [184] \\
\hline $\begin{array}{l}\text { Phyllidiella rosans } \\
\text { (P. bourguini) }\end{array}$ & $\begin{array}{l}\text { 9-Isocyanopupukeanane (21), } \\
\text { epi-9-isocyanopupukeanane }\end{array}$ & $\begin{array}{l}\text { Ichthyotoxic to killifish } \\
\text { Oryzias latipes }\end{array}$ & [373] \\
\hline Cadlina luteomarginata & Isocyanides (30), isothiocyanates (128) & $\begin{array}{l}\text { Toxic to goldfish } \\
\text { (Carassius auratus) }\end{array}$ & {$[126,127]$} \\
\hline Chromodoris africana & Kurospongin (36) & Ichthyotoxicity & [167-169] \\
\hline $\begin{array}{l}\text { Chromodoris africana, } \\
\text { C. quadricolor }\end{array}$ & $\begin{array}{l}\text { Latrunculins A (38) and B (37), kurospongin (36), } \\
\text { 2-thiazolidinone }\end{array}$ & Ichthyotoxicity & {$[167,170,171]$} \\
\hline $\begin{array}{l}\text { Felimida (Chromodoris) } \\
\text { luteorosea }\end{array}$ & $\begin{array}{l}\text { Norrisolide (130), polyrhaphin C (131), chelonaplysin } \\
\text { C (132), luteorosin (133), macfarlandin A (134) }\end{array}$ & Ichthyotoxicity & [149] \\
\hline
\end{tabular}


Table 3. Cont

\begin{tabular}{|c|c|c|c|}
\hline & Compounds (\#) & Activity & References (\#) \\
\hline $\begin{array}{l}\text { Doriprismatica } \\
\text { (Glossodoris) sedna }\end{array}$ & $\begin{array}{l}\text { 12-Deacetyl-23-acetoxy-20-methyl-12-epi-scalaradial } \\
(\mathbf{1 3 5}), \\
\text { 12-deacetyl-23-acetoxy-20-methyl-12-epi-deoxoscalarin, } \\
\text { 12-deacetyl-20-methyl-12-epi-deoxoscalarin }\end{array}$ & Ichthyotoxic to Gambusia affinis & {$[183,421]$} \\
\hline $\begin{array}{l}\text { Doriprismatica } \\
\text { (Glossodoris) } \\
\text { atromarginata }\end{array}$ & 12-Deacetoxy-12-oxodeoxoscalarin (136) & $\begin{array}{l}\text { Ichthyotoxic to mosquito fish } \\
\text { (G. affinis) }\end{array}$ & {$[380,381]$} \\
\hline $\begin{array}{c}\text { Felimida (Glossodoris) dalli, } \\
\text { Glossodoris rufomarginata, } \\
\text { Glossodoris pallida, } \\
\text { Glossodoris vespa, } \\
\text { Ardeadoris } \\
\text { (Glossodoris) averni }\end{array}$ & $\begin{array}{c}\text { Homoscalarane, scalarane, } \\
\text { 12-deacetyl-23-acetoxy-20-methyl-12-episcalaradial } \\
\text { (135) }\end{array}$ & $\begin{array}{l}\text { Ichthyotoxic to mosquito fish } \\
\text { (G. affinis) }\end{array}$ & {$[175,183,383]$} \\
\hline $\begin{array}{l}\text { Ceratosoma trilobatum, } \\
\text { C. gracillimum }\end{array}$ & $\begin{array}{c}\text { Pallescensin B (47), (-)-furodysinin (48), } \\
\text { (-)-dehydroherbadysidolide (49), (-)-herbadysidolide } \\
\text { (50), nakafuran-9 (51) }\end{array}$ & Ichthyotoxicity & {$[22,131,193]$} \\
\hline $\begin{array}{l}\text { Tethys fimbria, } \\
\text { Melibe viridis }\end{array}$ & Prostaglandin-1,15-lactones $(\mathbf{8 0})$ & $\begin{array}{l}\text { Ichthyotoxic to mosquito fish } \\
\text { (G. affinis) }\end{array}$ & {$[77,240]$} \\
\hline Dermatobranchus ornatus & $\begin{array}{l}\text { Ophirin (137), calicophirin B, 13-deacetoxyl } \\
\text { calicophirin B, 13-deacetoxyl-3-deacetyl calicophirin B }\end{array}$ & $\begin{array}{l}\text { Inhibitory activity against the } \\
\text { growth of silkworm Bombyx mori, } \\
\text { and inhibition of cell division in } \\
\text { fertilized starfish eggs }\end{array}$ & {$[387,422,423]$} \\
\hline Janolus cristatus & Janolusimide (138) & Toxic to mice & {$[388,390]$} \\
\hline \multicolumn{4}{|c|}{ Tylodinoidea (1) } \\
\hline $\begin{array}{l}\text { Umbraculum } \\
\text { mediterraneum }\end{array}$ & Umbraculumins A-C (139) & $\begin{array}{l}\text { Ichthyotoxic to mosquito fish } \\
\text { (G. affinis) }\end{array}$ & {$[263,391-393]$} \\
\hline \multicolumn{4}{|c|}{ Cephalaspidea (7) } \\
\hline Bulla gouldiana & Niuhinone B, isopulo'upone (140) & $\begin{array}{l}\text { Ichthyotoxicity and } \\
\text { shrimp toxicity }\end{array}$ & [278] \\
\hline Bulla occidentalis & Niuhinone B & $\begin{array}{l}\text { Ichthyotoxicity and } \\
\text { shrimp toxicity }\end{array}$ & [274] \\
\hline Navanax inermis & $\begin{array}{l}\text { Niuhinone-B, isopulo'upone (140), } \\
\text { 5,6-dehydroagajne-3 (141) }\end{array}$ & $\begin{array}{l}\text { Ichthyotoxicity and } \\
\text { shrimp toxicity }\end{array}$ & [278] \\
\hline Philinopsis depicta & Niuhinone B, aglajne 3 (88) & $\begin{array}{l}\text { Toxic to G. affinis and } \\
\text { Artemia salina }\end{array}$ & {$[270]$} \\
\hline Philinopsis speciosa & $\begin{array}{l}\text { Niuhinone A, B, pulo'upone (90), kulolide-1 (271), } \\
\text { pupukeamide, tolytoxin-23-acetate }\end{array}$ & $\begin{array}{l}\text { Ichthyotoxicity and } \\
\text { shrimp toxicity }\end{array}$ & {$[272,273,275-277]$} \\
\hline Haminoea cyanomarginata & Brominated tetrahydropyran (142) & $\begin{array}{l}\text { Ichthyotoxic to mosquito fish } \\
\text { (G. affinis) }\end{array}$ & {$[77]$} \\
\hline Haminoea cymbalum & $\begin{array}{l}\text { Brominated tetrahydropyran (142), kumepaloxane } \\
\qquad(\mathbf{9 1 )}\end{array}$ & $\begin{array}{l}\text { Ichthyotoxic to mosquito fish } \\
\text { (G. affinis) }\end{array}$ & {$[280]$} \\
\hline \multicolumn{4}{|c|}{ Anaspidea (7) } \\
\hline Aplysia fasciata & $\begin{array}{l}\text { 4-Acetylaplykurodin-B (143), aplykurodinone B (144), } \\
\text { 3-epi-aplykurodinone B (145) }\end{array}$ & Ichthyotoxicity & [396] \\
\hline Aplysia juliana & $\begin{array}{l}\text { Pyropheophorbides } a \text { and } b \text {, halogenated diterpenoid } \\
\text { lactone, julianin-S }\end{array}$ & Lethal to crabs & [288] \\
\hline Aplysia kurodai & Aplykurodin B (146) & Ichthyotoxicity & [398] \\
\hline Aplysia parvula & Aplyparvunin (147), (3Z)-bromofucin (148) & Ichthyotoxicity & {$[399,400]$} \\
\hline Aplysia vaccaria & Crenulides (149) & Ichthyotoxicity & {$[401,402]$} \\
\hline Aplysia depilans & Aplyolides A-E (150-151) & Ichthyotoxicity & [403] \\
\hline Stylocheilus longicauda & $\begin{array}{l}\text { Makalika ester (99), makalikone ester (100), } \\
\text { malyngamide I (152), malyngamide O (102), } \\
\text { malyngamide P (103), lyngbyatoxin A acetate (101) }\end{array}$ & Ichthyotoxicity & [302-304] \\
\hline \multicolumn{4}{|c|}{ Sacoglossa (15) } \\
\hline Oxynoe panamensis & Caulerpicin (153), caulerpin (154) & Toxic to rats and mice & [406] \\
\hline $\begin{array}{l}\text { Oxynoe olivacea, Ascobulla } \\
\quad \text { fragilis }\end{array}$ & Caulerpenyne (155), oxytoxin 1 (156) and 2 & Ichthyotoxicity & {$[316,407]$} \\
\hline Lobiger serradifalci & Oxytoxin 1 (156) & Ichthyotoxicity & {$[316,407]$} \\
\hline Ascobulla ulla & Ascobullin A (107) and B & & [316] \\
\hline $\begin{array}{c}\text { Ascobulla ulla, Oxynoe } \\
\text { antillarum, Lobiger } \\
\text { souberveii, Volvatella sp., } \\
\text { Elysia subornata, E. patina, } \\
\text { E. nisbeti }\end{array}$ & Caulerpenyne (155), oxytoxin-1 (156) & Ichthyotoxicity & {$[316,409]$} \\
\hline
\end{tabular}


Table 3. Cont.

\begin{tabular}{|c|c|c|c|}
\hline & Compounds (\#) & Activity & References (\#) \\
\hline Elysia expansa & $\begin{array}{c}\text { Caulerpenyne (155), dihydrocaulerpenyne, } \\
\text { expansinol }\end{array}$ & Ichthyotoxicity & [411] \\
\hline $\begin{array}{l}\text { Costasiella ocellifera } \\
\text { (C. lilianae) }\end{array}$ & Avrainvilleol (112) & Toxic to sympatric reef fishes & [325] \\
\hline Placida dendritica & Iso-placidene-A (116) & $\begin{array}{l}\text { Strong ichthyotoxicity against } \\
\text { Gambusia affinis }\end{array}$ & [332] \\
\hline Cyerce cristallina & Cyercene A (157) and B, cyercenes $1-5(\mathbf{1 5 8 , 1 5 9 )}$ & $\begin{array}{l}\text { Strong ichthyotoxicity against } \\
\text { G. affinis }\end{array}$ & {$[326,327]$} \\
\hline \multicolumn{4}{|c|}{ Pulmonata (2) } \\
\hline Siphonaria maura & Vallartanones B & $\begin{array}{l}\text { In laboratory assays against krill } \\
\text { and fish (Thallasoma lunare) }\end{array}$ & [350] \\
\hline Trimusculus costatus & $\begin{array}{c}6 \beta, 7 a-D i a c e t o x y l a b-8,13-d i e n-15-o l(\mathbf{1 1 7}) \\
2 \alpha, 6 \beta, 7 a \text { a-triacetoxylabda-8,13-dien-15-ol (118) }\end{array}$ & $\begin{array}{l}\text { Toxic to brine shrimp } \\
\text { (Artemia salina) }\end{array}$ & [333] \\
\hline
\end{tabular}

\subsubsection{Pulmonata}

Trimusculus costatus from South Africa presents the labdanes 6 $\beta, 7 a-d i a c e t o x y l a b-8,13-d i e n-15-o l$ (117) and $2 \alpha, 6 \beta, 7 a-t r i a c e t o x y l a b d a-8,13-d i e n-15-o l$ (118), both toxic to the brine shrimp Artemia salina in the laboratory [333]. Siphonaria species present two different types of polypropionates, some of them located in the mucus and mantle border and reported to be ichthyotoxic [27,350]. Siphonaria maura from Mexico presents Vallartanone B, which in laboratory assays was rejected when applied to krill at $100 \mu \mathrm{g} / \mathrm{mg}$ and offered to the fish Thallasoma lunare [350].

\subsection{Antimicrobials}

Many marine organisms possess compounds to avoid microbial infections, and heterobranchs are no exception. Antimicrobial compounds against marine microorganisms described in heterobranchs are reported here (Figure 8, Table 4). To the best of our knowledge, however, euarminids, pleurobranchoids, tylodinoids, pteropods, and sacoglossans have not been studied for this activity to date.

\subsubsection{Nudibranchia}

Doridacea

Notodoris citrina from the Red Sea presents several imidazole alkaloids, among which isonaamidine-A (160) has been reported to strongly inhibit the AI-2 channel of the marine pathogen Vibrio harveyi, acting as a quorum sensing inhibitor [424,425]. Some of the compounds of N. citrina have been also found in the calcareous sponge Leucetta chagosensis, which is the slug diet at different geographical localities [424,425]. Isonaamidine-A (160) has also been found in Notodoris gardineri from the Philippines [426].

Several species of the colorful Phyllidids have been reported to contain isocyanate compounds with diverse bioactive properties [1,101-105]. As previously mentioned, this is a particularly difficult group to study since many species and genera are similar in shape and color, resulting in many misidentifications over the years [99], although some species have been studied in depth [101-105,427]. Phyllidiella pustulosa presents compounds obtained from the sponge Acanthella cavernosa [119]. Acanthella sponges are the dietary origin for different sesquiterpene isocyanides and related compounds in specimens from China and Vietnam [119-122]. Recent chemical analysis of the South China Sea nudibranchs, P. pustulosa and Phyllidia coelestis, as well as A. cavernosa, reported a nitrogenous cadinane-type sesquiterpenoid, xidaoisocyanate A (24), among other sesqui- and di-terpenoids [117]. Moreover, axisonitrile-3 (25) and several minor related sesquiterpenes were isolated from the same species, P. pustulosa, from Fiji [118]. Moreover, P. pustulosa and Phyllidia ocellata from Australia also present some stereoisomers of 4-isocyano-9-amorphene and of 10-isocyano-4-amorphene, respectively, while Phyllidia picta from Bali contains the axane sesquiterpenoids pictaisonitrile-1 (23) and pictaisonitrile-2 [112]. Phyllidia sp. from Sri Lanka contains 3-isocyano-theonellin (161), closely related to a cyanide obtained from the 
demosponge Axinyssa [113]. P. varicosa presents two 9-thiocyanatopupukeanane sesquiterpenes (126), found also in its demosponge prey Axinyssa aculeata [110]. Several of these compounds are reported to have an antimicrobial role.<smiles>CN1C(=O)N=C(Nc2nc(Cc3ccc(O)cc3)cn2Cc2ccc(O)cc2)C1=O</smiles><smiles>C=[N+][C@]1(C)CC[C@H](/C(C)=C/C=C/C(C)C)CC1</smiles><smiles>C=C[C@]1(C)CC[C@@H](O)[C@@](C)(CC[C@H]2C(C)=CC[C@@H](Br)C2(C)C)O1</smiles>

162 Glandulaurencianol A<smiles>C=C[C@@](C)(O[C@@H](C)CCC)O[C@@H](C)CC[C@H]1C[C@H](Br)CC[C@]1(C)O</smiles>

165 Diemenensin-A

163 Glandulaurencianol C

164 Punctatol<smiles>CCC[C@H](C)C[C@@H](C)C[C@H](C)/C=C(\C)c1oc(=O)c(C)c(O)c1C</smiles><smiles>C[C@@H](O)C/C=C/C=C/CCC/C=C/c1cccnc1</smiles>

167 Haminol A<smiles>CC(=O)O[C@@H](C)C/C=C/C=C/C=C/CCCc1cccnc1</smiles><smiles>CC(=O)O[C@@H](C)C/C=C/C=C/CCC/C=C/c1cccnc1</smiles>

169 Haminol 2

Figure 8. Structures of selected antimicrobial compounds in heterobranch molluscs. These molecules may also display other activities, as reported in the text.

\section{Dendronotida}

Only homarine (79) has been described in this group as a potential antimicrobial [428], and it is found in the species Marionia blainvillea [235].

Aeolidida

Again, homarine (79) has been found in nine aeolid species as mentioned above (Table 2), and it has been reported as a potential antimicrobial, probably derived from their cnidarian food sources [235,428].

\subsubsection{Cephalaspidea}

In cephalaspideans, homarine (79) has also been described in Aglaja tricolorata, originating probably from their diet of other heterobranchs [235].

\subsubsection{Anaspidea}

Regarding sea hares, Aplysia punctata possesses three brominated diterpenes, glandulaurencianols A-C (162,163), obtained from the red algae Laurencia glandulifera, along with punctatol (164) [429,430]. 
All these compounds showed a laurencianol skeleton, known for its antibacterial activity and a common algal dietary source [431]. Moreover, the cosmopolitan Aplysia juliana presents two toxic chlorophyll derivatives, pyropheophorbides $a$ and $b$, and a halogenated diterpenoid lactone, while its purple secretion also includes an antibacterial and cytotoxic peptide, julianin-S, and their egg masses are protected from microbial infections by unsaturated fatty acids [288,432-434].

Table 4. Antimicrobial compounds in the different heterobranch groups. In brackets: number of species with antimicrobial compounds, number of the compounds in figures, and reference numbers. \# Numbers.

\begin{tabular}{|c|c|c|c|}
\hline Species (\#) & Compounds (\#) & Activity & References (\#) \\
\hline \multicolumn{4}{|c|}{ Nudibranchia (11) } \\
\hline $\begin{array}{l}\text { Notodoris citrina, } \\
\text { Notodoris gardineri }\end{array}$ & Iso-naamidine-A (160) & $\begin{array}{c}\text { Inhibits the AI- } 2 \text { channel } \\
\text { of the marine pathogen } \\
\text { Vibrio harveyi }\end{array}$ & {$[123,426]$} \\
\hline $\begin{array}{l}\text { Phyllidiella pustulosa, } \\
\text { Phyllidia coelestis, } \\
\text { Phyllidia varicosa, } \\
\text { Phyllidia sp. }\end{array}$ & $\begin{array}{c}\text { Xidaoisocyanate A (24), } \\
\text { axisonitrile-3 (25), } \\
\text { 4-isocyano-9-amorphene, } \\
\text { 9-thiocyanato-pupukeanane } \\
\text { (126), 3-isocyanotheonellin (161) }\end{array}$ & Antimicrobial & {$[103,110,114,115,117,118,427]$} \\
\hline $\begin{array}{l}\text { Marionia blainvillea, } \\
\text { Phestilla lugubris, } \\
\text { Cuthona caerulea }\end{array}$ & Homarine (79) & Antimicrobial & {$[235]$} \\
\hline \multicolumn{4}{|c|}{ Cephalaspidea (1) } \\
\hline Aglaja tricolorata & Homarine (79) & Antibacterial & [235] \\
\hline \multicolumn{4}{|c|}{ Anaspidea (3) } \\
\hline Aplysia punctata & $\begin{array}{l}\text { Glandulaurencianols A-C } \\
(\mathbf{1 6 2 , 1 6 3 )}, \text { punctatol }(\mathbf{1 6 4})\end{array}$ & Antibacterial & {$[429,430]$} \\
\hline Aplysia juliana & $\begin{array}{l}\text { Pyropheophorbides a and } b \text {, } \\
\text { halogenated diterpenoid lactone, } \\
\text { julianin-S }\end{array}$ & Antibacterial & {$[288,432,433]$} \\
\hline Dolabella auricularia & Dolabellanin A & Antibacterial & {$[435]$} \\
\hline \multicolumn{4}{|c|}{ Pulmonata (4) } \\
\hline Siphonaria spp. & $\begin{array}{c}\text { Siphonarienolone (119), } \\
\text { diemenensins A (165) and B, } \\
\text { siphonarin A (120), } \\
\text { Vallartanones A and B }\end{array}$ & Antimicrobial & {$[27,340,344,348]$} \\
\hline Siphonaria diemenensis & Diemenensin A (165) & Antibacterial & {$[341]$} \\
\hline Siphonaria pectinata & Pectinatone (166) & Antimicrobial & {$[341,343]$} \\
\hline
\end{tabular}

Dolabella auricularia is another anaspidean known for protecting their eggs from bacterial pathogens, with a de novo biosynthesized glycoprotein, dolabellanin A, located in the albumen gland, showing antibacterial activity [435].

\subsubsection{Pulmonata}

Some Siphonaria species possess polypropionates in their mucus and mantle border [27]. Compounds with a 2-pyrone and furanone rings, such as siphonarienolone (119), structurally related to the polypropionates of cephalaspideans, are present in several species from Australia, the West and East Atlantic, and South Africa $[27,340]$. Both S. diemenensis and S. pectinata display antimicrobial activity due to the presence of diemenensin-A (165) and pectinatone (166), respectively [340,341,343].

\subsection{Antifouling}

Potentially, all surfaces under water are possible substrates for fouling colonization. Marine organisms have developed an amazing array of mechanisms to avoid fouling, and these include 
the use of chemicals [436]. In heterobranch molluscs, all nudibranchs except euarminids, as well as cephalaspideans, have been reported to possess antifouling compounds (Figure 9, Table 5).<smiles>C/C=C/C=C/C=C/c1cccnc1</smiles>

173 Tridachiahydropyrone<smiles>CCC(=O)[C@@H](C)/C=C(\C)C1[C@@](C)(c2oc(OC)c(C)c(=O)c2C)C=C(C)[C@@H]2O[C@@]12C</smiles><smiles>CC/C=C(\C)[C@@H]1C(C)=CC(C)=C[C@]1(C)c1oc(OC)c(C)c(=O)c1C</smiles><smiles>CC/C=C(\C)c1cc(OC)c(C)c(=O)o1</smiles><smiles>CC1(C)CCC[C@]2(C)[C@@]1(C)CC[C@@]2(C)C=O</smiles>

185 Austrodoral<smiles>CC1(C)CCC[C@@]2(C)[C@](C)(C(=O)O)CC[C@]12C</smiles>

186 Austrodoric acid<smiles>C=C(C(CC)OO)[C@H]1C(C)=C[C@]2(C)[C@H](c3oc(OC)c(C)c(=O)c3C)[C@]12C</smiles>

172 Phototridachiapyrone $J$<smiles>CCC(=O)[C@H](C)/C=C(\C)[C@H]1C(C)=CC(C)=C[C@]1(C)c1oc(OC)c(C)c(=O)c1C</smiles><smiles>CCC(=O)C(C)/C=C(\C)C1C(C)=CC(C)=C[C@]1(C)c1oc(OC)c(C)c(=O)c1C</smiles>

180 Photodeoxytridachione

OMe<smiles>CC/C=C(\C)C1C(C)=CC(C)(C)[C@H]1Cc1oc(OC)c(C)c(=O)c1C</smiles>

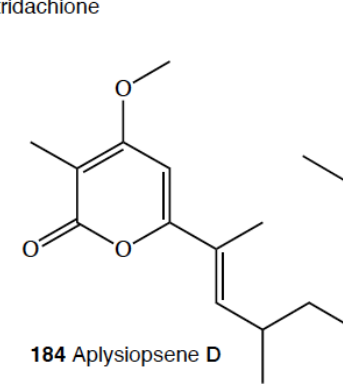<smiles>COC1=C(C)C(=O)C2(C)OC(C)(C=C(C)C2/C(C)=C\CC(C)C)C1(C)O</smiles>

181 Tridachiahydropyrone $\mathrm{C}$

Figure 9. Structures of selected antifouling compounds, pheromones, tissue regeneration compounds, sunscreens, and other ecological activities in heterobranch molluscs. These molecules may also display other activities, as reported in the text. 


\subsubsection{Nudibranchia}

Doridacea

Since the isolation of 9-isocyanopupukeanane (21) from Phillidia varicosa [106], phyllidids have been shown to be chemically rich, presenting many nitrogenous mono-, bi- and tri-cyclic sesquiterpenes, usually traced back to their sponge prey $[1,4,22,101-107,110,111,114,116,118-120,122,374-377,437]$. Some of these compounds are potent antifouling agents, effective against barnacle larvae, such as the bisabolene 3-isocyanotheonellin (161) of P. varicosa from Sri Lanka, and a sesquiterpene isonitrile from the Japanese Phyllidiella pustulosa [102,103,114-116,437]. Moreover, from Phyllidia sp. collected at Sri Lanka, some nitrogenous bisabolene sesquiterpenes exhibited a potent in vitro antifouling activity against barnacle larvae [114,115]. Different studies on Phyllidia ocelata, P. varicosa, Phyllidiella pustulosa, and Phillidiopsis krempfi with the aim of identifying antifouling activity reported three sesquiterpene isonitriles, namely, 10-epi-axisonitrile-3, 10-isocyano-4-cadinene, and 2-isocyanotrachyopsane, as well as a peroxide, 1,7-epidioxy-5-cadinene, among others [102,116]. These molecules display potent antifouling activity against larvae of the barnacle Balanus amphitrite $\left(\mathrm{EC}_{50}=0.14 \mu \mathrm{g} / \mathrm{mL}\right)$, while axisonitrile-3 (25) has an $\mathrm{EC}_{50}$ value of $3,2 \mu \mathrm{g} / \mathrm{mL}$ [437]. In fact, these natural products are present in many phyllidid species, such as P. varicosa, P. coelestis, P. ocellata, P. picta, Phyllidia sp., Phillidiopsis krempfi, Phyllidiella pustulosa, and P. rosans (P. bourguini) [102,103,116,119-122,373,437]. Moreover, Reticulidia fungia presents sesquiterpenes such as reticulidin A (215) with antifouling activity [438].

Dendronotida

As reported above, some species present homarine (79), such as the Mediterranean Marionia blainvillea, a compound that has also been proven to display potent antifouling activity $[235,428,439]$. This activity was previously reported for the gorgonian Eunicella singularis and the soft coral Gersemia antarctica, and homarine (79) has been suggested to be incorporated in dendronotids from their octocoral cnidarian food prey $[235,428,439]$. The presence of homarine (79) in the mucus secretion of the slugs would inhibit the growth of microorganisms in the mucus [235].

Aeolidida

Homarine (79) is also found in this group, particularly in Cratena pilata and Cuthona gymnota from the Atlantic, Hermissenda crassicornis from the Pacific (locations mistaken in [235]), Cuthona coerulea from the Mediterranean, and Phestilla lugubris from Australia [235,440]. In this case, homarine (79) is originated from their hydrozan cnidarian prey and may also be used to avoid microbial colonization of the slug mucus $[235,441,442]$.

\subsubsection{Cephalaspidea}

Again, homarine (79) is reported here, although in a different context. The Mediterranean Aglaja tricolorata feeds on other heterobranchs, and may, therefore, accumulate their natural products, in this case homarine (79) [235,442].

Another compound has been reported to present antifouling activity in the mantle of Sagaminopteron nigropunctatum and S. psychedelicum [282]. This is the polybrominated diphenyl ether 3,5-dibromo-2-(2' $4^{\prime}$-dibromo-phenoxy)-phenol (92), which is also found in their prey, the demosponge Dysidea granulosa, together with other polybrominated diphenyl ethers [282]. This compound (92) is selectively accumulated in the parapodia of the slugs at a concentration of $8-10 \%$, while it is present in other tissues of the slug and in the sponge at only $2-4 \%$ [282]. Its antifouling activity has been reported to be very high against marine bacteria, diatoms, barnacle larvae, and mussel juveniles [443].

Haminoea cyanomarginata from the Mediterranean is also protected against fouling by a brominated tetrahydropyran (142) [77]. This compound was previously found in an Australian sponge and later reported in H. cymbalum from India [77]. Haminols are 3-alkylpyridines also found in Haminoea species, which, among other activities, have been tested as antifouling molecules. These compounds include 
haminols A-C (167-168) and haminols 1-6 (169) [444], which are structurally related to the navenones (170) mentioned below. Haminol 2 (169) was the most potent compound, with low toxicity and strong activity against larvae of the barnacle Amphibalanus amphitrite [445]. De novo biosynthesis of haminols was proven in the Mediterranean H. orbignyana [446].

Table 5. Antifouling compounds in the different heterobranch groups. In brackets: number of species with antifouling compounds, number of the compounds in figures, and reference numbers. \# Numbers.

\begin{tabular}{|c|c|c|c|}
\hline Species (\#) & Compounds (\#) & Activity & References (\#) \\
\hline \multicolumn{4}{|c|}{ Nudibranchia (15) } \\
\hline $\begin{array}{l}\text { Phyllidia varicosa, Phyllidia } \\
\text { rosans (P. bourguini) }\end{array}$ & $\begin{array}{l}\text { 9-Isocyanopupukeanane (21), } \\
\text { 3-isocyanotheonellin (161) }\end{array}$ & $\begin{array}{c}\text { Antifouling against } \\
\text { barnacle larvae }\end{array}$ & {$[93,106]$} \\
\hline Phyllidia sp. & 3-Isocyanotheonellin (161) & $\begin{array}{l}\text { Antifouling activity against } \\
\text { barnacle larvae }\end{array}$ & {$[114,115]$} \\
\hline $\begin{array}{l}\text { Phyllidia ocelata, P. varicosa, } \\
\text { P. coelestis, P. picta, Phyllidiella } \\
\text { pustulosa, Phillidiopsis krempfi }\end{array}$ & $\begin{array}{c}\text { 10-epi-Axisonitrile-3, } \\
\text { 10-isocyano-4-cadinene, } \\
\text { 2-isocyanotrachyopsane, } \\
\text { 1,7-epidioxy-5-cadinene, } \\
\text { 4-isocyano-9-amorphene and } \\
10 \alpha \text {-isocyano-4-amorphene, } \\
\text { 9-thiocyanatopupukeanane sesquiterpenes }\end{array}$ & $\begin{array}{l}\text { Antifouling activity against } \\
\text { barnacle larvae }\end{array}$ & {$[110,112]$} \\
\hline \multicolumn{4}{|c|}{ Cephalaspidea (9) } \\
\hline Aglaja tricolorata & Homarine (79) & Antifouling activity & {$[235,441]$} \\
\hline $\begin{array}{l}\text { Sagaminopteron } \\
\text { nigropunctatum, } \\
\text { S. psychedelicum }\end{array}$ & $\begin{array}{c}3,5 \\
\text { Dibromo-2-(2', } 4^{\prime} \text {-dibromo-phenoxy)phenol } \\
(\mathbf{9 2})\end{array}$ & $\begin{array}{l}\text { Antifouling activity against } \\
\text { marine bacteria, diatoms, } \\
\text { barnacle larvae, and } \\
\text { mussel juveniles }\end{array}$ & {$[282,443]$} \\
\hline
\end{tabular}

\subsection{Trail Following and Alarm Pheromones}

In nature, behavioral and chemical defenses of heterobranchs are often combined to increase survival chances [1,2]. Heterobranchs display a high number of strategies, among which alarm pheromones are used to communicate and induce behavioral changes (Figure 9, Table 6) [1,2]. Doridacean nudibranchs and cephalaspideans, and perhaps some anaspideans, display trail-following behavior, which also implies some chemoreception mechanisms.

\subsubsection{Nudibranchia}

Doridacea

A trail-following behavior has been reported in some chromodoridids, such as Hypselodoris (Risbecia) tryoni, but the potential chemicals involved have not yet been described [447]. Whether this is related to defense or to reproduction remains to be further investigated.

Tambja and Roboastra are protected by the potent alkaloids tambjamines (65-70), which are obtained from their prey, for example, the bryozoan Sessibugula translucens for Tambja abdere and T. eliora, and these two slug species in turn for the voracious Roboastra tigris [61,226-228]. All these slugs are able 
to detect the tambjamines (65-70) secreted in mucous trails through chemoreception mechanisms, thus being able to find conspecifics and food (bryozoan) for Tambja species or detect food (slugs) for Roboastra [61,226]. When Tambja abdere specimens are disturbed, they release higher amounts of tambjamines (65-70), and, thus, they are also considered to be alarm pheromones [61,226]. Similar examples include Tambja ceutae and the bryozoan Bugula dentata, Tambja stegosauriformis and B. dentata, as well as some Nembrotha species and their ascidian prey, Atapozoa sp. [207,229-231].

\subsubsection{Cephalaspidea}

Several genera in this group have been reported to secrete alarm pheromones and display trail-following behavior. Navenones A-C (170) were isolated long ago from Navanax inermis and reported to be used as alarm signals [394]. Navenones (170) are accumulated in a specialized ventral gland and are released within its yellow slime trail when the animals are disturbed, inducing an avoidance alarm response in the conspecifics that follow them [269,394,448]. Navenones (170) are suggested to be de novo biosynthesized [448]. These slugs may also be cannibalistic, but, interestingly, the secretion is not released when a small slug is attacked by a larger conspecific [318].

Haminoea species similarly release alarm pheromones that induce escape behavior in the trail-following conspecifics [271,449]. The Mediterranean species H. exigua, H. fusari, H. orbignyana, $H$. orteai, and $H$. navicula present haminols (167-169), oxygenated 3-alkylpyridines that are secreted in their mucous trail $[19,446]$. Haminols (167-169) are biosynthesized through sequential addition of acetic acid units to nicotinic acid [446,450]. Haminols consist of several structures similar to navenones (170), the haminols A-C (167-168) and the haminols 1-6 (169) [444]. Similarly, H callidegenita presents haminols 7-11, which are also suggested to act as alarm pheromones [271,451]. The Pacific H. japonica also presents a series of alkylphenols, which are structurally similar to navenone-C and are suggested to act as alarm pheromones [271,451].

The widespread Scaphander lignarius lives in sandy bottoms, feeding usually on foraminiferans [452,453]. This species presents the $\omega$-arylmethylketones, lignarenones (171), de novo biosynthesized through a polyketide pathway from benzoic acid and accumulated in the Blochmann's gland [454-456]. Lignarenones (171) are released within the bright yellow slime that S. lignarius secretes when disturbed and are also suggested to be used as alarm pheromones [454-456].

Table 6. Alarm signal compounds in the different heterobranch groups. In brackets: number of species with alarm signal compounds, number of the compounds in figures, and reference numbers. \# Numbers.

\begin{tabular}{|c|c|c|c|}
\hline Species (\#) & Compounds (\#) & Activity & References (\#) \\
\hline \multicolumn{4}{|c|}{ Nudibranchia (7) } \\
\hline Tambja abdere, T. eliora, Roboastra tigris & Tambjamines (65-70) & Alarm pheromones and cues & [223] \\
\hline $\begin{array}{l}\text { Tambja ceutae, Tambja stegosauriformis, } \\
\text { Nembrotha spp. }\end{array}$ & Tambjamines $(\mathbf{6 5}-70)$ & Alarm pheromones and cues & [226-228] \\
\hline \multicolumn{4}{|c|}{ Cephalaspidea (10) } \\
\hline Navanax inermis & Navenones A-C (170) & Alarm pheromones & {$[394,448]$} \\
\hline $\begin{array}{c}\text { Haminoea exigua, H. fusari, H. orbignyana, } \\
\text { H. orteai, H. navicula }\end{array}$ & Haminols (167-169) & $\begin{array}{l}\text { Alarm pheromones employed } \\
\text { during cross copulation, escape } \\
\text { reaction in conspecifics }\end{array}$ & {$[19,449]$} \\
\hline Haminoea navicula & Haminols A and B $(\mathbf{1 6 7 , 1 6 8 )}$ & Alarm pheromones & [449] \\
\hline Haminoea orteai & Haminols A-C $(167,168)$ & Alarm pheromones & [444] \\
\hline Haminoea fusari, H. hydatis & Haminols 1-6 (169) & Alarm pheromones & {$[271,445]$} \\
\hline Haminoea japonica & Navenone-C (170) & Alarm pheromones & {$[271,445]$} \\
\hline Haminoea callidegenita & Haminols 7-11 & Alarm pheromones & {$[271,451]$} \\
\hline Scaphander lignarius & Lignarenones (171) & Alarm pheromones & [453-455] \\
\hline \multicolumn{4}{|c|}{ Anaspidea (1) } \\
\hline Aplysia californica & $\begin{array}{c}\text { Aplysiapalythines A-C } \\
\text { (mycosporine-like amino acids, } \\
\text { MAAs), asterina, palythine }\end{array}$ & $\begin{array}{c}\text { Alarm cues, causing avoidance } \\
\text { behaviors in neighboring } \\
\text { conspecifics }\end{array}$ & {$[457,458]$} \\
\hline
\end{tabular}




\subsubsection{Anaspidea}

Mycosporine-like amino acids (MAAs) have been suggested to act as alarm cues in the sea hare Aplysia californica [457].

\subsection{Sunscreens and UV Protection}

Avoiding UV radiation (UVR) is very relevant for marine organisms that live in shallow waters, since the damaging effects of UVR on cells and tissues are potentially huge [459]. In heterobranch molluscs, those living close to the surface (plankton and pteropods) or living on algae (for food and camouflage; sea hares and sacoglossans) are the most susceptible to UVR, and UV-protecting compounds have indeed been described in anaspideans, pteropods, and sacoglossa (Figure 9, Table 7).

\subsubsection{Anaspidea}

As mentioned above, sea hares are generalist herbivores. Among them, Aplysia species possess many dietary compounds from their algal food, such as many halogenated terpenoids and some carotenoids, which may provide UVR protection [459,460]. Furthermore, A. californica contains mycosporine-like amino acids (MAAs), the most common photoprotective molecules reported in marine organisms $[457,459]$.

\subsubsection{Pteropoda}

The sea butterflies Limacina helicina and Clione limacina also possess MAAs originated from phytoplanktonic microalgal species, which provide them with UV protection [461].

\subsubsection{Sacoglossa}

Polypropionates from sacoglossans have been reported to be used as sunscreens in several species $[412,461]$. These compounds are de novo biosynthesized by the slugs, and their biosynthesis is affected by UVR [462,463]. Elysia species possess $\gamma$-pyrone propionates, such as phototridachiapyrone J (172) in the Atlantic E. patagonica [412], and tridachiahydropyrone (173) and phototridachiahydropyrone (174) in the Caribbean Elysia crispata [78,317]. Phototridachiahydropyrone (174) seems to originate from a rearrangement mechanism during the photochemical electrocyclic formation of tridachiahydropyrone (173) under prolonged UVR exposition [464]. Similar $\gamma$-pyrone compounds, tridachiapyrones A-F $(\mathbf{1 7 5}, \mathbf{1 7 6})$, as well as elysiapyrones $(\mathbf{1 7 7})$, along with other compounds, were found in the Pacific E. (Tridachiella) diomedea [413,415-419]. E. viridis feeds on the green algae Codium vermiliara and biosynthesizes the polypropionate (+) elysione (178) [463,465]. Elysione (178) is also found in E. chlorotica, which feeds on Cladophora algae [414]. Tridachiapyrone A (175) is the enantiomer of $(+)$ elysione (178), and like tridachiapyrone $C(\mathbf{1 7 6})$ and crispatene, it has been suggested that these metabolites represent the protected forms of $(+)$ elysione (178) under strong light irradiation $[414,466]$. All of these polyene $\gamma$-pyrone compounds are localized in cell membranes, where they may act as sunscreens, thus protecting the photosynthetic apparatus of the chloroplasts [466,467].

Placobranchus ocellatus and Placobranchus sp. from the Pacific Ocean also present propionate-derived $\gamma$-pyrones, such as 9,10-deoxytridachione (179), photodeoxytridachione (180), tridachiahydropyrone B and C (181), and iso-9,10-deoxy-tridachione, probably also used as sunscreens [19,412,466,468,469]. In specimens from India, the elysiapyrone-related compounds ocellapyrones (182) were also found [468].

\subsection{Tissue Regeneration}

As in terrestrial organisms, vagile marine organisms, as well as heterobranchs, may use autotomy and tissue regeneration as a mechanism to distract predators and escape [1,2]. In fact, many nudibranchs and sacoglossa may lose part of their mantle or their cerata [1,2]. The known compounds involved in these mechanisms are reported here (Figure 9, Table 8). 
Table 7. Photoprotective compounds in the different heterobranch groups. In brackets: number of species with photoprotective compounds, number of the compounds in figures, and reference numbers.

\begin{tabular}{|c|c|c|c|}
\hline Species (\#) & Compounds (\#) & Activity & References (\#) \\
\hline \multicolumn{4}{|c|}{ Anaspidea (1) } \\
\hline Aplysia californica & $\begin{array}{l}\text { Aplysiapalythines A, B, C (mycosporine-like } \\
\text { amino acids, MAAs), asterine, palythine }\end{array}$ & Sunscreens & [457] \\
\hline \multicolumn{4}{|c|}{ Pteropoda (2) } \\
\hline $\begin{array}{l}\text { Limacina helicina, } \\
\text { Clione limacina }\end{array}$ & Mycosporine-like amino acids (MAAs) & UV photoprotection & [461] \\
\hline \multicolumn{4}{|c|}{ Sacoglossa (8) } \\
\hline Cyerce cristallina & Cyercene A (157) and B, cyercenes 1-5 $(\mathbf{1 5 8 , 1 5 9 )}$ & $\begin{array}{l}\text { Protection against } \\
\text { sunlight-induced } \\
\text { damage }\end{array}$ & {$[326,327]$} \\
\hline Elysia patagonica & Phototridachiapyrone J (172) & Sunscreens & [412] \\
\hline Elysia crispata & $\begin{array}{c}\text { Tridachiahydropyrone (173), } \\
\text { phototridachiahydropyrone (174) }\end{array}$ & Sunscreens & {$[317,464]$} \\
\hline Elysia (Tridachiella) diomedea & $\begin{array}{l}\text { Tridachiapyrones A-F (175,176), elysiapyrones } \\
\text { (177) }\end{array}$ & $\begin{array}{l}\text { Sunscreens, } \\
\text { photoprotection }\end{array}$ & [417-419] \\
\hline Elysia viridis, E. chlorotica & Elysione (178) & Sunscreens & {$[463,465]$} \\
\hline $\begin{array}{l}\text { Placobranchus ocellatus, } \\
\text { Placobranchus sp. }\end{array}$ & $\begin{array}{c}\text { 9,10-Deoxy-tridachione (179), } \\
\text { photodeoxytridachione (180), } \\
\text { tridachiahydropyrone B and C (181), } \\
\text { iso-9,10-deoxy-tridachione, ocellapyrones (182) }\end{array}$ & Sunscreens & {$[466,468,469]$} \\
\hline
\end{tabular}

\subsubsection{Nudibranchia}

\section{Doridacea}

Peltodoris atromaculata feeds on the sponge Petrosia ficiformis, accumulating polyacetylenes, petroformynes, and other compounds, although the autotomy mechanism of the slug does not seem to be related with this chemistry, and, in fact, may be related to stress or senescence instead [1,210,470].

\section{Dendronotida}

Tethys fimbria presents de novo biosynthesized prostaglandin (PG) lactones (80-81) involved in predator distraction by the release of their cerata [237-239]. When T. fimbria is molested, cerata are detached together with a copious amount of mucus and continue to move for some time. Although PGEs and PGFs have been suggested to be involved in defense and reproduction, respectively, a role in tissue regeneration has also been suggested, since they are common hormonal compounds [237-240,471,472]. In fact, $\mathrm{PGE}_{2}-1,15$-lactone (80) and $\mathrm{PGE}_{3}-1,15$-lactone (81) are found in the cerata, detached when disturbed to distract potential predators and reverting to the free acid forms, $\mathrm{PGE}_{2}$ and $\mathrm{PGE}_{3}$, which are suggested to be the defensive compounds [237].

\subsubsection{Sacoglossa}

Many sacoglossans also release their cerata when disturbed. Among them, the Mediterranean Ercolania viridis presents $\gamma$ - and $\alpha$-pyrone polypropionates, including cyercenes (113, 157-159) [473]. Cyercene polypropionates $(\mathbf{1 1 3}, \mathbf{1 5 7 - 1 5 9 )}$ are also found in the Mediterranean Cyerce cristallina, which also displays cerata autotomy [326,327], as well as in C. nigricans from Australia [328]. Moreover, in Aplysiopsis formosa from the Atlantic Ocean, the $\alpha$-pyrones aplysiopsenes A-D $(\mathbf{1 8 3}, \mathbf{1 8 4})$ have been found [325]. The implication of polypropionates in autotomy and further cerata regeneration has been further demonstrated by experiments with Hydra [474]. However, some sacoglossa may also present cerata autotomy without possessing polypropionates, such as the Atlantic Mourgona germaineae, which instead possesses prenylated bromohydroquinones obtained from the calcareous green alga Cymopolia barbata [330], similarly to Costasiella ocellifera from Avrainvillea longicaulis [325]. In contrast, some 
species may present polypropionates without displaying autotomy behavior, such as Placida dendritica, which possesses polypropionate $\gamma$-pyrones (116) with no regenerative activity on the Hydra assay [332]. Evolutionary trends are probably behind this behavioral and chemical variability [2].

Table 8. Tissue-regenerator compounds in the different heterobranch groups. In brackets: number of species with tissue-regenerator compounds, number of the compounds in figures, and reference numbers. \# Numbers.

\begin{tabular}{|c|c|c|c|}
\hline Species (\#) & Compounds (\#) & Activity & References (\#) \\
\hline \multicolumn{4}{|c|}{ Nudibranchia (1) } \\
\hline Tethys fimbria & $\begin{array}{l}\text { PGE2-1,15-lactone (80), } \\
\text { PGE3-1,15-lactone (81) }\end{array}$ & $\begin{array}{l}\text { Predator distraction by } \\
\text { the release of their cerata, } \\
\text { cerata regeneration }\end{array}$ & {$[237,238]$} \\
\hline \multicolumn{4}{|c|}{ Sacoglossa (6) } \\
\hline Ercolania viridis & Cyercenes $(\mathbf{1 1 3}, \mathbf{1 5 7 - 1 5 9 )}$ & $\begin{array}{c}\text { Cerata autotomy, cerata } \\
\text { regeneration }\end{array}$ & [332] \\
\hline $\begin{array}{l}\text { Cyerce cristallina, } \\
\text { C. nigricans }\end{array}$ & Cyercenes $(\mathbf{1 1 3}, \mathbf{1 5 7 - 1 5 9 )}$ & $\begin{array}{l}\text { Cerata autotomy, cerata } \\
\text { regeneration }\end{array}$ & {$[326-328]$} \\
\hline Aplysiopsis formosa & $\begin{array}{c}\text { Aplysiopsenes A-D } \\
(\mathbf{1 8 3 , 1 8 4 )}\end{array}$ & $\begin{array}{l}\text { Cerata autotomy and } \\
\text { cerata regeneration }\end{array}$ & [475] \\
\hline $\begin{array}{l}\text { Mourgona germaineae, } \\
\text { Costasiella ocellifera }\end{array}$ & $\begin{array}{c}\text { Prenylated } \\
\text { bromohydroquino-nes }\end{array}$ & Cerata autotomy & {$[325,330]$} \\
\hline
\end{tabular}

\subsection{Other Ecological Activities}

Some nudibranchs have been reported to display activities other than those mentioned above $[1,2]$. These may include metabolites that may be considered stress metabolites, as well as compounds involved in reproduction or in hormonal responses, as reported below (Figure 9, Table 9).

\subsubsection{Nudibranchia}

\section{Doridacea}

The Antarctic slug Doris kerguelenensis possesses diterpenoid glycerols (2) and terpenoid glyceryl esters of different types (ent-labdane, halimane, isocopalane diterpenoids) in its mantle many $[59,62,64,370,381,476]$. D. kerguelenensis may also present some nor-sesquiterpenes in its mantle, austrodoral (185) and its oxidized derivative austrodoric acid (186), which have been detected in higher amounts after the animals were kept in aquarium for 15 days before freezing [64]. This is the reason why austrodoral (185) has been suggested to be a stress metabolite, although perhaps some physiological alterations may also be behind these higher amounts of austrodoral (185) [64].

Table 9. Other ecological activities in the different heterobranch groups. In brackets: number of species with active compounds, number of the compounds in figures, and reference numbers. \# Number.

\begin{tabular}{|c|c|c|c|}
\hline Species (\#) & Compounds (\#) & Activity & References (\#) \\
\hline \multicolumn{4}{|c|}{ Nudibranchia (3) } \\
\hline Doris kerguelenensis & $\begin{array}{l}\text { Austrodoral (185), austrodoric acid } \\
\text { (186) }\end{array}$ & Stress metabolites & {$[64,65]$} \\
\hline Tethys fimbria & PGs-lactones $(\mathbf{8 0 , 8 1 )}$ & Role in reproduction & {$[237,238]$} \\
\hline Dermatobranchus ornatus & $\begin{array}{c}\text { Eunicellin, ophirin (187), } \\
\text { calicophirin B (188), } \\
\text { 13-deacetoxycalicophirin B, } \\
\text { 13-deacetoxy-3-deacetylcalicophirin }\end{array}$ & $\begin{array}{l}\text { Inhibition of cell division } \\
\text { in fertilized starfish eggs }\end{array}$ & {$[22,243,387,477]$} \\
\hline
\end{tabular}


Dendronotida

Prostaglandins (PGs) (80-81) from Tethys fimbria have been reported to be de novo biosynthesized, having different roles in the species, and being located in different body parts of the slug [237-239]. As previously mentioned, $\mathrm{PGE}_{2}-1,15$-lactone (80) and $\mathrm{PGE}_{3}-1,15$-lactone (81) are found in the cerata, reverting to the free acid forms $\mathrm{PGE}_{2}$ and $\mathrm{PGE}_{3}$ probably for defense [237]. In their reproductive system, instead, PGF-lactones are found, and these have been suggested to have a role in reproduction [239].

\section{Euarminida}

Some species have been reported to inhibit cell division in embryos or eggs of sympatric species to avoid competition and/or further predation by their adults, for example, against sea urchins or sea stars [1,2]. An example is Dermatobranchus ornatus from China, which presents several types of diterpenes that inhibit cell division in fertilized starfish eggs [22]. These compounds include four eunicellin diterpenes, such as ophirin (187). In fact, two of these compounds are probably taken from its gorgonian prey, Muricella sinensis [22], while another one was previously found in an unidentified Pacific soft coral [387]. Furthermore, D. ornatus possesses a calicophirin diterpenoid (188) probably from a gorgonian prey, Muricella sp. [477].

\section{Pharmacological Activity}

Marine natural products may have many diverse applications that are beneficial for humans and, thus, may become potentially very useful drugs [5,6,8,10,29-31,33]. Some recent reviews offer wide summaries of the different compounds and activities, as well as a historical perspective [31-33,35-40, $42,43,123,478-482]$. Overall, it remains clear that natural products are still the best option to find novel bioactive entities and potentially be modified to find leads to fight several human diseases.

\subsection{Cytotoxicity and Antitumoral Activity}

Many reviews have dealt with this topic in depth, and, therefore, we include here only a brief summary of all the activities described [31,42,479]. Among the most active compounds, it is worth mentioning jorumycin (189) from the doridacean Jorunna funebris, ulapualides (190) from Hexabranchus sanguineus, kabiramides (62) from Hexabranchus sp., aplyronines (191) and dolastatins (192) from the anaspidean Dolabella auricularia, and bursatellanins (193) from Bursatella leachii, as well as kahalalides (194) from the sacoglossan Elysia rufescens, all of which are under clinical trials for antitumoral activity $[36,43,45,46,479]$. It is important to remember that cytotoxic, anticancer, and antitumoral compounds are strongly needed, since cancer remains one of the deadliest diseases worldwide [42]. In 2018, about 18 million new cancer cases were reported globally, producing around 10 million deaths [483]. Thus, many studies are being developed to find new compounds with novel modes of action, and marine organisms, such as heterobranch molluscs, are considered to be reservoirs of new bioactive compounds that are potentially useful [42]. In fact, about 30\% of the top twenty drugs currently on the market originate from a natural source (mostly plants), while approximately 50\% of the marketed drugs are naturally derived or based on natural compounds [31,480,484]. Comparing marine and terrestrial natural products, it has been reported by the NCI (USA) that more than $1 \%$ of marine compounds present antitumoral activity compared to the $0.01 \%$ for terrestrial compounds [481]. Many natural compounds present cytotoxic effects against macromolecules expressed by cancer cells, such as in oncogenic signal transduction pathways, and display growth inhibition of human tumor cells [39,42,43,482]. Moreover, many studies on the mechanism of action of marine natural compounds inhibiting tumor growth indicate that it involves processes of apoptosis, necrosis, and lysis of the tumor cells, both in vitro and in vivo [42,485]. All heterobranch groups reviewed here possess some anticancer, antitumoral, and/or cytotoxic compounds, except pteropods (Figures 10-23, Table 10). The natural products described include a wide variety of compounds, from terpenoids and steroids, to peptides, polyketides, as well as nitrogen-containing metabolites. 


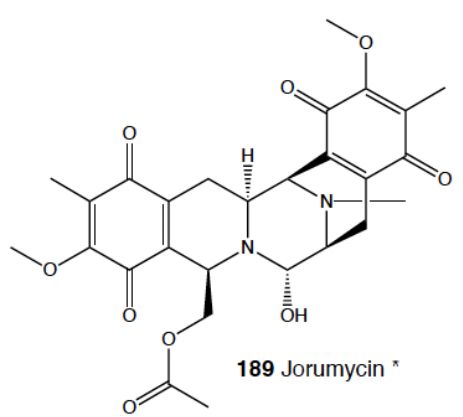

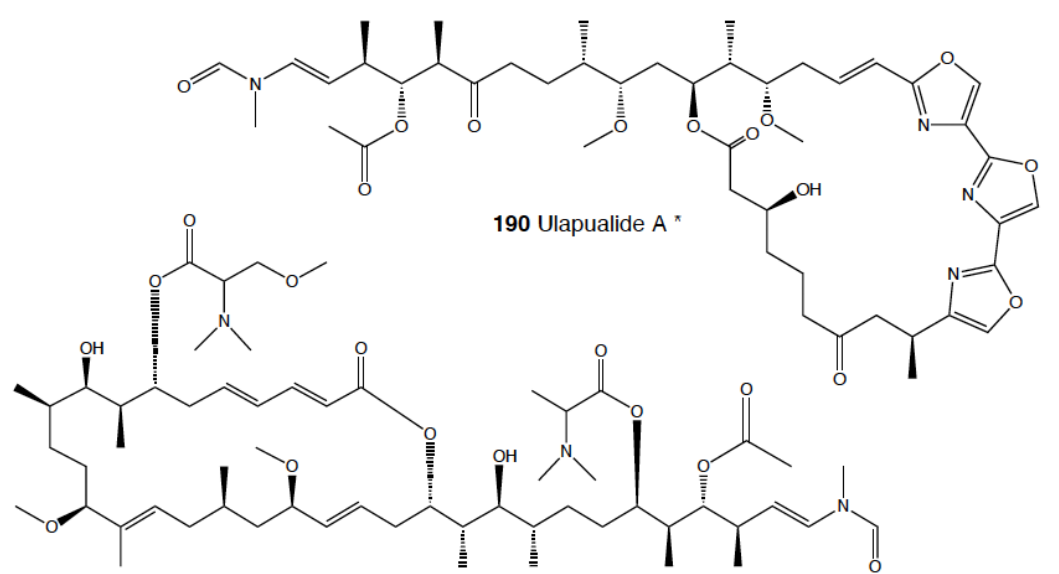<smiles>C/C=C/C(C)CC(C)CCCC(C)CC(C)CCCC=CCCCC/C=C(\C)CCCC(C)COCC</smiles><smiles>CC(C)[C@H]1NC(=O)c2csc(n2)CNC(=O)c2csc(n2)[C@H](CCC(N)=O)NC(=O)[C@H](C)NC(=O)[C@H]2CCCN2C1=O</smiles><smiles>N#CCCOc1ccc([C@@H](O)[C@H](CO)NC=O)cc1</smiles>

191 Aplyronine A *

192 Dolastatin 3 *<smiles>C=C1CCC[C@]2(C)C3(C)CC/C(=C/C(=O)OC(CO)CO)CC[C@]3(C)[C@]12C</smiles>

193 Bursatellin *

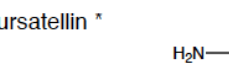

95 Palmadorin A<smiles>C=C1CCC[C@@H]2[C@]1(C)CC[C@@H](C)[C@]2(C)CC/C(C)=C/C(=O)OC(CO)COC(C)=O</smiles><smiles>C=C1CCC[C@]2(C)C1CC[C@H]1C/C(=C/C(=O)OCC(O)CO)CC[C@@]12C</smiles><smiles>CC(=O)OCC(CO)OC(=O)C=C1CC[C@@H]2[C@](C)(CC[C@]3(C)C(C)(C)CCC[C@]23C)C1</smiles><smiles>CC1(C)CCCC2(C)[C@H]3CC/C(=C/C(=O)OC(CO)CO)C[C@H]3CC[C@@]12C</smiles>

194 Kahalalide $F$ *

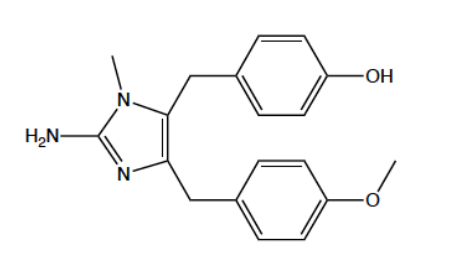<smiles>CC(CO)COC(=O)C=C1CCC2C(C)CCC3(C)CCCC(C)(C)C2CCC13</smiles>

201 Naamidine A

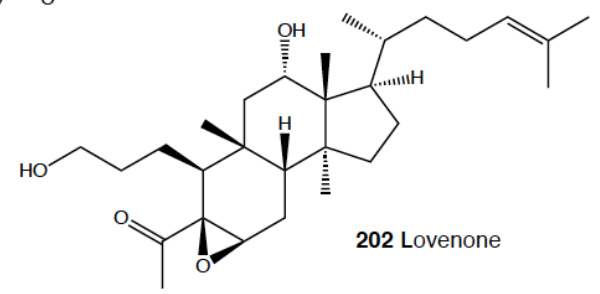

Figure 10. Structures of selected cytotoxic and antitumoral compounds in some heterobranch molluscs. These molecules may also display other activities, as reported in the text. ${ }^{*}=$ compounds in clinical trials. 


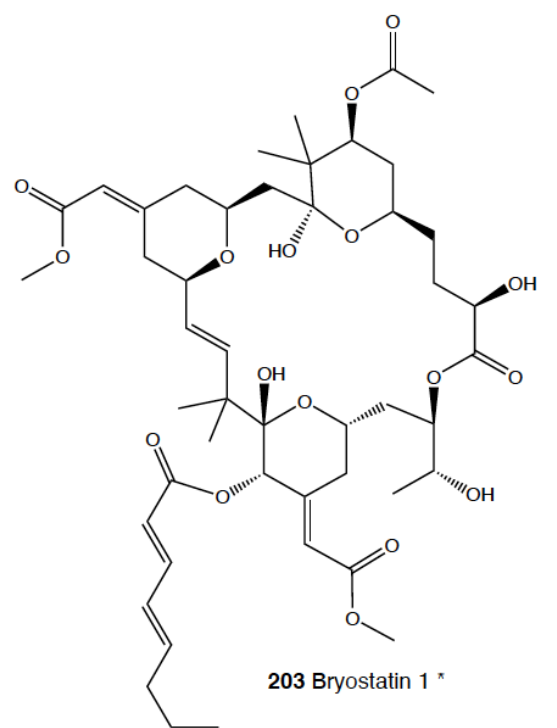<smiles>C#[N+]C(COCCCCCCCCCCCCCCCC)COC(C)=O</smiles>

205 Actinofide<smiles>CCO[C@H]1OC(=O)C2=C1[C@@]1(C)CCCC(C)(C)[C@@]1(C)C[C@H]2O</smiles>

206 Dendocarbin J

207 Isodrimeninol<smiles>CC1(C)CCCC(C)(C)C12CCC1=C(C2)C(=CO)OC1=O</smiles><smiles>CC(C)C1CC2CCC[C@](C)(NC=O)C1C2</smiles>

209 1-formamido-10(1,2)abeopupukeanane<smiles>CC(=CC=CC(C)C)[C@H]1CC[C@@](C)(C#N)CC1</smiles>

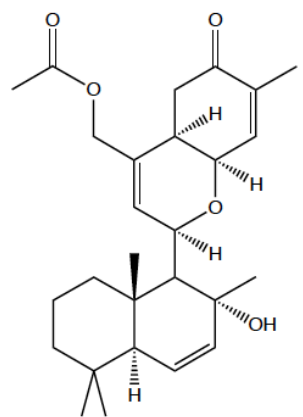

216 Ansellone A

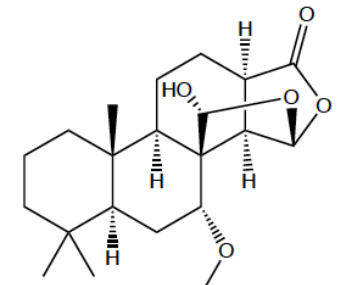

220 Aplyroseol-2

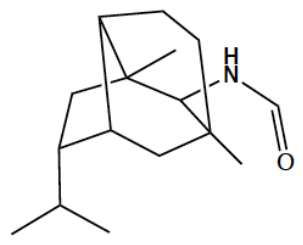

210 2-formamidopupukeanane<smiles>CC(C)=CCC[C@](C)(N)[C@H]1CC=C(C)CC1</smiles>

214 7-isocyano-7,8dihydro- $\propto$-bisabolene<smiles>CC(=O)O[C@H]1O[C@H](C2=CC(=O)OC2)C[C@H]2[C@]1(C)CC[C@H]1[C@@]2(C)CC[C@]2(C)C(C)(C)CCC[C@]12C</smiles>

217 Inorolide C

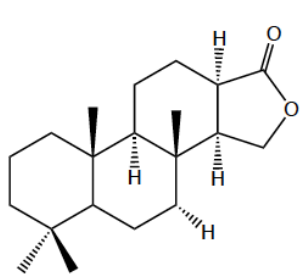

221 Spongian-16-one<smiles>CC1=C[C@H]2C(C(C)C)CC[C@](C)(N=C=S)[C@@]2(C)CC1</smiles>

211 Axinisothiocyanate $\mathrm{K}$<smiles>CCCCCCCCCCC=CC1=C[C@]2(C)C[C@H](O)[C@@H](Cl)C(C)(C)[C@@]2(C)CC1</smiles><smiles>C=C1C=C[C@@H]2C(=C1)O[C@]1(C)CC[C@H](C)C(C)(C)CCC[C@@]21C</smiles>

218 Puupehenone

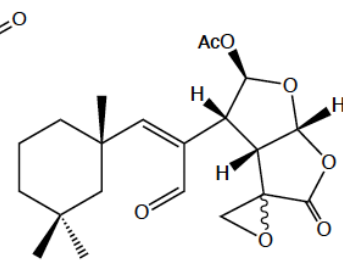

219 Epoxygoniolide-1

Figure 11. Structures of selected cytotoxic and antitumoral compounds in some Doridacea nudibranchs. These molecules may also display other activities, as reported in the text. * = compounds in clinical trials. 
<smiles>CC=C1C(C2(C)CCCC(C)(C)C2)=CC[C@H]2[C@@H](OC(C)=O)O[C@@H](OC(C)=O)[C@@H]12</smiles>

224 Gracilin A

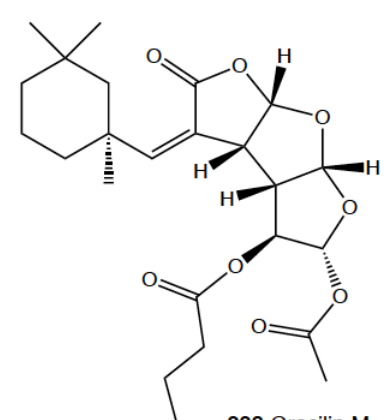

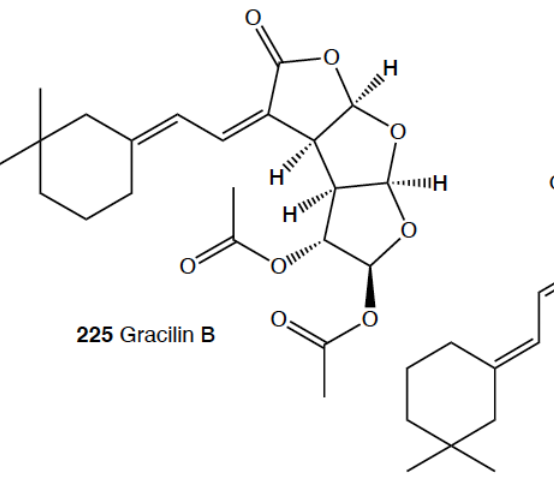

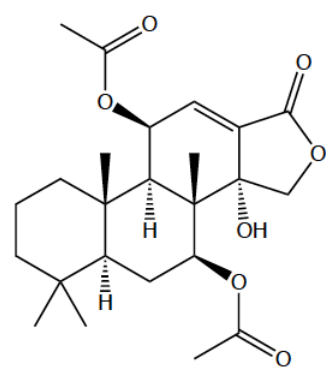

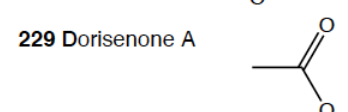
226 Gracilin C<smiles>COC(O)O</smiles>

227 Gracilin G<smiles>C[C@]12CC[C@@]3(C)c4cocc4CC[C@]3(C)[C@@]1(C)CC(=O)[C@@H](O)[C@@]2(C)CO</smiles><smiles>CC(=O)OC1CC2C3(C)CCC4C(C)(C)CCCC4(C)C3CC(O)C2(C)[C@H]1CO</smiles>

233 Heteronemin<smiles>COC(C)C(C)CCC(O)C(C)C(OC(C)=O)C(C)/C=C/N(C)C=O</smiles><smiles></smiles><smiles>CC(=O)O[C@H]1C=C2[C@H]3CC=C4CO[C@H](OC(C)=O)[C@]4(C)[C@H]3CC[C@]2(C)[C@@]2(C)CCCC(C)(C)[C@@]12C</smiles>

234 Mooloolabene D

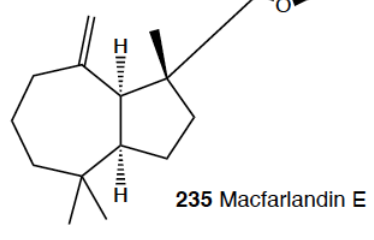

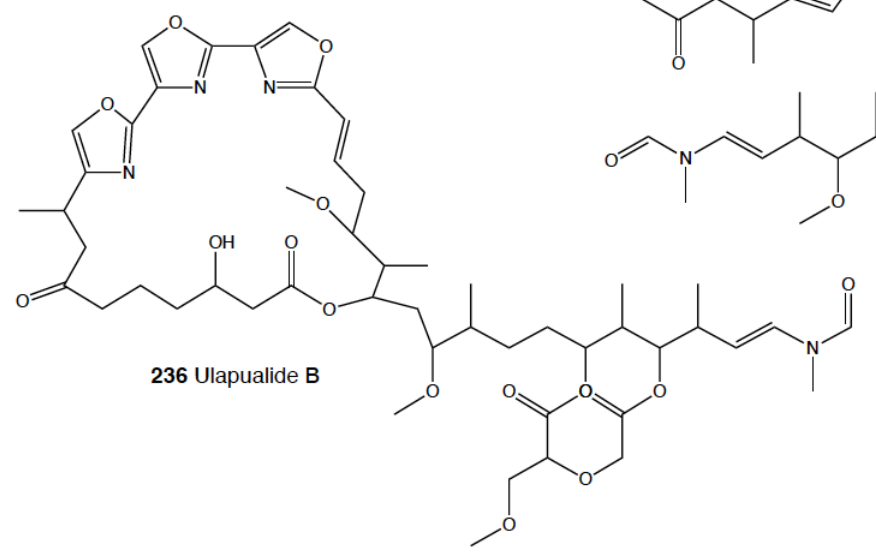

238 Kabiramide $A$

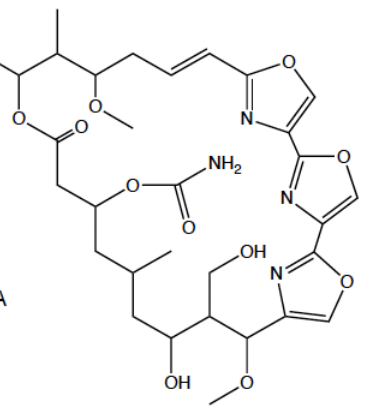

Figure 12. Structures of selected cytotoxic and antitumoral compounds in some Doridacea nudibranchs. These molecules may also display other activities, as reported in the text. 


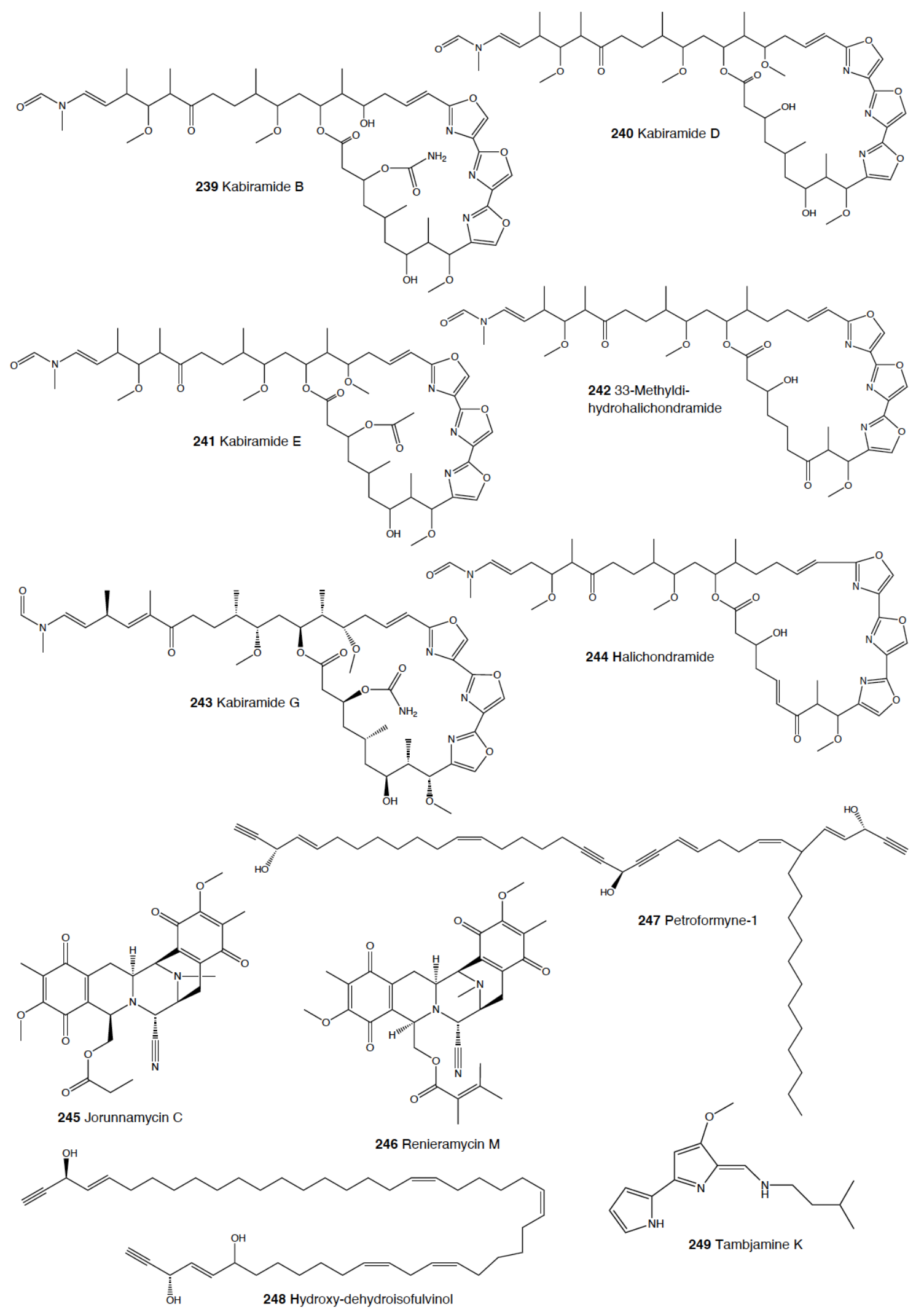

Figure 13. Structures of selected cytotoxic and antitumoral compounds in some Doridacea nudibranchs. These molecules may also display other activities, as reported in the text. 
<smiles>CC/C=C/C/C=C1\C[C@]2(O)C=C(Cl)C(=O)[C@@H]2[C@H](OC(C)=O)[C@H]1OC(C)=O</smiles>

250 Punaglandin 1<smiles>C=C1CCCC(C)(C)[C@H]1CCC(C)=CC(=O)NC(N)=NC(=O)C=C(C)C</smiles>
251 Dotofide

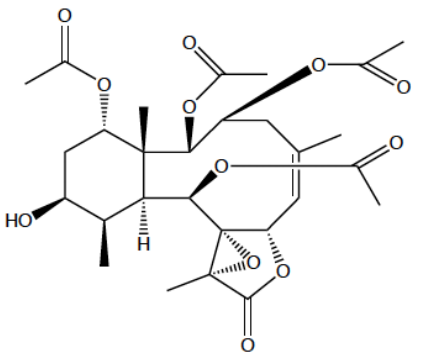
255 Excavatolide C<smiles>C=CC(O)=C(C)CC=C(C)CCC=C(C)CC(=O)CC(C)C</smiles>
252 Prenylated hydroquinone<smiles>C[N+](C)(C)C(Cc1c[nH]c2cc(Br)ccc12)C(=O)O</smiles>

253 Bromohypaphorine
254 Brianthein W

256 11-episinulariolide acetate

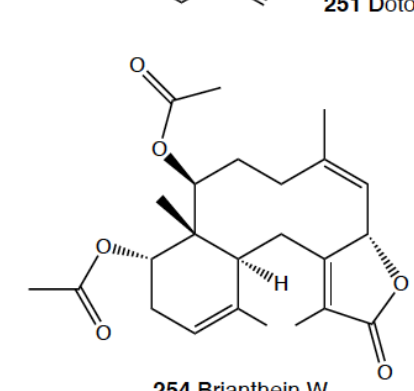<smiles>C=C(/C=C\CC)C(=O)Cc1nc(NCCCCCNC(=N)N)no1</smiles>

257 Phidianidine A<smiles>C=C1[C@@H](CCO)[C@]2(C)C[C@@H](Cl)[C@@H](Cl)C(C)(C)[C@]2(C)C[C@H]1OC(C)=O</smiles><smiles>C=C1[C@H](O)C[C@]2(C)C(C)(C)C[C@@H](Cl)C[C@]2(C)[C@H]1CC(O)C1CC(=O)NC1=O</smiles><smiles>C=C1CC(C(O)C[C@@H]2C(=C)[C@@H](O)C[C@]3(C)C(C)(C)[C@H](Cl)[C@@H](Cl)C[C@]23C)C(=O)N1</smiles>

259 Dichlorolissoclimide<smiles>[CH][C@]12CCCN1C(=O)[C@H](CCC)[C@@]1(O)O[C@@](C)(NC(=O)C(C)(C)/C=C(\C)c3cccc(NC)c3C)C(=O)N21</smiles>

258 Chlorolissoclimide

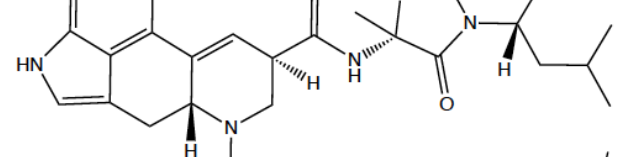

260 Haterumaimide $A$ 262 Keenamide A<smiles>C=C1[C@H](O)C[C@]2(C)C(C)(C)[C@H](O)[C@@H](O)C[C@]2(C)[C@H]1C[C@H](O)[C@@H]1CC(=O)NC1=O</smiles>

$2613 ß-H y d r o x y-$ chlorolissoclimide
264 Ergosinine

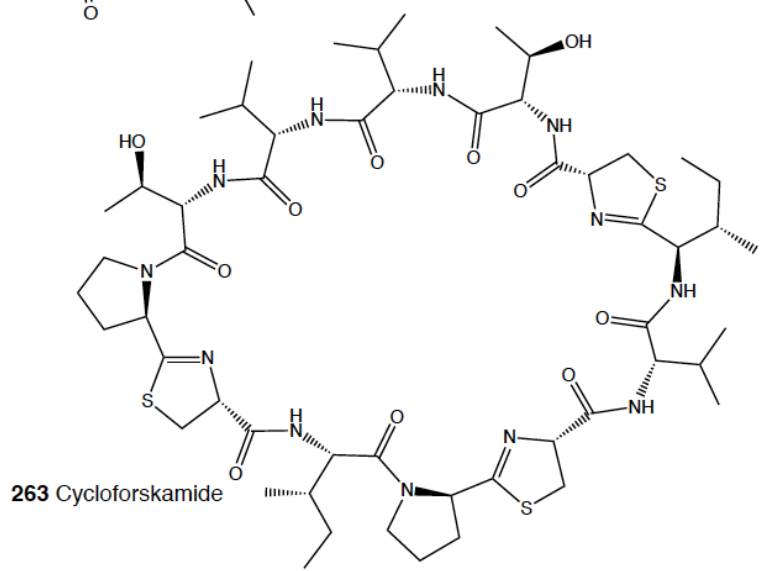

Figure 14. Structures of selected cytotoxic and antitumoral compounds in some Dendronotida, Euarminida, and Aeolidida nudibranchs, and Pleurobranchoidea. These molecules may also display other activities, as reported in the text. 


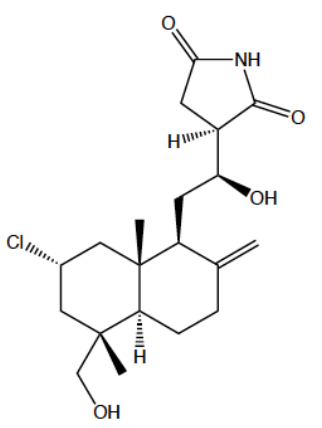

265 Haterumaimide J

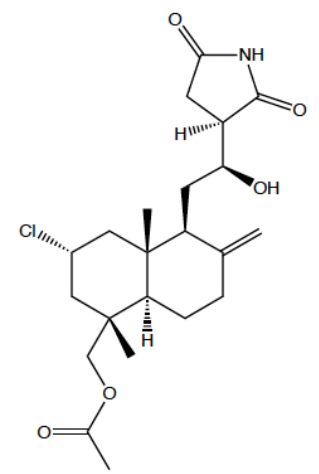

266 Haterumaimide K

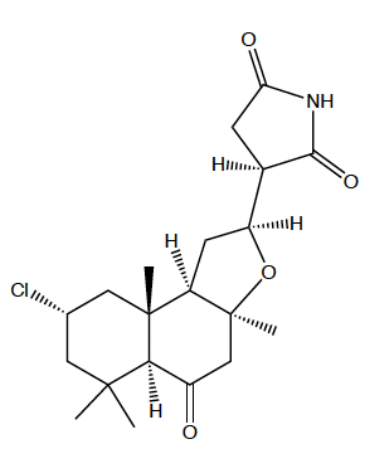

269 Haterumaimide I

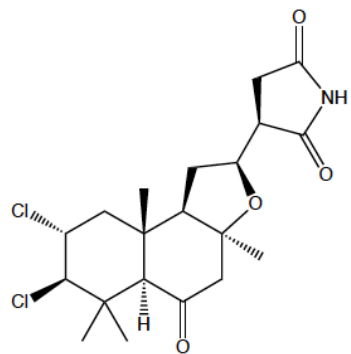

267 Haterumaimide C

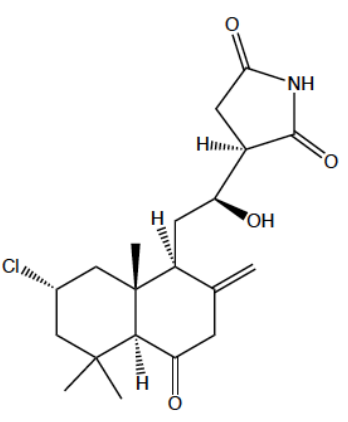

268 Haterumaimide G<smiles>CCCCCC(O)CNC(=O)C1=NOC2(C=C(Br)C(OC)=C(Br)C2O)C1</smiles>

270 Iso-fistularin-3<smiles>CC(=O)O[C@@H](Cc1ccccc1)C(=O)N1CCC[C@H]1C(=O)N[C@H](C(=O)N[C@@H](C)C(C)C)C(C)C</smiles>

272 Kulolide-2<smiles>C#CCCC[C@H](OC(=O)[C@H](C)NC(=O)[C@@H](NC(=O)[C@@H]1CCCN1C(=O)[C@@H](Cc1ccccc1)OC(=O)[C@@H](C(C)C)N(C)C(=O)[C@H](NC(=O)C(C)(C)[AlH2])C(C)C)C(C)C)C(C)C</smiles>

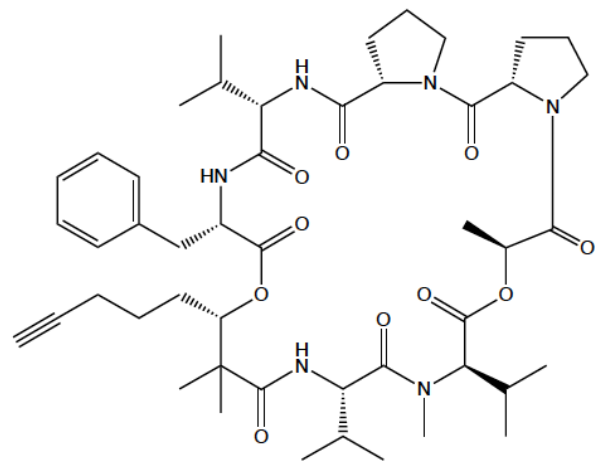

274 Kulokainalide-1

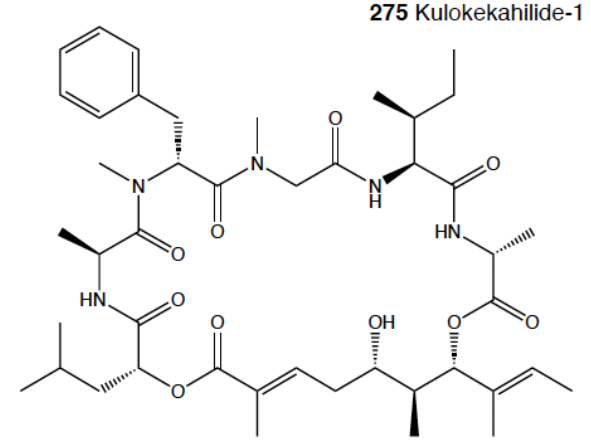

276 Kulokekahilide-2

Figure 15. Structures of selected cytotoxic and antitumoral compounds in some Pleurobranchoidea, Tylodinoidea, and Cephalaspidea. These molecules may also display other activities, as reported in the text. 


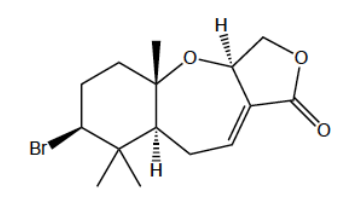

277 Aplysistatin<smiles>CO/C=C(/C)C=CC(Cl)C(C)(Cl)/C=C/Br</smiles>

281 linear monoterpene<smiles>CC(=O)O[C@H]1C[C@@]2(C)C3=CC[C@](C)(C(Br)CO)C[C@H]3[C@H](O)C[C@]2(C)[C@@]2(O)CC[C@H]12</smiles>

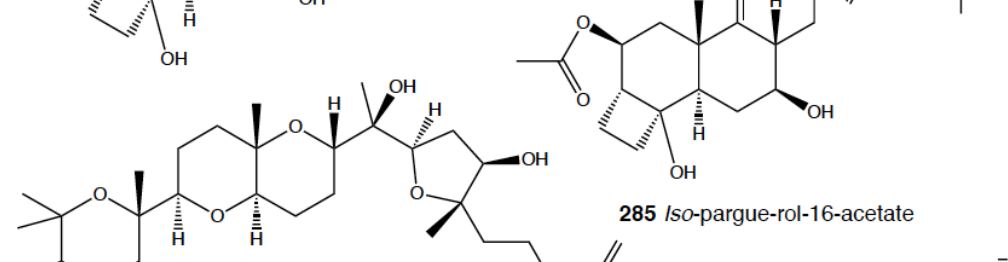

287 Aplysqualenol $\mathrm{A}$<smiles>COCC(C(=O)O)N(C)C</smiles><smiles>C=C1C[C@H](O)[C@@H](O)C(C)(C)C12CCC(C)=C(Cl)C2</smiles>

278 Elatol
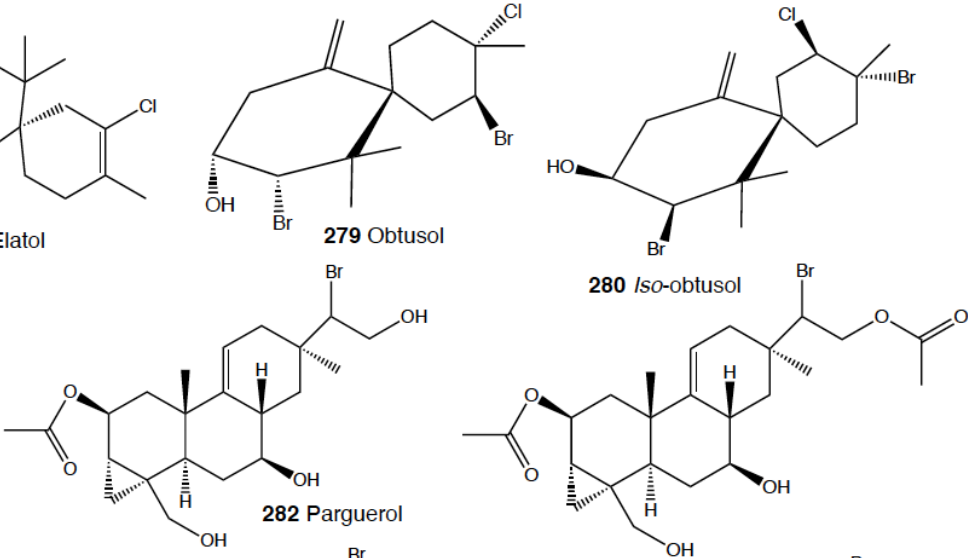
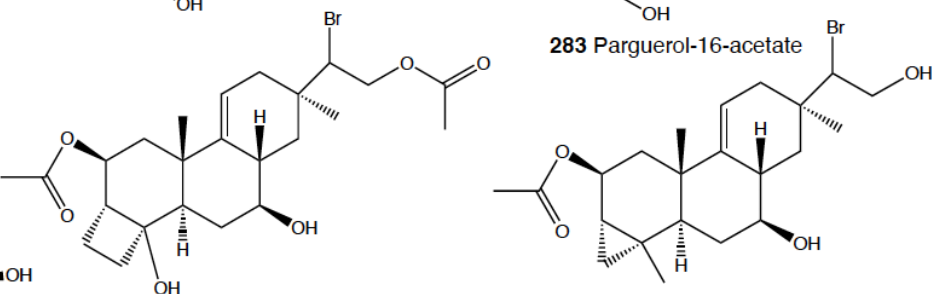

285 Iso-pargue-rol-16-acetate

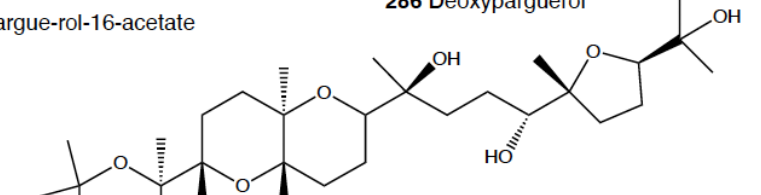

288 Thyrsiferol

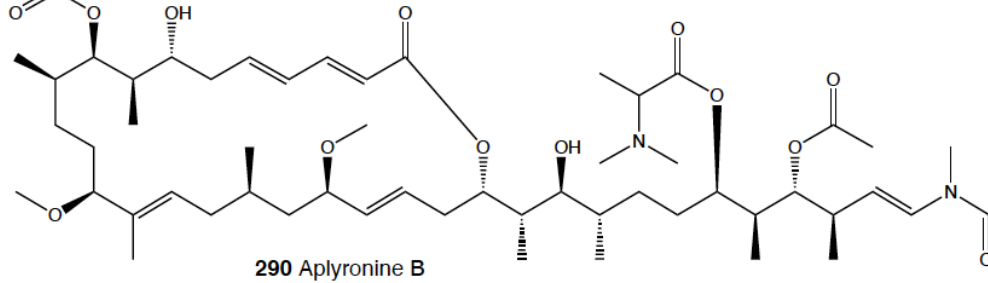

290 Aplyronine B

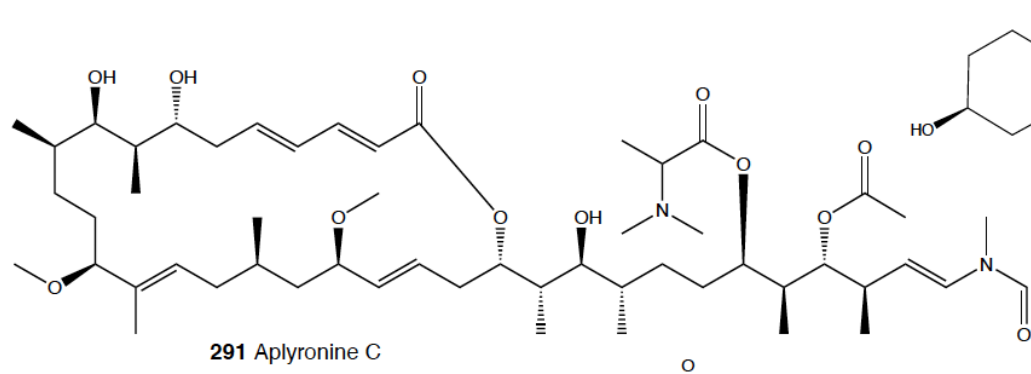

291 Aplyronine C

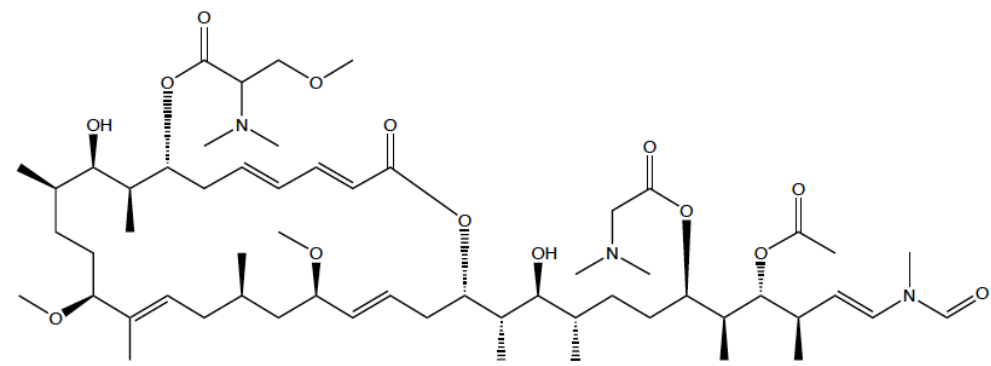

Figure 16. Structures of selected cytotoxic and antitumoral compounds in some Anaspidea. These molecules may also display other activities, as reported in the text. 


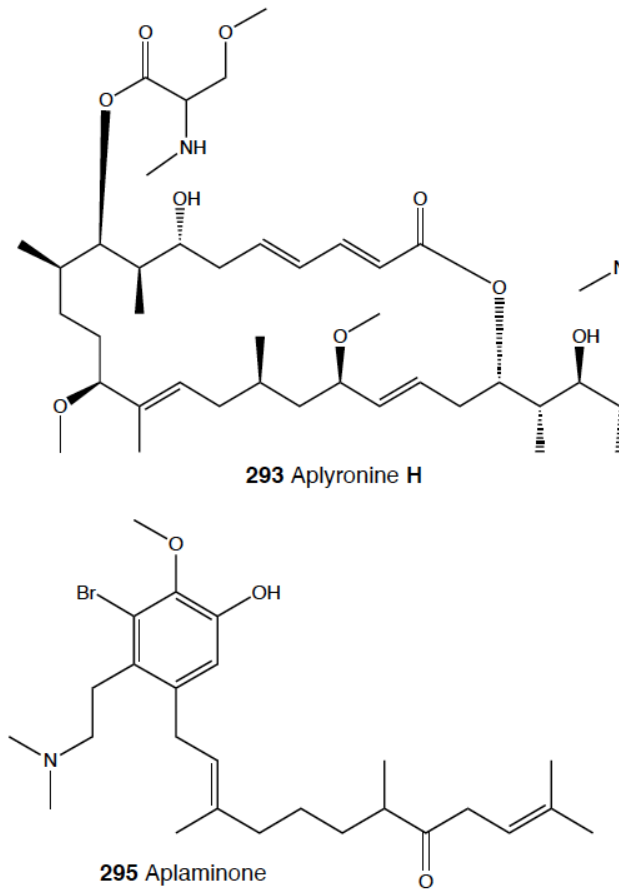<smiles>[B]c1c(CCN(C)C)c(CCC(C)CCCC(C)C(C)=O)cc(OS(=O)(=O)O)c1OC</smiles><smiles>Cc1cc2c(cc1Br)C1(C)CCC(C)C1(C)O2</smiles>

304 Aplysin<smiles>CCC(C)CCC(C)C(C)C(OC(C)=O)C(C)/C=C/N(C)C=O</smiles><smiles>COC(=O)c1ccc(N2C(=O)C3(C(=O)OC)C(C)C2CN3C)cc1</smiles><smiles>CC1(Cl)C[C@](C)(/C=C/Cl)C(O)C[C@H]1Cl</smiles>

298 Aplysiaterpenoid A<smiles>CCC(C)=CCc1cc(O)c(OC)c(Br)c1CCN(C)C</smiles>
296 Neoaplaminone<smiles>CC1(C)O[C@](C)(/C=C/Cl)[C@@H](Cl)C[C@H]1[Hg]</smiles><smiles>[B]/C=C(/CC[C@@H](O)C(C)(Cl)C[B])[C@@H](C)C[B]</smiles>

300 Kurodainol<smiles>C=C[C@](C)(O)CC[C@@H]1[C@@](C)(O)CC[C@]2(C)C(C)(C)[C@H](Br)CC[C@@]12C</smiles>

303 Isoconcinndiol

302 Aplysiadiol<smiles>Cc1cc2c(cc1Br)[C@@]1(CO)CCC(C)[C@@]1(C)O2</smiles>

305 Aplysinol<smiles>CC(C)CCC[C@@H](C)[C@@]1(C)C[C@@H]2OC(=O)C[C@H]3[C@@H](O)CC[C@]1(C)[C@]23C</smiles>

306 Aplykurodin A

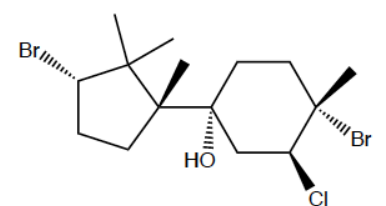

307 Oculiferane

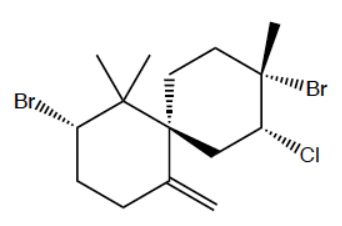

308 Epi-obtusane

Figure 17. Structures of selected cytotoxic and antitumoral compounds in some Anaspidea. These molecules may also display other activities, as reported in the text. 
<smiles>CC(=O)OCCC(C)C(=O)CCC(=CCl)C(Cl)Cl</smiles>

309 Acetate of halogenated monoterpene-1

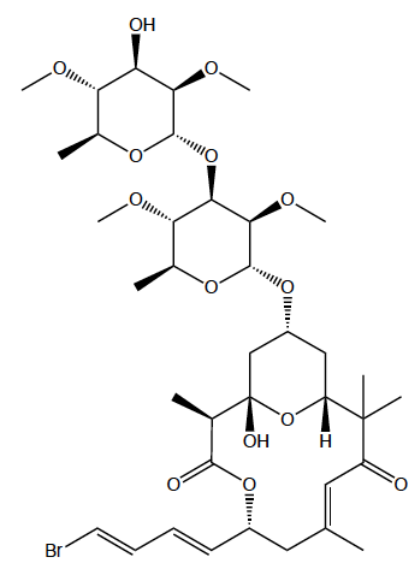

312 Auriside A *<smiles>CCc1oc([C@H](C)[C@@H]2O[C@@]3(OC(C(C)CC)=C(C)C(=O)C3C)[C@@H](C)[C@H](OC(=O)CC(C)C)[C@@H]2C)c(C)c(=O)c1C</smiles>

318 Auripyrone $A$

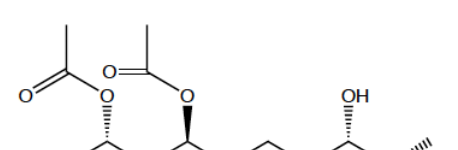<smiles>CCCCCCCCCC(C)OC1=CCCCC1</smiles>

320 Dolabelide A<smiles>CC(=O)OCCC(C)C(=O)CC/C(=C/Cl)C(Cl)Cl</smiles>

310 Acetate of halogenated monoterpene-2<smiles>CO[C@@H]1[C@H](OC(N)=O)[C@H](OC)[C@H](OC)O[C@@H]1C</smiles><smiles>CC(=O)OCC/C(C)=C(Cl)/C=C/C(C)(Cl)CBr</smiles>

311 Acetate of halo311 Acetate of halo-
genated monoterpene-3 314 Aurilol<smiles>CC(=CC=O)C[C@@H](C=CC=CBr)OC=O</smiles>

313 Auriside B *<smiles>CCC[C@H](C/C(C)=C/[C@H](O)[C@@H](C)[C@@H](C[C@H](O)CCC/C=C(\C)CC[C@@H]1CCCCC(C)CC[C@H](C)C[C@@H](C)C(=O)O1)OC(C)=O)OC(C)=O</smiles>

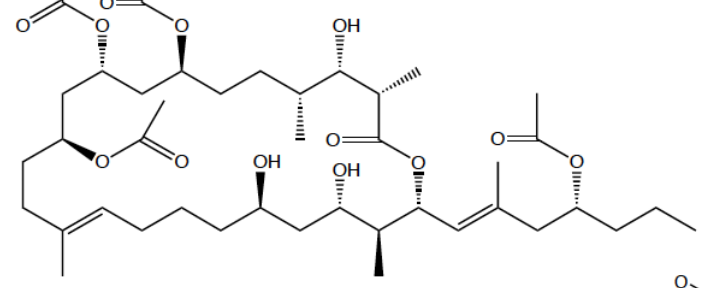

22 Dolabelide C<smiles>CCCCCC1=CC(=O)[C@H](C)[C@@]2(O1)O[C@H]([C@@H](C)c1oc(CC)c(C)c(=O)c1C)[C@@H](C)[C@H](OC(=O)[C@H](C)CC)[C@@H]2C</smiles>

321 Dolabelide B

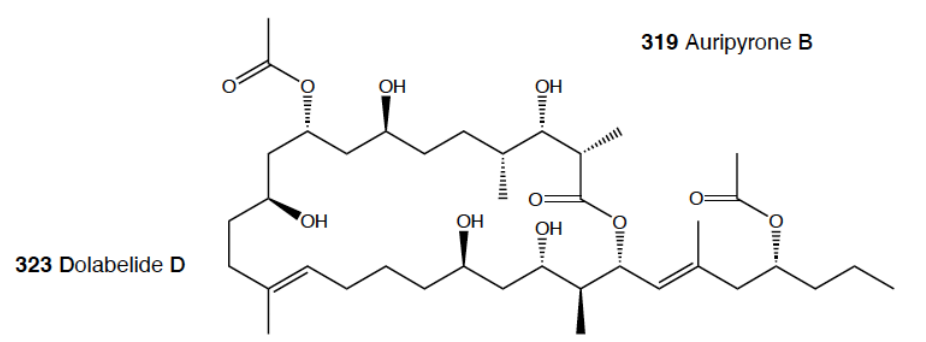

319 Auripyrone B

Figure 18. Structures of selected cytotoxic and antitumoral compounds in some Anaspidea. These molecules may also display other activities, as reported in the text. ${ }^{*}=$ compounds in clinical trials. 

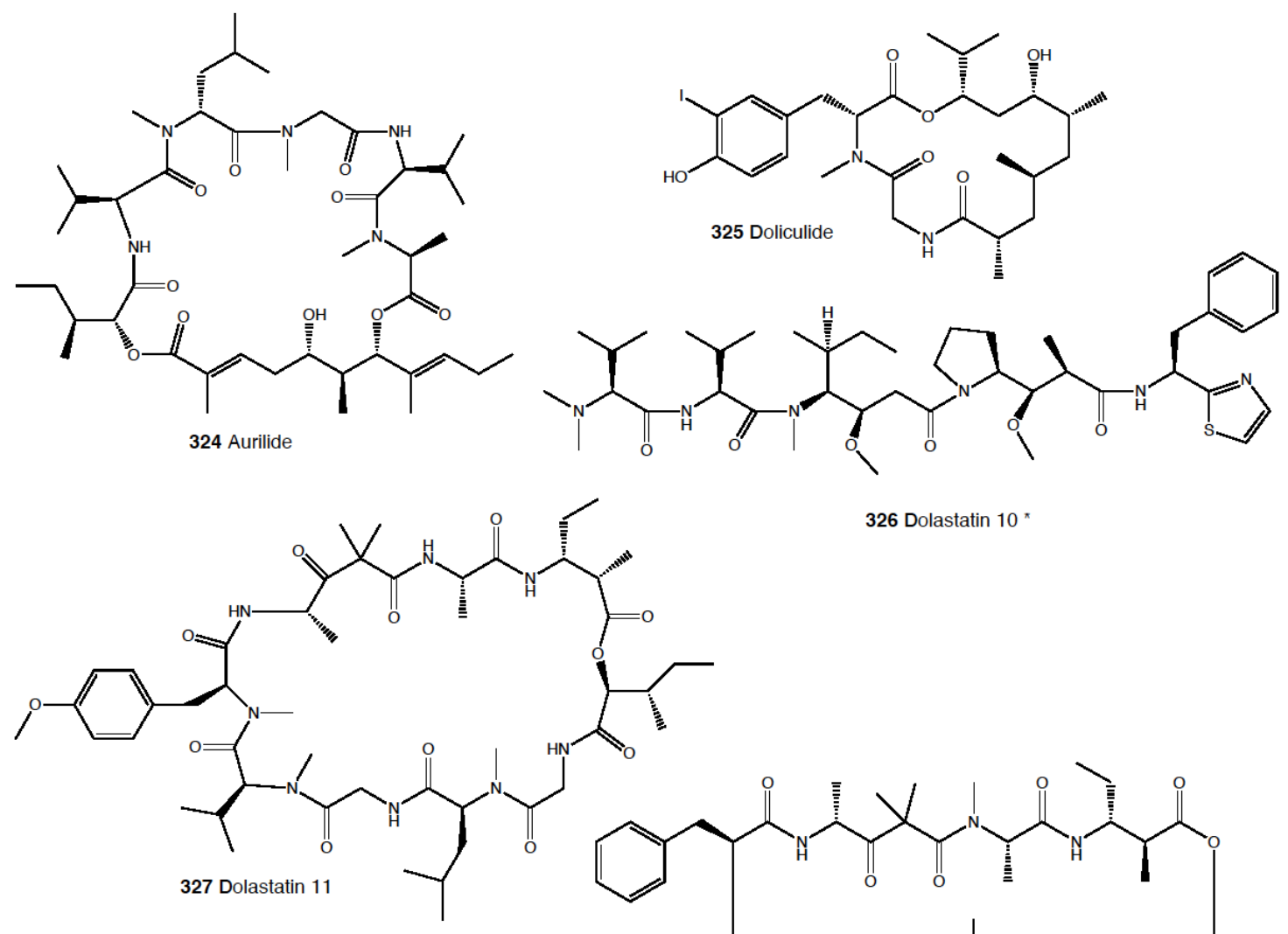

326 Dolastatin 10 *<smiles>CC[C@H](C)C(C)(C)C(=O)NCC(=O)N(C)[C@@H](CC(C)C)C(=O)NCC(=O)N(C)[C@H](C(=O)N(C)C)C(C)C</smiles><smiles>C/C=C(\NC(=O)C(NC(=O)C(NC(=O)C(CO)OC)C(C)C)C(C)C)C(=O)NC1CCC(O)N(C(Cc2ccccc2)C(=O)NC)C1=O</smiles>
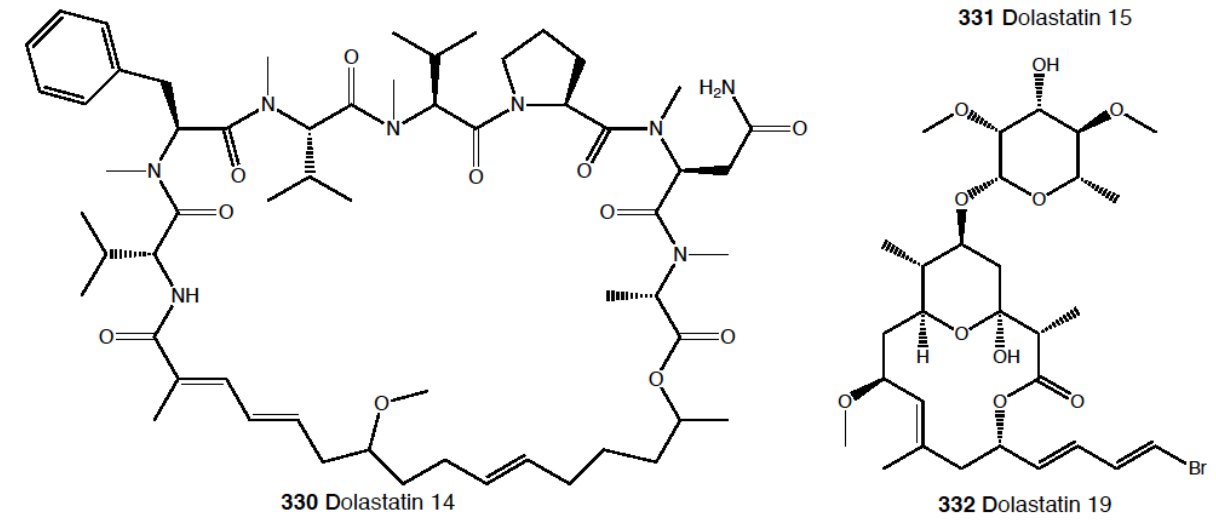

Figure 19. Structures of selected cytotoxic and antitumoral compounds in some Anaspidea. These molecules may also display other activities, as reported in the text. ${ }^{*}=$ compounds in clinical trials. 

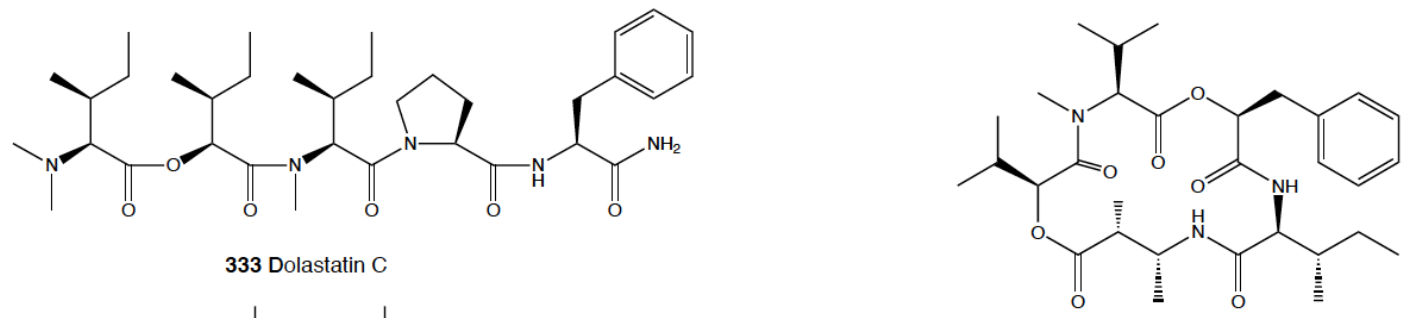<smiles>CC[C@H](C)[C@H](NC(=O)[C@@H](C(C)C)N(C)C)[C@@H](C)CC(=O)N1CCC[C@H]1[C@H](OC)[C@H](CC(=O)N1CCC[C@H]1[C@H](C)C(=O)OC[C@H](O)Cc1ccccc1)OC</smiles>

334 Dolastatin D

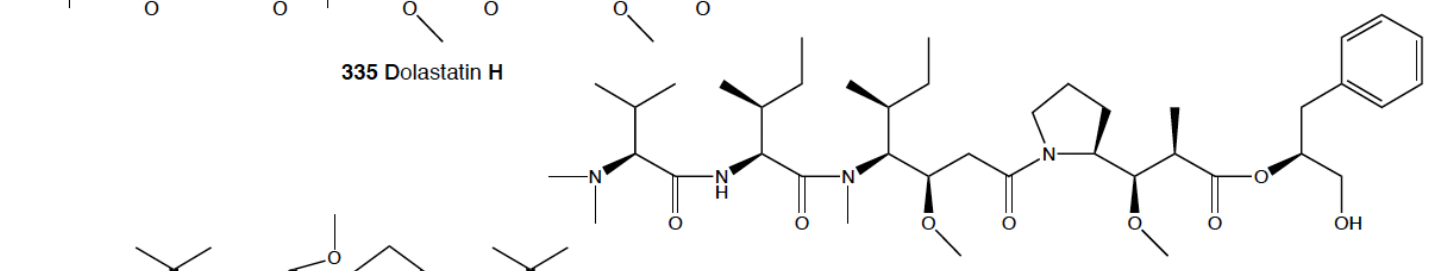

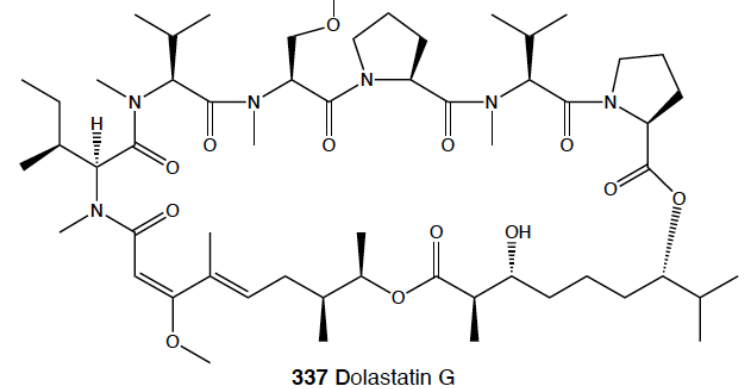

336 Iso-dolastatin H

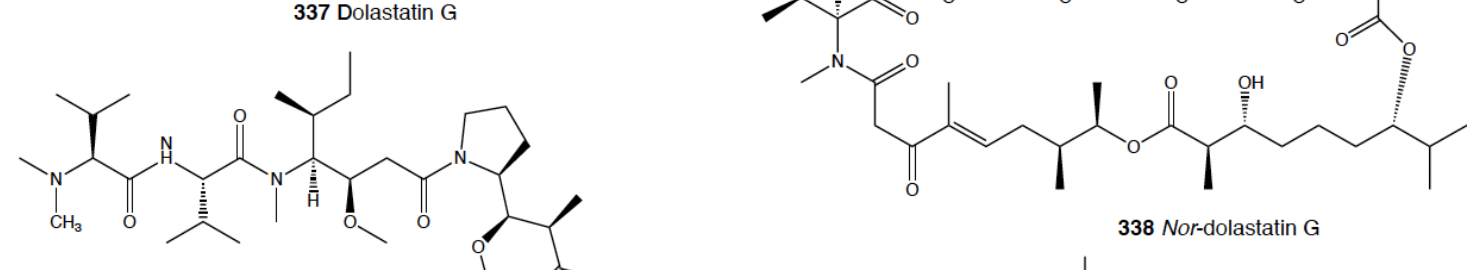

339 Auristatin E
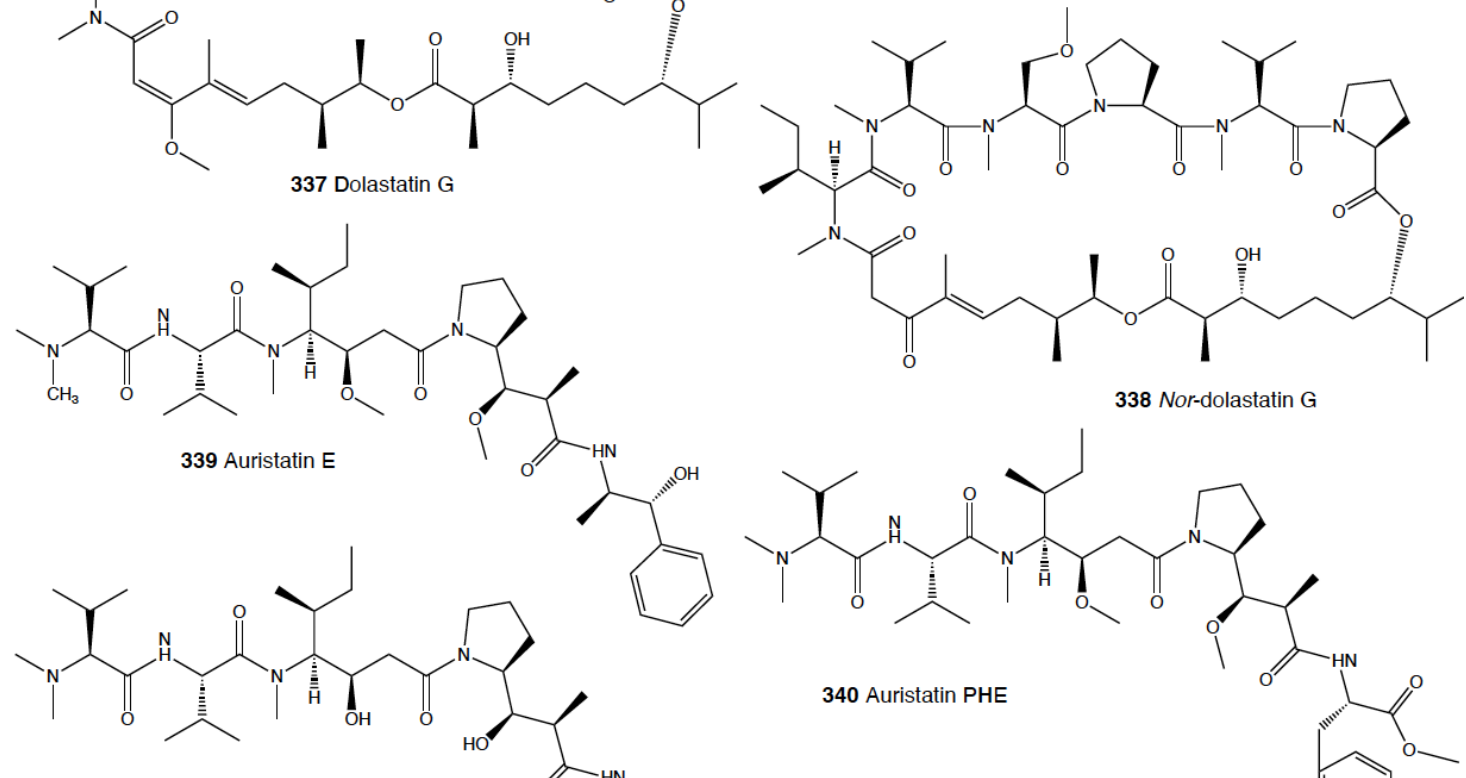<smiles>CC(C)[C@H](NC(=O)[C@@H](C(C)C)N(C)C)C(=O)N(C)C</smiles>

340 Auristatin PHE

341 Auristatin PYE

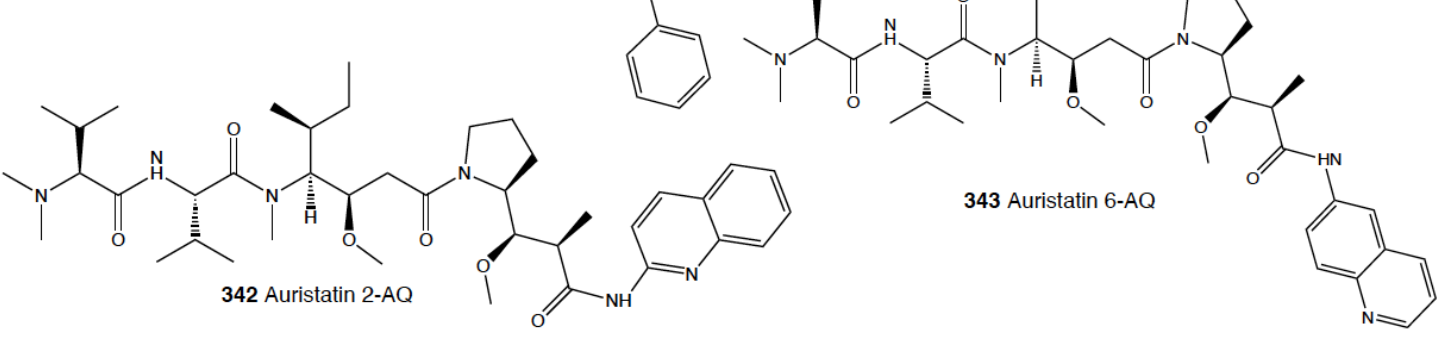

Figure 20. Structures of selected cytotoxic and antitumoral compounds in some Anaspidea. These molecules may also display other activities, as reported in the text. 

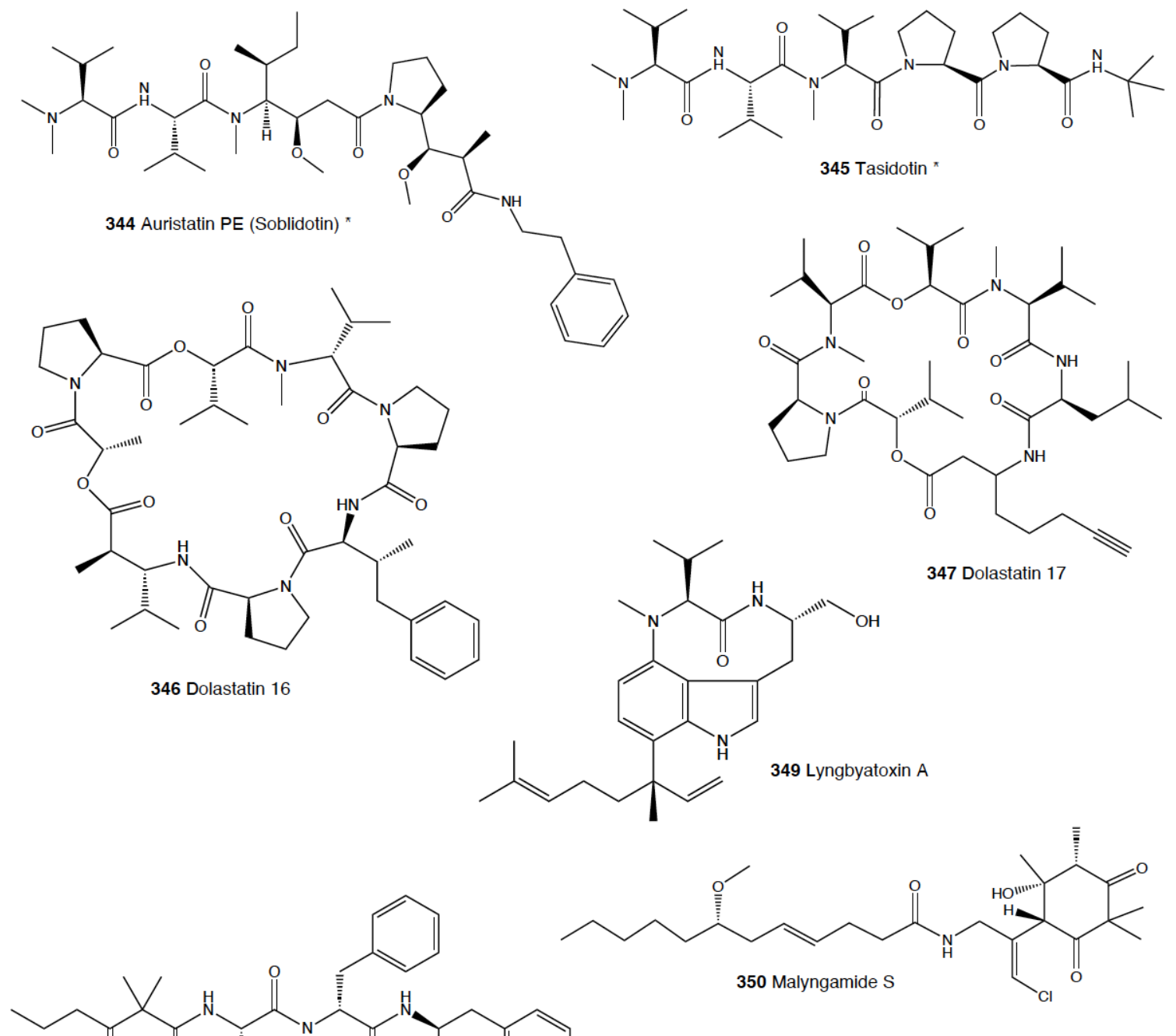<smiles>C=C([C@H](CC(C)C)NC(=O)C(C)(C)C(=O)CCC)N(C)[C@@H](C)C(=O)N[C@H](Cc1ccccc1)c1nccs1</smiles>

348 Dolastatin 18
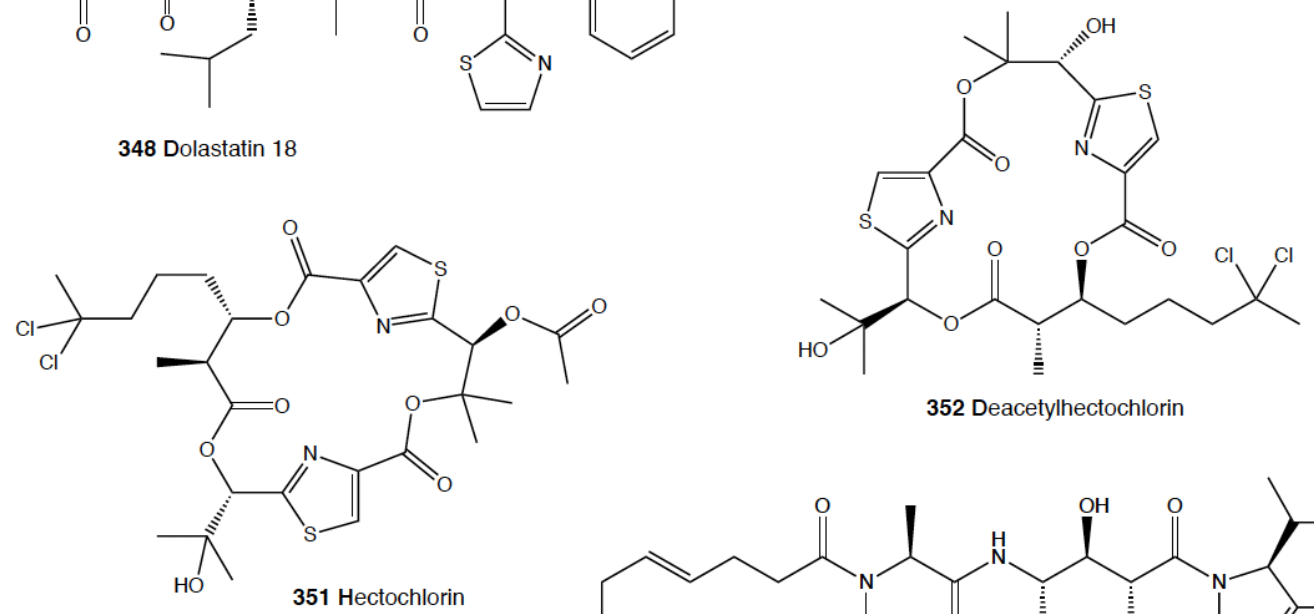

352 Deacetylhectochlorin

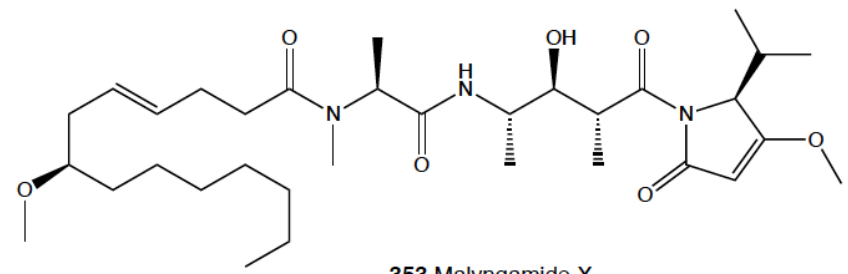

Figure 21. Structures of selected cytotoxic and antitumoral compounds in some Anaspidea. These molecules may also display other activities, as reported in the text. ${ }^{*}=$ compounds in clinical trials. 


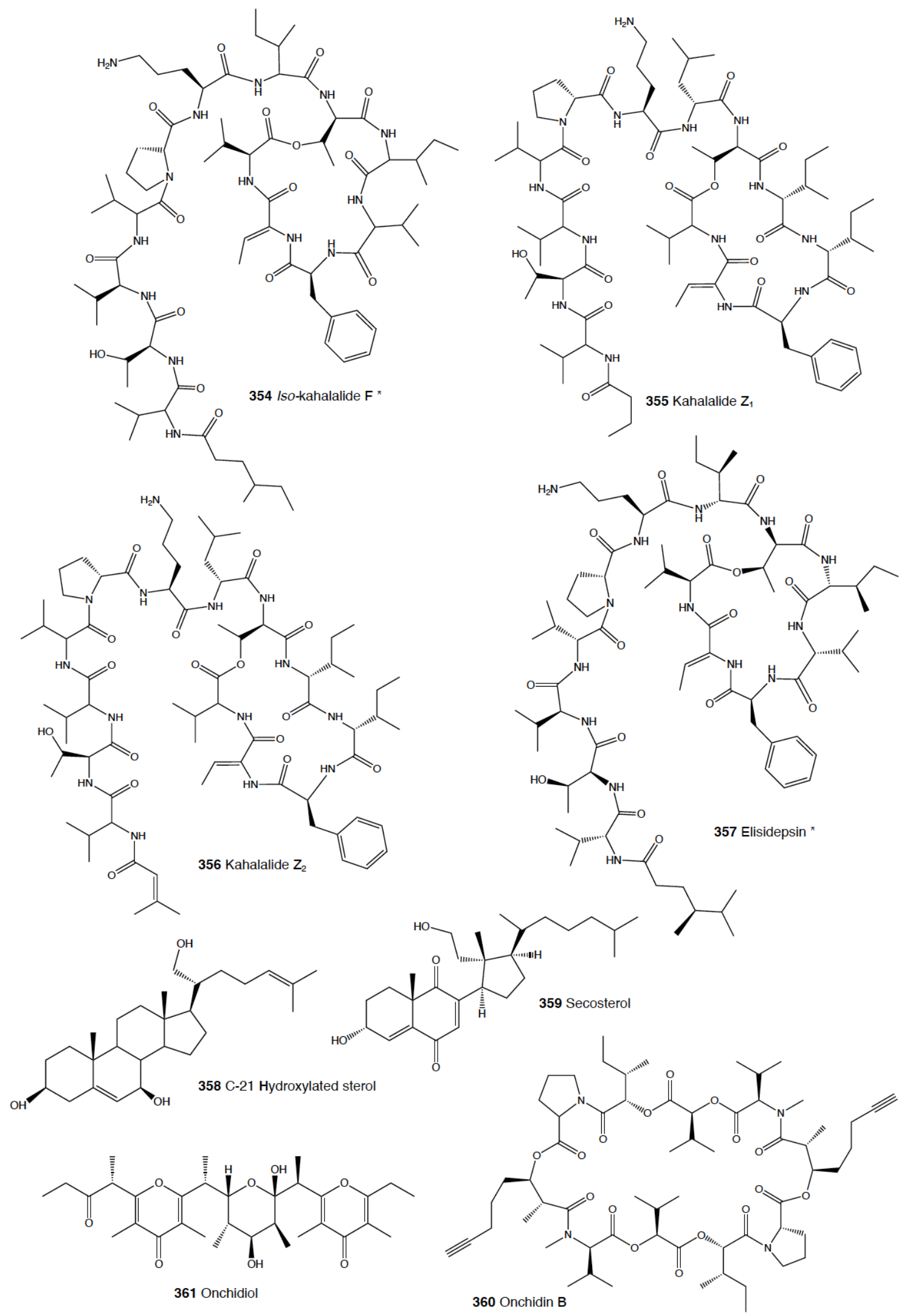

Figure 22. Structures of selected cytotoxic and antitumoral compounds in some Sacoglossa and Pulmonata. These molecules may also display other activities, as reported in the text. ${ }^{*}=$ compounds in clinical trials. 
<smiles>CCC(=O)O[C@H](/C(C)=C/[C@@H](C)c1oc(CC)c(C)c(=O)c1C)[C@@H](C)[C@H](OC(=O)CC(C)C)[C@@H](C)c1oc([C@@H](C)[C@@H](CC)OC(C)=O)c(C)c(=O)c1C</smiles><smiles>CCc1oc([C@H](C)/C=C(\C)[C@@H](O)[C@@H](C)[C@H](O)[C@@H](C)c2oc([C@@H](C)[C@@H](O)CC)c(C)c(=O)c2C)c(C)c(=O)c1C</smiles>

362 3-Acetyl-11-(3-methylbutanoyl)-13-propanoyl-ilikonapyrone<smiles>C=C1CCC[C@@]2(C)CC[C@H](C(C)C)[C@@]2(O)C1=O</smiles>

368 Millecrone A<smiles>CC1=C2CC[C@@H](C)[C@]2(C)C2C(CC1=O)C2(C)C</smiles>

369 Millecrone B<smiles>COC(=O)/C(C)=C/C=C/C(C)C1CC=C(C)CC1</smiles><smiles>C=C1CCC[C@]2(C)CC[C@H](C(C)C)[C@]2(O)[C@H]1C</smiles>

366 Sanguinamide B

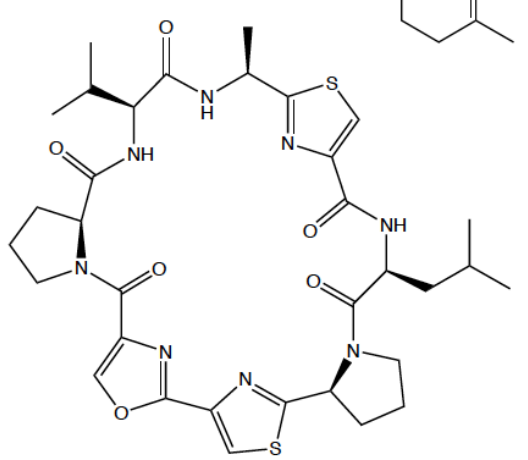

370 Millecrol A<smiles>C=C1CC[C@H]2C(C(C)C)CC[C@](C)(O)[C@H]2C1</smiles>

365 Deoxysecomanoalide

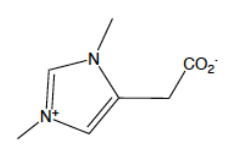

367 Zooanemonin<smiles>C=C1CCC(C(C)C)C2(O)CC(CC)=CCC1C2(O)O</smiles>

372 DO1<smiles>C/C=C(\C)CCC(/C=C/C(O)(CC)CC)CC</smiles><smiles>C=[N+][C@]1(C)C=C[C@H]([C@H](C)CC[C@H]2C3(C)CC[C@H](O3)C2(C)C)[C@H](CCN)CC1</smiles><smiles>COc1ccc(C/C(=N\O)C(=O)NCCc2cc(Br)c(OCCC[N+](C)(C)C)c(Br)c2)cc1Br</smiles>

376 Aplysamine 2

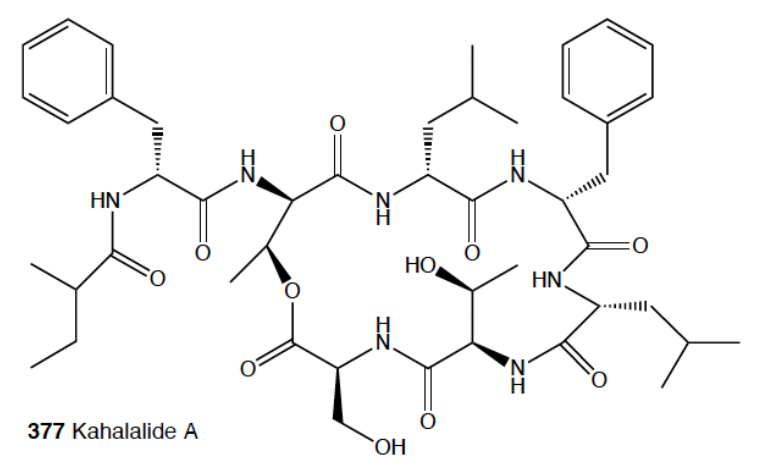

Figure 23. Structures of selected cytotoxic and antitumoral compounds in some Pulmonata, as well as selected antibiotic compounds in Doridacea, Euarminida, Tylodinoidea, Anaspidea, and Sacoglossa, and an antiparasitic compound from a Doridacea. These molecules may also display other activities, as reported in the text. 


\subsubsection{Nudibranchia}

Doridacea

The Antarctic slug Doris kerguelenensis presents clerodane and labdane diterpenes, such as palmadorins (195-200), among other compounds [66,67]. Palmadorins A (195), B (196), D (197), $\mathrm{M}$ (198), N (199), and O (200) have been described to inhibit human erythroleukemia cells (HEL) at low $\mathrm{IC}_{50}$ (micromolar), and palmadorin $\mathrm{M}$ (198) has been reported to inhibit Jak2, STAT5, and Erk1/2 activation in HEL cells, producing apoptosis at $5 \mu \mathrm{M}$ [67]. The Mediterranean and Atlantic Doris verrucosa, contains the de novo biosynthesized verrucosins, diterpenoid acid glycerides, among which verrucosins A (124) and B are potent activators of protein kinase C, and they promote tentacle regeneration in the freshwater hydrozoan Hydra vulgaris [370,371,486]. Notodoris nudibranchs feed on Leucetta calcareous sponges, presenting sponge-derived imidazole alkaloids $[424,426,487,488]$. In the Red Sea, N. citrina and N. gardineri obtain their chemicals from Leucetta chagosensis, presenting among others, naamidine A (201) and iso-naamidine-A (160) [424,426]. Naamidine A (201) was later tested from the sponge (from different localities) as a selective inhibitor of the epidermal growth factor (EGF) and was found to inhibit human tumor xenografts in mice, as well as displaying antitumour activity that promotes caspase-dependent apoptosis in tumor cells [489,490].

Adalaria loveni from the North Sea presents lovenone (202), a degraded triterpenoid suggested to come from an unidentified bryozoan prey [491]. Lovenone (202) was reported to present modest cytotoxicity to two HTCLs (human tumor cell lines) [491]. Another bryozoan-feeder, Polycera atra accumulates bryostatins (203) from Bugula neritina, also including them in their spawn [340,492-494]. Bryostatins (203) are polyketide macrolides known to be biosynthesized by a microbial symbiont, Endobugula sertula [495]. Bryostatins (203) are highly bioactive compounds, with bryostatin 1 (203), for example, being investigated in more than 20 clinical trials (two phase I trials) against multiple carcinomas and Alzheimer's disease [31,42,123,496,497]. Bryostatin 1 (203) modulates the Bcl-2 and p53 oncoproteins in human diffuse large-cell lymphoma WSU-DLCL2, inducing a decrease in the expression of Bcl-2 [498]. Furthermore, bryostatin 1 (203) showed a notable activity of modulating the paclitaxel inhibitor of protein kinase C (PKC) [499-501], as well as inducing ubiquitination and proteasome degradation of Bcl-2 in lymphoblastic leukemia, allowing for the growth of progenitor cells from bone marrow [502]. Moreover, bryostatins (203) are strong activators of PKC, regulating the activation, growth, and differentiation of cells [503].

Another interesting species is the Chinese Actinocyclus papillatus, which presents the mildly cytotoxic (-)-actisonitrile (204) in its mantle, along with actinofide (205), a terpenoid diacylguanidine [361,504,505]. Both enantiomers, (-)- and (+)-actisonitrile (204), were tested for cytotoxicity against tumor and non-tumor mammalian cells, resulting in a parallel concentration-dependent toxic profile at a micromolar concentration [504]. On the other hand, actinofide (205), a guanidine moiety acylated by two terpenoid acid units, allowed for the synthesis of a series of structural analogues which were tested for growth inhibitory activity against some cancer cell lines in vitro [506-508]. Actinofide (205) and some of its analogues were tested against six cancer cell lines: two human carcinoma cancer cell lines (MCF-7 (breast) and A549 (non-small-cell lung cancer, NSCLC)) of epithelial origin, two human cancer cell lines from glial origin (Hs683 oligodendroglioma and U373 glioblastoma of astrocytic origin), and two melanoma models (mouse B16F10 and human SKMEL-28 cell lines), resulting in many relevant activities [479]. Actinofide (205) presents $\mathrm{GI}_{50}$ values of $8.3 \pm 1.8$ for Hs683, $15.7 \pm 10.1$ for U373, $23.4 \pm 5.5$ for A549, $23.4 \pm 5.9$ for MCF-7, $24.2 \pm 8.2$ for SKMEL-28, and $7.5 \pm 3.1$ for B16F10 [479,505]. The most active compounds are reported to be those with one or two $\mathrm{N}-\mathrm{C}_{15}$ residues, and a preliminary correlation between structure and activity was proposed [479].

Aldisa andersoni from the Indo-Pacific contains some phorbazoles, peculiar chlorinated phenyl-pyrrolyloxazoles, such as 9-chloro-phorbazole D (5) and N1-methyl-phorbazole A (6), along with phorbazoles A (7), B (8), and C described in the sponge Phorbas aff. clathrata $[55,56,75,76]$. 
Both 9-chloro-phorbazole D (5) and N1-methyl-phorbazole A (6) produce cytostatic effects in vitro against several HTCLs [75]. More specifically, N1-methyl-phorbazole A (6) inhibits human SKMEL-28 melanoma and U373 glioblastoma cells [75].

Dendrodoris carbunculosa from Japan possesses drimane sesquiterpenoids, the dendocarbins A-N $(\mathbf{1 6 , 2 0 6 )}$, along with isodrimeninol (207) and 11-epivaldiviolide (208), some of them displaying cytotoxicity against murine leukemia $\mathrm{P} 388$ cell lines [87]. In particular, the $\mathrm{IC}_{50}$ values against adriamycin (ADR)- and vincristine (VCR)-resistant P388 cells (P388/ADR and P388/VCR, respectively), as well as those against sensitive P388 strain (P388/S) were reported for all compounds, with dendocarbin $\mathrm{J}$ (206) and 11-epivaldiviolide (208) showing moderate cytotoxicity against both sensitive and resistant cell strains [86]. The $\mathrm{IC}_{50}$ values for dendocarbin J (206) were $17 \mu \mathrm{g} / \mathrm{mL}$ for P388/S, $4 \mu \mathrm{g} / \mathrm{mL}$ for P388/VCR(-), $4 \mu \mathrm{g} / \mathrm{mL}$ for P388/VCR(+), $11 \mu \mathrm{g} / \mathrm{mL}$ for P388/ADR(-), and $8 \mu \mathrm{g} / \mathrm{mL}$ for P388/ADR(+), while for 11-epivaldiviolide (208) the values were 3.2, 2.5, 2.5, 2.5, and $2.5 \mu \mathrm{g} / \mathrm{mL}$, respectively [86]. The origin of 11-epivaldiviolide (208) could be dietary, since it was first described in the sponge Dysidea fusca [509].

Regarding phyllidids, several species are described to present bioactive compounds. In Thailand, Phyllidia coelestis presents two cytotoxic pupukeanane sesquiterpenoids, 1 -formamido10(1,2)-abeopupukeanane (209) and 2-formamidopupukeanane (210), which show in vitro growth inhibitory activity against four human cancer cell lines [111]. In particular, this activity was tested against HeLa (cervical), MCF-7 (breast), KB (oral cavity), and HT-29 (colon) cancer cell lines with IC $_{50}$ values between 0.05 and $10 \mu \mathrm{M}$ [111,510]. Furthermore, both molecules $(\mathbf{2 0 9}, \mathbf{2 1 0})$ present selectivity, weakly inhibiting the growth of human gingival fibroblasts by $65 \%$ and $25 \%$ at $20 \mu \mathrm{M}$, respectively [111,510]. Phyllidiella pustulosa also contains many sesquiterpenoids, as abovementioned, and specimens from Okinawa, for example, possess the moderately cytotoxic substituted axinisothiocyanate $\mathrm{K}$ derivative (211) and an isocyano compound [377]. In Fiji, P. pustulosa contains the isothiocyanate axisonitrile-3 (25), which is weakly cytotoxic $\left(\mathrm{IC}_{50}>20 \mu \mathrm{g} / \mathrm{mL}\right.$ ), in addition to some related sesquiterpenes [118,427]. In southern China, both $P$. coelestis and P. pustulosa present several nitrogenous terpenoids from their demosponge prey, Acanthella cavernosa [117]. Among these compounds, a bisabolane-type sesquiterpenoid (212), a theonellin isothiocyanate (213), and 7-isocyano-7,8-dihydro- $\propto$-bisabolene (214) display cytotoxicity against several HCCLs [117]. In particular, they all show strong cytotoxicity against HCCL SNU-398 with $\mathrm{IC}_{50}$ values of $0.50,2.15$, and $0.50 \mu \mathrm{M}$, respectively [117]. Furthermore, the bisabolane sesquiterpenoid (212) presents broad cytotoxicity, being active against HCCLs A549, HT-29, and Capan-1, with $\mathrm{IC}_{50}$ values of 8.60,3.35, and $1.98 \mu \mathrm{M}$, respectively [117]. Contrastingly, Reticulidia fungia from Okinawa presents the cytotoxic carbonimidic dichlorides, reticulidins A (215) and B, which are two uncommon sponge sesquiterpenes, probably obtained from their diet of Pseudaxinyssa sponges $[438,511,512]$. Both compounds are moderately cytotoxic in vitro against KB cells, with $\mathrm{IC}_{50}$ values of $\sim 1 \mu \mathrm{M}$ for both, and against mouse L1210 leukemia cells, with $\mathrm{IC}_{50}$ values of $\sim 2$ and $\sim 0.3 \mu \mathrm{M}$, respectively [438].

Chromodoridids are also reported to possess cytotoxic and anticancer compounds. In the Paficic, Cadlina luteomarginata and its sponge prey Phorbas sp. Contain, among other compounds, ansellone A (216), a sesterterpenoid that moderately activates the cyclic adenosine monophosphate (cAMP) signaling pathway, with an $\mathrm{EC}_{50}$ value of $14 \mathrm{mM}$ in the HEK293 cell-based test [513]. The modulation of the cAMP signaling pathway is used in stem cell techniques, and it is relevant to treat diseases such as cancer, heart failure, and neurodegenerative diseases [514]. On the other hand, several Chromodoris species possess latrunculin A (38), a PKS-NRPS-derived macrolide, reported to be cytotoxic [141]. Latrunculin A (38) was found in C. lochi and its sponge prey Spongia (Cacospongia) mycofijiensis in Fiji [141]. In fact, latrunculins A (38) and B (37) were first described from the Red Sea Negombata (Latrunculia) magnifica and later in other sponges (Hyattela sp.) [168]. Latrunculins $(37,38)$ were then reported in several Chromodoris species at different localities, including C. africana, C. annae, C. elisabethina, C. hamiltoni, C. kuiteri, C. magnifica, and C. quadricolor [153,155,164,170,171]. C. (Glossodoris) also obtains latrunculin B (37) from the demosponge Latrunculia magnifica [171]. Latrunculins $(37,38)$ interfere 
with the cytoskeleton, disrupting the organization of cell microfilaments, and inhibit the proliferation of cancer cells due to their strong actin binding properties [153,164,515-517]. A PKS-NRPS-derived mycothiazole (129) found in C. lochi from Vanuatu and its prey sponge (see above) possesses selective cytotoxicity, inhibits the hypoxia-inducible factor-1 (HIF-1), and also suppresses the mitochondrial respiration at complex I in sensitive cell lines ( $\mathrm{IC}_{50}$ values of $0.36-13.8 \mathrm{nM}$ for HeLa, P815, RAW 264.7, MDCK, HeLa S3, 4T1, B16, and CD4/CD8 T cells) [103-106]. Latrunculins A (38) and B (37) display antimigratory activity against highly metastatic human prostate cancer $\mathrm{PC}-3 \mathrm{M}-\mathrm{CT}^{+}$cells and murine brain-metastatic melanoma B16B15b cells [515,518]. Latrunculin A (38) presented $\mathrm{IC}_{50}$ values of $\sim 0.5$ $\mu \mathrm{M}$ against murine P388 leukemia, human HT-29 colon cancer, and human A549 NSCLC, with more than a fivefold in vitro growth inhibitory effects against A549 NSCLC than to P388 leukemia [519]. Latrunculin A (38), coded NSC613011 on the NCI database, has an $\mathrm{IC}_{50}$ mean value of $\sim 0.7 \mu \mathrm{M}$ in the 60 cancer cell line panel, with a more than twofold log magnitude difference between the most sensitive and the most resistant cancer cell lines, being as active against MDR NCI/ADR-RES as against cells without the MDR phenotype [47]. Finally, latrunculin A (38) induces apoptosis in cancer cells via activation of the caspase-3/caspase-7 pathway and displays strong anticancer effects in peritoneal dissemination models of MKN45 and NUGC-4 human gastric cancer in mice [455]. In vivo anticancer assays using A549 NSCLC xenografts also show that latrunculin A (38) increased the life span of treated tumor-bearing mice by $46 \%$ compared to controls [520].

Chromodoris lochi from Indonesia, instead, presents sponge-derived polyketides, such as laulimalide (39) and isolaulimalide (40) from the sponge Hyattella sp., both compounds being cytotoxic due to their microtubule-stabilizing action at a different binding site to taxanes, located on two adjacent $\beta$-tubulin units between tubulin protofilaments of a microtubule [521,522]. Therefore, these compounds (39-40), with $\mathrm{IC}_{50}$ values of $15 \mathrm{ng} / \mathrm{mL}$ in the $\mathrm{KB}$ cell line, are being tested as potential antitumor agents $[142,523,524]$. Laulimalide (39) inhibits growth in more than ten cancer cell lines at low nanomolar concentrations, while isolaulimalide (40) is effective at low micromolar values [142,525,526]. As previously mentioned, laulimalide (39) is a microtubule stabilizer, like the plant compounds taccalonolide and paclitaxel, but laulimalide (39) has been reported to cause the formation of aberrant, structurally distinct mitotic spindles, differently from the other two molecules [527]. Moreover, laulimalide (39) has an effect in P-gp-overexpressing cancer cells and against cell lines resistant to paclitaxel and epothilones $[525,528]$. Further studies have shown that in ovarian cancer cells, the increased expression of $\beta$ II- and $\beta$ III tubulin isotypes induces resistance to laulimalide (39), as does the downregulation of vimentin expression in human ovarian carcinoma cells [529,530]. Moreover, assays in vivo tested the anticancer activity of laulimalide (39) in two xenograft models, the human MDA-MB-435 breast cancer and the human HT-1080 fibrosarcoma models, describing little tumor growth inhibition accompanied by a strong toxicity and mortality, contrasting to paclitaxel [525].

Furthermore, inorolides A-C (217), sesquiterpenoids found in the Japanese Chromodoris inornata (C. aspersa) and other scalarane terpenoids are cytotoxic against murine L1210 leukemia and human epidermoid carcinoma KB cell lines [156]. Particularly, inorolides A-C (217) display $\mathrm{IC}_{50}$ values of $\sim 7, \sim 5$, and $\sim 4 \mu \mathrm{M}$, respectively, while sesterterpenoids like deoxoscalarin (46) and its analogues, deoxoscalarin-3-one, 21-hydroxydeoxoscalarin, 21-acetoxydeoxoscalarin, and 12-O-acetyl-16-O-deacetyl-12,16-episcalarolbutenolide, display values of $\sim 3, \sim 2, \sim 9, \sim 1$, and $\sim 5 \mu \mathrm{M}$, respectively [156]. Some of these metabolites have been reported also in Hyrtios sponges and reviewed for their bioactivity [156,531].

Similarly, cytoxicity has been reported in several compounds from other Chromodoris species, such as a sponge diterpene found in C. petechialis from Hawai'i, puupehenone (218), an oxygenated diterpene of C. elisabethina from Australia, a spongian diterpene of $C$. kunei from Okinawa, furanoditerpenoids found in C. reticulata from China, and the mildly toxic diterpenes from a Chromodoris sp. from Australia [22,154,158,160,186]. Puupehenone (218) is active at $\mathrm{IC}_{50}$ values of $1 \mu \mathrm{g} / \mathrm{mL}$ to P388, $0.1-1 \mu \mathrm{g} / \mathrm{mL}$ to A-549 and MCF-7, as well as $1-10 \mu \mathrm{g} / \mathrm{mL}$ to HCT-8 $[22,154,158,160,186]$. 
Goniobranchus species also possess some cytotoxic compounds. In Australia, G. splendidus has a cytotoxic spiroepoxide lactone, epoxygoniolide-1 (219), suspected to originate from its dietary sponge prey [532]. Epoxygoniolide-1 (219) shows moderate cytotoxicity to NCIH-460, SW60, and HepG2 cancer cells [532]. G. (Chromodoris) sinensis from China presents aplyroseol-2 (220) [131]. G. reticulatus from Australia presents a dialdehyde sesquiterpene, together with the ring-closed acetal, both bioactive against P388 mouse leukemia cells $[161,186]$. G. reticulatus contains spongian-16-one (221), aplytandiene-3 (222), aplysulfurin (223), aplyroseol-2 (220), and gracilins A (224), B (225), C (226), G (227), and M (228), all of which display cytotoxicity against HeLa S3 cells [190]. Moreover, gracilins B (225) and C (226), as well as some isomers, obtained from the demosponge Spongionella sp. are cytotoxic against a wider panel of HTCLs, and have also been reported as cyclosporine A mimics and BACE1 and ERK inhibitors (see below) $[533,534]$. Gracilins M-Q (228) showed a significant potency against the HeLa S3 cell line [113]. In Japan, G. (Chromodoris) obsoletus contains dorisenones A-D (229), cytotoxic sponge diterpenoids, along with related compounds, such as 11 $\beta$-hydroxyspongi-12-en-16-one (230), spongian-16-one (221) [154]. All of these compounds are active against murine lymphoma L1210 and human epidermoid carcinoma KB cells at $\mathrm{IC}_{50}$ submicromolar (as low as $\mathrm{IC}_{50} 0.2 \mu \mathrm{g} / \mathrm{mL}$ ) and low micromolar values, respectively, and although dorisenone $\mathrm{D}$ and a related compound have also been tested in vivo against P388 leukemia, they show no activity [154]. Similarly, in G. collingwoodii, some spongian-16-one diterpenes are reported to be inactive to a range of HTCLs [186].

The spongian diterpenes of Glossodoris cincta from Egypt and Sri Lanka have also been reported to be cytotoxic [22,166,380,381,535-537]. The compound 12-epi-scalaradial found in G. cincta and G. hikuerensis is the most active, inhibiting the epidermal growth factor receptor (EGFR) implicated in many cancers, and also inhibiting the human recombinant PLA2 at $0.02 \mu \mathrm{M}$. Doriprismatica (Glossodoris) atromarginata presents furanoditerpenoids and scalarane sesterterpenes originating from its dietary sponges Spongia (Hyatella) sp. and Hyrtios spp., depending on the geographical location (Australia, Sri Lanka, India) $[93,176,181,386-388]$. The most active metabolites were spongiadiol (35), spongiadiol diacetate (231), epi-spongiadiol (232), 12-deacetoxy-12-oxodeoxoscalarin (136), heteronemin (233), and mooloolabene D (234) [180,381,383-386,519,535,538-540]. In particular, spongiadiol (35) is active against P388 murine leukemia cells at an $\mathrm{IC}_{50}$ of $0.5 \mu \mathrm{g} / \mathrm{mL}$. Other species, such as Felimida (Glossodoris) dalli, Doriprismatica (Glossodoris) sedna, Glossodoris rufomarginata, Glossodoris pallida, Glossodoris vespa, and Ardeadoris (Glossodoris) averni, also present homoscalarane and scalarane metabolites, among which 12-deacetyl-23-acetoxy-20-methyl-12-epi-scalaradial (135) moderately inhibits mammalian phospholipase A2 $\left(\mathrm{IC}_{50}=18 \mu \mathrm{M}\right)[175,183,383]$. Heteronemin $(\mathbf{2 3 3})$, also found in several chromodoridid species and derived from dietary sponges, such as Heteronema erecta, blocks tumor cell intravasation through the lymph-endothelial barrier in a three-dimensional (3D) cell culture model, using spheroids of the MCF-7 breast cancer cell [541,542].

Hypselodoris infucata from Bali presents (-)-furodysinin (48), which is active against the HeLa cell line with an $\mathrm{IC}_{50}$ of $102.7 \mu \mathrm{g} / \mathrm{mL}$ [214]. Felimida (Chromodoris) macfarlandi from California presents macfarlandines A-E (134,235), from which macfarlandin E (235) displays unique Golgi-modifying properties [139,140,149,543].

Hexabranchus sanguineus is a chemically rich species, transferring several compounds to their egg masses, including the macrolides ulapualides A (190) and B (236) in Hawai'i, presenting three contiguous oxazole rings with the attached lipid-like side chain ending in the N-methyl-N-alkenylformamide group [222]. Ulapualide A (190) has also been found in sponges and, thus, is suggested to be of dietary origin in the slug [544]. Both compounds are reported to display activity against murine L1210 leukemia cells, with $\mathrm{IC}_{50}$ values of $\sim 10$ and $\sim 30 \mathrm{nM}$, respectively [222]. Ulapualide A (190) has been described to be a potent actin-depolymerizer [545]. Later, ulapualides C-E (237) have been found in egg masses from Hawai'i, and ulapualide C (237) is reported to display cytotoxicity against several HTCLs, although it is 2-4 times less potent than ulapualides A (190) and B (236) [546]. A different study found several kabiramides, including kabiramide A (238), B (239), D (240), and E (241), along with the halichondramide derivatives, dihydrohalichondramide (63) and 33-methylhalichondramide (242), in 
egg masses of the same species from a different locality [217-221]. Kabiramides (238-241) contain a macrolide ring with contiguous trisoxazole rings [547]. Kabiramide C (62) was traced to a Halichondria sponge and further reported in the sponge Pachastrissa nux together with other kabiramides, as well as to some adult slug specimens at a lower concentration [221,222,548]. Kabiramide C (62) presents growth inhibitory effects in vitro against human MCF-7 breast cancer cells $\left(\mathrm{IC}_{50} \sim 0.5 \mu \mathrm{M}\right)$, ten times higher than for human fibroblasts ( $\mathrm{IC}_{50} \sim 8 \mu \mathrm{M}$ ), displaying bioselectivity [548]. The mechanism of action has been described as kabiramide $C(62)$ binding to actin and its actin complex, which is achieved through a two-step binding reaction and forms a very stable and long-lived complex [549]. Kabiramide G (243) presents an even stronger bioselectivity, with $\mathrm{IC}_{50}$ values of $0.02 \mu \mathrm{M}$ against MCF-7 cancer cells and $>2 \mu \mathrm{M}$ for human fibroblasts [548]. Kabiramides A (238) and B (239) were active with $\mathrm{IC}_{50}$ values of $\sim 10$ $\mathrm{nM}$, and kabiramides $\mathrm{D}(\mathbf{2 4 0})$ and $\mathrm{E}$ (241) with $\mathrm{IC}_{50}$ values of $\sim 30 \mathrm{nM}$, against the murine L1210 leukemia cell line [220]. On the other hand, dihydrohalichondramide (63) and 33-methylhalichondramide (242) inhibit growth in the murine $\mathrm{L} 1210$ leukemia cell line with $\mathrm{IC}_{50}$ values of $\sim 40$ and $\sim 60 \mathrm{nM}$, respectively, in this case by disrupting actin microfilaments [220,550]. Halichondramide (244) presents also a wide array of bioactivities, including cytotoxic and cytostatic activities and antiproliferative and antimigratory effects in vitro, as reported elsewhere [479,551,552]. Most of these compounds probably originate from a sponge diet [218]. A mechanism of detoxification has been suggested for the slug to deal with halichondramide and transform it into less toxic compounds [218,221].

Another interesting species is Jorunna funebris, which in India presents the cytotoxic isoquinoline alkaloid jorumycin (189) [166,553,554]. Jorumycin (189) is cytotoxic at very low concentrations, with an $\mathrm{IC}_{50}$ of $12.5 \mathrm{ng} / \mathrm{mL}$ against some cancer cell lines, such as P388, A549, HT29, and MEL28, including cells resistant to apopototic stimuli, and having a saframycin-like structure similar to ecteinascidin 743 , one of the most active marine-derived antitumor agents isolated from the tunicate Ecteinascidia turbinata and an approved drug already on the market [43,553,555-557]. A synthetic compound derived from jorumycin (189) is in phase II clinical studies for endometrial and cervical cancer, as well as solid human tumors and hematological diseases (Ewing sarcoma, urothelial carcinoma, and multiple myeloma) [556,558,559]. Specimens from Thailand, instead, present jorunnamycins A-C (245), along with renieramycins (246), which are also cytotoxic, while specimens from Sri Lanka presented several isoquinoline-quinone metabolites from the sponge Xestospongia sp. [22,560]. Jorunnamycins A-C (245) are reported to be obtained after treatment of the samples with potassium cyanide, yielding more stable compounds while still conserving high cytotoxicity against HTCLs [560]. Jorunnamycin C (245) and renieramycin $\mathrm{M}$ (246) present $\mathrm{IC}_{50}$ values at low nanomolar ranges against human colon (HCT-116) and breast (MDA-MB-435) cancer cells [561]. Their mechanism of action has been reported as the downregulation of protein tyrosine phosphatase receptor type K (PTPRK) in vitro, since PTPRK is a tumor suppressor gene product that may be involved in colon cancer [516,561-563]. Some structurally related compounds were also found in specimens from South China, such as the fennebricins A and B, and other molecules, probably also from a Xestospongia sp. [564,565].

The Mediterranean Peltodoris atromaculata, and the sponges on which it feeds on, Petrosia ficiformis and Haliclona fulva, contain cytotoxic long-chain fulvinol-like polyacetylenes, namely, petroformynes (247) [566-569]. These compounds are structurally very similar to the sponge compounds neopetroformynes and are active against murine P388 leukemia cells with $\mathrm{IC}_{50}$ values of 0.09-0.45 $\mu \mathrm{M}$ [570]. Further metabolites from this slug include some other polyacetylenes, such as the hydroxy-dehydroisofulvinol (248), very similar to fulvinol, which is active against four cell lines, i.e., murine P388 leukemia, A549 NSCLC, HT-29 colon cancer, and SKMEL-28, at IC50 2 2 M [571]. Hydroxy-dehydroisofulvinol (248) presents an $\mathrm{IC}_{50}$ value of $\sim 3 \mu \mathrm{M}$ against the SKMEL28 melanoma cell line [571].

Finally, nembrothids also present some cytoxocity. The alkaloids tambjamines (65-70), as mentioned above, are found in several Tambja species (T. capensis, T. ceutae, T. eliora, T. morosa, T. stegosauriformis, T. verconis) along with their bryozoan prey (Bugula dentata or Sessibugula translucens) in different geographical localities [21,88,207,223,228,572,573]. Roboastra species feeding on Tambja 
species also present tambjamines (65-70), and R. tigris obtains them from T. abdere and T. eliora [223]. Tambjamines (65-70) have also been found in Nembrotha spp. and the tunicate Atapozoa sp. [226,227]. Some tambjamines (65-70), which are similar to the bacterial compounds prodigiosins, have been described to cause DNA damage and induce apoptosis [223,574-577]. Tambjamine D (68) is active against several tumor cell lines by intercalating into DNA, as well as by promoting single-strand DNA oxidative cleavage, although a lack of selectivity was described [228,578-586]. Tambjamine $\mathrm{K}$ (249) and the tetrapyrrole (72) display concentration-dependent cytotoxicity against tumor and non-tumor mammalian cells, with $\mathrm{IC}_{50}$ values between $\sim 0.004$ and $15 \mu \mathrm{M}$ and $\mathrm{IC}_{50} \sim 19 \mu \mathrm{M}$ against mouse 3T3-L1 fibroblasts for tambjamine K (249) [232,584,587]. In fact, tambjamine K (249) is very selective, showing a 4000-fold differential sensitivity between human Caco-2 colon cancer cells and HeLa cervix cancer cells [229]. Tambjamine C (67), instead, is a good transmembrane anion transporter, similar to prodigiosins, which are relevant in cancer cell biology and cancer cell migration, and they are expressed differently in diverse cancer cells [581-586].

\section{Dendronotida}

Within this group, several species have been described to present cytotoxic compounds. Punaglandins (250) are cytotoxic PGs obtained by Tritonia sp. From its octocoral prey, Telesto riisei, active at an $\mathrm{IC}_{50}$ of $0.03 \mu \mathrm{M}$ to mouse leukemia cells [587]. Dotofide (251) is found in Doto pinnatifida and is active against several cell lines using the MTT colorimetric assay [505]. Against human glioma, dotofide (251) shows a $\mathrm{GI}_{50}$ value of $18.1 \mu \mathrm{M}$ for Hs683 oligodendroglioma (ATCC HTB-138), and of $28.8 \mu \mathrm{M}$ for U373 glioblastoma (ECACC 08061901) [505]. For human carcinoma, dotofide (251) displays $\mathrm{GI}_{50}$ values of $29.4 \mu \mathrm{M}$ for A549 NSCLC (DSMZ ACC107), and $28.1 \mu \mathrm{M}$ for MCF-7 breast carcinoma (DSMZ ACC115) [505]. Finally, for melanoma, it displays $\mathrm{GI}_{50}$ values of $60.5 \mu \mathrm{M}$ for human SKMEL-28 (ATCC HTB-72) and $9.6 \mu \mathrm{M}$ for mouse B16F10 (ATCC CRL-6475) [505].

The sesquiterpenes tritoniopsins A-D (75-78) are found in Tritoniopsis elegans and its soft coral prey Cladiella krempfi, where the slug accumulates tritoniopsin A (75) in its mantle at higher concentrations than the coral or other slug tissues [238]. Rat cell lines were used to test the cytotoxicity of tritoniopsin A (75), resulting in a weak to moderated activity [234].

\section{Euarminida}

The previously mentioned eunicellin diterpenes (187) from Dermatobranchus ornatus display moderate cytotoxicity to A-549, SKOV-3, SK-MEL-2, and HCT-15, along with inhibition of cell division in fertilized starfish eggs [22]. The South African slug Leminda millecra possesses sesquiterpenes and prenylquinones from its diet of octocorals, mainly of the genus Alcyonium and gorgonians such as Leptogorgia palma [588-590]. Among them, a prenylated hydroquinone (252) possesses moderate inhibitory activity, with values of $\mathrm{GI}_{50}$ around $6-9 \mu \mathrm{M}$ against WHCO1 and WHCO6 esophageal cancer cell lines, inducing apoptosis via generation of reactive oxygen moieties $[589,590]$.

\section{Aeolidida}

Hermissenda crassicornis presents L-6-bromohypaphorine (253), reported to be an agonist of human a7 nicotinic acetylcholine receptor [591]. In Phyllodesmium briareum, brianthein W (254) is reported to have an $\mathrm{ED}_{50}$ of $0.76 \mu \mathrm{g} / \mathrm{mL}$ against $\mathrm{P}-388$, while excavatolide $\mathrm{C}$ (255) displays an $\mathrm{ED}_{50}$ of $0.3 \mu \mathrm{g} / \mathrm{mL}$ for P-388, and an $\mathrm{ED}_{50}$ of $1.9 \mu \mathrm{g} / \mathrm{mL}$ for KB, A-549, HT-29 [248]. Both compounds were traced to the diet the octocoral Briareum sp. [248]. Similarly, P. magnum possesses 11-episinulariolide acetate (256) with an $\mathrm{ED}_{50}$ of $1.2 \mu \mathrm{g} / \mathrm{mL}$ for P-388, $\mathrm{ED}_{50}$ of $1.9 \mu \mathrm{g} / \mathrm{mL}$ for HT-29, and $\mathrm{ED}_{50}$ of $0.8 \mu \mathrm{g} / \mathrm{mL}$ for HL-60 [248]. Moreover, the previously mentioned diterpene trocheliophorol (84) from Phyllodesmium longicirrum has been reported as cytotoxic [245].

Phidianidines A (257) and B are bromoindole alkaloids from the Chinese slug Phidiana militaris [361,592]. Phidianidines (257) are the only known marine source of the 1,2,4-oxadiazole system, and their interesting structure promoted their synthesis, as well as that of several analogues [593-605]. Phidianidines (257) show 
cytotoxicity against several cell lines, such as C6 and HeLa tumor cells at nanomolar concentrations [592]. Their $\mathrm{IC}_{50}$ values stand from $\sim 0.4$ to $>100 \mu \mathrm{M}$ in three cancer cell lines, with no selectivity against mouse 3T3-L1 fibroblasts and rat $\mathrm{H} 9 \mathrm{c} 2$ cardiomyocytes $\left(\mathrm{IC}_{50}: \sim 0.1\right.$ and $\left.\sim 5 \mu \mathrm{M}\right)[592,606]$. Human HeLa cervix cancer cells are very sensitive to the growth inhibitory effects of phidianidines (257), contrarily to Caco-2 colon cancer cells [606]. Phidianidines (257) are also selective and potent ligands with partial agonist activity against the $\mu$ opiod receptor (when compared to $\delta$ - and $k$-opiod receptors), which is involved in cancer progression [593,607]. Virtual screening allowed for the identification of phidianidine A (257) as a potential ligand for CXCR4, a chemokine receptor involved in several diseases, including cancer progression, metastasis, and immunodeficiency disorders, and competing with natural ligand CXCL12 as observed by molecular docking, proving that it is a CXCR4 antagonist [608]. Moreover, phidianidine A (257) significantly reduced the CXCL12-induced migration at $50 \mu \mathrm{M}$ in a rat cell line of pituitary adenoma [609].

\subsubsection{Pleurobranchoidea}

Pleurobranchus albiguttatus and P. forskalii from the Philippines contain the cytotoxic chlorinated diterpenes chlorolissoclimide (258), dichlorolissoclimide (259), haterumaimides (260), and $3 \beta$-hydroxychlorolissoclimide (261), which are acquired from its tunicate prey Lissoclinum [610]. These were tested against the NCI panel of 60 tumor cell lines [610]. In Indonesia, P. forskalii presents a cyclic hexapeptide instead, keenamide A (262), containing a thiazoline and an isoprene residue, which has been reported active against four cancer cell lines (P388, A549, MEL20, and HT29) with IC 50 values of 2.5-8 $\mu \mathrm{M}[611,612]$. In Japan, P. forskalii contains a macrocyclic dodecapeptide, cycloforskamide (263), contaning three thiazoline heterocycles [612]. Cycloforskamide (263) displays an $\mathrm{IC}_{50}$ value of $5.8 \mu \mathrm{M}$ against murine P388 leukemia cells [387]. Unfortunately, the low sensitivity of this model resulted in the NCI not pursuing this compound further $[613,614]$. In Japan, P. forskalii also presented ergosinine (264), an alkaloid only described previously in terrestrial higher plants and fungi, which is a known activator of caspase-3 $[615,616]$. The tunicate-derived compounds chlorolissoclimide (258) and dichlorolissoclimide (259) have been further tested, resulting in $\mathrm{IC}_{50}$ values of 0.7 and $1.25 \mu \mathrm{M}$ against the NCI 60 cell lines panel, respectively, and also displaying selectivity toward melanoma cell lines $[610,613,617,618]$. Furthermore, both compounds $(\mathbf{2 5 8 , 2 5 9 )}$ inhibit growth in the Corbett-Valeriote soft agar disk diffusion test, but with no selectivity for solid tumors, while the related $3 \beta$-hydroxychlorolissoclimide (261) presents some selectivity for solid tumors in the same test [610]. In particular, chlorolissoclimide (258) and dichlorolissoclimide (259) were active against murine P388 leukemia cells resistant to adriamycin by blocking the translation elongation via inhibition of translocation, thus producing an accumulation of ribosomes on mRNA $[610,618,619]$. On the other hand, haterumaimides A-Q $(\mathbf{2 6 0 , 2 6 5 - 2 6 9 )}$ also present interesting activities, as do their synthetic derivatives, against the NCI 60 cell lines panel, with $\mathrm{IC}_{50}$ values of $0.08-1 \mu \mathrm{M}$ for haterumaimide $\mathrm{D}$, and from $0.5 \mathrm{nM}$ to $>20 \mu \mathrm{M}$ for haterumaimides J (265) and $\mathrm{K}$ (266) and haterumaimides C (267), G (268), and I (269), respectively [610,617,620-624].

\subsubsection{Tylodinoidea}

As previously mentioned, Tylodina perversa obtains brominated isoxazoline alkaloids from sponges of the genus Aplysina [257,625]. Among them, iso-fistularin-3 (270) presents a $\mathrm{IC}_{50}$ value of $\sim 9 \mu \mathrm{M}$ against human HeLa cervix carcinoma cells [625].

\subsubsection{Cephalaspidea}

The most active species in this group is Philinopsis speciosa. Because its molecules are structurally similar to cyanobacterial compounds, it has been hypothesized that P. speciosa obtains them through its diet of the sea hares Stylocheilus longicauda and Dolabella auricularia, which in turn feed on cyanobacteria [276]. In Hawai'i, P. speciosa presents the cyclodepsipeptide kulolide-1 (271), which displays potent antitumoral activity against L-1210 leukemia and P388 murine leukemia cell lines, with $\mathrm{IC}_{50}$ values of 0.7 and $2.1 \mu \mathrm{g} / \mathrm{mL}$, respectively, although these assays are highly sensitive to proapoptotic 
stimuli [277,614]. Kulolide-1 (271) also produced morphological changes in rat 3Y1 fibroblast cells at $50 \mu \mathrm{M}$ [277]. Further chemical analysis of the species yielded some more related peptides, such as kulolide-2 (272), kulolide-3 (273), kulokainalide-1 (274) and the bidepsipeptides kulokekahilide-1 (275) and kulokekahilide-2 (276) [276,626,627]. Kulokainalide-1 (274) and kulokekahilide-1 (275) are reported to be moderately cytotoxic, while kulokekahilide-2 (276) is highly effective. Kulokekahilide-1 (275) shows growth inhibitory effects with an $\mathrm{IC}_{50}$ of $\sim 2 \mu \mathrm{M}$ in murine P388 leukemia cells, while kulokekahilide-2 (276) presents a higher potency with an $\mathrm{IC}_{50}$ of $4.2 \mathrm{nM}[626,627]$. Kulokekahilide-2 (276) also displays activity against human SK-OV-3 ovarian and tMDA-MB-435 breast cancer cell lines, with $\mathrm{IC}_{50}$ values of 7.5 and $14.6 \mathrm{nM}$, respectively [627]. For A-10 (non-transformed rat (Rattus norvegicus) aortic cells), kulokekahilide-2 (276) shows an $\mathrm{IC}_{50}$ of $59.1 \mathrm{nM}$, acting selectively [627]. In other cancer cell lines, namely, human A549 NSCLC, K562 chronic myelogenous leukemia, and MCF-7 breast cancer, kulokekahilide-2 (276) shows IC 50 values of $\sim 0.2 \mathrm{nM}$ [628]. In a methodologically different study, the $\mathrm{IC}_{50}$ values for kulokekahilide-2 (276) were not the same, with $\sim 19$ and $\sim 4 \mathrm{nM}$ for murine P388 leukemia and human HeLa cervix carcinoma cells, respectively [629]. Some very potent analogues have also been synthesized, with $\mathrm{IC}_{50}$ values of $\sim 0.001$ and $\sim 0.008 \mathrm{nM}$, respectively, allowing the authors to ascertain the best substituents for cytotoxic activity [628].

Moreover, several polyunsaturated fatty acids with cytotoxic activity against a range of human cancer cells lines, including HT-29, MCF7, and A2058, were described from Arctic specimens of Scaphander lignarius [630].

\subsubsection{Anaspidea}

Sea hares have been proven to contain many interesting cytotoxic compounds, many of them derived from the algae or the cyanobacteria that they feed on [1,2]. Within the genus Aplysia, many species have been studied, including A. angasi, A. dactylomela, A. depilans, A. fasciata, A. juliana, A. kurodai, A. oculifera, and A. punctata [1,2]. A. angasi (also reported as A. dactylomela), which showed growth inhibitory activity against murine lymphocytic leukemia P338 cells due to the presence of the brominated tricyclic 6-7-5-fused sesquiterpene, aplysistatin (277) [631]. Aplysistatin (277) showed an $\mathrm{IC}_{50}$ value of $\sim 8 \mu \mathrm{M}$ for P388 leukemia cells and human KB cancer cells [613,631].

A. dactylomela presents a wide variety of metabolites [631-634]. Some dietary halogenated chamigrene sesquiterpenes were described in specimens from the Canary Islands, such as elatol (278) and obtusol (279), previously found in the red algae Laurencia elata and L. microcladia, while iso-obtusol (280) was found in L. obtusa [631-634]. Elatol (278) is a potent, non-selective, cytotoxic natural product, with $\mathrm{IC}_{50}$ values between $1-10 \mu \mathrm{M}$ against ten cancer cell lines in several studies $[631,635,636]$. Remarkably, elatol (278) is proapoptotic in murine B16F10 melanoma cells by decreasing Bcl-x and increasing Bak, caspase-9 and p53 expression, although it is known that B16F10 melanoma cells are very sensitive to these stimuli [636-638]. Obtusol (279) and iso-obtusol (280) show a much weaker effect inhibiting growth in vitro $[631,633,635]$. A linear halogenated monoterpene (281) was also found, showing growth inhibitory effects towards HM02 (gastric carcinoma), HEP-G2 (liver carcinoma), and MCF-7 (breast carcinoma) cancer cells with $\mathrm{IC}_{50}$ values of $\sim 1 \mu \mathrm{M}$ [631]. Some tricyclic monobromoditerpenes were also found in A. dactylomela specimens, such as parguerol (282), parguerol-16-acetate (283), iso-parguerol (284), iso-parguerol-16-acetate (285), and deoxyparguerol (286), which were also present in red algae, such as Jania rubens $[639,640]$. In Bahamas and Puerto Rico, however, specimens of this sea hare contain different chemistry [639]. Parguerol (282) and the previously mentioned related compounds present in vitro growth inhibitory effects at low micromolar values on murine P388 leukemia, are highly sensitive to proapoptotic stimuli as previously discussed, and are also significantly sensitive to Ehrlich ascite carcinoma $[614,639,640]$. These activities were more potent with iso-parguerol (284) derivatives [639,640]. In the Caribbean, some other compounds are present, such as the bromotriterpene polyether aplysqualenol A (287), which displays potent $\mathrm{IC}_{50}$ values in the NCI assay (60 cancer cell lines panel), particularly an $\mathrm{IC}_{50}$ of $\sim 0.4 \mu \mathrm{M}$ in human SNB-19 central nervous system cancer and T-47D breast cancer cells [641]. Aplysqualenol A (287) 
has been described to be a ligand for DYNLL1 (light chain of dynein type 1), also indicating some anticancer potential [642-645]. In China, specimens of $A$. dactylomela also present a brominated triterpene polyether, thyrsiferol (288), previously reported in the red algae Laurencia thyrsifera [646,647]. Thyrsiferol (288) has been reported to display a strong growth inhibitory in vitro activity against mouse P388 leukemia cells, and only moderate activity in solid tumors cell lines, with $\mathrm{IC}_{50}$ values of $\sim 0.02$ and $\sim 17 \mu \mathrm{M}$ for P388 and A549 NSCLC cancer cell lines, respectively [614,648,649]. Apparently, thyrsiferol (288) inhibits hypoxia-induced HIF-1 activation in T47D human breast tumor cells and suppresses hypoxic induction of HIF-1 target genes (VEGF and GLUT-1) at the mRNA level, also suppressing mitochondrial respiration in complex I [648].

A. depilans presents an endoperoxide sterol (289) with an $\mathrm{IC}_{50}$ value of $2.5 \mu \mathrm{M}$ for human HCT-116 colorectal cancer cells [606,650,651]. A. fasciata from Spain presents a degraded sterol, 3-epi-aplykurodinone B (145) with an $\mathrm{IC}_{50}$ value of $\sim 8 \mu \mathrm{M}$ against mouse P388 leukemia, human A549 NSCLC, HT-29 colon cancer, and SKMEl-28 melanoma [397]. A. juliana contains two chlorophyll derivatives, pyropheophorbides $a$ and $b$, and a halogenated diterpenoid lactone, derived from its diet of green algae, as well as a cytotoxic peptide, julianin-S, which is secreted within its purple ink [288,432-434].

A. kurodai has been widely studied over the years, containing a series of compounds that include polyketide macrolides, halogenated and brominated mono- and di-terpenes, brominated sesquiterpenoids, sterols, alkaloids, peptides, and others [1,2]. Aplyronines A-H (191,290-293) are polyketide macrolides found in Pacific specimens along with aplaminal (294), some of them being tested in antitumor clinical trials [46,652-656]. For human HeLa-S3 cancer cells, $\mathrm{IC}_{50}$ values were $0.5 \mathrm{nM}$ for aplyronine A (191), $3 \mathrm{nM}$ for aplyronine B (290), $22 \mathrm{nM}$ for aplyronine C (291), $0.08 \mathrm{nM}$ for aplyronine D (292), and $10 \mathrm{nM}$ for aplyronine $\mathrm{H}(\mathbf{2 9 3})[653,657,658]$. However, in a different study with the same cell line, $\mathrm{IC}_{50}$ values were $\sim 0.4 \mathrm{nM}$ for aplyronine $\mathrm{A}$ (191), $\sim 4 \mathrm{nM}$ for aplyronine $\mathrm{B}$ (290), and $\sim 20 \mathrm{nM}$ for aplyronine $\mathrm{C}$ (291) [652]. It has been suggested that the methylated amino acids ( $\mathrm{N}, \mathrm{N}, \mathrm{O}$-trimethyl-serine or $\mathrm{N}, \mathrm{N}$-dimethyl-alanine) in position 22 are important for the inhibition activity of these compounds [653]. Aplyronine A (191) is registered at the NCI database as NSC687160, with a mean $\mathrm{IC}_{50}$ value of $\sim 0.2 \mathrm{nM}$ in the 60 cancer cell lines, but being selective against some cell lines and most active against MDR cancer cell line NCI/ADR-RES, with an $\mathrm{IC}_{50}$ value of $\sim 0.2 \mathrm{nM}$, as well as for P388 murine leukemia, Lewis murine lung carcinoma, Erhlich murine carcinoma, colon 26 murine carcinoma, and B16 murine melanoma, but very moderated against HOP-92 (NSCLC), OVCAR-4 (ovarian cancer), TK-10 and UO-31 (renal cancers), and BT-549 and T47-D (breast cancers) [652]. Aplyronine A (191) also presents proapoptotic effects in cancer cells [46]. Aplyronine A (191) was in fact suggested to inhibit the actin microfilaments, since it can depolymerize F-actin and inhibit actin polymerization, forming a complex with monomeric actin (1:1), in a similar way to the well-known tubulin inhibitors vincristine and vinblastine currently employed in some cancer treatments $[479,659,660]$. Later, other studies suggested that aplyronine A (191) forms a 1:1:1 heterotrimeric complex with actin and tubulin, and this is what actually inhibits tubulin polymerization; thus, synthesis is being carried out [661-664]. Furthermore, an analogue of aplyronine D (292) is being analyzed as an antibody-drug conjugate (ADC) and for bearing a linker suitable for bioconjugation [665]. Overall, aplyronines (191,290-293) are extremely toxic molecules with huge potential as leads, but they are not yet known to be attached to a suitable $\mathrm{mAb}$ [666]. Aplaminal (294) is a triazabicyclo-[3.2.1]-octane, displaying an $\mathrm{IC}_{50}$ value of $\sim 2 \mu \mathrm{M}$ against human HeLa S3 cervix carcinoma cells [654].

In Japan, A. kurodai presents aplaminone (295), neoaplaminone (296), and neoaplaminone sulfate (297), formed from a bromine-containing dopamine and a sesquiterpenoid [667]. Both aplaminone (295) and neoaplaminone sulfate (297) show $\mathrm{IC}_{50}$ values of $\sim 1 \mu \mathrm{M}$ for human HeLa cervix cancer cells, while neoaplaminone (296) is active at $\mathrm{IC}_{50} \sim 1 \mathrm{nM}$ [667]. In Japan, A. kurodai specimens also contain aplysiaterpenoid A (298) and aplysiapyranoids A-D (299), displaying moderate cytotoxicities against Vero, MDCK, and B16 cell lines ( $\mathrm{IC}_{50} 19-96 \mu \mathrm{g} / \mathrm{mL}$ ) [668,669]. Moreover, mono- and di-terpenes, such as kurodainol (300), aplysiaterpenoids A-D (298), aplysin-20 (301), iso-aplysin-20, aplysiadiol (302), 
epi-aplysin-20, and ent-isoconcinndiol (303), are found in A. kurodai specimens and are suggested to originate from isoconncindiol of the red algae Laurencia snyderae [668-674]. A. kurodai also contains other compounds, including aplydilactone, a dieicosanoid lactone, aplysepsine, and a 1,4-benzoidiasepine alkaloid $[675,676]$. The egg masses and albumen gland moreover contain cytotoxic peptides, such as aplysianin A or aplysianin E, the latter highly tumor-lytic at $10 \mathrm{ng} / \mathrm{mL}$ against MM 46 and MM 48 mice tumor cells [294,677-679].

Furthermore, A. kurodai presents some brominated sesquiterpenoids, such as (-)-aplysin (304), aplysinol (305), and aplykurodin A (306) and B (146) [398,680]. (-)-Aplysin (304), originating from its diet on algae, was in fact one of the first halogenated compounds found in marine organisms, and it shows $\mathrm{IC}_{50}$ values of $4-8 \mu \mathrm{M}$ for several cancer cells, with a mean $\mathrm{IC}_{50}$ value of $\sim 30 \mu \mathrm{M}$ at the NCI 60 cell line panel and no selectivity [680,681]. (-)-Aplysin (304) was active against the human A549 NSCLC xenograft with $18 \%$ of tumor growth reduction in vivo as compared to the control, supposedly by acting as a sensitizer for tumor necrosis factor-related apoptosis, producing TRAIL-induced apoptosis in cancer cells via the P38 MAPK/survivin pathway [682]. (-)-Aplysin (304) is also effective against human glioma cells by increasing miR-181 expression, sensitizing the cytotoxic effects of the alkylating drug temozolomide, and inducing cell cycle arrest and apoptosis through the inhibition of the PI3K/Akt signaling, which is relevant in the survival of glioma cells [683].

In Egypt, A. oculifera contains two halogenated sesquiterpenes, oculiferane (307) and epi-obtusane (308), which displayed $\mathrm{IC}_{50}$ values between 2 and $8 \mu \mathrm{M}$ against human PC-3 prostate cancer, A549 NSCLC, MCF-7 breast cancer, HepG2 liver cancer, and HCT116 colon cancer [684]. A. punctata from Spanish coasts present atypical acetates of halogenated monoterpenes, among which three compounds (309-311) show $\mathrm{IC}_{50}$ values between 1.5 and $2.5 \mu \mathrm{M}$ against P388, HT-29, A-549, and MEL-28 cancer cell lines [685].

Another sea hare, Dolabella auricularia, is one of the most studied marine invertebrates, with many bioactive natural products, including polyketides, halogenated terpenes, and peptides, along a wide geographical range $[1,2]$. Several excellent reviews deal with $D$. auricularia most bioactive compounds $[46,478,479]$, and, therefore, only a brief summary will be included here. This sea hare is able to modify dietary molecules from brown and red algae and also to de novo biosynthesize peptides and polypropionates, while it may also contain cyanobacterial metabolites [686]. We will summarize the cytotoxic activities of aurisides A and B (312,313), aurilol (314), doliculols A and B (315,316), dolabellin (317), auripyrones A and B (318,319), dolabelides A-D (320-323), aurilide (324), doliculide (325), auristatins (339-344), and finally, dolastatins (192,326-338,346-348). In Japan, among the dietary compounds from red algae, the macrolide glycosides aurisides A and B $(312,313)$ and aurilol (314), a polyether bromotriterpene, are cytotoxic to HeLa tumor cell line $[687,688]$. Aurisides A and B $(\mathbf{3 1 2}, \mathbf{3 1 3})$ present a carbon backbone 5,7,13-trihydroxy-3,9-dioxoheptadecanoic acid with a bromine-substituted conjugated diene moiety, a cyclic hemiacetal, and a 14-membered lactone [688]. Auriside A (312) displays $\mathrm{IC}_{50}$ values of $\sim 0.2 \mu \mathrm{M}$ against human HeLa S3 cervix cancer cells, while auriside B (313) is less potent $\left(\mathrm{IC}_{50} 2 \mu \mathrm{M}\right)$, and both are being studied for their synthesis [688-690]. Aurilol (314) presents $\mathrm{IC}_{50}$ values of $\sim 7 \mu \mathrm{M}$ against human HeLa S3 cancer cells, and it is structurally similar to enshuol, a bromo triterpenic polyether with a dioxabicyclo-(5.4.0)-undecane ring system described in Laurencia, thus supporting a dietary origin in the slug [687]. Doliculols A and B $(315,316)$, non-halogenated acetylenic cyclic ethers similar to Laurencia ethers, are moderately cytotoxic macrolides [691-694]. Dolabellin (317), a bisthiazole metabolite found in Indian specimens, showed $\mathrm{IC}_{50}$ values of $\sim 10 \mu \mathrm{M}$ against human HeLa S3 cervix carcinoma cells [695].

In D. auricularia from Japan, auripyrones A and B $(318,319)$ were described to have $\mathrm{IC}_{50}$ values of $\sim 0.5 \mu \mathrm{M}$ against human HeLa S3 carcinoma cells and are being synthesized [696-700]. Furthermore, Japanese specimens contain the macrolides dolabelides A-D (320-323), displaying $\mathrm{IC}_{50}$ values of $\sim 8$ and $\sim 2 \mu \mathrm{M}$, for dolabelides A and B $(320,321)$ respectively, while dolabelides $C$ and $D(322,323)$ showed both values of $\sim 2 \mu \mathrm{M}$ against human HeLa S3 cervix cancer cells, and synthesis studies are being carried out $[692,693,701,702]$. 
The cyclic depsipeptide aurilide (324) was found in Japanese D. auricularia specimens, while aurilides B and C were found in the cyanobacterium Lyngbya majuscula from Papua New Guinea [703-705]. Aurilide (324) displayed an $\mathrm{IC}_{50}$ mean value of $\sim 0.01 \mu \mathrm{M}$ in the NCI 60 cell line panel and was selective for renal, ovarian, and prostate cancer cell lines. It was active in the in vivo NCI hollow fiber assay, but inactive due to high toxicity in a xenograft model $[705,706]$. The mechanism of action of aurilide (324) seems to involve microtubule stabilization, since it does not interact with tubulin, thus being different from taxol [705]. Furthermore, aurilide (324) has been reported to selectively bind to prohibitin 1 (PHB1) in the mitochondria, activating the proteolytic processing of optic atrophy 1 (OPA1) and resulting in mitochondria-induced apoptosis [707].

Doliculide (325) is a mixed peptide-polyketide-originated compound found in Japanese specimens of D. auricularia, possessing an iodo-N-Me-tyrosine and a glycine, which inhibits growth of human HeLa S3 cervix carcinoma cells ( $\mathrm{IC}_{50} \sim 2 \mathrm{nM}$ ) [708]. Its action mechanism consists of binding to actin and stopping cancer cells at the G2/M phase of the cell cycle, thus interfering in normal actin assemblage and producing the hyperassemblage of purified actin in the form of F-actin [709]. Synthesis and computational studies are being developed [710-712]. Doliculide (325) inhibits proliferation and impairs the migratory potential of human MCF-7 and MDA-MB-231 breast cancer cells, while modifying senescence-related genes at non-toxic concentrations in p 53 wild-type cancer cells by up to $13 \%$ [713].

The most famous compounds of all heterobranchs are the diverse cytotoxic linear and cyclic peptides of $D$. auricularia, the dolastatins $(192,326-338,346-348)$, which were probably used by the Romans [46,197]. Dolastatins (192,326-338,346-348) include many different active molecules, including linear and cyclic peptides, depsipeptides, peptides containing thiazole and oxazole heterocycles, and macrolides [479]. Dolastatins (192,326-338,346-348) are found in small amounts in sea hares and are suggested to originate from their diet, particularly from cyanobacteria of the genera Symploca, Caldora and Lyngbya [714-716]. Among the most known dolastatins, dolastatin 3 (192) and dolastatins 10-15 (326-331) display mild to strong biological activities and were further studied, such as the macrocyclic lactone dolastatin 19 (332); dolastatins C (333), D (334), H (335) and iso-dolastatin H (336); dolastatin G (337); and nor-dolastatin G (338) [694,717-724]. Dolastatin G (337) and nor-dolastatin G (338) show moderate cytotoxicity and are analogs of lyngbyastatin 2 and nor-lyngbyastatin 2 described in the cyanobacterium Lyngbya majuscula from Guam [725]. Dolastatin 19 (332) is structurally similar to the previously mentioned aurisides A (312) and B (313). In general, these compounds did not pass phase II trials alone, and several studies are being developed to use them in combination with other structures $[478,479,726]$.

Dolastatin 3 (192), a cyclic peptide with two thiazole rings, was also found in D. auricularia from Japan, and further synthesized, showing an $\mathrm{IC}_{50}<1 \mu \mathrm{M}$ in P388 murine leukemia cells [718,727]. Dolastatin 3 (192) was also found in Lyngbya majuscula from Palau [728]. Dolastatin 3 (192) induces a $78 \%$ life extension in vivo in the murine P388 lymphocytic leukemia model, and a 52\% life extension in murine colon carcinoma 38 [728].

Dolastatin 10 (326) is a linear pentapeptide with four unique residues described in 1987 from D. auricularia collected at the Indian Ocean, and later found in the cyanobacterium Symploca hydnoides together with its methyl derivative, symplostatin 1 , and has been often reviewed in the literature [478,714,726,729-731]. Dolastatin 10 (326) was tested in phase I trials by the NCI but failed later in phase II for advanced and metastatic soft tissue sarcoma, advanced hepatobiliary cancers, pancreatic cancers, and others because of its side effects [478,479,726,731,732]. However, in 2011, brentuximab vedotin (Adcetris ${ }^{\circledR}$ ), an antibody-dolastatin 10 conjugate (ADC), was approved by the FDA (Food and Drugs Administration) for the treatment of Hodgkin's lymphoma [43]. This ADC is composed of a highly toxic "warhead" derived from dolastatin 10 (326) which is attached to a specific targeting moiety, a monoclonal antibody $(\mathrm{mAb})$ directed to a particular epitope on the cancer cell [726]. Dolastatin 10 (326) inhibits microtubule assembly, causing cells to accumulate in metaphase, but it produced bone marrow toxicity in initial trials, local irritation at the injection site, and some mild 
peripheral neuropathy $[733,734]$. Dolastatin 10 (326) exhibits cytotoxic effects against human lung and breast cancer cell lines via both Bcl-2 phosphorylation and caspase-3 protein activation, and it modulates p53 oncoproteins in human diffuse large-cell lymphoma [735,736]. Other studies describe dolastatin 10 (326) activity against ovarian carcinoma xenografts as well as mouse P388 and L1210 leukemia, B16 melanoma, M5076 sarcoma, human LOX melanoma, and MX-1 breast cancer xenografts [736-738]. Dolastatin 10 (326) is not only an inhibitor of tubulin polymerization, it also inhibits tubulin-dependent GTP hydrolysis as well as the binding of vinblastine, maytansine, and vincristine to tubulin, although the binding site on tubulin is not the same as that of the vinca alkaloids $[733,739]$.

Auristatins (339-344) are peptides related to dolastatin 10 (326) (see below), approved by the FDA as microtubule-destabilizing agents (MDA), and used as antibody-drug conjugates (ADCs) [740-743]. Auristatins (339-344) were synthesized by Pettit's group in the 1990s while working on dolastatins, and they included auristatin E (339), auristatin PHE (340), auristatin PYE (341), and two aminoquinoline derivatives, auristatin -2-AQ (342) and auristatin-6-AQ (343), all active against tumor lines (between $10-100 \mathrm{pM}$ ) [32,744-746]. Several derivatives of auristatins are (or are expected to be soon) in preclinical trials as "ADC warheads", some reaching phase I, such as DZ-2384 [478,726]. Auristatin PE (344), also named soblidotin, TZT-1027, or YHI-501, is a microtubule active drug that exerts a considerable antivascular effect along with a potent cytotoxic effect in several models, including murine P388 leukemia, colon 26 cancer, Lewis lung carcinoma, B16 melanoma, and M5076 sarcoma, as well as human MX-1 breast cancer and LX-1 and SBC-3 SCLC xenografts [747,748]. Auristatin PE (344) entered clinical trials for advanced and metastatic soft tissue sarcomas, NSCLCs, and others, but did not proceeded beyond phase II due to toxicity and/or a lack of efficacy in the trials [726]. More than 30 ADCs in clinical trials are based on auristatins $[43,555,717,749]$.

Several excellent reviews, such as those of Newman, have dealt with dolastatin-10 (326) and all its derivatives, their evolution as ADC warheads, the auristatin-based ADCs, and the approved and/or tested drugs, such as brentuximab vedotin, polatuzumab vedotin, enfortumab vedotin, ladiratuzumab vedotin, lifastuzumab vedotin, PSMA-ADC, RC-48, telisotuzumab vedotin, tisotumab vedotin, BA-3021, CX-2029, HuMax-AXL-107 (enapotamab vedotin), pinatuzumab vedotin, ABBV-085, AGS67E, ALT-P7, CDX-014, losatuxizumab vedotin, SGN-CD48A, rituximab-MC-vc-MMAE (TRS-005), GM-103, HT-1511, OBI-999, depatuxizumab mafadotin, AGS-16C3F, GSK-2857916 (belantamab mafodotin), W-0101, cofetuzumab pelidotin, NG-HER2 ADC, XMT-1536, ASN-004, ARX-788, lupartumab amadotin, AGS-62P1, and ZW-49, among others [478,666,726]. We strongly recommend these reviews for further details on the different status of the many derivatives that are currently being tested and those that are in clinical trials.

Dolastatin 11 (327), 12 (328), 13 (329), and 14 (330) are further depsipeptides isolated from D. auricularia, while dolastatin 12 (328) was also reported in Lyngbya majuscula-Schizothrix calcicola cyanobacterial assemblages [750-753]. In the NCI cell line panel, dolastatin 11 (327) showed an $\mathrm{IC}_{50}$ mean value of $\sim 0.07 \mu \mathrm{M}$, while dolastatin 12 (328) displayed different $\mathrm{IC}_{50}$ values in several assays, such as $1 \mathrm{nM}$ for human NCI-H460 NSCLC, $30 \mathrm{nM}$ for human SF-295 CNS cancer, $\sim 0.1 \mu \mathrm{M}$ for mouse neuro-2a neuroblastoma and $1 \mu \mathrm{M}$ for P388 leukemia cells [750,754,755]. Dolastatin 11 (327) produces a massive rearrangement of the actin filament network in cells, inducing a cytoplasmic retraction and further cell division arrest at the level of cytokinesis [239,241]. Dolastatin 12 (328) also targets actin microfilaments [753]. The values of $\mathrm{IC}_{50}$ for dolastatin 13 (329) and 14 (330) against the murine P388 leukemia cell line are reported to be 14 and $20 \mathrm{nM}$, respectively [751,752].

Dolastatin 15 (331) is another linear peptide from $D$. auricularia widely used as a potential warhead, with an $\mathrm{IC}_{50}$ of $3-5 \mathrm{nM}$, and with many derivatives being tested after chemical modifications, for example, replacing the C-terminal (S)-dolapyrrolidinone unit with some diverse amides while maintaining its anti-tubulin activity [756-761]. Dolastatin 15 (331) also produces microtubule depolymerization in vitro, possibly binding to the vinca domain of tubulin, and it is a classical inducer of apoptosis in cancer cells, acting as a conventional proapoptotic cytotoxic agent [762-764]. Dolastatin 15 (331) presents an $\mathrm{IC}_{50}$ against the NCI panel about ten times higher than that of dolastatin 
10 (326), that is, 2 vs. $0.2 \mathrm{nM}$, and it is three to four times more potent than vincristine, a clinically used common antiproliferative agent [765]. Tasidotin (345), an analog of dolastatin 15 (331) where the carboxyl-terminal ester group is replaced by a tert-butyl amide, is also a proapoptotic cytotoxic compound, tested against many different cancer lines, but it did not go beyond phase II clinical trials because of its lack of efficacy [766-768].

Dolastatin 16 (346), instead, is a cyclic depsipeptide with two amino acids, dolamethylleuine and dolaphenvaline, described in D. auricularia from Papua New Guinea, and found also in Lyngbya majuscula from Madagascar and Symploca cf. hydnoides from Guam [769-771]. In the NCI cell line panel, dolastatin 16 (346) displayed an $\mathrm{IC}_{50}$ mean value of $\sim 0.3 \mu \mathrm{M}[770,772]$. Specimens of D. auricularia from Papua New Guinea also contained dolastatin 17 (347), another cyclodepsipeptide with a novel acetylenic $\beta$-amino acid named dolayne (Doy), similar to that of onchidin (121), which has submicromolar values of $\mathrm{IC}_{50}$ against four cancer cell lines $[773,774]$. Dolastatin $18(348)$ was found in $D$. auricularia from the Indian Ocean, contains a thiazole ring, and shows submicromolar values of $\mathrm{IC}_{50}$ against mouse P388 lymphocytic leukemia and human NCI-H460 NSCLC cell lines [775]. D. auricularia from California contains dolastatin 19 (332), a macrocyclic lactone related to the previously mentioned aurisides $(312,313)$, showing in vitro growth inhibition for breast MCF-7 and colon KM20L2 cancer cells with $\mathrm{IC}_{50}$ values of $\sim 1 \mu \mathrm{M}$ [776]. Similarly, other dolastatins from specimens from Japan and the Indian Ocean, such as dolastatin D (334), dolastatin G (337), nor-dolastatin G (338), dolastatin H (335), and iso-dolastatin $\mathrm{H}$ (336), also display activity against some cancer cell lines, such as human HeLa S3 cancer cells [721,723,724].

Stylocheilus and Bursatella are also cyanobacterial feeders containing interesting cytotoxic compounds [1,2,4]. Aplysiatoxin (96) and debromoaplysiatoxin (97) were found in S. longicauda from Hawai'i, originating from Lyngbya majuscula [302,303,777]. The mixture of these two compounds was toxic to mice $\left(\mathrm{LD}_{100} 0.3 \mathrm{mg} / \mathrm{kg}\right.$ ), and both compounds are potent PKC activators that are being tested as anticancer lead structures (along with some derivatives) based on their anti-proliferative activity while removing their tumor-promoting activities [778-780]. Further studies on different populations of S. longicauda also from Hawai'i reported complex proline esters, makalika (99) and makalikone (100), together with lyngbyatoxin A (349) with antitumor properties, again from a diet of L. majuscula [304,305]. Makalikone (100) shows moderate activity against P388, A549, and HTB38 cancer cell lines, with $\mathrm{IC}_{50}$ values between 2.5 and $5 \mu \mathrm{g} / \mathrm{mL}$ [305]. Lyngbyatoxin A (349) is toxic to mice $\left(\mathrm{LD}_{100} 0.3 \mathrm{mg} / \mathrm{kg}\right)$, and it has been reported to act as a tumor promoter [781]. Lyngbyatoxin $\mathrm{A}$ acetate (101), also found in the sea hare and its cyanobacterial prey in Hawai'i, displays very potent toxicity against several cancer cell lines, with $\mathrm{IC}_{50}$ values $\sim 0.05 \mu \mathrm{g} / \mathrm{mL}$ [305]. Furthermore, some alkaloids such as malyngamides $\mathrm{O}(\mathbf{1 0 2})$ and $\mathrm{P}$ (103) were found in S. longicauda and L. majuscula [307,781,782]. Malyngamide $\mathrm{O}$ (102) shows $\mathrm{IC}_{50}$ values of $2 \mu \mathrm{g} / \mathrm{mL}$ against the cancer cell lines P388, A549, and HT29 [123]. In Guam, S. longicauda accumulates malyngamydes and transforms malyngamyde B into an acetate [307]. In fact, more than 30 malyngamides have been isolated from cyanobacteria and sea hares, and they have been observed to be N-substituted amides of long-chain methoxylated fatty acids, which are characterized by presenting a trans double bond and a 7S configuration of the oxygen-bearing carbon [479].

Bursatella leachii also feeds on "Lyngbya", accumulating lyngbyatoxin A (349) and debromoaplysiatoxin (97) in the digestive gland [783]. In New Zealand, B. leachii presents an alkaloid derived also from cyanobacteria, malyngamide S (350), with cytotoxic properties, while in Thailand, it presents hectochlorin (351) and deacetylhectochlorin (352), which are also cytotoxic compounds previously isolated from Lyngbya majuscula and structurally similar to dolabellin from Dolabella auricularia [784-786]. Malyngamide S (350) and malyngamide X (353), both found in $B$. leachii, possess in vitro growth inhibitory properties against several cancer cell lines, with $\mathrm{IC}_{50}$ values between $\sim 4$ and $\sim 8 \mu \mathrm{M}$ against murine P388 leukemia and human A549 NSCLC, NCI-H187 (SCLC), HT-29 colon cancer, HL60 leukemia, KB and BC breast cancer lines [307,786,787]. Hectochlorin (351) and deacetylhectochlorin (352) show growth inhibitory effects in vitro against human KB, NCI-H187 
SCLCL, and BC breast cancer cell lines, with deacetylhectochlorin (352) displaying a mean $\mathrm{IC}_{50}$ value of $\sim 1 \mu \mathrm{M}$, and hectochlorin (351) a mean $\mathrm{IC}_{50}$ value of $\sim 5 \mu \mathrm{Min}$ the $\mathrm{NCI}$ cell panel (being more potent against colon, melanoma, ovarian, and renal cell lines) [784,785]. Additionally, hectochlorin (351) seems to be cytostatic rather than cytotoxic in regard to the obtained dose-response curves [785].

\subsubsection{Sacoglossa}

Within this group, caulerpenyne (155)—a sesquiterpene found in Elysia spp. and other species (see above), as well as in its diet of the green algae Caulerpa-is active against several cancer cell lines at $\mathrm{IC}_{50} \sim 10 \mu \mathrm{M}$, while it has an $\mathrm{IC}_{50} \sim 40 \mu \mathrm{M}$ in the NCI panel [316,411,788-790]. Caulerpenyne (155) is not selective for normal (hamster fibroblasts, human keratinocytes, and melanocytes) and cancer cells [790,791]. Caulerpenyne (155) induces tubulin aggregation, inhibiting the polymerization of tubulin and bundling of the residual microtubules, but it does not bind to colchicine, taxol, or vinca-alkaloid binding domains [790,792]. It has been shown that caulerpenyne (155) may block the stimulation of mitogen-activated protein kinase (MAPK), thus affecting the control of cell proliferation, differentiation, or death [790,793].

Kahalalides (194,354-356) are cyclodepsipeptides found in Elysia species (E. rufescens, E. ornata, and E. grandifolia) and their algal food, Bryopsis pennata [331,794-797]. Kahalalides (194,354-356) include more than 20 structurally diverse molecules, ranging from a C-31 tripeptide to a C-77 tridecapeptide, where each peptide contains a different fatty acid chain [794]. Among them, kahalalide F (194), a cyclic peptide connected by an amidic bond to a short fatty acid chain, is the most potent, being reported to show antitumour activity and tested in phase I trials in patients with hormone-refractory prostate cancer [797,798]. Treating cancer cells with kahalalide F (194) resulted in critical changes in lysosomal membranes and large vacuoles, producing cell swelling, while it is also reported to display specific interactions with cell membrane proteins [482,799]. Kahalalide F (194) inhibits the PI3K-AKT signaling pathway in the breast cancer cell lines SKBR3 and BT474 [800]. The $\mathrm{IC}_{50}$ values of kahalalide $\mathrm{F}$ (194) in the NCI 60 cell line panel were from 0.2 to $10 \mu \mathrm{M}$, with hormone-independent prostate cancer cells being the most sensitive [267]. Kahalalide F (194) also displays in vivo activity against human prostate hormone-independent xenograft models and in the hollow fiber test [794,801-803]. Kahalalide F (194) was tested in several oncological clinical trials and was taken to phase II, although it failed to be effective [804,805]. Kahalalide F (194) is found in nature as a mixture with iso-kahalalide F (354), also possessing interesting bioactivities $[331,806]$. Iso-kahalalide F $\mathbf{3 5 4})$ also entered phase II clinical trials for liver cancer, melanoma, and NSCLC patients, but was also ineffective [807]. The origin of these compounds has been suggested to be Mycoplasma spp. Or Vibrio spp. Bacteria, since they are affiliated with E. rufescens and its mucus [808]. In E. ornata from India, two more compounds, kahalalide $Z_{1}$ (355) and kahalalide $Z_{2}$ (356), were found, differing from kahalalide $F$ (194) in the $\mathrm{N}$-terminal acid moiety and some aminoacid units of the peptide chain, and displaying a bioactivity profile comparable with kahalalide F (194) [795]. Furthermore, elisidepsin trifluoroacetate (PM02734, IrvalecR), a kahalalide-derived synthetic cyclic depsipeptide (357), displays cytotoxic activity, causing cell death by inhibiting the AKT/mTOR pathway [331,809]. Elisidepsin (357) also underwent clinical development after showing $\mathrm{IC}_{50}$ values between 0.4 and $\sim 9 \mu \mathrm{M}$ in a 23 cancer cell lines, including breast, colon, head and neck, lung, ovary, pancreas, prostate, and melanoma types [810-812]. Elisidepsin (357) acts at the cell membrane level, interacting directly with glycosylceramides in the membrane of cancer cells, while inducing necrosis-like cell death in the yeast Saccharomyces cerevisiae [813-815]. Elisidepsin (357) is active in vivo against human melanoma, liver, pancreas, breast, and prostate cancer xenografts [816]. However, in clinical trials, elisidepsin (357) has been ineffective to date [811,817].

\subsubsection{Pulmonata}

Trimusculus species present a single type of labdane diterpenoids, such as T. costatus and T. reticulatus from different geographic localities $[333,334,818]$. In Chile and South Africa, T. costatus and T. peruvianus metabolites present cytotoxicity [333,335-337]. An atypical C-21 hydroxylated sterol (358) from 
T. peruvianus presented $\mathrm{IC}_{50}$ values of $\sim 6 \mu \mathrm{M}$ when tested against human HCT- 116 and HT29 colon cancer cells [819]. A secosterol (359) from T. costatus was also active, with an $\mathrm{IC}_{50}$ value of $\sim 3 \mu \mathrm{M}$ against the WHCO1 esophageal cancer cell line [337].

Siphonaria species, S. capensis, S. concinna, S. cristatus, and S. serrata, contain de novo biosynthesized polypropionates, and some of which also present cytotoxic activity [27,339-352]. In particular, isopectinatone, siphonarienolone (119) and others are active at $2.5 \mu \mathrm{g} / \mathrm{mL}$ against P388, A549, HT29, and MEL28, while pectinatone (166) and siphonarienfuranone are active at $5 \mu \mathrm{g} / \mathrm{mL}$, and siphonarienedione, siphonarienone, and isosiphonarienolone are active at $10 \mu \mathrm{g} / \mathrm{mL}$ [27,339-352]. Onchidiidids present sesquiterpenoids, depsipeptide acetates, and propionates with 32 carbon atoms, two $\gamma$-pyrone rings, and a number of hydroxyl groups [12]. Onchidium species possess cytotoxic cyclic depsipeptides, such as onchidin (121), and the tropical Onchidium sp. also possesses cytotoxic acetates and propionates $[358,359,820]$. Onchidin (121) and onchidin B (360) are active against murine P388 leukemia and human $\mathrm{KB}$ oral cancer cells at $\mathrm{IC}_{50}$ values of $\sim 7 \mu \mathrm{M}[358,359]$. In China, Onchidium sp. presents bis- $\gamma$-pyrone polypropionates, such as onchidione (122) and related compounds, such as onchidiol (361) and ilikonapyrones $(362,363)$ lacking the hemiketal ring, in different populations $[12,357,360,362,821-823]$. Both kinds of compounds were tested against HCCLs, resulting in 3-acetyl-11-(3-methylbutanoyl)-13-propanoyl-ilikonapyrone (362) being active, inhibiting growth in all tested cell lines with $\mathrm{IC}_{50}$ between 3 and $9 \mu \mathrm{M}$ (A549 NSCLC, MCF-7 breast cancer, PC-3 prostate cancer, Hs683 oligodendroglioma, U373 glioblastoma, and SKMEL-28 melanoma), and being comparable to etoposide and camptothecin [357]. This compound (362) seems to be active against cancer cells that present resistance to proapoptotic stimuli [357]. Moreover, onchidione (122) and the related 3-acetyl-onchidionol and 4-epi-onchidione were reported to have significant effects on the splicing of XBP1 mRNA, which is an important regulator of some genes related to the growth of tumors [821].

Table 10. Cytotoxic and antitumoral compounds in the different heterobranch groups. In brackets: number of species with these compounds, number of the compounds in figures, and reference numbers. \# Numbers.

\begin{tabular}{|c|c|c|c|}
\hline Species (\#) & Compounds (\#) & Activity & References (\#) \\
\hline \multicolumn{4}{|c|}{ Nudibranchia (59) } \\
\hline Doris kerguelenensis & $\begin{array}{c}\text { Palmadorins A (195), B (196), D (197), M (198), } \\
\text { N (199), and O (200) }\end{array}$ & $\begin{array}{l}\text { Inhibition of human erythroleukemia cells } \\
\text { (HEL), inhibition of Jak2, STAT5, and Erk1/2 } \\
\text { activation in HEL cells }\end{array}$ & {$[66,67,824]$} \\
\hline Doris verrucosa & Verrucosins A (124) and B & Activation of protein kinase $\mathrm{C}$ & {$[371,420]$} \\
\hline Notodoris citrina, $N$. gardineri & Naamidine A (201), iso-naamidine-A (160) & $\begin{array}{l}\text { Inhibition of the epidermal growth factor } \\
\text { (EGF), inhibition of human tumor } \\
\text { xenografts in mice, and promotion of } \\
\text { caspase-dependent apoptosis in tumor cells }\end{array}$ & {$[424,489,490]$} \\
\hline Adalaria loveni & Lovenone (202) & Cytotoxic to two HTCLs & [491] \\
\hline Polycera atra & Bryostatins (203) & $\begin{array}{l}\text { Cytotoxic to P388 lymphocytic leukemia } \\
\text { and Alzheimer's disease cells }\end{array}$ & {$[424,486,487]$} \\
\hline Actinocyclus papillatus & (-)-Actisonitrile (204), actinofide (205) & Cytotoxic to tumor and non-tumor cells & {$[361,479,503,504]$} \\
\hline Aldisa andersoni & $\begin{array}{c}\text { 9-Chloro-phorbazole D (5), } \\
\text { N1-methyl-phorbazole A (6), phorbazoles A (7), } \\
\text { B (8), and C }\end{array}$ & $\begin{array}{l}\text { Cytostatic effects in vitro against several } \\
\text { HTCLs (human SKMEL-28 melanoma and } \\
\text { U373 glioblastoma cells) }\end{array}$ & {$[55,75,76]$} \\
\hline Phyllidiella coelestis & $\begin{array}{l}\text { 1-Formamido-10(1 } \rightarrow 2) \text {-abeopupukeanane } \\
\text { (209), 2-formamidopupukeanane }(\mathbf{2 1 0})\end{array}$ & $\begin{array}{l}\text { Cytotoxic to HeLa, MCF-7, KB, HT-29 } \\
\text { cancer cell lines }\end{array}$ & [111] \\
\hline Phyllidiella pustulosa & $\begin{array}{c}\text { Axinisothiocyanate } K(211) \text {, isothiocyanate } \\
\text { axisonitrile-3 (25) }\end{array}$ & Cytotoxic to NBT-T2 cells & {$[123,377]$} \\
\hline Phyllidiella coelestis, P. pustulosa & $\begin{array}{l}\text { Bisabolane-type sesquiterpenoid (212), } \\
\text { theonellin isothiocyanate (213), } \\
\text { 7-isocyano-7,8-dihydro- } \alpha \text {-bisabolene (214) }\end{array}$ & Cytotoxic to several HCCLs & [117] \\
\hline
\end{tabular}


Table 10. Cont.

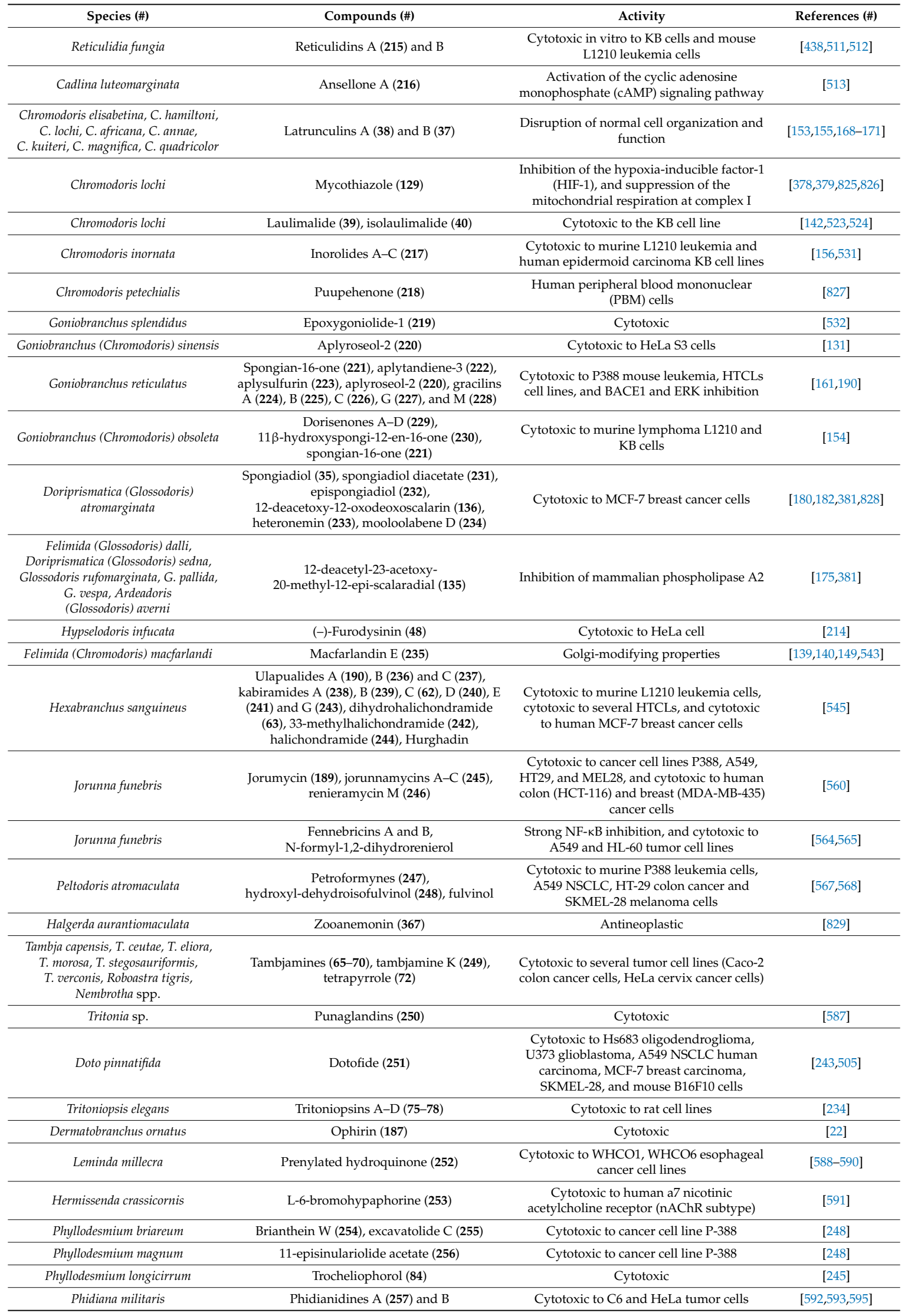


Table 10. Cont.

\begin{tabular}{|c|c|c|c|}
\hline Species (\#) & Compounds (\#) & Activity & References (\#) \\
\hline \multicolumn{4}{|c|}{ Pleurobranchoidea (2) } \\
\hline Pleurobranchus albiguttatus, P. forskalii & $\begin{array}{c}\text { Chlorolissoclimide (258), dichlorolissoclimide } \\
\text { (259), haterumaimides A (260), C (267), J (265), } \\
\text { K (266), G (268), I (269), } \\
\text { 3B-hydroxylissoclimide (261) }\end{array}$ & Cytotoxic to melanoma cells & {$[610,619]$} \\
\hline P. forskalii & $\begin{array}{c}\text { Keenamide A (262), cycloforskamide (263), } \\
\text { ergosinine (264) }\end{array}$ & $\begin{array}{l}\text { Cytotoxic to P-388, A-549, MEL-20, and } \\
\text { HT-29 tumor cell lines }\end{array}$ & {$[611,612]$} \\
\hline Tylodina perversa & Iso-fistularin 3 (270) & $\begin{array}{l}\text { Cytotoxic to human HeLa cervix } \\
\text { carcinoma cells }\end{array}$ & {$[257,625]$} \\
\hline \multicolumn{4}{|c|}{ Cephalaspidea (2) } \\
\hline Philinopsis speciosa & $\begin{array}{c}\text { Kulolides } 1 \text { (271), } 2 \text { (272) and } 3 \text { (273), } \\
\text { kulokainalide } 1 \text { (274), lulokekahilides } 1 \text { (275) } \\
\text { and } 2 \text { (276) }\end{array}$ & $\begin{array}{l}\text { Cytotoxic to L-1210, P388 leukemia, human } \\
\text { SK-OV-3 ovarian, tMDA-MB-435 breast } \\
\text { cancer, human A549 NSCLC, K562 chronic } \\
\text { myelogenous leukemia, HeLa cervix } \\
\text { carcinoma, and MCF-7 breast cancer } \\
\text { cell lines }\end{array}$ & {$[277,626-628]$} \\
\hline \multicolumn{4}{|c|}{ Anaspidea (11) } \\
\hline $\begin{array}{l}\text { Aplysia angasi, A. dactylomela, } A \text {. } \\
\text { depilans, A. fasciata, A. juliana, } A \text {. } \\
\text { kurodai, A. oculifera, A. punctata }\end{array}$ & Aplysistatin (277) & $\begin{array}{l}\text { Cytotoxic to mouse P388 leukemia, human } \\
\text { KB cancer, and HeLa cervix carcinoma cells }\end{array}$ & {$[613,631,820]$} \\
\hline Aplysia dactylomela & $\begin{array}{l}\text { Elatol (278), obtusol (279), iso-obtusol (280), } \\
\text { linear halogenated monoterpene (281) }\end{array}$ & $\begin{array}{l}\text { Cytotoxic to ten cancer cell lines, B16F10 } \\
\text { melanoma, HM02 gastric carcinoma, } \\
\text { HEP-G2 liver carcinoma, and MCF-7 breast } \\
\text { carcinoma cancer cells }\end{array}$ & {$[631-633,633]$} \\
\hline A. dactylomela & $\begin{array}{c}\text { Parguerol (282), parguerol-16-acetate (283), } \\
\text { iso-parguerol (284), iso-parguerol-16-acetate } \\
\text { (285), deoxyparguerol (286) }\end{array}$ & $\begin{array}{l}\text { Cytotoxic to P388 leukemia and Ehrlich } \\
\text { ascite carcinoma cells }\end{array}$ & {$[611,636,640]$} \\
\hline Aplysia juliana & Pyropheophorbides $a$ and $b$, julianin $S$ & Cytotoxic & {$[288,432]$} \\
\hline Aplysia kurodai & $\begin{array}{l}\text { Aplyronines A (191), B (290), C (291), D (292) } \\
\text { and H (293), aplaminal (294) }\end{array}$ & $\begin{array}{l}\text { Cytotoxic to human HeLa S3 cervix } \\
\text { carcinoma cells }\end{array}$ & {$[653,654,657,658]$} \\
\hline A. kurodai & $\begin{array}{l}\text { Aplaminone (295), neoaplaminone (296), } \\
\text { neoaplaminone sulfate (297) }\end{array}$ & $\begin{array}{l}\text { Cytotoxic to human HeLa S3 cervix } \\
\text { carcinoma cells }\end{array}$ & [667] \\
\hline A. kurodai & $\begin{array}{c}\text { Aplysiaterpenoid A (298), aplysiapyranoids } \\
\text { A-D (299) }\end{array}$ & Cytotoxic to Vero, MDCK, and B16 cells & {$[668,669]$} \\
\hline A. kurodai & $\begin{array}{c}\text { Kurodainol (300), aplysiaterpenoids A-D (298), } \\
\text { aplysin-20 (301), iso-aplysin-20, aplysiadiol } \\
\text { (302), epi-aplysin-20, ent-isoconcinndiol (303), } \\
\text { aplysianin A }\end{array}$ & $\begin{array}{l}\text { Induction of growth inhibitory effects in } \\
\text { various cancer cell lines }\end{array}$ & [668-674] \\
\hline A. kurodai & $\begin{array}{c}\text { (-)-Aplysin (304), aplysinol (305), aplykurodins } \\
\text { A (306) and B (146) }\end{array}$ & $\begin{array}{l}\text { Cytotoxic to various cancer cell lines, } \\
\text { human A549 NSCLC, and human } \\
\text { glioma cells }\end{array}$ & {$[680,682,683]$} \\
\hline Aplysia oculifera & Oculiferane (308), epi-obtusane (309) & $\begin{array}{l}\text { Cytotoxic to PC-3 prostate, A549 NSCLC, } \\
\text { MCF-7 breast, HepG2 liver, and HCT116 } \\
\text { colon cancer cell lines }\end{array}$ & [684] \\
\hline Aplysia punctata & Halogenated monoterpenes (310-312) & Cytotoxic to four tumor cell lines & [685] \\
\hline Dolabella auricularia & Dolabellanin A & Antineoplastic & [435] \\
\hline D. auricularia & $\begin{array}{l}\text { Auripyrones A (319) and B, dolabelides A (320), } \\
\text { B (321), C (322) and D (323) }\end{array}$ & Cytotoxic to human HeLa S3 cancer cells & {$[687,696,701,702]$} \\
\hline D. auricularia & Doliculide (325) & $\begin{array}{l}\text { Cytotoxic to human HeLa S3, MCF-7, and } \\
\text { MDA-MB-231 breast cancer cells }\end{array}$ & [708] \\
\hline
\end{tabular}


Table 10. Cont.

\begin{tabular}{|c|c|c|c|}
\hline Species (\#) & Compounds (\#) & Activity & References (\#) \\
\hline Stylocheilus longicauda & $\begin{array}{l}\text { Aplysiatoxin (96), debromoaplysiatoxin }(97), \\
\text { makalika (99), makalikone (100), lyngbyatoxin A } \\
(349) \text {, lyngbyatoxin A acetate }(\mathbf{1 0 1}), \\
\text { malyngamide B, O (102) and P (103) }\end{array}$ & $\begin{array}{l}\text { Cytotoxic to P388, A549, HT29, and HTB38 } \\
\text { cancer cell lines, and toxic to mice }\end{array}$ & $\begin{array}{l}{[302,304,305,307,} \\
\quad 777-779]\end{array}$ \\
\hline Bursatella leachii & $\begin{array}{l}\text { Lyngbyatoxin A (349), debromoaplysiatoxin (97), } \\
\text { hectochlorin (351), deacetylhectochlorin (352), } \\
\text { malyndamides S (350) and X (353) }\end{array}$ & $\begin{array}{c}\text { Cytotoxic to murine P388 leukemia, human } \\
\text { A549, NSCLC, NCI-H187 (SCLC), HT-29 } \\
\text { colon cancer, HL60 leukemia, KB, and BC } \\
\text { breast cancer }\end{array}$ & [783-787] \\
\hline Elysia subornata & Caulerpenyne (155) & $\begin{array}{c}\text { Cytotoxic to neuroblastoma SK-N-SH } \\
\text { cell line }\end{array}$ & {$[316,411,788-790]$} \\
\hline Elysia rufescens & Kahalide F (194), iso-kahalalide F (354) & $\begin{array}{l}\text { Cytotoxic to A549 and Hs683 cell lines, and } \\
\text { breast cancer cell lines SKBR3 and BT474 }\end{array}$ & {$[331,797,800]$} \\
\hline Elysia ornata & $\begin{array}{l}\text { Kahalides } F(194), Z_{1}(356), Z_{2}(355) \\
\text { elisidepsin (356) }\end{array}$ & $\begin{array}{l}\text { Cytotoxic to A549 and Hs683, breast, colon, } \\
\text { head, neck, lung, ovary, pancreas, prostate, } \\
\text { and melanoma cell lines }\end{array}$ & {$[795,797,810-812]$} \\
\hline Trimusculus costatus & Secosterol (359) & $\begin{array}{l}\text { Cytotoxic to WHCO1 esophageal cancer } \\
\text { cell line }\end{array}$ & [337] \\
\hline $\begin{array}{l}\text { Siphonaria capensis, S. concinna, } \\
\text { S. cristatus, S. serrata }\end{array}$ & Siphonarienfuranon, capensinone, denticulatins & Cytotoxic & {$[339,346,352]$} \\
\hline Siphonaria spp. & $\begin{array}{l}\text { Siphonarienolone (119), diemenensins A (165) } \\
\text { and B, siphonarin A (120), vallartanones A and B }\end{array}$ & Cytotoxic & $\begin{array}{l}{[27,134,340-344,} \\
348,351]\end{array}$ \\
\hline Onchidium sp. & $\begin{array}{c}\text { onchidin (121), onchidin B (360), onchidione } \\
\text { (122), onchidiol (361), ilikonapyrones }(362,363) \text {, } \\
\text { onchidionol }\end{array}$ & $\begin{array}{l}\text { Cytotoxic to murine } \mathrm{P} 388 \text { and } \mathrm{KB} \text { oral } \\
\text { cancer cells, and regulation of some genes } \\
\text { related to tumor growth }\end{array}$ & {$[131,358,359,821]$} \\
\hline
\end{tabular}

\subsection{Antibiotic Activity}

Most groups of heterobranchs present compounds with antibiotic activity, the exceptions being dendronotacean and aeolidacean nudibranchs, pleurobranchoideans, cephalaspideans, and pteropods (Figure 23, Table 11) [1,2]. This is an open field for research, since bacterial strains are becoming resistant or multiresistant to known antibiotics, and new molecules are strongly needed to target them [31,830].

\subsubsection{Nudibranchia}

\section{Doridacea}

Both olepupuane (14) and polygodial (13), previously mentioned above, are found in different dendrodorid nudibranchs and show antifungal activity against Saccharomyces cerevisiae IFO 0203 and Hansenula anomala IFO 0136 [81,831]. Moreover, extracts of the egg masses of Dendrodoris fumata show antibacterial activity against Escherichia coli, Staphylococcus aureus and Pseudomonas aeruginosa, thus protecting embryos against bacterial infection [832].

Phyllidids, well-studied colorful nudibranchs, often contain isocyanate compounds [1,2]. These isocyanates display a wide array of activities, including antibiotic activity, and have been well studied in recent years [101-105]. One of the best-known species is Phyllidiella pustulosa, with compounds obtained from its dietary sponges, mainly Acanthella cavernosa, from different geographical localities [119-122]. P. pustulosa from Fiji presents axisonitrile-3 (25), displaying strong growth inhibition against Mycobacterium tuberculosis (MIC $2 \mu \mathrm{g} / \mathrm{mL}$ ) [118,427]. Similarly, Phyllidia picta from Bali contains the axane sesquiterpenoids pictaisonitrile-1 (23) and pictaisonitrile-2, while Phyllidia coelestis and P. pustulosa from China, as well as their probable sponge prey A. cavernosa, present a nitrogenous cadinane-type sesquiterpenoid, xidaoisocyanate A (24), among other terpenoids [112,113,117]. Furthermore, Phyllidia varicosa presents two 9-thiocyanatopupukeanane sesquiterpenes (126), sequestered from the sponge Axinyssa aculeata [110]. Altogether, 9-isocyanopupukeanane (21) and epi-9-isocyanopupukeanane, as well as their thiocyano derivatives, are moderately antibacterial against Bacillus subtilis and antifungal against Candida albicans, and they were also further isolated from Phyllidiella rosans (P. bourguini) [110,373]. 
Doriprismatica (Glossodoris) atromarginata from Australia, Sri Lanka, and India, possesses different compounds from its demosponge preys (Spongia (Hyatella) sp., Hyrtios spp., and Hyattella cribriformis), two scalarane sesterterpenes in their MDFs, some pentacyclic scalaranes, and heteronemin (233) [22,92,166,176,180,380-382]. Heteronemin (233), a scalarin-skeleton sesterterpene first reported in the sponge Heteronema erecta, displays antibacterial activity towards $M$. tuberculosis $\mathrm{H}_{37} \mathrm{Rv}$, with a MIC of $6.25 \mu \mathrm{g} / \mathrm{mL}[85,180,833]$. Other Glossodoris species from Australia, G. hikuerensis and G. vespa, also contain heteronemin (233) in their viscera, along with scalaradial (44), 12-deacetoxy-12-oxoscalaradial (43), and 12-deacetoxy-12-oxo-deoxoscalarin (136) in their mantle [178]. In particular, 12-epi-scalaradial of G. hikuerensis and G. cincta shows antimicrobial activity at $10 \mu \mathrm{g} /$ disk against S. aureus, B. subtilis, and C. albicans [166].

Some compounds described in Chromodoris willani collected in Okinawa contain two sesterterpenes, deoximanoalide (364) and deoxysecomanoalide (365), biotransformed from manoalide and secomanoalide, respectively, possessing antimicrobial activity against E. coli and B. subtilis, and showing inhibition of snake venom phospholipase A2 at 0.2-0.5 $\mu \mathrm{g}$ [159]. On the other hand, nakafuran-8 (54) and nakafuran-9 (51), found in several chromodorid species as reported above, were tested against E. coli, S. aureus, P. aeriginosa and B. subtilis in a disk diffusion assay, displaying no antibacterial activity [157,165]. In contrast, in Chromodoris petechialis, puupehenone (218) shows a MIC of $3 \mu \mathrm{g} / \mathrm{mL}$ against $C$. albicans [158].

Hawaiian specimens of the bright red "Spanish dancer" nudibranch, Hexabranchus sanguineus, yielded several bioactive macrolides (see above) [222]. Specimens of H. sanguineus from Fiji additionally yielded two thiazole cyclic peptides, sanguinamide A (64) and B (366) [219]. Both sanguinamide A (64) and B (366) were found at very low concentrations, 0.0023 and $0.011 \%$ dry weight, respectively [219]. Sanguinamide B (366) showed a moderate antibacterial activity against $P$. aeruginosa, reducing twitching motility $[834,835]$. H. sanguineus specimens from different locations showed different compounds, most of them probably from dietary sponges (Halichondria, Axinella, and Dysidea) [22,219,545,836-838]. In Indonesia, Hawai'i and Japan, H. sanguineus presents two trisoxazole macrolides, ulapualide A (190) and B (236), that inhibit the growth of C. albicans, while halichondramides (244) and kabiramides A-E $\mathbf{( 6 2 , 2 3 8 - 2 4 1 , 2 4 3 ) ~ i n h i b i t e d ~ s e v e r a l ~ f u n g i ~ [ 2 1 8 , 2 2 2 , 5 4 6 , 5 4 7 , 8 3 6 ] . ~}$

The Indian Jorunna funebris possesses, among other related metabolites, the isoquinoline alkaloid jorumycin (189), which is very similar to renieramycin E from the sponge Reniera sp. [166,553,839]. Jorumycin (189) presents antimicrobial activity against Bacillus subtilis and Staphylococcus aureus [557]. Jorumycin (189) was found in the mucus secretion, and, thus, a defensive role was proposed for it [166]. J. funebris and its prey, Xestospongia spp., present several isoquinolinequinones and bistetrahydroisoquinolines, among which some isoquinolinequinones also display antibacterial activity [553,560,564,565,840].

Although the metabolites have not yet been described, the organic extract of Halgerda stricklandi displays modest activity against Staphylococcus aureus, but no activity against a range of several other bacteria and fungi [840]. Halgerda aurantiomaculata contains a tryptophane derivative called zooanemonin (367), previously isolated from several sponges and the sea anemone Anemonia sulcata, which is also reported to show antibacterial activity [841].

Finally, within the Nembrothidae, the previously mentioned alkaloids tambjamines $(\mathbf{6 5 - 7 0 , 2 4 9 )}$ also possess antimicrobial activity from their diet [223]. Particularly, their blue tetrapyrrol (72), presumably derived from a diet of ascidians, is active against $B$. subtilis at $5 \mu \mathrm{g} / \mathrm{disc}$ [157].

\section{Euarminida}

Chemical studies of the South African Leminda millecra described some sesquiterpenes from dietary origin, including millecrones A and B (368,369) and millecrols A and B (370,371) [588,589]. Millecrone A (368), originating from the soft coral Alcyonium fauri, inhibited the growth of Candida albicans at $50 \mu \mathrm{g} /$ disk, while millecrone B (369) from the gorgonian Leptogorgia palma was active against both Staphylococcus aureus and Bacillus subtilis at $50 \mu \mathrm{g} /$ disk [21,589]. In contrast, millecrol B (371) was only active against $B$. subtilis at $50 \mu \mathrm{g} /$ disk [21]. 
Furthermore, Dermatobranchus otome from Japan presents the germacrane sesquiterpenoids DO1 (372), DO2 (373), and DO3 (374), displaying antibacterial activity against B. subtilis [842].

Extracts of Armina babai also display antimicrobial activity against Pseudomonas sp. and Proteus mirabilis, although the compounds have not yet been described [843]. A. babai from India possesses a ceramide also found in the gorgonian Acabaria undulata [842,844].

\subsubsection{Tylodinoidea}

As mentioned above, the Australian Tylodina corticalis selectively accumulates some bromotyrosine-derived alkaloids from the sponge Pseudoceratina purpurea, which contains a larger variety of these compounds [258]. Among them, hexadellin (375) and aplysamine 2 (376) display mild antibiotic activity against E. coli and S. aureus at concentrations of 125-250 $\mu \mathrm{g} / \mathrm{mL}$ [262].

\subsubsection{Anaspidea}

Aplysia, as mentioned above, is one of the most studied genera, with many NPs displaying a wide range of activities around the world [1,2]. In particular, the brominated diterpenes, glandulaurencianols A-C (162,163), as well as punctatol (164) from Aplysia punctata, probably from the red algae Laurencia glandulifera, possess the laurencianol skeleton, a known antibacterial diterpene from Laurencia glandulifera that is active against Escherichia coli and Bacillus subtilis [429-431]. Moreover, a purple secretion of the sea hare $A$. juliana contains julianin-S, an antibacterial peptide suggested to protect its egg masses from microbial infections, together with some unsaturated fatty acids [288,434]. Similarly, aplysianin E from A. kurodai eggs shows antifungal activity against $C$. albicans at $\mathrm{IC}_{50}>16 \mu \mathrm{g} / \mathrm{mL}$ [672-674].

As mentioned above, Dolabella auricularia, possesses the glycoprotein dolabellanin A, probably de novo biosynthesized [435]. Besides its antineoplastic activity, dolabellanin A also shows antibacterial activity against E. coli, which may protect the egg masses from bacterial pathogens [435].

Finally, bursatellin (105), a diol nitrile alkaloid found in Bursatella leachii plei from Puerto Rico, is structurally related to the well-known antibiotic chloramphenicol [311]. In the Mediterranean, both the + and - isomers of bursatellin (105) are found in the external extracts of B. leachii leachii and B. leachii savignyana [312].

\subsubsection{Sacoglossa}

In this group, the previously mentioned cyclodepsipeptides kahalalides A (377) and F (194) from Elysia rufescens and its algal food, Bryopsis sp., are active against mycobacteria, with kahalalide A (377) inhibiting M. tuberculosis $\mathrm{H} 37 \mathrm{Rv}$ by $83 \%$ at $12.5 \mu \mathrm{g} / \mathrm{mL}$, and kahalalide F (194) by $67 \%$ at $12.5 \mu \mathrm{g} / \mathrm{mL}[331,411,794,797]$. Kahalalide F (194) also inhibited Mycobacterium intracellulare at a MIC of $25 \mu \mathrm{g} / \mathrm{mL}$ [331]. Kahalalides (194,354-356) are also found in E. rufescens, E. ornata and E. grandifolia, and their algal diet Bryopsis pennata [794,795], with kahalalide F (194) always being the most active compound [794,795]. Kahalalide F (194) is found in a mixture together with its isomer iso-kahalalide F (354), which also shows relevant bioactivities [331,806]. Both compounds have been suggested to originate from bacterial symbionts, although more research is needed to prove this [808].

Chlorodesmin (114), from the Australian Cyerce nigricans, is a diterpenoid previously known from the green algae Chlorodesmis fastigiata with antibacterial and antifungal activity [845,846].

\subsubsection{Pulmonata}

Several species of Siphonaria (S. capensis, S. concinna, S. cristatus, and S. serrata) possess different types of polypropionates in their mantle and mucous secretion, affecting gramm + bacteria [338]. Species from Australia, West and East Atlantic, and South Africa displayed antimicrobial activity due to acyclic compounds with a 2-pyrone and furanone rings (type I), such as siphonarienolone (119), which were similar to the polypropionates of cephalaspideans [340-346]. On the other hand, polypropionates with a profuse polyoxygenated network that frequently cyclizes (Type II), such as siphonarin A (120), similar to those of actinomycetes, are found in Siphonaria species from Australia, New Zealand, North-East Pacific, Pacific Islands, and South Africa [347-352]. S. diemenensis and 
S. pectinata present diemenensin-A (165) and pectinatone (166) [340,341,343]. Diemenensin-A (165) inhibited S. aureus and B. subtilis at $1 \mu \mathrm{g} /$ disc and $5 \mu \mathrm{g} /$ disc, respectively, while pectinatone (166) inhibited S. aureus, B. subtilus, C. albicans, and S. cerevisiae [341,343].

Table 11. Number of antibiotic compounds in the different heterobranch groups. In brackets: number of species with antibiotic compounds, number of the compounds in figures, and reference numbers. \# Number.

\begin{tabular}{|c|c|c|c|}
\hline Species (\#) & Compounds (\#) & Activity & References (\#) \\
\hline \multicolumn{4}{|c|}{ Nudibranchia (21) } \\
\hline Phyllidiella pustulosa & Axisonitrile-3 (25) & $\begin{array}{l}\text { Antimycobacterial activity against } \\
\text { Mycobacterium tuberculosis }\end{array}$ & [427] \\
\hline P. pustulosa, P. coelestis & Xidaoisocyanate A (24) & Antibiotic activity & [117] \\
\hline Phyllidia picta & Pictaisonitrile 1 (23) and 2 & Antibiotic activity & [112] \\
\hline Phyllidia varicosa & 9-Thiocyanatopupukeanane (126) & Antibiotic activity & [247] \\
\hline Phyllidiella rosans & $\begin{array}{l}\text { 9-Isocyanopupukeanane (21), } \\
\text { epi-9-isocyanopupukeanane }\end{array}$ & $\begin{array}{l}\text { Antibacterial activity against Bacillus subtilis } \\
\text { and Candida albicans }\end{array}$ & [110] \\
\hline $\begin{array}{l}\text { Doriorismatica (Glossodoris) } \\
\text { atromarginata }\end{array}$ & Scalaranes, heteronemin (233) & $\begin{array}{l}\text { Antimycobacterial activity against } \\
\text { M. tuberculosis } \mathrm{H}_{37} \mathrm{Rv} \\
\end{array}$ & [833] \\
\hline $\begin{array}{l}\text { Glossodoris hikuerensis, } \\
\text { G. vespa, G. cincta }\end{array}$ & $\begin{array}{c}\text { Heteronemin (233), scalaradial (44), } \\
\text { 12-deacetoxy-12-oxoscalaradial (43), } \\
\text { 12-deacetoxy-12-oxo-deoxoscalarin (136), } \\
\text { 12-epi-scalaradial }\end{array}$ & Antibiotic activity & [178] \\
\hline $\begin{array}{l}\text { Felimida (Chromodoris) } \\
\text { macfarlandi }\end{array}$ & Macfarlandines D and E (235) & $\begin{array}{l}\text { Antibacterial activity against } B \text {. subtilis in } \\
\text { the disk assay system at } 10 \text { gg per disk, and } \\
\text { activity against Vibrio anguillarum and } \\
\text { Beneckea harveyi at } 100 \text { gg per disk }\end{array}$ & {$[139,140,149,543]$} \\
\hline Chromodoris willani & $\begin{array}{l}\text { Deoximanoalide (364), } \\
\text { deoxysecomanoalide (365) }\end{array}$ & $\begin{array}{c}\text { Antimicrobial activity against Escherichia } \\
\text { coli and B. subtilis, and inhibitor of snake } \\
\text { venom phospholipase A2 }\end{array}$ & [159] \\
\hline Chromodoris spp. & $\begin{array}{l}\text { Nakafuran-8 (54), nakafuran-9 (51), } \\
\text { puupehenone (218) }\end{array}$ & $\begin{array}{l}\text { Antibacterial activity against } E \text {. coli, } \\
\text { Staphylococcus aureus, Pseudomonas } \\
\text { aeruginosa, B. subtilis, and antifungal } \\
\text { activity against } C \text {. albicans }\end{array}$ & {$[157,158,165]$} \\
\hline Hexabranchus sanguineus & $\begin{array}{l}\text { Kabiramides A-E (238, 239, 62, 240, 241), } \\
\text { sanguinamides A (64), B (366), } \\
\text { halichondriamides (244), ulapualides A } \\
\text { (190) and B (236) }\end{array}$ & $\begin{array}{l}\text { Antibacterial activity against } P \text {. aeruginosa, } \\
\text { and antifungal activity against } C \text {. albicans }\end{array}$ & {$[208,219,221,222,545,834-837]$} \\
\hline Jorunna funebris & $\begin{array}{c}\text { Jorumycin (189), jorunnamycins } \\
\mathrm{A}-\mathrm{C}(\mathbf{2 4 5})\end{array}$ & $\begin{array}{c}\text { Antimicrobial activityagainst B. subtilis and } \\
\text { S. aureus }\end{array}$ & {$[166,553,560]$} \\
\hline Halgerda aurantiomaculata & Zooanemonin (367) & Antibacterial & [841] \\
\hline $\begin{array}{c}\text { Roboastra tigris, Tambja abdere, } \\
\text { T. eliora }\end{array}$ & 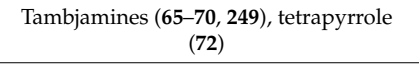 & Antibacterial activity against $B$. subtilis & [223] \\
\hline Leminda millecra & $\begin{array}{l}\text { Millecrones A (368) and B (369), } \\
\text { millecrols A (370) and B (371) }\end{array}$ & $\begin{array}{l}\text { Antibiotic activity against } C \text {. albicans, } \\
\text { S. aureus and B. subtilis }\end{array}$ & [588] \\
\hline Dermatobranchus otome & DO1 (372), DO2 (373), DO3 (374) & Antibacterial activity against $B$. subtilis & [842] \\
\hline Armina babai & Extracts & $\begin{array}{l}\text { Antibacterial activity against } P \text { seudomonas } \\
\text { sp. and Proteus mirabilis }\end{array}$ & [843] \\
\hline \multicolumn{4}{|c|}{ Tylodinoidea (1) } \\
\hline Tylodina corticalis & Hexadellin (375), aplysamine 2 (376) & $\begin{array}{c}\text { Antibacterial activity against E. coli and } \\
\text { S. aureus }\end{array}$ & [262] \\
\hline \multicolumn{4}{|c|}{ Anaspidea (5) } \\
\hline Aplysia punctata & $\begin{array}{l}\text { Glandulaurencianols A-C }(\mathbf{1 6 2}, \mathbf{1 6 3}), \\
\text { punctatol }(\mathbf{1 6 4})\end{array}$ & $\begin{array}{l}\text { Antibacterial activity against B. subtilis and } \\
\text { E. coli }\end{array}$ & [429-431] \\
\hline Aplysia juliana & Julianin-S & Antibacterial activity & [288] \\
\hline Aplysia kurodai & Aplysianin E & Antifungal activity against $C$. albicans & [672-674] \\
\hline Dolabella auricularia & Dolabellanin A & Antibacterial activity against $E$. coli & [435] \\
\hline $\begin{array}{l}\text { Bursatella leachii plei, } B . \\
\text { leachii savignyana }\end{array}$ & Bursatellin (105) & Antibiotic activity & {$[311,312]$} \\
\hline \multicolumn{4}{|c|}{ Sacoglossa (4) } \\
\hline Elysia rufescens & $\begin{array}{l}\text { Kahalalides A (377) and F (194), } \\
\text { iso-kahalalide F (354) }\end{array}$ & $\begin{array}{c}\text { Antimycobacterial activity against } \\
\text { Mycobacterium tuberculosis and } \\
\text { M. intracellulare }\end{array}$ & [794] \\
\hline Elysia ornata, E. grandifolia & Kahalalide F (194) & $\begin{array}{l}\text { Antimycobacterial activity against } \\
\text { M. tuberculosis and M. intracellulare }\end{array}$ & {$[331,411,797]$} \\
\hline Cyerce nigricans & Chlorodesmin (114) & Antibacterial and antifungal activity & {$[845,846]$} \\
\hline \multicolumn{4}{|c|}{ Pulmonata (7) } \\
\hline $\begin{array}{l}\text { Siphonaria australis, } \\
\text { S. diemenensis, S. capensis, } \\
\text { S. concinna, S. cristatus, } \\
\text { S. serrata, S. pectinata }\end{array}$ & $\begin{array}{l}\text { Siphonarienolone (119), siphonarin A } \\
\text { (120), pectinatone (166) }\end{array}$ & Antimicrobial activity & {$[340-343,346]$} \\
\hline
\end{tabular}




\subsection{Antiparasitic Activity}

Currently, another important need is to identify antiparasitic compounds, although the antiparasitic activities included here mainly comprise compounds related to antiplasmodial effects. Within heterobranchs, antimalarial compounds have been described in several doridacean nudibranchs, while only one species of sacoglossa has been cited to possess antileishmanial activity [1,2] (Figures 23 and 24, Table 12).

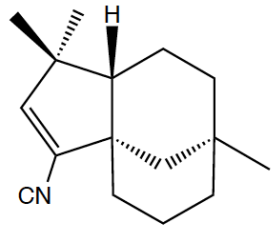

379 2-Isocyanoclovene

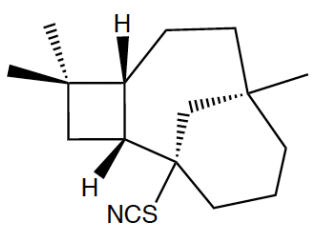

382 1-isothiocyanatoepicaryolane<smiles>CC(=O)O[C@H](CC[C@H](C)[C@H]1CCC(C)=C[C@H]1O)[C@@](C)(O)CCC=C(C)C</smiles>

385 Dactyloditerpenol acetate<smiles>Cn1cc(Cc2ccc(O)cc2)nc1N</smiles>

386 Dorimidazole A

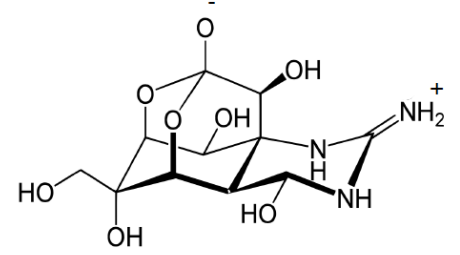<smiles>CC1=C[C@@]2(C)[C@@H](C(C)C)CC[C@](C)(C#N)[C@@H]2CC1</smiles>

383 10-thiocyano-4-cadinene

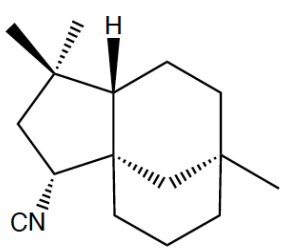

380 2-Isocyanoclovane

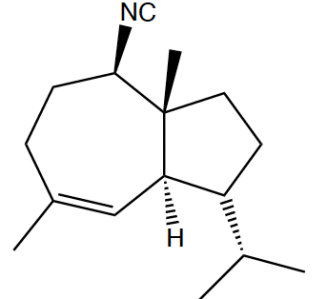

381 4,5-epi-10-isocyanoisodauc-6-ene

387 Tetrodotoxin

Figure 24. Structures of selected antiparasitic compounds and antivirals from Doridacea and Sacoglossa, anti-inflammatory compounds from Anaspidea, and compounds with other pharmacological activities in heterobranch molluscs. These molecules may also display other activities, as reported in the text. 


\subsubsection{Nudibranchia}

Doridacea

The doridacean nudibranch Notodoris gardineri from the Philippines presents the imidazole alkaloids iso-naamidine-A (160) and dorimidazole-A (386), the latter exhibiting anthelminthic activity against the nematode parasite Nippostrongylus brasiliensis at $50 \mu \mathrm{g} / \mathrm{mL}$ [424,426]. Moreover, Chromodoris lochi from Vanuatu contains the PKS-NRPS-derived mycothiazole (129) which is described to possess anthelminthic activity against the nematode parasite $N$. brasiliensis at $50 \mu \mathrm{g} / \mathrm{mL}$ [378]. Mycothiazole (129) has also been found in the prey sponge of the slug, the sponge Spongia (Cacospongia) mycofijiensis [379].

Among the numerous nitrogenated compounds reported from phyllidid nudibranchs, mostly obtained from their sponge prey, several have been found to have antiplasmodial activity [44,847]. Axisonitrile-3 (25) shows an $\mathrm{IC}_{50}$ towards Plasmodium falciparum of $16.5 \mathrm{ng} / \mathrm{mL}$ for chloroquine-resistant strain W2 and no associated cytotoxicity [848]. Axisonitrile-3 (25) has been reported to interfere with the detoxification of heme, a degradation product of hemoglobin digestion within infected erythrocytes, and to form a binary complex with iron in protoporphyrin IX, producing heme accumulation, which results in toxicity to the malaria parasite [849].

Table 12. Antiparasitic compounds in the different heterobranch groups. In brackets: number of species with antiparasitic compounds, number of the compounds in figures, and reference numbers. \# Number.

\begin{tabular}{|c|c|c|c|}
\hline Species (\#) & Compounds (\#) & Activity & References (\#) \\
\hline \multicolumn{4}{|c|}{ Nudibranchia (4) } \\
\hline Phyllidiella pustulosa & $\begin{array}{c}\text { Axisonitrile-3 (25), } \\
\text { pustulosaisonitrile-1 (378), } \\
\text { 10-thiocyano-4-cadinene (383) }\end{array}$ & $\begin{array}{c}\text { Activity against } \\
\text { Plasmodium falciparum }\end{array}$ & {$[118,123,848-850]$} \\
\hline Phyllidia ocellata & $\begin{array}{c}\text { 2-Isocyanoclovene (379), } \\
\text { 2-isocyanoclovane (380), } \\
\text { 4,5-epi-10-isocyanoisodauc-6-ene (381), } \\
\text { 1-isothiocyanatoepicaryolane (382) }\end{array}$ & $\begin{array}{c}\text { Activity against } \\
\text { Plasmodium falciparum }\end{array}$ & [376] \\
\hline Notodoris gardineri & $\begin{array}{c}\text { Iso-naamidine-A (160), dorimidazole } \\
\mathrm{A}(\mathbf{3 8 6})\end{array}$ & Anthelminthic activity & {$[424,426]$} \\
\hline Chromodoris lochi & Mycothiazole (129) & $\begin{array}{l}\text { Anthelminthic and toxic } \\
\text { activity }\end{array}$ & [378] \\
\hline \multicolumn{4}{|c|}{ Sacoglossa (3) } \\
\hline $\begin{array}{c}\text { Elysia rufescens, E. ornata, } \\
\text { E. grandifolia }\end{array}$ & Kahalalides $(194,354-356,377)$ & Antileishmanial activity & [794-797] \\
\hline
\end{tabular}

Pustulosaisonitrile-1 (378) from Phyllidiella pustulosa from Australia presents moderate levels of in vitro antimalarial activity [850]. Among the diverse nitrogenous mono-, biand tri-cyclic sesquiterpenes found in Phyllidia ocelata and Phyllidiella pustulosa from different geographical locations, several are reported to possess antimalarial activity against Plasmodium falciparum [102,118-120,122,375-377]. In particular, in P. ocellata from Australia, 2-isocyanoclovene (379), its dihydro analogue 2-isocyanoclovane (380) and 4,5-epi-10-isocyanoisodauc-6-ene (381) present $\mathrm{IC}_{50}$ values of $0.26-0.30 \mu \mathrm{M}$, while 1-isothiocyanatoepicaryolane (382) has an $\mathrm{IC}_{50}>10 \mu \mathrm{M}$ [376]. In P. pustulosa from Fiji, 10-thiocyano-4-cadinene (383) shows moderate antiplasmodial activity [118,123].

\subsubsection{Sacoglossa}

The depsipeptides kahalalides $(194,354-356,377)$ found in different Elysia species, such as E. rufescens, E. ornata, E. grandifolia, and their algal food Bryopsis pennata, have been reported to possess antileishmanial properties [794-797]. Kahalalides $(\mathbf{1 9 4 , 3 5 4 - 3 5 6 , 3 7 7 )}$ are active against Leishmania spp. At micromolar ranges, and their lethality is linked to the alteration of the plasmatic membrane of the protozoan [794-797]. 


\subsection{Antiviral Activity}

Marine organisms are considered an underexplored source of antiviral compounds [851-853]. Many of the drugs currently employed produce strong side effects and develop resistances [853]. Viral diseases cause a huge number of deaths annually; for example, human immunodeficiency virus (HIV) is one of the top five most deadly diseases worldwide [853]. Furthermore, new viruses are appearing with extreme virulence, such as COVID-19, with no known treatment to date [854]. Therefore, the need for new antiviral drugs is clear, and heterobranchs, with their amazing biodiversity and chemodiversity, may perhaps contribute to this. To date, only doridacean nudibranchs, sea hares, and sacoglossans have been reported to possess antiviral compounds (Figure 24, Table 13).

Table 13. Antiviral compounds in the different heterobranch groups. In brackets: number of species with antiviral compounds, number of the compounds in figures, and reference numbers. \# Number.

\begin{tabular}{|c|c|c|c|}
\hline Species (\#) & Compounds (\#) & Activity & References (\#) \\
\hline \multicolumn{4}{|c|}{ Nudibranchia (7) } \\
\hline Cadlina luteomarginata & Ansellone A (216) & $\begin{array}{l}\text { Activation of the latent proviral } \\
\text { HIV-1 gene expression }\end{array}$ & [855] \\
\hline $\begin{array}{l}\text { Chromodoris } \\
\text { mandapamensis, } \\
\text { Glossodoris cincta }\end{array}$ & $\begin{array}{l}\text { Spongiadiol (35), } \\
\text { epi-spongiadiol (232) }\end{array}$ & $\begin{array}{l}\text { Activity against herpes simplex } \\
\text { virus, type } 1 \text { (HSV-1) and P388 } \\
\text { murine leukemia cells }\end{array}$ & {$[166,535]$} \\
\hline Chromodoris hamiltoni & $\begin{array}{l}\text { Latrunculins A (38) and } \\
\text { B (37) }\end{array}$ & Activity against HIV-1 & {$[153,155]$} \\
\hline $\begin{array}{l}\text { Chromodoris africana, } \\
\text { C. quadricolor }\end{array}$ & Latrunculin B (37) & Activity against HIV-1 & {$[155,853]$} \\
\hline Chromodoris petechialis & Puupehenone (218) & Anti-HIV-1 & [797] \\
\hline \multicolumn{4}{|c|}{ Anaspidea (1) } \\
\hline Dolabella auricularia & Dolastatin 3 (192) & Activity against HIV life cycle & {$[718,728,853]$} \\
\hline \multicolumn{4}{|c|}{ Sacoglossa (3) } \\
\hline $\begin{array}{l}\text { Elysia rufescens, E. } \\
\text { grandifolia, E. ornata }\end{array}$ & $\begin{array}{l}\text { Kahalalide F (194), } \\
\text { iso-kahalalide F (354) }\end{array}$ & $\begin{array}{c}\text { Activity against herpes simplex } \\
\text { virus II }\end{array}$ & {$[331,794,795,797,853]$} \\
\hline
\end{tabular}

\subsubsection{Nudibranchia}

\section{Doridacea}

The chromodoridid Cadlina luteomarginata presents compounds with the tricyclic ansellane carbon skeleton, among other compounds, obtained from its sponge prey Phorbas sp. [513]. Among them, ansellone A (216) from the sponge was tested for the "shock and kill" approach to a sterilizing HIV-1 cure [855]. Ansellone A (216), together with other sponge compounds, was found to activate the latent proviral HIV-1 gene expression, as well as to possess LRA profiles comparable to prostratin, which is in phase I as a potential HIV treatment [855].

Several chromodorid species contain spongiadiol (35) from the sponges they feed on, among other spongian diterpenes $[22,166,380,381,535,536]$. This is the case of Chromodoris mandapamensis and Glossodoris cincta (G. atromarginata) specimens from different localities, which present these compounds in their mantle and digestive gland $[22,166,380,381,535,536]$. Spongiadiol (35) is active against the herpes simplex virus, showing an $\mathrm{IC}_{50}$ of $0.25 \mu \mathrm{g} / \mathrm{mL}$ against herpes simplex virus type I [535,537]. Chromodoris hamiltoni presents a wide arsenal of chemicals, among which the 2-thiazolidinone macrolides latrunculins A (38) and B (37) from its diet of sponges are found at different localities [154,156]. Latrunculin B (37) is also present in C. africana and C. quadricolor [170,171]. Latrunculin B (37), a very active compound, as previously mentioned, was reported in the sponge Latrunculia magnifica [168-170]. The $\mathrm{EC}_{50}$ of latrunculin B (37) against HIV-1 is $16.4 \mu \mathrm{M}$, thus showing a moderate activity while being non-cytotoxic [853]. Doriprismatica (Glossodoris) atromarginata also presents furanoditerpenoids and scalarane sesterterpenes originating from its dietary sponges Spongia (Hyatella) sp. and Hyrtios 
spp., depending on the geographical location (Australia, Sri Lanka, and India) [92,175,180,381,382]. Some of these compounds are reported as antivirals, particularly spongiadiol (35) and epi-spongiadiol (232) $[180,383-386,519,535,539]$. Puupehenone (218) from Chromodoris petechialis is also active against HIV-1 [797].

\subsubsection{Anaspidea}

Dolabella auricularia presents some diet-derived cyclic depsipeptides reported to exhibit a wide range of activity against different stages of the HIV life cycle [718]. Dolastatin 3 (192) from D. auricularia was further isolated from the circumtropical cyanobacterium Lyngbya majuscula from Palau [718,728]. Dolastatin-3 (192) inhibits HIV-1 integrase at relatively high concentrations, with $\mathrm{EC}_{50}$ of $5 \mathrm{mM}$ for the terminal cleavage and $4.1 \mathrm{mM}$ for the strand-transfer reactions [728]. The activity of dolastatin-3 (192) was lost after some time in the laboratory, since it was a difficult-to-handle molecule and also presented some cytotoxicity; therefore, it was not taken forward for further investigation [728].

\subsubsection{Sacoglossa}

In this group, the previously mentioned depsipeptides kahalalides $(194,354-356,377)$ are found in Elysia rufescens, E. grandifolia, and E. ornata, as well as in the green algae Bryopsis pennata in their diet [47,49]. Among them, kahalalide F (194) is the most bioactive compound, although all kahalalides possess many activities as reported above. Kahalalide F (194) presents antiviral properties against herpes simplex virus II, while kahalalides A (377) and G (384) are inactive [331,794-797]. Kahalalide F (194) is found along with its isomer, iso-kahalalide $\mathrm{F}$ (354), both displaying a wide array of bioactivities and suggested to be of bacterial origin $[331,806,808]$. Kahalalide $\mathrm{F}(\mathbf{1 9 4})$ also exhibits moderate activity against HIV-1, with an $\mathrm{EC}_{50}$ of $14.2 \mu \mathrm{M}$, while it is not cytotoxic against human peripheral blood mononuclear (PBM) cells [853]. Kahalalides A (377) and G (384), contrastingly, are not active against HIV-1 [853].

\subsection{Anti-Inflammatory Activity}

Only a few nudibranchs and some sea hares are known to possess anti-inflammatory compounds, while there have been no studies to date regarding the remaining groups (Figure 24, Table 14).

Table 14. Anti-inflammatory compounds in the different heterobranch groups. In brackets: number of species with anti-inflammatory compounds, number of the compounds in figures, and reference numbers. \# Number.

\begin{tabular}{|c|c|c|c|}
\hline Species (\#) & Compounds (\#) & Activity & References (\#) \\
\hline \multicolumn{4}{|c|}{ Nudibranchia (11) } \\
\hline $\begin{array}{l}\text { Glossodoris rufomarginata, } \\
\text { G. pallida, G. vespa, } \\
\text { G. averni, G. hikuerensis, } \\
\text { G. atromarginata, G. cincta }\end{array}$ & Scalaradial (44) & $\begin{array}{l}\text { Potent inhibition of } \mathrm{PLA}_{2} \text {, and } \\
\text { potent anti-inflammatory } \\
\text { activity }\end{array}$ & {$[175,177,381,383,856-858]$} \\
\hline Goniobranchus splendidus & Gracilins (224-228) & $\begin{array}{l}\text { Cyclosporine A mimics, BACE1 } \\
\text { and ERK inhibition }\end{array}$ & {$[190,533,534]$} \\
\hline $\begin{array}{l}\text { Tethys fimbria, Melibe } \\
\text { viridis }\end{array}$ & $\begin{array}{c}\text { Prostaglandin } \\
\text { E-1,15-lactones }(\mathbf{8 0}, \mathbf{8 1})\end{array}$ & $\begin{array}{l}\text { Reduction of inflammation after } \\
\text { autotomy and tissue } \\
\text { regeneration }\end{array}$ & {$[77,240]$} \\
\hline Tritonia sp. & Punaglandins (250) & Anti-inflammatory activity & [587] \\
\hline \multicolumn{4}{|c|}{ Anaspidea (3) } \\
\hline Aplysia depilans & $\begin{array}{l}\text { Carotenoids, } \\
\text { polyunsaturated fatty } \\
\text { acids }\end{array}$ & Anti-inflammatory activity & [859] \\
\hline Aplysia dactylomela & $\begin{array}{l}\text { Dactyloditerpenol } \\
\text { acetate (385) }\end{array}$ & Anti-neuroinflammatory activity & {$[860,861]$} \\
\hline Bursatella leachii & Malyngamide S (350) & Anti-inflammatory activity & [786] \\
\hline
\end{tabular}




\subsubsection{Nudibranchia}

Doridacea

As reported above, several species of Glossodoris present scalaradial (44) and other scalarane compounds derived from the sponges they feed on [22,166,175,180,381,383,856]. These include Glossodoris rufomarginata, G. pallida, G. vespa, G. averni, G. hikuerensis, G. atromarginata, and G. cincta from different geographical locations [22,166,175,178,380,381,383,536,856]. Scalaradial (44) is a potent anti-inflammatory compound [856], but it is also toxic to slugs, and, thus, after feeding, they quickly transform scalaradial (44) into its 12-deacetyl derivative or other related scalaranes in a detoxification process, locating them in MDFs in their mantle rims [2,4,22,166,176,177,383]. Scalaradial (44) was first found in the Mediterranean sponge Cacospongia mollior [857] and has been reported to display a potent inhibition of PLA 2 [858]. Similarly, Goniobranchus species usually present spongian cyclic diterpenes, which are often cytotoxic, as reported above, and obtained from their diet of Spongionella sponges [154,190,533]. Among these compounds, G. splendidus contains gracilins (224-228), some of which have been tested from the sponge and possess a high anti-inflammatory potential, such as cyclosporine A mimics and as BACE1 and ERK inhibitors [534].

\section{Dendronotida}

The invasive species Melibe viridis presents a prostaglandin lactone in its mucus and cerata which had been previously reported in Tethys fimbria [77,240]. In fact, T. fimbria, presents a wide array of de novo biosynthesized prostaglandins $(\mathbf{8 0 , 8 1})$ with different roles, which may include reducing inflammation in their tissues after autotomy and tissue regeneration [240].

Moreover, punaglandins (250) from Tritonia sp. show anti-inflammatory activity, and a synthetic 10-thiomethyl derivative enhances in vivo mineralization in human osteoblasts [587].

\subsubsection{Anaspidea}

Several species of sea hares have been studied to date for anti-inflammatory activity. Aplysia depilans presents 8 carotenoids and 22 polyunsaturated fatty acids obtained from their algal diet and found in the digestive gland which possess anti-inflammatory activity [859]. Aplysia dactylomela possesses dactyloditerpenol acetate (385); this is probably derived from laurenditerpenol from Laurencia intricata, which is reported to have a significant in vitro anti-neuroinflammatory activity [860,861].

Bursatella leachii feeds on cyanobacteria and accumulates its natural products usually in its digestive gland, using them for its own defense as previously discussed [311,312,783,784]. Among these compounds, the alkaloid malyngamide S (350) from New Zealand specimens presents anti-inflammatory properties [786].

\subsection{Against Neurodegenerative Diseases}

Activity against neurodegenerative diseases has been described for several marine natural compounds [862]. In heterobranch molluscs, compounds from several species have been tested, providing some interesting results (Figure 24, Table 15). The doridacean nudibranch Polycera atra feeds on the bryozoan Bugula neritina, accumulating the polyketide macrolides bryostatins (203) and transferring them to its spawn, as mentioned above [492-494]. Bryostatins (203) have been further traced to the symbiont Candidatus Endobugula sertula, where the biosynthetic genes have been described [495]. Among them, bryostatin 1 (203) is the most studied molecule as a potential treatment for many diseases, including cancer and Alzheimer disease (AD), and it is in phase I trials for AD [495,497].

The doridacean nudibranchs Goniobranchus obsoletus and G. splendidus from Australia possess many cyclic diterpenes of the spongian type, including gracilins (224-228) which are accumulated from feeding on Spongiella sponges [154,190,533]. Gracilins (224-228), as previously mentioned, 
possess several interesting properties as drug candidates and also show a potential role against neurodegenerative diseases, such as $\mathrm{AD}$, which is also being tested [534,863].

The chromodoridid Cadlina luteomarginata obtains ansellone A (216) from its diet of the sponge Phorbas sp. [513]. Ansellone A (216) shows cAMP activation $\left(\mathrm{EC}_{50}=14 \mathrm{mM}\right)$ comparable to that of forskolin in the HEK293 cell-based assay [513]. This activity is very useful in stem cell techniques, because modulating the cAMP signaling pathway is crucial for treating many diseases, such as cancer and heart failure, as well as neurodegenerative diseases [513].

In cephalaspideans, the cylichnidae Scaphander lignarius lives in soft bottom, muddy areas, usually feeding on foraminiferans $[229,231]$. As previously mentioned, S. lignarius specimens from the Mediterranean and East Atlantic present the so-called lignarenones (171), which are de novo biosynthesized and secreted in the Blochmann's gland [245]. These compounds are suggested to be used as alarm pheromones, similarly to other cephalaspidean species mentioned above. Interestingly, recent studies suggest that lignarenone $B(\mathbf{1 7 1})$ could also be used as a possible therapeutic candidate for the treatment of GSK3 $\beta$-involved pathologies, such as AD [864]. In silico binding studies revealed that lignarenone B (171) can act over the ATP and/or substrate binding regions of GSK3 $\beta$ [864]. The predicted inhibitory potential of lignarenone B (171) was experimentally validated by an in vitro assay showing a $\sim 50 \%$ increase in Ser9 phosphorylation levels of GSK3 $\beta$, while it also potentiates structural neuronal plasticity in vitro using neuronal primary cultures [865]. Future studies are aimed to test lignarenones in preclinical mouse models of AD.

Table 15. Compounds used against neurodegenerative diseases in the different heterobranch groups. In brackets: number of species with these compounds, number of the compounds in figures, and reference numbers. \# Number.

\begin{tabular}{|c|c|c|c|}
\hline Species (\#) & Compounds (\#) & Activity & References (\#) \\
\hline \multicolumn{4}{|c|}{ Nudibranchia (4) } \\
\hline Polycera atra & Bryostatin 1 (203) & Alzheimer disease (AD) & {$[492-494,866]$} \\
\hline $\begin{array}{l}\text { Goniobranchus obsoletus, } \\
\text { G. splendidus }\end{array}$ & Gracilins (224-228) & $\begin{array}{c}\text { Potential against } \\
\text { neurodegenerative } \\
\text { diseases }\end{array}$ & {$[533,534,863]$} \\
\hline Cadlina luteomarginata & Ansellone A (216) & $\begin{array}{c}\text { cAMP activation } \\
\text { (neurodegenerative } \\
\text { diseases) }\end{array}$ & [513] \\
\hline \multicolumn{4}{|c|}{ Cephalaspidea (1) } \\
\hline Scaphander lignarius & Lignarenone B (171) & Alzheimer disease (AD) & {$[864,867]$} \\
\hline
\end{tabular}

\subsection{Other Pharmacological Activities}

Other activities that were not included in the previous sections comprise those of a couple of nudibranch species and a pleurobranchoidea (Figure 24, Table 16). No other activities have been described in the remaining groups.

Janolusimide (138) is a tripeptide described in the Mediterranean euarminid nudibranch Janolus cristatus [388]. Janolusimide (138) is toxic to mice (LD $5 \mathrm{mg} / \mathrm{kg}$ ) and affects acetylcholine receptors, thus having a neurotoxic action at lower concentrations [388]. A N-methyl analogue, janolusimide B, was further described in the New Zealand bryozoan Bugula flabellata [390], suggesting a dietary origin for janolusimide (138), since J. cristatus has been reported to feed on bryozoans, including B. flabellata [390].

The pleurobranchoid genus Pleurobranchaea is often used as a model for neurobiology investigations because of its peculiar escape swimming behavior, which is achieved by alternating dorsal and ventral body flexions [868]. Furthermore, it is also interesting because P. maculata from New Zealand possesses tetrodotoxin (TTX) (387). TTX (387) is found in its adult tissues, gonads, and egg masses, thus suggesting a defensive role $[869,870]$. TTX (387) is a very potent neurotoxin that inhibits action 
potential in nerve cells, and it has been found in many poisonous animals, such as flatworms, arrow worms, ribbon worms, snails, blue-ringed octopus, xanthid crabs, sea stars, fish, and toads [871,872]. In some of these cases, it has been demonstrated that TTX (387) is produced by symbiotic bacteria from the Pseudoalteromonas, Pseudomonas, Vibrio, and other strains, and that it is bioaccumulated along the food chain. However, the bacterial origin of TTX (387) has not been proved in all cases [871,872].

Table 16. Other pharmacological activities in compounds from different heterobranch groups. In brackets: number of species with active compounds, number of the compounds in figures, and reference numbers. \# Number.

\begin{tabular}{cccc}
\hline Species (\#) & Compounds (\#) & Activity & References (\#) \\
\hline \multirow{2}{*}{ Janolus cristatus } & Nudibranchia (1) & \\
& Janolusimide (138) & Toxic to mice & {$[388,390]$} \\
Pleurobranchaea maculata & Tetrodotoxin (TTX) (387) & Neurotoxin & {$[869,870]$} \\
\hline
\end{tabular}

\section{Concluding Remarks}

Despite the fact that only a small proportion of heterobranch molluscs has been reported to date, they represent a particularly rich group of natural products. Their NPs display an astonishing variation in bioactivity, both ecological and pharmacological, reflecting the huge chemodiversity they possess (Figure 25). Biodiversity and chemodiversity correlate here to offer a huge amount of bioactive molecules in these peculiar group of molluscs. Heterobranchs indeed comprise a very diverse group of organisms that present almost all classes of natural products described to date, but not all of these NPs have been tested for potential bioactivities $[1,2,28]$. Thus, many more studies are expected to find not only new NPs but also their potential bioactivities.

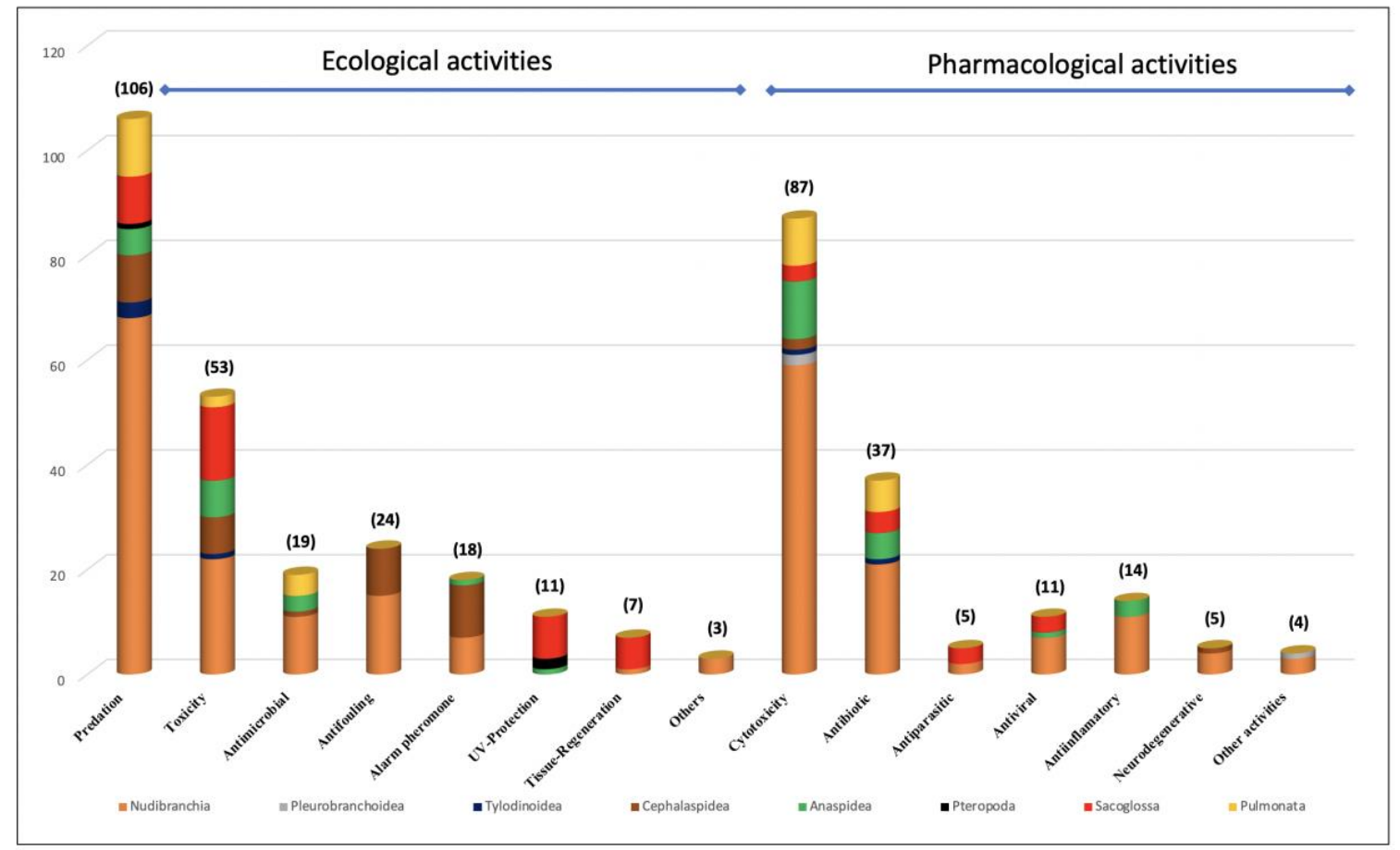

Figure 25. Number of species with bioactive compounds in the different heterobranch groups.

Regarding ecological activity, in fact, very few compounds from the total NPs described have been tested, as described above, and this keeps the door open for many other ecological interactions to be identified in the future. NPs from heterobranchs have been shown to be ecologically relevant, 
as in the case of those from other marine organisms, although many experiments should still be performed to complete the available information. Some molecules are shown to display multiple roles, as is the case in other marine invertebrates, while similar structures are shown to display similar roles in geographically distant localities by phylogenetically related species [1,2]. The most studied activity is feeding deterrence, followed by toxicity (Figure 25), although the NPs are not usually tested against sympatric species, raising doubts about their real effects in the habitat where the molluscs live. Reliable field data are scarce, and, therefore, the ecological significance of many compounds remains to be demonstrated.

The pharmacological activity of heterobranch NPs is still underexplored because we are only aware of a small part of their chemical arsenal. However, their potential is obvious from the molecules reported above, which are proven to be of interest in many fields, with some compounds being promising drugs, such as dolastatins, ulapualides, kabiramides, latrunculins, doliculides, and others. Further research is needed to develop these compounds. Overall, the most studied activities are cytotoxicity and anticancer activity, followed by antibiotic activity (Figure 25).

In this review, we discussed more than 450 metabolites isolated from ca. 400 species of heterobranch molluscs. Heterobranch molluscs are thus an important source of bioactive NPs, even if not all of them are produced by the molluscs themselves. John Faulkner once said that in order to find the most bioactive compounds in an ecosystem, heterobranchs would be the best shot to find them, because they have already selected them along evolution. This continues to appear to be true. While symbionts may be behind some of the NP syntheses, heterobranchs have evolved to use them for their own benefit $[1,2]$. In some cases, dietary cyanobacteria or other bacteria have been proven to be the source of compounds, but, in general, origin from symbionts remains difficult to prove [481]. In any case, if NPs can be traced to a microorganism, this may help to solve the supply problems for many of the bioactive NPs, either by culturing, by isolating the BGCs (biosynthetic gene clusters), or by using other metagenomic techniques $[873,874]$. Culturing the molluscs is a difficult-but-not-impossible task, which could also be useful for some heterobranch species. Moreover, possible strategies to improve MNP selection include many dereplication strategies described in the literature, in addition to the many chemical techniques used to obtain derivatives, as well as synthesis methods $[44,761,875]$. Furthermore, virtual screening, computational chemistry, as well as more studies on molecular targets are needed to overcome the limitations of studying MNPs. The use of nanotechnology to deliver drugs is also a promising field that requires further investigation; ADCs, for instance, show considerable potential [481]. As an example, kahalalide F (194) conjugated to $40 \mathrm{~nm}$ gold nanoparticles resulted in higher cell growth inhibition in HeLa cervical carcinoma cells than the compound alone $[481,876]$. Further research should also be devoted to this field. Overall, we have seen that heterobranch molluscs are extremely interesting in regard to the study of marine natural products in terms of both chemical ecology and biotechnology studies, providing many leads for further detailed research in these fields in the near future.

Author Contributions: Conceptualization and design C.A.; literature review, investigation, and data curation C.A. and C.A.-P.; writing-original draft preparation, review and editing, C.A. and C.A.-P.; funding acquisition, C.A. All authors have read and agreed to the published version of the manuscript.

Funding: Support for this work was provided by BLUEBIO grant to C.A. (CTM2016-78901/ANT) and the Ramon Areces Foundation to C.A.-P.

Acknowledgments: This is an AntECO (SCAR) contribution.

Conflicts of Interest: The authors declare no conflict of interest. 


\section{Abbreviations}

\begin{tabular}{|c|c|}
\hline $\mathrm{AD}$ & Alzheimer Disease \\
\hline ADCs & Antibody-drug conjugates \\
\hline ADMET & Absortion, Distribution, Metabolism, Excretion, and Toxicity \\
\hline ADR & Adriamycin resistant \\
\hline BGCs & Biosynthetic Gene Clusters \\
\hline cAMP & Cyclic Adenosine Monophosphate \\
\hline $\mathrm{EC}_{50}$ & Half maximal Effective Concentration \\
\hline $\mathrm{ED}_{50}$ & Half effective dose \\
\hline EGF & Epidermal Groth Factor \\
\hline EGFR & Epidermal Groth Factor Receptor \\
\hline ERK & Extracellular signal-regulated kinases \\
\hline FDA & Food and Drugs Administration \\
\hline $\mathrm{GI}_{50}$ & Maximal inhibition of cell proliferation \\
\hline HCCLs & Human Colon Cancer Cell Lines \\
\hline HEL & Human Erythroleukemia cells \\
\hline HeLa & Henrietta_Lacks cell line from cervical cancer cells \\
\hline HIF-1 & Hypoxia Inducible Factor 1 \\
\hline HTCLs & Human Tumor Cell Lines \\
\hline $\mathrm{KB}$ & Subline of the KERATIN-forming tumor cell line HeLa \\
\hline $\mathrm{IC}_{50}$ & Half minimal Inhibitory Concentration \\
\hline LD & Lethal Dose \\
\hline LRA & Latency Reversal Agent \\
\hline MAAs & Mycosporine-like Amino Acids \\
\hline MAPK & Mitogen-Activated Protein Kinase \\
\hline MDA & Microtubule-Desestabilizing Agent \\
\hline MDFs & Mantle Dermal Formations \\
\hline MDR & Multidrug resistant variant \\
\hline $\mathrm{MIC}$ & Minimum Inhibitory Concentration \\
\hline MNPs & Marine Natural Products \\
\hline MTT & Dimethyl Thiazolyl Diphenyl Tetrazolium Bromide \\
\hline $\mathrm{NCI}$ & National Cancer Institute \\
\hline NPs & Natural Products \\
\hline NSCLC & Nonsmall Cell Lung Cancer \\
\hline PBM & Peripheral Blood Mononuclear \\
\hline PG & Prostaglandins \\
\hline PKC & Protein Kinase C \\
\hline PSMA-ADC & Prostate-specific membrane antigen antibody-drug conjugate \\
\hline PTPRK & Protein Tyrosine Phosphatase Receptor type K \\
\hline TRAIL & Tumor necrosis factor-related apoptosis-inducing ligand \\
\hline TTX & Tetrodotoxin \\
\hline UVR & Ultra-Violet Radiation \\
\hline VCR & Vincristine resistant \\
\hline
\end{tabular}

\section{References}

1. Avila, C.; Núñez-Pons, L.; Moles, J. From the tropics to the poles: Chemical defensive strategies in sea slugs (Mollusca: Heterobranchia). In Chemical Ecology: The Ecological Impacts of Marine Natural Products; Puglisi, M.P., Becerro, M.A., Eds.; CRC Press: Boca Raton, FL, USA; Taylor and Francis: Abingdon, UK, 2018.

2. Avila, C. Natural products of opisthobranch molluscs: A biological review. Oceanogr. Mar. Biol. Annu. Rev. 1995, 33, 487-559.

3. Avila, C. A preliminary catalogue of natural substances of opistobranch molluscs from Western Mediterranean and near Atlantic. Sci. Mar. 1992, 56, 373-382.

4. Avila, C. Terpenoids in Marine Heterobranch Molluscs. Mar. Drugs 2020, 8, 162. [CrossRef] [PubMed] 
5. $\quad$ Blunt, J.W.; Carroll, A.R.; Copp, B.R.; Davis, R.A.; Keyzers, R.A.; Prinsep, M.R. Marine natural products. Nat. Prod. Rep. 2018, 35, 8-53. [CrossRef]

6. Carroll, A.R.; Copp, B.R.; Davis, R.A.; Keyzers, R.A.; Prinsep, M.R. Marine natural products. Nat. Prod. Rep. 2020, 37, 175-223. [CrossRef]

7. Puglisi, M.P.; Becerro, M.A. Chemical Ecology: The Ecological Impacts of Marine Natural Products; CRC Press: Boca Raton, FL, USA; Taylor and Francis: Abingdon, UK, 2018.

8. McClintock, J.B.; Baker, P.J. Marine Chemical Ecology; CRC Marine Science Series Press: Boca Raton, FL, USA, 2001.

9. Ianora, A.; Boersma, M.; Casotti, R.; Fontana, A.; Harder, J.; Hoffmann, F.; Pavia, H.; Potin, P.; Poulet, S.A.; Toth, G. New trends in marine chemical ecology. Estuar. Coasts 2006, 29, 531-551. [CrossRef]

10. Puglisi, M.P.; Sneed, J.M.; Sharp, K.H.; Ritson-Williams, R.; Paul, V.J. Marine chemical ecology in benthic environments. Nat. Prod. Rep. 2014, 31, 1510-1553. [CrossRef]

11. Tian, Y.; Li, Y.-L.; Zhao, F.-C. Secondary metabolites from polar organisms. Mar. Drugs 2017, 15, 28. [CrossRef]

12. Cimino, G.; Gavagnin, M. (Eds.) Progress in Molecular and Subcellular Biology; Subseries Marine Molecular Biotechnology; Springer: Berlin/Heidelberg, Germany, 2006; Volume 43.

13. Benkendorff, K. Molluscan biological and chemical diversity: Secondary metabolites and medicinal resources produced by marine molluscs. Biol. Rev. 2010, 85, 757-775. [CrossRef]

14. Kandyuk, R.P. Sterols and their functional role in Mollusks (a review). Hydrobiol. J. 2006, 42, 56-66. [CrossRef]

15. Garson, M. Marine natural products as antifeedants. In Comprehensive Natural Products II. Chemistry and Biology; Mander, L., Liu, H.W., Eds.; Elsevier Science: Amsterdam, The Netherlands, 2010; pp. 503-537.

16. Cimino, G.; Ghiselin, M.T. Marine natural products chemistry as an evolutionary narrative. In Marine Chemical Ecology; McClintock, J.B., Baker, P.J., Eds.; CRC Marine Science Series Press: Boca Raton, FL, USA, 2001; pp. 115-154.

17. McClintock, J.B.; Amsler, C.D.; Baker, B.J. Overview of the chemical ecology of benthic marine invertebrates along the Western Antarctic peninsula. Integr. Comp. Biol. 2010, 50, 967-980. [CrossRef] [PubMed]

18. Núñez-Pons, L.; Avila, C. Natural products mediating ecological interactions in Antarctic benthic communities: A mini-review of the known molecules. Nat. Prod. Rep. 2015, 32, 1114-1130. [CrossRef] [PubMed]

19. Cimino, G.; Ghiselin, M.T. Chemical defense and the evolution of opisthobranch gastropods. Proc. Calif. Acad. Sci. 2009, 60, 175-422.

20. Garson, M.J. Marine mollusks from Australia and New Zealand: Chemical and ecological studies. In Progress in Molecular and Subcellular Biology; Cimino, G., Gavagnin, M., Eds.; Springer: Berlin/Heidelberg, Germany, 2006; Volume 43, pp. 159-174.

21. Davies-Coleman, M.T. Secondary metabolites from the marine gastropod molluscs of Antarctica, Southern Africa and South America. In Progress in Molecular and Subcellular Biology; Cimino, G., Gavagnin, M., Eds.; Springer: Berlin/Heidelberg, Germany, 2006; Volume 43, pp. 133-157.

22. Wahidulla, S.; Guo, Y.W.; Fakhr, I.M.I.; Mollo, E. Chemical diversity in opisthobranch molluscs from scarcely investigated Indo-Pacific areas. In Progress in Molecular and Subcellular Biology; Cimino, G., Gavagnin, M., Eds.; Springer: Berlin/Heidelberg, Germany, 2006; Volume 43, pp. 175-198.

23. Miyamoto, T. Selected bioactive compounds from Japanese anaspideans and nudibranchs. In Progress in Molecular and Subcellular Biology; Cimino, G., Gavagnin, M., Eds.; Springer: Berlin/Heidelberg, Germany, 2006; Volume 43, pp. 199-214.

24. Wang, J.R.; He, W.F.; Guo, Y.W. Chemistry, chemoecology, and bioactivity of the South China Sea opisthobranch molluscs and their dietary organisms. J. Asian Nat. Prod. Res. 2013, 15, 185-197. [CrossRef] [PubMed]

25. Andersen, R.J.; Desjardine, K.; Woods, K. Skin chemistry of nudibranchs from the West Coast of North America. In Progress in Molecular and Subcellular Biology; Cimino, G., Gavagnin, M., Eds.; Springer: Berlin/Heidelberg, Germany, 2006; Volume 43, pp. 277-301.

26. Kamiya, H.; Sakai, R.; Jimbo, M. Bioactive molecules from sea hares. In Progress in Molecular and Subcellular Biology; Cimino, G., Gavagnin, M., Eds.; Springer: Berlin/Heidelberg, Germany, 2006; Volume 43, pp. 215-239.

27. Darias, J.; Cueto, M.; Díaz-Marrero, A.R. The chemistry of marine pulmonate gastropods. In Progress in Molecular and Subcellular Biology; Cimino, G., Gavagnin, M., Eds.; Springer: Berlin/Heidelberg, Germany, 2006; Volume 43, pp. 105-131.

28. Dean, L.J.; Prinsep, M.R. The chemistry and chemical ecology of nudibranchs. Nat. Prod. Rep. 2017, 34, 1359-1390. [CrossRef] [PubMed] 
29. Avila, C.; Taboada, S.; Núñez-Pons, L. Antarctic marine chemical ecology: What is next? Mar. Ecol. 2008, 29, 1-71. [CrossRef]

30. Paul, V.J. Ecological Roles of Marine Natural Products; Comstock Publishications Association: Ithaka, NY, USA, 1992.

31. Ruiz-Torres, V.; Encinar, J.A.; Herranz-López, M.; Pérez-Sánchez, A.; Galiano, V.; Barrajón-Catalán, E.; Micol, V. An updated review on marine anticancer compounds: The use of virtual screening for the discovery of small-molecule cancer drugs. Molecules 2017, 22, 1037. [CrossRef]

32. Newman, D.J.; Cragg, G.M. Marine natural products and related compounds in clinical and advanced preclinical trials. J. Nat. Prod. 2004, 67, 1216-1238. [CrossRef]

33. Baker, B.J. Marine Biomedicine: From Beach to Bedside; CRC Press: Boca Raton, FL, USA; Taylor and Francis: Abingdon, UK, 2015.

34. Haefner, B. Drugs from the deep: Marine natural products as drug candidates. Drug Discov. Today 2003, 8, 536-544. [CrossRef]

35. Clardy, J.; Walsh, C. Lessons from natural molecules. Nature 2004, 432, 829-837. [CrossRef]

36. Molinski, T.F.; Dalisay, D.S.; Lievens, S.L.; Saludes, J.P. Drug development from marine natural products. Nature Rev. Drug Discov. 2009, 8, 69-85. [CrossRef] [PubMed]

37. Cragg, G.M.; Grothaus, P.G.; Newman, D.J. New horizons for old drugs and drug leads. J. Nat. Prod. 2014, 77, 703-723. [CrossRef] [PubMed]

38. Mudit, M.; El Sayed, K.A. Cancer control potential of marine natural product scaffolds through inhibition of tumor cell migration and invasion. Drug Discov. Today 2016, 21, 1745-1760. [CrossRef] [PubMed]

39. Newman, D.J.; Cragg, G.M. Natural products as sources of new drugs over the 30 years from 1981 to 2010. J. Nat. Prod. 2012, 75, 311-335. [CrossRef]

40. Newman, D.J.; Cragg, G.M. Natural products as sources of new drugs from 1981 to 2014. J. Nat. Prod. 2016, 79, 629-661. [CrossRef] [PubMed]

41. White, J. Drug Addiction: From Basic Research to Therapy. Drug Alcohol. Rev. 2009, 28, 455. [CrossRef]

42. Khalifa, S.A.; Elias, N.; Farag, M.A.; Chen, L.; Saeed, A.; Hegazy, M.E.; Moustafa, M.S.; El-Wahed, A.; Al-Mousawi, S.M.; Musharraf, S.G.; et al. Marine natural products: A source of novel anticancer drugs. Mar. Drugs 2019, 17, 491. [CrossRef]

43. Newman, D.J.; Cragg, G.M. Marine-sourced anti-cancer and cancer pain control agents in clinical and late preclinical development. Mar. Drugs 2014, 12, 255-278. [CrossRef]

44. Gross, H.; König, G.M. Terpenoids from marine organisms: Unique structures and their pharmacological potential. Phytochem. Rev. 2006, 5, 115-141. [CrossRef]

45. Faircloth, G.; Cuevas, M.C. Kahalalide F and ES285: Potent anticancer agents from marine molluscs. In Progress in Molecular and Subcellular Biology; Cimino, G., Gavagnin, M., Eds.; Springer: Berlin/Heidelberg, Germany, 2006; Volume 43, pp. 363-379.

46. Kigoshi, H.; Kita, M. Antitumor effects of sea hare-derived compounds in cancer. In Handbook of Anticancer Drugs from Marine Origin; Kim, S.K., Ed.; Springer International Publishing: Cham, Switzerland, 2015; pp. 701-739.

47. Schrödl, M.; Jörger, K.M.; Klussmann-Kolb, A.; Wilson, N.G. Bye bye ‘Opisthobranchia'! A review on the contribution of mesopsammic sea slugs to euthyneuran systematics. Thalassas 2011, 27, 101-112.

48. Medina, M.; Lal, S.; Vallès, Y.; Takaoka, T.L.; Dayrat, B.A.; Boore, J.L.; Gosliner, T. Crawling through time: Transition of snails to slugs dating back to the Paleozoic, based on mitochondrial phylogenomics. Mar. Genom. 2011, 4, 51-59. [CrossRef] [PubMed]

49. Wägele, H.; Klussmann-Kolb, A.; Verbeek, E.; Schrödl, M. Flashback and foreshadowing; a review of the taxon Opisthobranchia. Org. Div. Evol. 2014, 14, 133-149. [CrossRef]

50. Zapata, F.; Wilson, N.G.; Howison, M.; Andrade, S.C.; Jörger, K.M.; Schrödl, M.; Goetz, F.E.; Giribet, G.; Dunn, C.W. Phylogenomic analyses of deep gastropod relationships reject Orthogastropoda. Proc. R. Soc. B Biol. Sci. 2014, 281, 20141739. [CrossRef] [PubMed]

51. WoRMS. World Register of Marine Species, Database. Available online: http://www.marinespecies.org (accessed on 11 November 2020).

52. Avila, C. Molluscan natural products as biological models: Chemical ecology, histology, and laboratory culture. In Progress in Molecular and Subcellular Biology; Cimino, G., Gavagnin, M., Eds.; Springer: Berlin/Heidelberg, Germany, 2006; Volume 43, pp. 1-23. 
53. Iken, K.; Avila, C.; Ciavatta, M.L.; Fontana, A.; Cimino, G. Hodgsonal, a new drimane sesquiterpene from the mantle of the Antarctic nudibranch Bathydoris hodgsoni. Tetrahedron Lett. 1998, 39, 5635-5638. [CrossRef]

54. Avila, C.; Iken, K.; Fontana, A.; Cimino, G. Chemical ecology of the Antarctic nudibranch Bathydoris hodgsoni Eliot, 1907: Defensive role and origin of its natural products. J. Exp. Mar. Biol. Ecol. 2000, 252, 27-44. [CrossRef]

55. Loughlin, W.A.; Muderawan, I.W.; McCleary, M.A.; Volter, K.E.; King, M.D. Studies towards the synthesis of phorbazoles A-D: Formation of the pyrrole oxazole skeleton. Aust. J. Chem. 1999, 52, 231-234. [CrossRef]

56. Radspieler, A.; Liebscher, J. Total synthesis of phorbazole C. Tetrahedron 2001, 57, 4867-4871. [CrossRef]

57. Moles, J.; Wägele, H.; Cutignano, A.; Fontana, A.; Ballesteros, M.; Avila, C. Giant embryos and hatchlings of Antarctic nudibranchs (Mollusca: Gastropoda: Heterobranchia). Mar. Biol. 2017, 164, 114. [CrossRef]

58. Gavagnin, M.; De Napoli, A.; Castelluccio, F.; Cimino, G. Austrodorin-A and-B: First tricyclic diterpenoid 2'-monoglyceryl esters from an Antarctic nudibranch. Tetrahedron Lett. 1999, 40, 8471-8475. [CrossRef]

59. Gavagnin, M.; De Napoli, A.; Cimino, G.; Iken, K.; Avila, C.; Garcia, F.J. Absolute configuration of diterpenoid diacylglycerols from the Antarctic nudibranch Austrodoris kerguelenensis. Tetrahedron Asym. 1999, 10, 2647-2650. [CrossRef]

60. Iken, K.; Avila, C.; Fontana, A.; Gavagnin, M. Chemical ecology and origin of defensive compounds in the Antarctic nudibranch Austrodoris kerguelenensis (Opisthobranchia: Gastropoda). Mar. Biol. 2002, 141, 101-109.

61. Carte, B.; Faulkner, D. Role of Secondary Metabolites in Feeding Associations between a Predatory Nudibranch, 2 Grazing Nudibranchs, and a Bryozoan. J. Chem. Ecol. 1986, 12, 795-804. [CrossRef] [PubMed]

62. Davies-Coleman, M.T.; Faulkner, D.J. New diterpenoic acid glycerides from the Antarctic nudibranch Austrodoris kerguelensis. Tetrahedron 1991, 47, 9743-9750. [CrossRef]

63. Gavagnin, M.; Trivellone, E.; Castelluccio, F.; Cimino, G.; Cattaneo-Vietti, R. Glyceryl ester of a new halimane diterpenoic acid from the skin of the antarctic nudibranch Austrodoris kerguelenensis. Tetrahedron Lett. 1995, 36, 7319-7322. [CrossRef]

64. Gavagnin, M.; Carbone, M.; Mollo, E.; Cimino, G. Austrodoral and austrodoric acid: Nor-sesquiterpenes with a new carbon skeleton from the Antarctic nudibranch Austrodoris kerguelenensis. Tetrahedron Lett. 2003, 44, 1495-1498. [CrossRef]

65. Gavagnin, M.; Carbone, M.; Mollo, E.; Cimino, G. Further chemical studies on the Antarctic nudibranch Austrodoris kerguelenensis: New terpenoid acylglycerols and revision of the previous stereochemistry. Tetrahedron 2003, 59, 5579-5583. [CrossRef]

66. Diyabalanage, T.; Iken, K.B.; McClintock, J.B.; Amsler, C.D.; Baker, B.J. Palmadorins A- C, diterpene glycerides from the Antarctic nudibranch Austrodoris kerguelenensis. J. Nat. Prod. 2010, 73, 416-421. [CrossRef] [PubMed]

67. Maschek, J.A.; Mevers, E.; Diyabalanage, T.; Chen, L.; Ren, Y.; McClintock, J.B.; Amsler, C.D.; Wu, J.; Baker, B.J. Palmadorin chemodiversity from the Antarctic nudibranch Austrodoris kerguelenensis and inhibition of Jak2/STAT5-dependent HEL leukemia cells. Tetrahedron 2012, 68, 9095-9104. [CrossRef]

68. Cutignano, A.; Zhang, W.; Avila, C.; Cimino, G.; Fontana, A. Intrapopulation variability in the terpene metabolism of the Antarctic opisthobranch mollusc Austrodoris kerguelenensis. Eur. J. Org. Chem. 2011, 5383-5389. [CrossRef]

69. Wilson, N.G.; Maschek, J.A.; Baker, B.J. A species flock driven by predation? Secondary metabolites support diversification of slugs in Antarctica. PLoS ONE 2013, 8, e80277. [CrossRef]

70. Gavagnin, M.; Fontana, A.; Ciavatta, M.L.; Cimino, G. Chemical studies on Antarctic nudibranch molluscs. Italian J. Zool. 2000, 1, 101-109. [CrossRef]

71. Graziani, E.I.; Andersen, R.J.; Krug, P.J.; Faulkner, D.J. Stable isotope incorporation evidence for the de novo biosynthesis of terpenoic acid glycerides by dorid nudibranchs. Tetrahedron 1996, 52, 6869-6878. [CrossRef]

72. Granato, A.C.; Berlinck, R.G.S.; Magalhaes, A.; Schefer, A.B.; Ferreira, A.G.; De Sanctis, B.; De Freitas, J.C.; Hajdu, E.; Migotto, A.E. Natural products from the marine sponges Aaptos sp. and Hymeniacidon aff. heliophila, and from the nudibranch Doris aff. verrucosa. Quim. Nov. 2000, 23, 594-599.

73. Ayer, S.W.; Andersen, R.J. Steroidal antifeedants from the dorid nudibranch Aldisa sanguinea cooperi. Tetrahedron Lett. 1982, 23, 1039-1042. [CrossRef]

74. Gavagnin, M.; Ungur, N.; Mollo, E.; Templado, J.; Cimino, G. Structure and synthesis of a progesterone homologue from the skin of the dorid nudibranch Aldisa smaragdina. Eur. J. Org. Chem. 2002, 9, 1500-1504. [CrossRef] 
75. Nuzzo, G.; Ciavatta, M.L.; Kiss, R.; Mathieu, V.; Leclercqz, H.; Manzo, E.; Villani, G.; Mollo, E.; Lefranc, F.; D'Souza, L.; et al. Chemistry of the nudibranch Aldisa andersoni: Structure and biological activity of phorbazole metabolites. Mar. Drugs 2012, 10, 1799-1811. [CrossRef]

76. Rudi, A.; Stein, Z.; Green, S.; Goldberg, I.; Kashman, Y.; Benayahu, Y.; Schleyer, M. Phorbazoles A-D, novel chlorinated phenylpyrrolyloxazoles from the marine sponge Phorbas aff. clathrata. Tetrahedron Lett. 1994, 35, 2589-2592. [CrossRef]

77. Mollo, E.; Gavagnin, M.; Carbone, M.; Castelluccio, F.; Pozone, F.; Roussis, V.; Templado, J.; Ghiselin, M.T.; Cimino, G. Factors promoting marine invasions: A chemoecological approach. Proc. Natl. Acad. Sci. USA 2008, 105, 4582-4586. [CrossRef]

78. Krug, P.J.; Boyd, K.G.; Faulkner, D.J. Isolation and synthesis of tanyolides A and B, metabolites of the nudibranch Sclerodoris tanya. Tetrahedron 1995, 51, 11063-11074. [CrossRef]

79. Marín, A.; López-Belluga, M.D.; Scognamiglio, G.; Cimino, G. Morphological and chemical camouflage of the Mediterranean nudibranch Discodoris indecora on the sponges Ircinia variabilis and Ircinia fasciculata. J. Mollus. Stud. 1997, 63, 431-439. [CrossRef]

80. Cimino, G.; De Rosa, S.; De Stefano, S.; Sodano, G.; Villani, G. Dorid nudibranch elaborates its own chemical defense. Science 1983, 219, 1237-1238. [CrossRef] [PubMed]

81. Gavagnin, M.; Mollo, E.; Castelluccio, F.; Ghiselin, M.T.; Calado, G.; Cimino, G. Can molluscs biosynthesize typical sponge metabolites? The case of the nudibranch Doriopsilla areolata. Tetrahedron 2001, 57, 8913-8916. [CrossRef]

82. Kubo, I.; Nakanishi, K. Insect antifeedants and repellents from African plants. In Host Plant Resistance to Pests; ACS Symposium Series; American Chemical Society: Washington, DC, USA, 1977; Volume 62, pp. 165-178.

83. Cimino, G.; De Rosa, S.; De Stefano, S.; Sodano, G. Observations on the toxicity and metabolic relationships of polygodial, the chemical defense of the nudibranch Dendrodoris limbata. Experientia 1985, 41, 1335-1336. [CrossRef]

84. Cimino, G.; Sodano, G.; Spinella, A. Occurrence of olepupuane in two Mediterranean nudibranchs: A protected form of polygodial. J. Nat. Prod. 1988, 51, 1010-1011. [CrossRef] [PubMed]

85. Cimino, G.; De Rosa, S.; De Stefano, S.; Sodano, G. Novel sesquiterpenoid esters from the nudibranch Dendrodoris limbata. Tetrahedron Letters. 1981, 22, 1271-1272. [CrossRef]

86. Sakio, Y.; Hirano, Y.J.; Hayashi, M.; Komiyama, K.; Ishibashi, M. Dendocarbins A-N, new drimane sesquiterpenes from the nudibranch Dendrodoris carbunculosa. J. Nat. Prod. 2001, 64, 726-731. [CrossRef]

87. Fontana, A.; Ciavatta, M.L.; Miyamoto, T.; Spinella, A.; Cimino, G. Biosynthesis of drimane terpenoids in dorid molluscs: Pivotal role of 7-deacetoxyolepupuane in two species of Dendrodoris nudibranchs. Tetrahedron 1999, 55, 5937-5946. [CrossRef]

88. Grkovic, T.; Appleton, D.R.; Copp, B.R. Chemistry and chemical ecology of some of the common opisthobranch molluscs found on the shores of NE New Zealand. Chem. N. Z. 2005, 69, 12-15.

89. Gavagnin, M.; Mollo, E.; Calado, G.; Fahey, S.; Ghiselin, M.T.; Ortea, J.; Cimino, G. Chemical studies of porostome nudibranchs: Comparative and ecological aspects. Chemoecology 2001, 11, 131-136. [CrossRef]

90. Avila, C.; Cimino, G.; Crispino, A.; Spinella, A. Drimane sesquiterpenoids in Mediterranean Dendrodoris nudibranchs: Anatomical distribution and biological role. Experientia 1991, 47, 306-310. [CrossRef]

91. Okuda, R.K.; Scheuer, P.J.; Hochlowski, J.E.; Walker, R.P.; Faulkner, D.J. Sesquiterpenoid constituents of eight porostome nudibranchs. J. Org. Chem. 1983, 48, 1866-1869. [CrossRef]

92. Karuso, P. Chemical ecology of the nudibranchs. In BioorganicMarine Chemistry; Scheuer, P.P.J., Ed.; Bioorganic Marine Chemistry; Springer: Berlin/Heidelberg, Germany, 1987; pp. 31-60.

93. Cimino, G.; Ghiselin, M.T. Chemical defense and evolutionary trends in biosynthetic capacity among Dorid nudibranchs (Mollusca: Gastropoda: Opisthobranchia). Chemoecology 1999, 9, 187-207. [CrossRef]

94. Faulkner, D.J. Marine Natural Products. Nat. Prod. Rep. 2001, 18, 1-49. [CrossRef] [PubMed]

95. Gaspar, H.; Gavagnin, M.; Calado, G.; Castelluccio, F.; Mollo, E.; Cimino, G. Pelseneeriol-1 and-2: New furanosesquiterpene alcohols from porostome nudibranch Doriopsilla pelseneeri. Tetrahedron 2005, 61, 11032-11037. [CrossRef]

96. Fontana, A.; Tramice, A.; Cutignano, A.; d'Ippolito, G.; Gavagnin, M.; Cimino, G. Terpene biosynthesis in the nudibranch Doriopsilla areolata. J. Org. Chem. 2003, 68, 2405-2409. [CrossRef]

97. Spinella, A.; Alvarez, L.A.; Avila, C.; Cimino, G. New acetoxy-ent-pallescensin-A sesquiterpenoids from the skin of the porostome nudibranch Doriopsilla areolata. Tetrahedron Lett. 1994, 35, 8665-8668. [CrossRef] 
98. Long, J.D.; Hay, M.E. Fishes learn aversions to a nudibranch's chemical defense. Mar. Ecol. Progr. Ser. 2006, 307, 199-208. [CrossRef]

99. Gaspar, H.; Cutignano, A.; Ferreira, T.; Calado, G.; Cimino, G.; Fontana, A. Biosynthetic evidence supporting the generation of terpene chemodiversity in marine mollusks of the genus Doriopsilla. J. Nat. Prod. 2008, 71, 2053-2056. [CrossRef]

100. Brunckhorst, D.J. The systematics and phylogeny of phyllidiid nudibranchs (Doridoidea). Rec. Aust. Mus. Suppl. 1993, 16, 1-107. [CrossRef]

101. Fusetani, N.; Wolstenholme, H.J.; Matsunaga, S.; Hirota, H. Two new sesquiterpene isonitriles from the nudibranch Phyllidia pustulosa. Tetrahedron Lett. 1991, 32, 7291-7294. [CrossRef]

102. Okino, T.; Yoshimura, E.; Hirota, H.; Fusetani, N. New antifouling sesquiterpenes from four nudibranchs of the family Phyllidiidae. Tetrahedron 1996, 52, 9447-9454. [CrossRef]

103. Hirota, H.; Okino, T.; Yoshimura, E.; Fusetani, N. Five new antifouling sesquiterpenes from two marine sponges of the genus Axinyssa and the nudibranch Phyllidia pustulosa. Tetrahedron 1998, 54, 13971-13980. [CrossRef]

104. Cimino, G.; Fontana, A.; Gavagnin, M. Marine opisthobranch molluscs: Chemistry and ecology in sacoglossan and dorids. Curr. Org. Chem. 1999, 3, 327-372.

105. Garson, M.J.; Simpson, J.S. Marine isocyanides and related natural products—Structure, biosynthesis and ecology. Nat. Prod. Rep. 2004, 21, 164-179. [CrossRef]

106. Burreson, B.J.; Scheuer, P.J.; Finer, J.; Clardy, J. 9-Isocyanopupukeanane, a marine invertebrate allomone with a new sesquiterpene skeleton. J. Am. Chem. Soc. 1975, 97, 4763-4764. [CrossRef]

107. Hagadone, M.R.; Burreson, B.J.; Scheuer, P.J.; Finer, J.S.; Clardy, J. Defense allomones of the nudibranch Phyllidia varicosa Lamarck 1801. Helv. Chim. Acta 1979, 62, 2484-2494. [CrossRef]

108. Ungur, N.; Gavagnin, M.; Fontana, A.; Cimino, G. Absolute stereochemistry of natural sesquiterpenoid diacylglycerols. Tetrahedron Asymmetry 1999, 10, 1263-1273. [CrossRef]

109. Ritson-Williams, R.; Paul, V.J. Marine benthic invertebrates use multimodal cues for defense against reef fish. Mar. Ecol. Progr. Ser. 2007, 340, 29-39. [CrossRef]

110. Yasman, Y.; Edrada, R.A.; Wray, V.; Proksch, P. New 9-thiocyanatopupukeanane sesquiterpenes from the nudibranch Phyllidia varicosa and its sponge-prey Axinyssa aculeata. J. Nat. Prod. 2003, 66, 1512-1514. [CrossRef]

111. Jaisamut, S.; Prabpai, S.; Tancharoen, C.; Yuenyongsawad, S.; Hannongbua, S.; Kongsaeree, P.; Plubrukarn, A. Bridged tricyclic sesquiterpenes from the tubercle nudibranch Phyllidia coelestis Bergh. J. Nat. Prod. 2013, 76, 2158-2161. [CrossRef]

112. Sim, D.C.-M.; Mudianta, I.W.; White, A.M.; Martiningsih, N.W.; Loh, J.J.M.; Cheney, K.L.; Garson, M.J. New sesquiterpenoid isonitriles from three species of phyllidid nudibranchs. Fitoterapia 2018, 126, 69-73. [CrossRef] [PubMed]

113. Iwashima, M.; Terada, I.; Iguchi, K.; Yamori, T. New biologically active marine sesquiterpenoid and steroid from the Okinawan sponge of the genus Axinyssa. Chem. Pharm. Bull. 2002, 50, 1286-1289. [CrossRef] [PubMed]

114. Gulavita, N.K.; De Silva, E.D.; Hagadone, M.R.; Karuso, P.; Scheuer, P.J.; van Duyne, G.D.; Clardy, J. Nitrogenous bisabolene sesquiterpenes from marine invertebrates. J. Org. Chem. 1986, 51, 5136-5139. [CrossRef]

115. Kitano, Y.; Ito, T.; Suzuki, T.; Nogata, Y.; Shinshima, K.; Yoshimura, E.; Chiba, K.; Tada, M.; Sakaguchi, I. (2002) Synthesis and antifouling activity of 3-isocyanotheonellin and its analogues. J. Chem. Soc. Perkin Trans. 2002, 1, 2251-2255. [CrossRef]

116. Fusetani, N.; Hirota, H.; Okino, T.; Tomono, Y.; Yoshimura, E. Antifouling activity of isocyanoterpenoids and related compounds isolated from a marine sponge and nudibranchs. J. Nat. Toxins 1996, 5, 249-259.

117. Wu, Q.; Chen, W.-T.; Li, S.-W.; Ye, J.-Y.; Huan, X.-J.; Gavagnin, M.; Yao, L.-G.; Wang, H.; Miao, Z.-H.; Li, X.-W.; et al. Cytotoxic nitrogenous terpenoids from two South China Sea nudibranchs Phyllidiella pustulosa, Phyllidia coelestis, and their sponge-prey Acanthella cavernosa. Mar. Drugs 2019, 17, 56. [CrossRef]

118. Wright, A.D. GC-MS and NMR analysis of Phyllidiella pustulosa and one of its dietary sources, the sponge Phakellia carduus. Comp. Biochem. Physiol. 2003, 134A, 307-313. [CrossRef] 
119. Dumdei, E.J.; Flowers, A.E.; Garson, M.J.; Moore, C.J. The biosynthesis of sesquiterpene isocyanides and isothiocyanates in the marine sponge Acanthella cavernosa (Dendy); evidence for dietary transfer to the dorid nudibranch Phyllidiella pustulosa. Comp. Biochem. Physiol. 1997, 118, 1385-1392. [CrossRef]

120. Manzo, E.; Ciavatta, M.L.; Gavagnin, M.; Mollo, E.; Guo, Y.-W.; Cimino, G. Isocyanide terpene metabolites of Phyllidiella pustulosa, a nudibranch from the South China Sea. J. Nat. Prod. 2004, 67, 1701-1704. [CrossRef]

121. Shimomura, M.; Miyaoka, H.; Yamada, Y. Absolute configuration of marine diterpenoid kalihinol A. Tetrahedron Lett. 1999, 40, 8015-8017. [CrossRef]

122. Lyakhova, E.G.; Kolesnikova, S.A.; Kalinovskii, A.I.; Stonik, V.A. Secondary metabolites of the Vietnamese nudibranch mollusc Phyllidiella pustulosa. Chem. Nat. Comp. 2010, 46, 534-538. [CrossRef]

123. Fisch, K.M.; Hertzer, C.; Böhringer, N.; Wuisan, Z.G.; Schillo, D.; Bara, R.; Kaligis, F.; Wägele, H.; König, G.M.; Schäberle, T.F. The potential of Indonesian heterobranchs found around Bunaken Island for the production of bioactive compounds. Mar. Drugs 2017, 15, 384. [CrossRef] [PubMed]

124. Wägele, H.; Ballesteros, M.; Avila, C. Defensive glandular structures in opisthobranch molluscs-from histology to ecology. Oceanogr. Mar. Biol. 2006, 44, 197.

125. Johnson, R.F.; Gosliner, T.M. Traditional taxonomic groupings mask evolutionary history: A molecular phylogeny and new classification of the chromodorid nudibranchs. PLoS ONE 2012, 7, e33479. [CrossRef]

126. Thompson, J.E.; Walker, R.P.; Wratten, S.J.; Faulkner, D.J. A chemical defense mechanism for the nudibranch Cadlina luteomarginata. Tetrahedron 1982, 38, 1865-1873. [CrossRef]

127. Faulkner, D.J.; Molinski, T.F.; Andersen, R.J.; Dumdei, E.J.; De Silva, E.D. Geographical variation in defensive chemicals from Pacific coast dorid nudibranchs and some related marine molluscs. Comp. Biochem. Physiol. C Toxicol. Pharmacol. 1990, 97, 233-240. [CrossRef]

128. Kubanek, J.; Graziani, E.I.; Andersen, R.J. Investigations of terpenoid biosynthesis by the dorid nudibranch Cadlina luteomarginata. J. Org. Chem. 1997, 62, 7239-7246. [CrossRef]

129. Hellou, J.; Andersen, R.J.; Thompson, J.E. Terpenoids from the dorid nudibranch Cadlina luteomarginata. Tetrahedron 1982, 38, 1875-1879. [CrossRef]

130. Dumdei, E.J.; Kubanek, J.; Coleman, J.E.; Pika, J.; Andersen, R.J.; Steiner, J.R.; Clardy, J. New terpenoid metabolites from the skin extracts, an egg mass, and dietary sponges of the Northeastern Pacific dorid nudibranch Cadlina luteomarginata. Can. J. Chem. 1997, 75, 773-789. [CrossRef]

131. Carbone, M.; Gavagnin, M.; Haber, M.; Guo, Y.-W.; Fontana, A.; Manzo, E.; Genta-Jouve, G.; Tsoukatou, M.; Rudman, W.B.; Cimino, G.; et al. Packaging and delivery of chemical weapons: A defensive trojan horse stratagem in Chromodorid nudibranchs. PLoS ONE 2013, 8, e62075. [CrossRef]

132. Hochlowski, J.E.; Faulkner, D.J. Chemical constituents of the nudibranch Chromodoris marislae. Tetrahedron Lett. 1981, 22, 271-274. [CrossRef]

133. Schulte, G.R.; Scheuer, P.J. Defense allomones of some marine mollusks. Tetrahedron 1982, 38, $1857-1863$. [CrossRef]

134. Hochlowski, J.E.; Faulkner, D.J.; Matsumoto, G.K.; Clardy, J. Norrisolide, a novel diterpene from the dorid nudibranch Chromodoris norrisi. J. Org. Chem. 1983, 48, 1141-1142. [CrossRef]

135. Bergquist, P.R.; Bowden, B.F.; Cambie, R.C.; Craw, P.A.; Karuso, P.; Poiner, A.; Taylor, W.C. The constituents of marine sponges. VI. Diterpenoid metabolites of the New Zealand sponge Chelonaplysilla violacea. Aust. J. Chem. 1993, 46, 623-632. [CrossRef]

136. Okuda, R.K.; Scheuer, P.J. Latrunculin-A, ichthyotoxic constituent of the nudibranch Chromodoris elisabethina. Experientia 1985, 41, 1355-1356. [CrossRef]

137. Carte, B.; Kernan, M.R.; Barrabee, E.B.; Faulkner, D.J.; Matsumoto, G.K.; Clardy, J. Metabolites of the nudibranch Chromodoris funerea and the singlet oxygen oxidation products of furodysin and furodysinin. J. Org. Chem. 1986, 51, 3528-3532. [CrossRef]

138. Kimura, J.; Hyosu, M. Two new sesterterpenes from the marine sponge, Coscinoderma mathewsi. Chem. Lett. 1999, 28, 61-62. [CrossRef]

139. Molinski, T.F.; Faulkner, D.J. Aromatic norditerpenes from the nudibranch Chromodoris macfarlandi. J. Org. Chem. 1986, 51, 2601-2603. [CrossRef]

140. Molinski, T.F.; Faulkner, D.J.; He, C.H.; Van Duyne, G.D.; Clardy, J. Three new rearranged spongian diterpenes from Chromodoris macfarlandi: Reappraisal of the structures of dendrillolides A and B. J. Org. Chem. 1986, 51, 4564-4567. [CrossRef] 
141. Kakou, Y.; Crews, P.; Bakus, G.J. Dendrolasin and latrunculin A from the Fijian sponge Spongia mycofijiensis and an associated nudibranch Chromodoris lochi. J. Nat. Prod. 1987, 50, 482-484. [CrossRef]

142. Corley, D.G.; Herb, R.; Moore, R.E.; Scheuer, P.J.; Paul, V.J. Laulimalides. New potent cytotoxic macrolides from a marine sponge and a nudibranch predator. J. Org. Chem. 1988, 53, 3644-3646. [CrossRef]

143. Kernan, M.R.; Barrabee, E.B.; Faulkner, D.J. Variation of the metabolites of Chromodoris funerea: Comparison of specimens from a Palauan marine lake with those from adjacent waters. Comp. Biochem. Physiol. B Comp. Biochem. 1988, 89, 275-278. [CrossRef]

144. Bobzin, S.C.; Faulkner, D.J. Diterpenes from the marine sponge Aplysilla polyrhaphis and the dorid nudibranch Chromodoris norrisi. J. Org. Chem. 1989, 54, 3902-3907. [CrossRef]

145. Dumdei, E.J.; De Silva, E.D.; Andersen, R.J.; Choudhary, M.I.; Clardy, J. Chromodorolide A, a rearranged diterpene with a new carbon skeleton from the Indian ocean nudibranch Chromodoris cavae. J. Am. Chem. Soc. 1989, 111, 2712-2713. [CrossRef]

146. Cimino, G.; Crispino, A.; Gavagnin, M.; Sodano, G. Diterpenes from the nudibranch Chromodoris luteorosea. J. Nat. Prod. 1990, 53, 102-106. [CrossRef]

147. de Silva, E.D.; Morris, S.A.; Miao, S.; Dumdei, E.; Andersen, R.J. Terpenoid metabolites from skin extracts of four Sri Lankan Nudibranchs in the Genus Chromodoris. J. Nat. Prod. 1991, 54, 993-997. [CrossRef]

148. Morris, S.A.; Silva, E.D.D.; Andersen, R.J. Chromodorane diterpenes from the tropical dorid nudibranch Chromodoris cavae. Can. J. Chem. 1991, 69, 768-771. [CrossRef]

149. Gavagnin, M.; Vardaro, R.R.; Avila, C.; Cimino, G.; Ortea, J. Ichthyotoxic diterpenoids from the Cantabrian nudibranch Chromodoris luteorosea. J. Nat. Prod. 1992, 55, 368-371. [CrossRef]

150. Chi, Y.; Hashimoto, F.; Nohara, T.; Nakamura, M.; Yoshizawa, T.; Yamashita, M.; Marubayashi, N. Tennen Yuki Kagobutsu Toronkai Koen Yoshishu. Available online: https://www.scienceopen.com/document?vid= 294f7cd1-f803-4b53-907a-bc3edf8ab46e (accessed on 11 November 2020).

151. Miyamoto, T.; Sakamoto, K.; Amano, H.; Higuchi, R.; Komori, T.; Sasaki, T. Three new cytotoxic sesterterpenoids, inorolide A, B, and C from the nudibranch Chromodoris inornata. Tetrahedron Lett. 1992, 33, 5811-5814. [CrossRef]

152. Puliti, R.A.; Gavagnin, M.A.; Cimino, G.U.; Mattia, C.A.; Mazzarella, L.E. Structure of chelonaplysin C: A spongian diterpenoid from nudibranch Chromodoris luteorosea. Acta Crystallogr. C 1992, 48, $2145-2147$. [CrossRef]

153. Pika, J.; Faulkner, D.J. Unusual chlorinated homo-diterpenes from the South African nudibranch Chromodoris hamiltoni. Tetrahedron 1995, 51, 8189-8198. [CrossRef]

154. Miyamoto, T.; Sakamoto, K.; Arao, K.; Komori, T.; Higuchi, R.; Sasaki, T. Dorisenones, cytotoxic spongian diterpenoids, from the nudibranch Chromodoris obsoleta. Tetrahedron 1996, 52, 8187-8198. [CrossRef]

155. McPhail, K.L.; Davies-Coleman, M.T. New spongiane diterpenes from the East African nudibranch Chromodoris hamiltoni. Tetrahedron 1997, 53, 4655-4660. [CrossRef]

156. Miyamoto, T.; Sakamoto, K.; Amano, H.; Arakawa, Y.; Nagarekawa, Y.; Komori, T.; Higuchi, R.; Sasaki, T. New cytotoxic sesterterpenoids from the nudibranch Chromodoris inornata. Tetrahedron 1999, 55, 9133-9142. [CrossRef]

157. Karuso, P.; Scheuer, P.J. Natural products from three nudibranchs: Nembrotha kubaryana, Hypselodoris infucata and Chromodoris petechialis. Molecules 2002, 7, 1-6. [CrossRef]

158. Yong, K.W.; Salim, A.A.; Garson, M.J. New oxygenated diterpenes from an Australian nudibranch of the genus Chromodoris. Tetrahedron 2008, 64, 6733-6738. [CrossRef]

159. Uddin, M.H.; Otsuka, M.; Muroi, T.; Ono, A.; Hanif, N.; Matsuda, S.; Higa, T.; Tanaka, J. Deoxymanoalides from the nudibranch Chromodoris willani. Chem. Pharm. Bull. 2009, 57, 885-887. [CrossRef]

160. Agena, M.; Tanaka, C.; Hanif, N.; Yasumoto-Hirose, M.; Tanaka, J. New cytotoxic spongian diterpenes from the sponge Dysidea cf. arenaria. Tetrahedron 2009, 65, 1495-1499. [CrossRef]

161. Suciati, S.; Lambert, L.K.; Garson, M.J. Structures and anatomical distribution of oxygenated diterpenes in the Australian nudibranch Chromodoris reticulata. Aust. J. Chem. 2011, 64, 757-765. [CrossRef]

162. Katavic, P.L.; Jumaryatno, P.; Hooper, J.N.; Blanchfield, J.T.; Garson, M.J. Oxygenated terpenoids from the Australian sponges Coscinoderma matthewsi and Dysidea sp., and the nudibranch Chromodoris albopunctata. Aust. J. Chem. 2012, 65, 531-538. [CrossRef] 
163. Katavic, P.L.; Jumaryatno, P.; Hooper, J.N.; Blanchfield, J.T.; Garson, M.J. Note of clarification about: Oxygenated Terpenoids from the Australian Sponges Coscinoderma matthewsi and Dysidea sp., and the Nudibranch Chromodoris albopunctata. Aust. J. Chem. 2013, 66, 1461.

164. Cheney, K.L.; White, A.; Mudianta, I.W.; Winters, A.E.; Quezada, M.; Capon, R.J.; Mollo, E.; Garson, M.J. Choose your weaponry: Selective storage of a single toxic compound, latrunculin A, by closely related nudibranch molluscs. PLoS ONE 2016, 11, e0145134. [CrossRef]

165. Schulte, G.; Scheuer, P.J.; McConnell, O.J. Two furanosesquiterpene marine metabolites with antifeedant properties. Helv. Chim. Acta 1980, 63, 2159-2167. [CrossRef]

166. Fontana, A.; Ciavatta, M.L.; D'Souza, L.; Mollo, E.; Naik, C.G.; Parameswaran, P.S.; Wahidulla, S.; Cimino, G. Selected chemo-ecological studies of marine opisthobranchs from Indian coasts. J. Indian Inst. Sci. 2001, 81, 403-415.

167. Tanaka, J.; Higa, T. The absolute configuration of kurospongin a new furanoterpene from a marine sponge, Spongia sp. Tetrahedron 1988, 44, 2805-2810. [CrossRef]

168. Kashman, Y.; Croweiss, A.; Shmueli, U. Latrunculin, a new 2-thiazolidinone macrolide from the marine sponge Latrunculia magnifica. Tetrahedron Lett. 1980, 21, 3629-3632. [CrossRef]

169. Kashman, Y.; Croweiss, A.; Kidor, R.; Blasberger, D.; Carmelya, S. Latrunculins: NMR study, two new toxins and a synthetic approach. Tetrahedron 1985, 41, 1905-1914. [CrossRef]

170. Guo, Y.W. Chemical Studies of the Novel Bioactive Secondary Metabolites from the Benthic Invertebrates: Isolation and Structure Characterization. Ph.D. Thesis, University of Naples, Naples, Italy, 1997.

171. Mebs, D. Chemical defense of a dorid nudibranch, Glossodoris quadricolor, from the Red Sea. J. Chem. Ecol. 1985, 11, 713-716. [CrossRef] [PubMed]

172. Jefford, C.W.; Bernardinelli, G.; Tanaka, J.I.; Higa, T. Structures and absolute configurations of the marine toxins, latrunculin A and laulimalide. Tetrahedron Lett. 1996, 37, 159-162. [CrossRef]

173. Ghosh, A.K.; Wang, Y. Total synthesis of (-)-laulimalide. J. Am. Chem. Soc. 2000, 122, 11027-11028. [CrossRef]

174. Gollner, A.; Mulzer, J. Total synthesis of neolaulimalide and isolaulimalide. Organic Lett. 2008, 10, 4701-4704. [CrossRef] [PubMed]

175. Manzo, E.; Gavagnin, M.; Somerville, M.J.; Mao, S.-C.; Ciavatta, M.L.; Mollo, E.; Schupp, P.J.; Garson, M.J.; Guo, V.; Cimino, G. Chemistry of Glossodoris nudibranchs: Specific occurrence of 12-keto scalaranes. J. Chem. Ecol. 2007, 33, 2325-2336. [CrossRef] [PubMed]

176. Rogers, S.D.; Paul, V.J. Chemical defenses of three Glossodoris nudibranchs and their dietary Hyrtios sponges. Mar. Ecol. Progr. Ser. 1991, 77, 221-232. [CrossRef]

177. Avila, C.; Paul, V.J. Chemical ecology of the nudibranch Glossodoris pallida: Is the location of diet-derived metabolites important for defense? Mar. Ecol. Progr. Ser. 1997, 150, 171-180. [CrossRef]

178. Winters, A.E.; White, A.M.; Dewi, A.S.; Mudianta, I.W.; Wilson, N.G.; Forster, L.C.; Garson, M.J.; Cheney, K.L. Distribution of defensive metabolites in nudibranch molluscs. J. Chem. Ecol. 2018, 44, 384-396. [CrossRef]

179. Zhukova, N.V. Lipids and fatty acids of nudibranch molluscs: Potential sources of bioactive compounds. Mar. Drugs 2014, 12, 4578-4592. [CrossRef]

180. Li, X.L.; Li, S.W.; Yao, L.G.; Mollo, E.; Gavagnin, M.; Guo, Y.W. The chemical and chemo-ecological studies on Weizhou nudibranch Glossodoris atromarginata. Magn Reson Chem. 2019, 1-7. [CrossRef]

181. Somerville, M.J.; Mollo, E.; Cimino, G.; Rungprom, W.; Garson, M.J. Spongian diterpenes from Australian nudibranchs: An anatomically guided chemical study of Glossodoris atromarginata. J. Nat. Prod. 2007, 70, 1836. [CrossRef]

182. Yong, K.W.; Mudianta, I.W.; Cheney, K.L.; Mollo, E. : Blanchfield, J.T.; Garson, M.J. Isolation of norsesterterpenes and spongian diterpenes from Dorisprismatica (=Glossodoris) atromarginata. J. Nat. Prod. 2015, 78, 421-430. [CrossRef]

183. Fontana, A.; Mollo, E.; Ortea, J.; Gavagnin, M.; Cimino, G. Scalarane and homoscalarane compounds from the nudibranchs Glossodoris sedna and Glossodoris dalli: Chemical and biological properties. J. Nat. Prod. 2000, 63, 527-530. [CrossRef]

184. Cimino, G.; De Rosa, S.; De Stefano, S.; Sodano, G. The chemical defense of four Mediterranean nudibranchs. Comp. Biochem. Physiol. B Comp. Biochem. 1982, 73, 471-474. [CrossRef]

185. Forster, L.C.; Winters, A.E.; Cheney, K.L.; Dewapriya, P.; Capon, R.J.; Garson, M.J. Spongian-16-one diterpenes and their anatomical distribution in the Australian nudibranch Goniobranchus collingwoodi. J. Nat. Prod. 2017, 80, 670-675. [CrossRef] [PubMed] 
186. Mudianta, W.; White, A.M.; Suciati, P.L.K.; Krishnaraj, R.R.; Winters, A.E.; Mollo, E.; Cheney, K.L.; Garson, M.J. Chemoecological studies on marine natural products: Terpene chemistry from marine mollusks. Pure Appl. Chem. 2014, 86, 995-1002. [CrossRef]

187. Winters, A.E.; White, A.M.; Cheney, K.L.; Garson, M.J. Geographic variation in diterpene-based secondary metabolites and level of defence in an aposematic nudibranch, Goniobranchus splendidus. J. Moll. Stud. 2019, 85, 133-142. [CrossRef]

188. Winters, A.E.; Green, N.F.; Wilson, N.G.; How, M.J.; Garson, M.J.; Marshall, N.J.; Cheney, K.L. Stabilizing selection on individual pattern elements of aposematic signals. Proc. R. Soc. B 2017, 284, 20170926. [CrossRef] [PubMed]

189. White, A.M.; Dewi, A.S.; Cheney, K.L.; Winters, A.E.; Blanchfield, J.T.; Garson, M.J. Oxygenated diterpenes from the Indo-Pacific nudibranchs Goniobranchus splendidus and Ardeadoris egretta. Nat. Prod. Commun. 2016, 11, 921-924. [CrossRef]

190. Hirayama, Y.; Katavic, P.L.; White, A.M.; Pierens, G.K.; Lambert, L.K.; Winters, A.E.; Kigoshi, H.; Kita, M.; Garson, M.J. New cytotoxic norditerpenes from the Australian nudibranchs Goniobranchus splendidus and Goniobranchus daphne. Aust. J. Chem. 2016, 69, 136-144. [CrossRef]

191. Mudianta, I.W.; White, A.M.; Garson, M.J. Oxygenated Terpenes from Indo-Pacific nudibranchs: Scalarane sesterterpenes from Glossodoris hikuerensis and 12-Acetoxy dendrillolide A from Goniobranchus albonares. Nat. Prod. Commun. 2015, 10, 865-868. [CrossRef]

192. White, A.M.; Pierens, G.K.; Forster, L.C.; Winters, A.E.; Cheney, K.L.; Garson, M.J. Rearranged diterpenes and norditerpenes from three Australian Goniobranchus mollusks. J. Nat. Prod. 2016, 79, 477-483. [CrossRef]

193. Mollo, E.; Gavagnin, M.; Carbone, M.; Guo, Y.-W.; Cimino, G. Chemical studies on Indopacific Ceratosoma nudibranchs illuminate the protective role of their dorsal horn. Chemoecology 2005, 15, 31-36. [CrossRef]

194. Cimino, G.; De Stefano, S.; Guerriero, A.; Minale, L. Furanosesquiterpenoids in sponges-III. Pallescensins AD from Disidea pallescens: New skeletal types. Tetrahedron Lett. 1975, 16, 1425-1428. [CrossRef]

195. Kazlauskas, R.; Murphy, P.T.; Wells, R.J.; Daly, J.J.; Schönholzer, P. Two sesquiterpene furans with new carbocyclic ring systems and related thiol acetates from a species of the sponge genus Dysidea. Tetrahedron Lett. 1978, 19, 4951-4954. [CrossRef]

196. Cameron, G.M.; Stapleton, B.L.; Simonsen, S.M.; Brecknell, D.J.; Garson, M.J. New sesquiterpene and brominated metabolites from the tropical marine sponge Dysidea sp. Tetrahedron 2000, 56, 5247-5252. [CrossRef]

197. Charles, C.; Braekman, J.C.; Daloze, D.; Tursch, B.; Declercq, J.P.; Germain, G.; Van Meerssche, M. Chemical studies of marine invertebrates. XXXIV. Herbadysidolide and herbasolide, two unusual sesquiterpenoids from the sponge Dysidea herbacea. Bull. Soc. Chim. Belg. 1978, 87, 481-486. [CrossRef]

198. Fontana, A.; Avila, C.; Martinez, E.; Ortea, J.; Trivellone, E.; Cimino, G. Defensive allomones in three species of Hypselodoris (gastropoda: Nudibranchia) from the Cantabrian sea. J. Chem. Ecol. 1993, 19, 339-356. [CrossRef]

199. Hochlowski, J.E.; Walker, R.P.; Ireland, C.; Faulkner, D.J. Metabolites of four nudibranchs of the genus Hypselodoris. J. Org. Chem. 1982, 47, 88-91. [CrossRef]

200. Grode, S.H.; Cardellina, J.H. Sesquiterpenes from the sponge Dysidea etheria and the nudibranch Hypselodoris zebra. J. Nat. Prod. 1984, 47, 76-83. [CrossRef]

201. García-Gómez, J.C.; Cimino, G.; Medina, A. Studies on the defensive behaviour of Hypselodoris species (Gastropoda: Nudibranchia): Ultrastructure and chemical analysis of mantle dermal formations (MDFs). Mar. Biol. 1990, 106, 245-250. [CrossRef]

202. Avila, C.; Cimino, G.; Fontana, A.; Gavagnin, M.; Ortea, J.; Trivellone, E. Defensive strategy of two Hypselodoris nudibranchs from Italian and Spanish coasts. J. Chem. Ecol. 1991, 17, 625-636. [CrossRef]

203. Cimino, G.; Fontana, A.; Giménez, F.; Marin, A.; Mollo, E.; Trivellone, E.; Zubia, E. Biotransformation of a dietary sesterterpenoid in the Mediterranean nudibranch Hypselodoris orsini. Experientia 1993, 49, 582-586. [CrossRef]

204. Fontana, A.; Trivellone, E.; Mollo, E.; Cimino, G.; Avila, C.; Martinez, E.; Ortea, J. Further chemical studies of Mediterranean and Atlantic Hypselodoris nudibranchs: A new furanosesquiterpenoid from Hypsdodoris webbi. J. Nat. Prod. 1994, 57, 510-513. [CrossRef] 
205. Haber, M.; Cerfeda, S.; Carbone, M.; Calado, G.; Gaspar, H.; Neves, R.; Maharajan, V.; Cimino, G.; Gavagnin, M.; Ghiselin, M.T.; et al. Coloration and defense in the nudibranch gastropod Hypselodoris fontandraui. Biol. Bull. 2010, 218, 181-188. [CrossRef] [PubMed]

206. Da Cruz, J.F.; Gaspar, H.; Calado, G. Turning the game around: Toxicity in a nudibranch-sponge predator-prey association. Chemoecology 2012, 22, 47-53. [CrossRef]

207. Pereira, F.R.; Berlinck, R.G.S.; Rodrigues Filho, E.; Veloso, K.; Ferreira, A.G.; Padula, V. Metabólitos secundários dos nudibrânquios Tambja stegosauriformis, Hypselodoris lajensis e Okenia zoobotryon e dos briozoários Zoobotryon verticillatum e Bugula dentata da costa do Brasil. Quim. Nova 2012, 35, 2194-2201. [CrossRef]

208. Cimino, G.; De Stefano, S.; Minale, L.; Trivellone, E. Furanosesquiterpenoids in sponges-V: Spiniferins from Pleraplysilla spinifera. Tetrahedron Lett. 1975, 16, 3727-3730. [CrossRef]

209. Mudianta, I.W.; Challinor, V.L.; Winters, A.E.; Cheney, K.L.; De Voss, J.J.; Garson, M.J. Synthesis and determination of the absolute configuration of $(-)-(5 \mathrm{R}, 6 \mathrm{Z})$-dendrolasin-5-acetate from the nudibranch Hypselodoris jacksoni. Beilstein J. Org. Chem. 2013, 9, 2925-2933. [CrossRef]

210. Avila, C. Substancias Naturales de Moluscos Opistobranquios: Estudio de su Estructura, Origen y Función en Ecosistemas Bentónicos. Ph.D. Thesis, University of Barcelona, Barcelona, Catalonia, Spain, 1993.

211. Avila, C.; Durfort, M. Histology of epithelia and mantle glands of selected species of doridacean mollusks with chemical defensive strategies. Veliger 1996, 39, 148-163.

212. Gaspar, H.; Rodrigues, A.I.; Calado, G. Comparative study of chemical defences from two allopatric north Atlantic subspecies of Hypselodoris picta (Mollusca: Opisthobranchia). Açoreana 2009, 6, 137-143.

213. McPhail, K.L.; Davies-Coleman, M.T.; Coetzee, P. A new furanosesterterpene from the South African nudibranch Hypselodoris capensis and a Dictyoceratida sponge. J. Nat. Prod. 1998, 61, 961-964. [CrossRef]

214. Mudianta, W.I.; Martiningsih, N.W.; Dodik Prasetia, I.N.; Nursid, M. Bioactive terpenoid from the balinese nudibranch Hypselodoris infucata. Indones. J. Pharm. 2016, 27, 104-110. [CrossRef]

215. Guella, G.; Mancini, I.; Guerriero, A.; Pietra, F. New furano-sesquiterpenoids from Mediterranean sponges. Helv. Chim. Acta 1985, 68, 1276-1282. [CrossRef]

216. Fontana, A.; Muniaín, C.; Cimino, G. First chemical study of patagonian nudibranchs: A new seco-11, 12-spongiane, tyrinnal, from the defensive organs of Tyrinna nobilis. J. Nat. Prod. 1998, 61, 1027-1029. [CrossRef] [PubMed]

217. Matsunaga, S.; Fusetani, N.; Hashimoto, K.; Koseki, K.; Noma, M. Bioactive marine metabolites. J. Ame. Chem. Soc. 1986, 13, 847-849. [CrossRef]

218. Pawlik, J.R.; Kernan, M.R.; Molinski, T.F.; Harper, M.K.; Faulkner, D.J. Defensive chemicals of the Spanish dancer nudibranch Hexabranchus sanguineus and its egg ribbons: Macrolides derived from a sponge diet. J. Exp. Mar. Biol. Ecol. 1988, 119, 99-109. [CrossRef]

219. Dalisay, D.S.; Rogers, E.W.; Edison, A.S.; Molinski, T.F. Trisoxazole macrolides and thiazole-containing cyclic peptides from the nudibranch Hexabranchus sanguineus. J. Nat. Prod. 2009, 72, 732-738. [CrossRef] [PubMed]

220. Matsunaga, S.; Fusetani, N.; Hashimoto, K.; Koseki, K.; Noguchi, H.; Noma, M.; Sankawa, U. Bioactive marine metabolites, part 25. Further kabiramides and halichondramides cytotoxic peptides from Hexabranchus egg masses. J. Org. Chem. 1989, 54, 1360-1363. [CrossRef]

221. Kernan, M.R.; Molinski, T.F.; Faulkner, D.J. Macrocyclic antifungal metabolites from the Spanish dancer nudibranch Hexabranchus sanguineus and sponges of the genus Halichondria. J. Org. Chem. 1988, 53, 5014-5020. [CrossRef]

222. Roesener, J.A.; Scheuer, P.J. Ulapualide A and B, extraordinary antitumor macrolides from nudibranch eggmasses. J. Am. Chem. Soc. 1986, 108, 846-847. [CrossRef]

223. Carté, B.; Faulkner, D.J. Defensive metabolites from three nembrothid nudibranchs. J. Org. Chem. 1983, 48, 2314-2318. [CrossRef]

224. Granato, A.C.; de Oliveira, J.H.; Seleghim, M.H.; Berlinck, R.G.; Macedo, M.L.; Ferreira, A.G.; Rocha, R.M.D.; Hajdu, E.; Peixinho, S.; Pessoa, C.O.; et al. Produtos naturais da ascidia Botrylloides giganteum, das esponjas Verongula gigantea, Ircinia felix, Cliona delitrix e do nudibrânquio Tambja eliora, da costa do Brasil. Quim. Nova 2005, 28, 192-198. [CrossRef]

225. Blackman, A.J.; Li, C.P. New tambjamine alkaloids from the marine bryozoan Bugula dentata. Aust. J. Chem. 1994, 47, 1625-1629. [CrossRef]

226. Paul, V.; Lindquist, N.; Fenical, W. Chemical defenses of the tropical ascidian Atapozoa sp. and its nudibranch predators Nembrotha spp. Mar. Ecol. Prog. Ser. 1990, 59, 109-111. [CrossRef] 
227. Lindquist, N.; Fenical, W. New tamjamine class alkaloids from the marine ascidian Atapozoa sp. and its nudibranch predators. Origin of the tambjamines in Atapozoa. Experientia 1991, 47, 504-506. [CrossRef]

228. Carbone, M.; Irace, C.; Costagliola, F.; Castelluccio, F.; Villani, G.; Calado, G.; Padula, V.; Cimino, G.; Cervera, J.L.; Santamaria, R.; et al. A new cytotoxic tambjamine alkaloid from the Azorean nudibranch Tambja ceutae. Bioorg. Med. Chem. Lett. 2010, 20, 2668-2670. [CrossRef] [PubMed]

229. Cronin, G.; Hay, M.; Fenical, W.; Lindquist, N. Distribution, density, and sequestration of host chemical defenses by the specialist nudibranch Tritonia hamnerorum found at high densities on the sea fan Gorgonia ventalina. Mar. Ecol. Prog. Ser. 1995, 119, 177-189. [CrossRef]

230. McClintock, J.B.; Bryan, P.J.; Slattery, M.; Baker, B.J.; Yoshida, W.Y.; Hamann, M.; Heine, J.N. Chemical ecology of three Antarctic gastropods. Antarct. J. 1994, 29, 151-154.

231. McClintock, J.B.; Baker, B.J.; Slattery, M.; Heine, J.N.; Bryan, P.J.; Yoshida, W.; Davies-Coleman, M.T.; Faulkner, D.J. Chemical defense of common Antarctic shallow-water nudibranch Tritoniella belli Eliot (Mollusca: Tritonidae) and its prey, Clavularia frankliniana Rouel (Cnidaria: Octocorallia). J. Chem. Ecol. 1994, 20, 3361-3372. [CrossRef]

232. Bryan, P.J.; McClintock, J.B.; Baker, B.J. Population biology and antipredator defenses of the shallow-water Antarctic nudibranch Tritoniella belli. Mar. Biol. 1998, 132, 259-265. [CrossRef]

233. McClintock, J.B.; Baker, B.J. Palatability and chemical defense in the eggs, embryos and larvae of shallow-water Antarctic marine invertebrates. Mar. Ecol. Progr. Ser. 1997, 154, 121-131. [CrossRef]

234. Ciavatta, M.L.; Manzo, E.; Mollo, E.; Mattia, C.A.; Tedesco, C.; Irace, C.; Guo, Y.-W.; Li, X.-B.; Cimino, G.; Gavagnin, M. Tritoniopsins A-D, cladiellane-based diterpenes from the south china sea nudibranch Tritoniopsis elegans and its prey Cladiella krempfi. J. Nat. Prod. 2011, 74, 1902-1907. [CrossRef]

235. Affeld, S.; Wägele, H.; Avila, C.; Kehraus, S.; König, G.M. Distribution of homarine in some Opisthobranchia (Gastropoda: Mollusca). Bonn. Zool. Beitr. 2007, 55, 181-190.

236. McClintock, J.B.; Baker, B.J.; Hamann, M.T.; Yoshida, W.; Slattery, M.; Heine, J.N.; Bryan, P.J.; Jayatilake, G.S.; Moon, B.H. Homarine as a feeding deterrent in common shallow-water antarctic lamellarian gastropod Marseniopsis mollis: A rare example of chemical defense in a marine prosobranch. J. Chem. Ecol. 1994, 20, 2539-2549. [CrossRef] [PubMed]

237. Cimino, G.; Crispino, A.; Di Marzo, V.; Sodano, G.; Spinella, A.; Villani, G. A marine mollusc provides the first example of in vivo storage of prostaglandins: Prostaglandin-1, 15-lactones. Experientia 1991, 47, 56-60. [CrossRef] [PubMed]

238. Cimino, G.; Spinella, A.; Sodano, G. Naturally occurring prostaglandin-1, 15-lactones. Tetrahedron Lett. 1989, 30, 3589-3592. [CrossRef]

239. Cimino, G.; Crispino, A.; Di Marzo, V.; Spinella, A.; Sodano, G. Prostaglandin 1, 15-lactones of the F series from the nudibranch mollusk Tethys fimbria. J. Org. Chem. 1991, 56, 2907-2911. [CrossRef]

240. Di Marzo, V.; Cimino, G.; Crispino, A.; Minardi, C.; Sodano, G.; Spinella, A. A novel multifunctional metabolic pathway in a marine mollusc leads to unprecedented prostaglandin derivatives (prostaglandin 1, 15-lactones). Biochem. J. 1991, 273, 593-600. [CrossRef]

241. Cutignano, A.; Moles, J.; Avila, C.; Fontana, A. Granuloside, a unique linear homosesterterpene from the Antarctic nudibranch Charcotia granulosa. J. Nat. Prod. 2015, 78, 1761-1764. [CrossRef]

242. Moles, J.; Wägele, H.; Cutignano, A.; Fontana, A.; Avila, C. Distribution of granuloside in the Antarctic nudibranch Charcotia granulosa (Gastropoda: Heterobranchia: Charcotiidae). Mar. Biol. 2016, 163, 54-65. [CrossRef]

243. Putz, A.; König, G.M.; Wägele, H. Defensive strategies of Cladobranchia (Gastropoda, Opisthobranchia). Nat. Prod. Rep. 2010, 27, 1386-1402. [CrossRef]

244. Affeld, S.; Kehraus, S.; Wägele, H.; König, G.M. Dietary derived sesquiterpenes from Phyllodesmium lizardensis. J. Nat. Prod. 2009, 72, 298-300. [CrossRef]

245. Coll, J.; Bowden, B.; Tapiolas, D.; Willis, R.; Djura, P.; Streamer, M.; Trott, L. Studies of Australian soft corals XXXV: The terpenoid chemistry of soft corals and its implications. Tetrahedron 1985, 41, 1085-1092. [CrossRef]

246. Slattery, M.; Avila, C.; Starmer, J.; Paul, V.J. A sequestered soft coral diterpene in the aeolid nudibranch Phyllodesmium guamensis. J. Exp. Mar. Biol. Ecol. 1998, 226, 33-49. [CrossRef]

247. Edrada, R.A.; Wray, V.; Witte, L.; van Ofwegen, L.; Proksch, P. Bioactive terpenes from the soft coral Heteroxenia sp. from Mindoro, Philippines. Z. Naturforsch. 2000, 55, 82-86. [CrossRef] [PubMed] 
248. Bogdanov, A.; Kehraus, S.; Bleidissel, S.; Preisfeld, G.; Schillo, D.; Piel, J.; Brachmann, A.O.; Wägele, H.; König, G.M. Defense in the Aeolidoidean Genus Phyllodesmium (Gastropoda). J. Chem. Ecol. 2014, 40, 1013-1024. [CrossRef]

249. Mao, S.C.; Gavagnin, M.; Mollo, E.; Guo, Y.-W. A new rare asteriscane sesquiterpene and other related derivatives from the Hainan aeolid nudibranch Phyllodesmium magnum. Biochem. System. Ecol. 2011, 39, 408-411. [CrossRef]

250. Bogdanov, A.; Hertzer, C.; Kehraus, S.; Nietzer, S.; Rohde, S.; Schupp, P.J.; Wägele, H.; König, G.M. Defensive diterpene from the Aeolidoidean Phyllodesmium longicirrum. J. Nat. Prod. 2016, 79, 611-615. [CrossRef]

251. Bogdanov, A.; Hertzer, C.; Kehraus, S.; Nietzer, S.; Rohde, S.; Schupp, P.J.; Wägele, H.; König, G.M. Secondary metabolome and its defensive role in the aeolidoidean Phyllodesmium longicirrum (Gastropoda, Heterobranchia, Nudibranchia). Beilstein J. Org. Chem. 2017, 13, 502-519. [CrossRef]

252. Gillette, R.; Saeki, M.; Huang, R.C. Defensive mechanisms in notaspid snails: Acid humor and evasiveness. J. Exp. Biol. 1991, 156, 335-347.

253. Willan, R.C. A review of the diets in the Notaspidea (Mollusca: Opisthobranchia). J. Malacol. Soc. Aust. 1984, 6, 125-142. [CrossRef]

254. Taboada, S.; Núñez-Pons, L.; Avila, C. Feeding repellence of Antarctic and sub-Antarctic benthic invertebrates against the omnivorous sea star Odontaster validus Koehler, 1906. Pol. Biol. 2013, 36, 13-25. [CrossRef]

255. Moles, J.; Núñez-Pons, L.; Taboada, S.; Figuerola, B.; Cristobo, J.; Avila, C. Anti-predatory chemical defences in Antarctic benthic fauna. Mar. Biol. 2015, 162, 1813-1821. [CrossRef]

256. Andersen, R.J.; Faulkner, D.J. Antibiotics from marine organisms of the Gulf of California. In Proceedings of the Abstracts from 3rd Conference on Food and Drugs from the Sea, Kingston, RI, USA, 20-23 August 1972; pp. 111-115.

257. Teeyapant, R.; Kreis, P.; Wray, V.; Witte, L.; Proksch, P. Brominated secondary compounds from the marine sponge Verongia aerophoba and the sponge feeding gastropod Tylodina perversa. Z. Naturforsch. 1993, 48, 630-644. [CrossRef]

258. Gotsbacher, M.P.; Karuso, P. New antimicrobial bromotyrosine analogues from the sponge Pseudoceratina purpurea and its predator Tylodina corticalis. Mar. Drugs 2015, 13, 1389-1409. [CrossRef] [PubMed]

259. Ebel, R.; Marin, A.; Proksch, P. Organ-specific distribution of dietary alkaloids in the marine opisthobranch Tylodina perversa. Biochem. System. Ecol. 1999, 27, 769-777. [CrossRef]

260. Thoms, C.; Wolff, M.; Padmakumar, K.; Ebel, R.; Proksch, P. Chemical defense of Mediterranean sponges Aplysina cavernicola and Aplysina aerophoba. Z. Naturforsch. 2004, 59, 113-122. [CrossRef] [PubMed]

261. Becerro, M.A.; Turon, X.; Uriz, M.J.; Templado, J. Can a sponge feeder be an herbivore? Tylodina perversa (Gastropoda) feeding on Aplysina aerophoba. Biol. J. Linn. Soc. 2003, 78, 429-438. [CrossRef]

262. Cimino G, De Rosa S, De Stefano S, Spinella A, Sodano G The zoochrome of the sponge Verongia aerophoba ("Uranidine"). Tetrahedron Lett. 1984, 25, 2925-2928. [CrossRef]

263. Cimino, G.; Sodano, G. Transfer of sponge secondary metabolites to predators. In Sponges in Time and Space: Biology, Chemistry, Paleontology; van Soest, R.W.M., van Kempen, T.M.G., Braekman, J.-C., Eds.; AA: Balkema, Rotterdam, 1994; pp. 459-472.

264. Thompson, T.E. Defensive acid-secretion in marine gastropods. J. Mar. Biolog. Assoc. 1960, 39, 115-122. [CrossRef]

265. Thompson, T.E. Investigation of the acidic allomone of the gastropod mollusc Philine aperta by means of ion chromatography and histochemical localisation of sulphate and chloride ions. J. Mollus. Stud. 1986, 52, 38-44. [CrossRef]

266. Moles, J.; Avila, C.; Malaquias, M.A.E. Unmasking Antarctic mollusc lineages: Novel evidence from philinoid snails (Gastropoda: Cephalaspidea). Cladistics 2019, 35, 487-513. [CrossRef]

267. Neves, R.; Gaspar, H.; Calado, G. Does a shell matter for defence? Chemical deterrence in two cephalaspidean gastropods with calcified shells. J. Mollus. Stud. 2009, 75, 127-131. [CrossRef]

268. Fontana, A.; Cutignano, A.; Giordano, A.; Coll, A.D.; Cimino, G. Biosynthesis of aglajnes, polypropionate allomones of the opisthobranch mollusc Bulla striata. Tetrahedron Lett. 2004, 45, 6847-6850. [CrossRef]

269. Cimino, G.; Sodano, G.; Spinella, A.; Trivellone, E. Aglajne-1, a polypropionate metabolite from the opisthobranch mollusk Aglaja depicta. Tetrahedron Lett. 1985, 26, 3389-3392. [CrossRef]

270. Cimino, G.; Sodano, G.; Spinella, A. New propionate-derived metabolites from Aglaja depicta and from its prey Bulla striata (opisthobranch mollusks). J. Org. Chem. 1987, 52, 5326-5331. [CrossRef] 
271. Marín, A.; Álvarez, L.A.; Cimino, G.; Spinella, A. Chemical defence in cephalaspidean gastropods: Origin, anatomical location and ecological roles. J. Mollus. Stud. 1999, 65, 121-131. [CrossRef]

272. Coval, S.J.; Scheuer, P.J. An intriguing C16-alkadienone-substituted 2-pyridine from a marine mollusk. J. Org. Chem. 1985, 50, 3024-3025. [CrossRef]

273. Coval, S.J.; Schulte, G.R.; Matsumoto, G.K.; Roll, D.M.; Scheuer, P.J. Two polypropionate metabolites from the cephalaspidean mollusk Philinopsis speciosa. Tetrahedron Lett. 1985, 26, 5359-5362. [CrossRef]

274. Cutignano, A.; Calado, G.; Gaspar, H.; Cimino, G.; Fontana, A. Polypropionates from Bulla occidentalis: Chemical markers and trophic relationships in cephalaspidean molluscs. Tetrahedron Lett. 2011, 52, 4595-4597. [CrossRef]

275. Nakao, Y.; Yoshida, W.Y.; Scheuer, P.J. Pupukeamide, a linear tetrapeptide from a cephalaspidean mollusk Philinopsis speciosa. Tetrahedron Lett. 1996, 37, 8993-8996. [CrossRef]

276. Nakao, Y.; Yoshida, W.Y.; Szabo, C.M.; Baker, B.J.; Scheuer, P.J. More peptides and other diverse constituents of the marine mollusk Philinopsis speciosa. J. Org. Chem. 1998, 63, 3272-3280. [CrossRef]

277. Reese, M.T.; Gulavita, N.K.; Nakao, Y.; Hamann, M.T.; Yoshida, W.Y.; Coval, S.J.; Scheuer, P.J. Kulolide: A cytotoxic depsipeptide from a cephalaspidean mollusk, Philinopsis speciosa. J. Am. Chem. Soc. 1996, 118, 11081-11084. [CrossRef]

278. Spinella, A.; Álvarez, L.A.; Cimino, G. Predator-prey relationship between Navanax inermis and Bulla gouldiana: A chemical approach. Tetrahedron 1993, 49, 3203-3210. [CrossRef]

279. Cruz-Rivera, E. Evidence for chemical defence in the Cephalaspidean Nakamigawaia spiralis Kuroda and Habe, 1961. J. Mollus. Stud. 2011, 77, 95-97. [CrossRef]

280. Poiner, A.; Paul, V.J.; Scheuer, P.J. Kumepaloxane, a rearranged trisnor sesquiterpene from the bubble shell Haminoea cymbalum. Tetrahedron 1989, 45, 617-622.

281. Chang, E.S. Possible Anti-Predation Properties of the Egg Masses of the Marine Gastropods Dialula sandiegensis, Doris montereyensis and Haminoea virescens (Mollusca, Gastropoda); Friday Harbor Laboratories Student Research Papers; Friday Harbor Laboratories: Washington, DC, USA, 2014; p. 528.

282. Becerro, M.A.; Starmer, J.A.; Paul, V.J. Chemical defenses of cryptic and aposematic gastropterid molluscs feeding on their host sponge Dysidea granulosa. J. Chem. Ecol. 2006, 32, 1491-1500. [CrossRef]

283. Pereira, R.B.; Andrade, P.B.; Valentão, P. Chemical diversity and biological properties of secondary metabolites from sea hares of Aplysia genus. Mar. Drugs 2016, 14, 39. [CrossRef]

284. Ellingson, R.A.; Krug, P.J. Evolution of poecilogony from planktotrophy: Cryptic speciation, phylogeography, and larval development in the gastropod genus Alderia. Evolution 2006, 60, 2293-2310. [CrossRef]

285. Hunt, B.P.V.; Pakhomov, E.A.; Hosie, G.W.; Siegel, V.; Ward, P.; Bernard, K. Pteropods in Southern Ocean ecosystems. Prog. Oceanogr. 2008, 78, 193-221. [CrossRef]

286. Jörger, K.M.; Norenburg, J.L.; Wilson, N.G.; Schrödl, M. Barcoding against a paradox? Combined molecular species delineations reveal multiple cryptic lineages in elusive meiofaunal sea slugs. BMC Evol. Biol. 2012, 12, 245. [CrossRef]

287. Kinnel, R.B.; Dieter, R.K.; Meinwald, J.; Van Engen, D.; Clardy, J.; Eisner, T.; Stallard, M.O.; Fenical, W. Brasilenyne and cis-dihydrorhodophytin: Antifeedant medium-ring haloethers from a sea hare (Aplysia brasiliana). PNAS 1979, 76, 3576-3579. [CrossRef]

288. Kamiya, H.; Muramoto, K.; Goto, R.; Sakai, M.; Endo, Y.; Yamazaki, M. Purification and characterization of an antibacterial and antineoplastic protein secretion of a sea hare, Aplysia juliana. Toxicon 1989, 27, 1269-1277. [CrossRef]

289. Kamio, M.; Grimes, T.V.; Hutchins, M.H.; van Dam, R.; Derby, C.D. The purple pigment aplysioviolin in sea hare ink deters predatory blue crabs through their chemical senses. Anim. Behav. 2010, 80, 89-100. [CrossRef]

290. Kamio, M.; Nguyen, L.; Yaldiz, S.; Derby, C.D. How to produce a chemical defense: Structural elucidation and anatomical distribution of aplysioviolin and phycoerythrobilin in the sea hare Aplysia californica. Chem. Biodivers. 2010, 7, 1183-1197. [CrossRef] [PubMed]

291. Derby, C.D. Escape by inking and secreting: Marine molluscs avoid predators through a rich array of chemicals and mechanisms. Biol. Bull. 2007, 213, 274-289. [CrossRef]

292. Kicklighter, C.E.; Shabani, S.; Johnson, P.M.; Derby, C.D. Sea hares use novel antipredatory chemical defenses. Curr. Biol. 2005, 15, 549-554. [CrossRef]

293. Sheybani, A.; Nusnbaum, M.; Caprio, J.; Derby, C.D. Responses of the sea catfish Ariopsis felis to chemical defenses from the sea hare Aplysia californica. J. Exp. Mar. Biol. Ecol. 2009, 368, 153-160. [CrossRef] 
294. Johnson, P.M.; Kicklighter, C.E.; Schmidt, M.; Kamio, M.; Yang, H.; Elkin, D.; Michel, W.C.; Tai, P.C.; Derby, C.D. Packaging of chemicals in the defensive secretory glands of the sea hare Aplysia californica. J. Exp. Biol. 2006, 209, 78-88. [CrossRef]

295. Nusnbaum, M.; Derby, C.D. Effects of sea hare ink secretion and its escapin-generated components on a variety of predatory fishes. Biol. Bull. 2010, 218, 282-292. [CrossRef]

296. Kicklighter, C.E.; Derby, C.D. Multiple components in ink of the sea hare Aplysia californica are aversive to the sea anemone Anthopleura sola. J. Exp. Mar. Biol. Ecol. 2006, 334, 256-268. [CrossRef]

297. Kamio, M.; Ko, K.C.; Zheng, S.; Wang, B.; Collins, S.L.; Gadda, G.; Tai, P.C.; Derby, C.D. The chemistry of escapin: Identification and quantification of the components in the complex mixture generated by an L-amino acid oxidase in the defensive secretion of the sea snail Aplysia californica. Chem. Eur. J. 2009, 15, 1597-1603. [CrossRef]

298. Pennings, S.C. Multiple factors promoting narrow host range in the sea hare, Aplysia californica. Oecologia 1990, 82, 192-200. [CrossRef] [PubMed]

299. Ginsburg, D.W.; Paul, V.J. Chemical defenses in the sea hare Aplysia parvula: Importance of diet and sequestration of algal secondary metabolites. Mar. Ecol. Progr. Ser. 2001, 215, 261-274. [CrossRef]

300. Stierle, D.B.; Wing, R.M.; Sims, J.J. Marine natural products, XI Costatone and costatolide, new halogenated monoterpenes from the red seaweed, Plocamium costatum. Tetrahedron Lett. 1976, 49, 4455-4458. [CrossRef]

301. Paul, V.J.; Arthur, K.E.; Ritson-Williams, R.; Ross, C.; Sharp, K. Chemical defenses: From compounds to communities. Biol. Bull. 2007, 213, 226-251. [CrossRef] [PubMed]

302. Kato, Y.; Scheuer, P.J. Aplysiatoxin and debromoaplysiatoxin, constituents of the marine mollusk Stylocheilus longicauda (Quoy and Gaimard, 1824). J. Am. Chem. Soc. 1974, 96, 2245-2246. [CrossRef] [PubMed]

303. Kato, Y.; Scheuer, P.J. The aplysiatoxins. Pure Appl. Chem. 1975, 41, 1-14. [CrossRef]

304. Rose, A.F.; Scheuer, P.J.; Springer, J.P.; Clardy, J. Stylocheilamide, an unusual constituent of the sea hare Stylocheilus longicauda. J. Am. Chem. Soc. 1978, 100, 7665-7670. [CrossRef]

305. Gallimore, W.A.; Galario, D.L.; Lacy, C.; Zhu, Y.; Scheuer, P.J. Two complex proline esters from the sea hare Stylocheilus longicauda. J. Nat. Prod. 2000, 63, 1022-1026. [CrossRef]

306. Todd, J.S.; Gerwick, W.H. Malyngamide I from the tropical marine cyanobacterium Lyngbya majuscula and the probable structure revision of stylocheilamide. Tetrahedron Lett. 1995, 36, 7837-7840. [CrossRef]

307. Gallimore, W.A.; Scheuer, P.J. Malyngamides O and P from the sea hare Stylocheilus longicauda. J. Nat. Prod. 2000, 63, 1422-1424. [CrossRef]

308. Pennings, S.C.; Paul, V.J. Sequestration of dietary secondary metabolites by three species of sea hares: Location, specificity and dynamics. Mar. Biol. 1993, 117, 535-546. [CrossRef]

309. Paul, V.J.; Pennings, S.C. Diet-derived chemical defenses in the sea hare Stylocheilus longicauda (Quoy et Gaimard 1824). J. Exp. Mar. Biol. Ecol. 1991, 151, 227-243. [CrossRef]

310. Capper, A.; Cruz-Rivera, E.; Paul, V.J.; Tibbetts, I.R. Chemical deterrence of a marine cyanobacterium against sympatric and non-sympatric consumers. Hydrobiologia 2006, 553, 319-326. [CrossRef]

311. Gopichand, Y.; Schmitz, F.J. Bursatellin: A new diol dinitrile from the sea hare Bursatella leachii pleii. J. Org. Chem. 1980, 45, 5383-5385. [CrossRef]

312. Cimino, G.; Gavagnin, M.; Sodano, G.; Spinella, A.; Strazzullo, G. Revised structure of Bursatellin. J. Org. Chem. 1987, 52, 2303-2306. [CrossRef]

313. Yoshida, W.Y.; Bryan, P.J.; Baker, B.J.; Mcclintock, J.B. Pteroenone: A defensive metabolite of the abducted Antarctic pteropod Clione antarctica. J. Org. Chem. 1995, 60, 780-782. [CrossRef]

314. Bryan, P.J.; Yoshida, W.Y.; McClintock, J.B.; Baker, B.J. Ecological role for pteroenone, a novel antifeedant from the conspicuous Antarctic pteropod Clione antarctica (Gymnosomata: Gastropoda). Mar. Biol. 1995, 122, 271-277.

315. McClintock, J.B.; Janssen, J. Pteropod abduction as a chemical defence in a pelagic Antarctic amphipod. Nature 1990, 346, 462-464. [CrossRef]

316. Gavagnin, M.; Mollo, E.; Montanaro, D.; Ortea, J.; Cimino, G. Chemical studies of Caribbean sacoglossans: Dietary relationships with green algae and ecological implications. J. Chem. Ecol. 2000, 26, 1563-1578. [CrossRef]

317. Gavagnin, M.; Mollo, E.; Cimino, G.; Ortea, J. A new $\gamma$-dihydropyrone-propionate from the Caribbean sascoglossan Tridachia crispata. Tetrahedron Lett. 1996, 37, 4259-4262. [CrossRef] 
318. Gavagnin, M.; Mollo, E.; Castelluccio, F.; Montanaro, D.; Ortea, J.; Cimino, G. A novel dietary sesquiterpene from the marine sacoglossan Tridachia crispata. Nat. Prod. Lett. 1997, 10, 151-156. [CrossRef]

319. Ireland, C.; Faulkner, D.J. The defensive secretion of the opisthobranch mollusc Onchidella binneyi. Bioorg. Chem. 1978, 7, 125-131. [CrossRef]

320. Paul, V.J.; Sun, H.H.; Fenical, W. Udoteal, a linear diterpenoid feeding deterrent from the tropical green alga Udotea flabellum. Phytochemistry 1982, 21, 468-469. [CrossRef]

321. Gavagnin, M.; Spinella, A.; Crispino, A.; Epifanio, R.D.A.; Marn, A.; Cimino, G. Chemical-components of the Mediterranean ascoglossan Thuridilla hopei. Gazz. Chim. Ital. 1993, 123, 205-208.

322. Carbone, M.; Ciavatta, M.L.; De Rinaldis, G.; Castelluccio, F.; Mollo, E.; Gavagnin, M. Identification of thuridillin-related aldehydes from Mediterranean ascoglossan mollusk Thuridilla hopei. Tetrahedron 2014, 70, 3770-3773. [CrossRef]

323. Paul, V.; Ciminiello, P.; Fenical, W. Diterpenoid feeding deterrents from the Pacific green-alga Pseudochlorodesmis furcellata. Phytochemistry 1988, 27, 1011-1014. [CrossRef]

324. Somerville, M.J.; Katavic, P.L.; Lambert, L.K.; Pierens, G.K.; Blanchfield, J.T.; Cimino, G.; Mollo, E.; Gavagnin, M.; Banwell, M.G.; Garson, M.J. Isolation of thuridillins D-F, diterpene metabolites from the Australian sacoglossan mollusk Thuridilla splendens; relative configuration of the epoxylactone ring. J. Nat. Prod. 2012, 75, 1618-1624. [CrossRef]

325. Hay, M.E.; Duffy, J.E.; Paul, V.J.; Renaud, P.E.; Fenical, W. Specialist herbivores reduce their susceptibility to predation by feeding on the chemically defended seaweed Avrainvillea longicaulis. Limnol. Oceanogr. 1990, 35, 1734-1747. [CrossRef]

326. Vardaro, R.R.; Di Marzo, V.; Crispino, A.; Cimino, G. Cyercenes, novel polypropionate pyrones from the autotomizing Mediterranean mollusc Cyerce cristallina. Tetrahedron 1991, 47, 5569-5576. [CrossRef]

327. Di Marzo, V.; Vardaro, R.R.; De Petrocellis, L.; Villani, G.; Minei, R.; Cimino, G. Cyercenes, novel pyrones from the ascoglossan mollusc Cyerce cristallina. Tissue distribution, biosynthesis and possible involvement in defense and regenerative processes. Experientia 1991, 47, 1221-1227. [CrossRef]

328. Roussis, V.; Pawlik, J.R.; Hay, M.E.; Fenical, W. Secondary metabolites of the chemically rich ascoglossan Cyerce nigricans. Experientia 1990, 49, 327-329. [CrossRef]

329. Jensen, K.R. Defensive behavior and toxicity of the ascoglossan opisthobranch Mourgona germaineae Marcus. J. Chem. Ecol. 1984, 10, 475-486. [CrossRef] [PubMed]

330. Högberg, H.E.; Thompson, R.H.; King, T.J. The cymopols, a group of prenylated bromohydroquinones from the green calcareous alga Cymopolia barbata. J. Chem. Soc. Perkin Trans. I 1976, 1, 1696-1701. [CrossRef]

331. Hamann, M.T.; Otto, C.S.; Scheuer, P.J.; Dunbar, D.C. Kahalalides: Bioactive peptides from a marine mollusk Elysia rufescens and its algal diet Bryopsis sp. J. Org. Chem. 1996, 61, 6594-6600. [CrossRef] [PubMed]

332. Vardaro, R.R.; Di Marzo, V.; Cimino, G. Placidenes: Cyercene-like polypropionate $\gamma$-pyrones from the Mediterranean ascoglossan mollusc Placida dendritica. Tetrahedron Lett. 1992, 33, 2875-2878. [CrossRef]

333. Gray, C.A.; Davies-Coleman, M.T.; McQuaid, C. Labdane diterpenes from the South African marine pulmonate Trimusculus costatus. Nat. Prod. Lett. 1998, 12, 47-53. [CrossRef]

334. Manker, D.C.; Faulkner, D.J. Investigation of the role of diterpenes produced by marine pulmonates Trimusculus reticulatus and T. conica. J. Chem. Ecol. 1996, 22, 23-35. [CrossRef]

335. Díaz-Marrero, A.R.; Dorta, E.; Cueto, M.; Rovirosa, J.; San-Martín, A.; Loyola, A.; Darias, J. Labdane diterpenes with a new oxidation pattern from the marine pulmonate Trimusculus peruvianus. Tetrahedron 2003, 59, 4805-4809. [CrossRef]

336. Rovirosa, J.; Quezada, E.; San-Martin, A. New diterpene from the mollusc Trimusculus peruvianus. Bol. Soc. Chil. Quim. 1992, 37, 143-145.

337. Van Wyk, A.W.W.; Gray, C.A.; Whibley, C.E.; Osoniyi, O.; Hendricks, D.T.; Caira-Mino, R.; Davies-Coleman, M.T. Bioactive metabolites from the South African marine mollusk Trimusculus costatus. J. Nat. Prod. 2008, 71, 420-425. [CrossRef]

338. Wiggering, B.; Neiber, M.T.; Gebauer, K.; Glaubrecht, M. One species, two developmental modes: a case of geographic poecilogony in marine gastropods. BMC Evol. Biol. 2020, 20, 76. [CrossRef] [PubMed]

339. Manker, D.C.; Garson, M.J.; Faulkner, D.J. De novo biosynthesis of polypropionate metabolites in the marine pulmonate Siphonaria denticulata. J. Chem. Soc. Chem. Commun. 1988, 16, 1061-1062. [CrossRef]

340. Paul, M.C.; Zubía, E.; Ortega, M.J.; Salvá, J. New polypropionates from Siphonaria pectinata. Tetrahedron 1997, 53, 2303-2308. [CrossRef] 
341. Hochlowski, J.E.; Faulkner, D.J. Antibiotics from the marine pulmonate Siphonaria diemenensis. Tetrahedron Lett. 1983, 24, 1917-1920. [CrossRef]

342. Hochlowski, J.E.; Faulkner, D.J. Metabolites of the marine pulmonate Siphonaria australis. J. Org. Chem. 1984, 49, 3838-3840. [CrossRef]

343. Biskupiak, J.E.; Ireland, C.M. Pectinatone, a new antibiotic from the mollusc Siphonaria pectinata. Tetrahedron Lett. 1983, 24, 3055-3058. [CrossRef]

344. Norte, M.; Cataldo, F.; González, A.G.; Rodríguez, M.L.; Ruiz-Pérez, C. New metabolites from the marine mollusc Siphonaria grisea. Tetrahedron 1990, 46, 1669-1678. [CrossRef]

345. Norte, M.; Fernández, J.J.; Padilla, A. Isolation and synthesis of siphonarienal a new polypropionate from Siphonaria grisea. Tetrahedron Lett. 1994, 35, 3413-3416. [CrossRef]

346. Beukes, D.R.; Davies-Coleman, M.T. Novel polypropionates from the South African marine mollusc Siphonaria capensis. Tetrahedron 1999, 55, 4051-4056. [CrossRef]

347. Hochlowski, J.E.; Faulkner, D.J.; Matsumoto, G.K.; Clardy, J. The denticulatins, two propionate metabolites from the pulmonate Siphonaria denticulata. J. Am. Chem. Soc. 1983, 105, 7413-7415. [CrossRef]

348. Hochlowski, J.; Coll, J.; Faulkner, D.J.; Clardy, J. Novel metabolites of four Siphonaria species. J. Am. Chem. Soc. 1984, 106, 6748-6750. [CrossRef]

349. Roll, D.M.; Biskupiak, J.E.; Mayne, C.L.; Ireland, C.M. Muamvatin, a novel tricyclic spiro ketal from the Fijian mollusk Siphonaria normalis. J. Am. Chem. Soc. 1986, 108, 6680-6682. [CrossRef]

350. Manker, D.C.; Faulkner, D.J. Vallartanones A and B, polypropionate metabolites of Siphonaria maura from Mexico. J. Org. Chem. 1989, 54, 5374-5377. [CrossRef]

351. Manker, D.C.; Faulkner, D.J.; Stout, T.J.; Clardy, J. The baconipyrones. Novel polypropionates from the pulmonate Siphonaria baconi. J. Org. Chem. 1989, 54, 5371-5374. [CrossRef]

352. Brecknell, D.J.; Collett, L.A.; Davies-Coleman, M.T.; Garson, M.J.; Jones, D.D. New non-contiguous polypropionates from marine molluscs: A comment on their natural product status. Tetrahedron 2000, 56, 2497-2502. [CrossRef]

353. Mary J., G. The biosynthesis of marine natural products. Chem. Rev. 1993, 93, 1699-1733.

354. Abramson, S.N.; Radic, Z.; Manker, D.; Faulkner, D.J.; Taylor, P. Onchidal: A naturally occurring irreversible inhibitor of acetylcholinesterase with a novel mechanism of action. Mol. Pharm. 1989, 36, 349-354.

355. Young, C.M.; Greenwood, P.G.; Powell, C.J. The ecological role of defensive secretions in the intertidal pulmonate Onchidella borealis. Biol. Bull. 1986, 171, 391-404. [CrossRef]

356. Biskupiak, J.E.; Ireland, C.M. Cytotoxic metabolites from the mollusc Peronia peronii. Tetrahedron Lett. 1985, 26, 4307-4310. [CrossRef]

357. Carbone, M.; Ciavatta, M.L.; Wang, J.R.; Cirillo, I.; Mathieu, V.; Kiss, R.; Mollo, E.; Guo, Y.W.; Gavagnin, M. Extending the record of bis- $\gamma$-pyrone polypropionates from marine pulmonate mollusks. J. Nat. Prod. 2013, 76, 2065-2073. [CrossRef]

358. Rodríguez, J.; Fernández, R.; Quiñoá, E.; Riguera, R.; Debitus, C.; Bouchet, P. Onchidin: A cytotoxic depsipeptide with C 2 symmetry from a marine mollusc. Tetrahedron Lett. 1994, 35, 9239-9242. [CrossRef]

359. Fernández, R.; Rodríguez, J.; Quiñoá, E.; Riguera, R.; Muñoz, L.; Fernández-Suárez, M.; Debitus, C. Onchidin B: A new cyclodepsipeptide from the mollusc Onchidium sp. J. Am. Chem. Soc. 1996, 118, 11635-11643. [CrossRef]

360. Carbone, M.; Gavagnin, M.; Mattia, C.A.; Lotti, C.; Castelluccio, F.; Pagano, B.; Mollo, E.; Guo, Y.W.; Cimino, G. Structure of onchidione, a bis- $\gamma$-pyrone polypropionate from a marine pulmonate mollusk. Tetrahedron 2009, 65, 4404-4409. [CrossRef]

361. Guo, Y.W.; Gavagnin, M.; Carbone, M.; Mollo, E.; Cimino, G. Recent Sino-Italian collaborative studies on marine organisms from the South China Sea. Pure Appl. Chem. 2012, 84, 1391-1405. [CrossRef]

362. Wang, J.R.; Carbone, M.; Gavagnin, M.; Mándi, A.; Antus, S.; Yao, L.G.; Cimino, G.; Kurtán, T.; Guo, Y.W. Assignment of absolute configuration of bis- $\gamma$-pyrone polypropionates from marine pulmonate molluscs. Eur. J. Org. Chem. 2012, 6, 1107-1111. [CrossRef]

363. Young, R.M.; Baker, B.J. Defensive chemistry of the Irish nudibranch Archidoris psuedoargus (Gastropoda opisthobranchia). Planta Med. 2016, 82, 597. [CrossRef]

364. Zubia, E.; Gavagnin, M.; Crispino, A.; Martinez, E.; Ortea, J.; Cimino, G. Diasteroisomeric ichthyotoxic acylglycerols from the dorsum of two geographically distinct populations of Archidoris nudibranchs. Experientia 1993, 49, 268-271. [CrossRef] 
365. Gustafson, K.; Andersen, R.J. Chemical studies of British Columbia nudibranchs. Tetrahedron 1985, 41, 1101-1108. [CrossRef]

366. Soriente, A.; Sodano, G.; Reed, K.C.; Todd, C. A new ichthyotoxic diacylglycerol from the nudibranch Archidoris pseudoargus. Nat. Prod. Lett. 1993, 3, 31-35. [CrossRef]

367. Cimino, G.; Crispino, A.; Gavagnin, M.; Trivellone, E.; Zubía, E.; Martínez, E.; Ortea, J. Archidorin: A new ichthyotoxic diacylglycerol from the Atlantic dorid nudibranch Archidoris tuberculata. J. Nat. Prod. 1993, 56, 1642-1646. [CrossRef]

368. Andersen, R.J.; Sum, F.W. Farnesic acid glycerides from the nudibranch Archidoris odhneri. Tetrahedron Lett. 1980, 21, 797-800. [CrossRef]

369. Gustafson, K.; Andersen, R.J.; Chen, M.H.; Clardy, J.; Hochlowski, J.E. Terpenoic acid glycerides from the dorid nudibranch Archidoris montereyensis. Tetrahedron Lett. 1984, 25, 11-14. [CrossRef]

370. Gavagnin, M.; Ungur, N.; Castelluccio, F.; Cimino, G. Novel verrucosins from the skin of the Mediterranean nudibranch Doris verrucosa. Tetrahedron 1997, 53, 1491-1504. [CrossRef]

371. Cimino, G.; Gavagnin, M.; Sodano, G.; Puliti, R.; Mattia, C.A.; Mazzarella, L. Verrucosin-A and-B, ichthyotoxic diterpenoic acid glycerides with a new carbon skeleton from the dorid nudibranch Doris verrucosa. Tetrahedron 1988, 44, 2301-2310. [CrossRef]

372. Avila, C.; Ballesteros, M.; Cimino, G.; Crispino, A.; Gavagnin, M.; Sodano, G. Biosynthetic origin and anatomical distribution of the main secondary metabolites in the nudibranch mollusc Doris verrucosa. Comp. Biochem. Physiol. B Comp. Biochem. 1990, 97, 363-368. [CrossRef]

373. Fusetani, N.; Wolstenholme, H.J.; Matsunaga, S. Co-occurrence of 9-isocyanopupukeanane and its C-9 epimer in the nudibranch Phyllidia bourguini. Tetrahedron Lett. 1990, 31, 5623-5624. [CrossRef]

374. Kassuhlke, K.E.; Potts, B.C.; Faulkner, D.J. New nitrogenous sesquiterpenes from two Philippine nudibranchs, Phyllidia pustulosa and P. varicosa, and from a Palauan sponge, Halichondria cf. lendenfeldi. J. Org. Chem. 1991, 56, 3747-3750. [CrossRef]

375. Fusetani, N.; Wolstenholme, H.J.; Shinoda, K.; Asai, N.; Matsunaga, S.; Onuki, H.; Hirota, H. Two sesquiterpene isocyanides and a sesquiterpene thiocyanate from the marine sponge Acanthella cf. cavernosa and the nudibranch Phyllidia ocellata. Tetrahedron Lett. 1992, 33, 6823-6826. [CrossRef]

376. White, A.M.; Pierens, G.K.; Skinner-Adams, T.; Andrews, K.T.; Bernhardt, P.V.; Krenske, E.H.; Mollo, E.; Garson, M.J. Antimalarial isocyano and isothiocyanato sesquiterpenes with tri-and bicyclic skeletons from the nudibranch Phyllidia ocellata. J. Nat. Prod. 2015, 78, 1422-1427. [CrossRef]

377. Jomori, T.; Shibutani, T.; Ahmadi, P.; Suzuka, T.; Tanaka, J. A New Isocyanosesquiterpene from the nudibranch Phyllidiella pustulosa. Nat. Prod. Commun. 2015, 10, 1913-1914. [CrossRef]

378. Crews, P.; Kakou, Y.; Quinoa, E. Mycothiazole, a polyketide heterocycle from a marine sponge. J. Am. Chem. Soc. 1988, 110, 4365-4368. [CrossRef]

379. Sonnenschein, R.N.; Johnson, T.A.; Tenney, K.; Valeriote, F.A.; Crews, P. A reassignment of (-)-mycothiazole and the isolation of a related diol. J. Nat. Prod. 2006, 69, 145-147. [CrossRef] [PubMed]

380. De Silva, E.D.; Scheuer, P.J. Furanoditerpenoids from the dorid nudibranch Casella atromarginata. Heterocycles 1982, 17, 167-170.

381. Fontana, A.; Cavaliere, P.; Ungur, N.; D'Souza, L.; Parameswaram, P.S.; Cimino, G. New scalaranes from the nudibranch Glossodoris atromarginata and its sponge prey. J. Nat. Prod. 1999, 62, 1367-1370. [CrossRef] [PubMed]

382. Gross, H.; Wright, A.D.; Reinscheid, U.; König, G.M. Three new spongian diterpenes from the Fijian marine sponge Spongia sp. Nat. Prod. Commun. 2009, 4, 315-322. [CrossRef] [PubMed]

383. Gavagnin, M.; Mollo, E.; Docimo, T.; Guo, Y.W.; Cimino, G. Scalarane metabolites of the nudibranch Glossodoris rufomarginata and its dietary sponge from the South China Sea. J. Nat. Prod. 2004, 67, 2104-2107. [CrossRef]

384. Betancur-Galvis, L.; Zuluaga, C.; Arnó, M.; González, M.A.; Zaragozá, R.J. Cytotoxic effect (on tumor cells) and in vitro antiviral activity against herpes simplex virus of synthetic spongiane diterpenes. J. Nat. Prod. 2002, 65, 189-192. [CrossRef]

385. Kamel, H.N.; Kim, Y.B.; Rimoldi, J.M.; Fronczek, F.R.; Ferreira, D.; Slattery, M. Scalarane sesterterpenoids: Semisynthesis and biological activity. J. Nat. Prod. 2009, 72, 1492-1496. [CrossRef]

386. Wu, S.Y.; Sung, P.J.; Chang, Y.L.; Pan, S.L.; Teng, C.M. Heteronemin, a spongean sesterterpene, induces cell apoptosis and autophagy in human renal carcinoma cells. BioMed Res. Int. 2015, 2015, 1-13. [CrossRef] 
387. Hochlowski, J.E.; Faulkner, D.J. A diterpene related to cladiellin from a Pacific soft coral. Tetrahedron Lett. 1980, 21, 4055-4056. [CrossRef]

388. Sodano, S.; Spinella, A. Janolusimide, a lipophilic tripeptide toxin from the nudibranch mollusc Janolus cristatus. Tetrahedron Lett. 1986, 27, 2505-2508. [CrossRef]

389. Cimino, G.; De Rosa, S.; De Stefano, S.; Sodano, G. Marine natural products: New results from Mediterranean invertebrates. Pure Appl. Chem. 1986, 58, 375-386. [CrossRef]

390. Wang, J.; Prinsep, M.R.; Gordon, D.P.; Page, M.J.; Copp, B.R. Isolation and stereospecific synthesis of janolusimide B from a New Zealand collection of the bryozoan Bugula flabellata. J. Nat. Prod. 2015, 78, 530-533. [CrossRef] [PubMed]

391. Gavagnin, M.; Spinella, A.; Cimino, G.; Sodano, G. Stereochemistry of ichthyotoxic diacylglycerols from opisthobranch molluscs. Tetrahedron Lett. 1990, 31, 6093-6094. [CrossRef]

392. Cimino, G.; Crispino, A.; Spinella, A.; Sodano, G. Two ichthyotoxic diacylglycerols from the opisthobranch mollusc Umbraculum mediterraneum. Tetrahedron Lett. 1988, 29, 3613-3616. [CrossRef]

393. Cimino, G.; Spinella, A.; Scopa, A.; Sodano, G. Umbraculumin-B, an unusual 3- hydroxybutyric acid ester from the opisthobranch mollusc Umbraculum mediterraneum. Tetrahedron Lett. 1989, 30, 1147-1148. [CrossRef]

394. Sleeper, H.L.; Fenical, W. Navenones A-C: Trail-breaking alarm pheromones from the marine opisthobranch Navanax inermis. J. Am. Chem. Soc. 1977, 99, 2367-2368. [CrossRef]

395. Imperato, F.; Minale, L.; Riccio, R. Constituents of the digestive gland of molluscs of the genus Aplysia. II. Halogenated monoterpenes from Aplysia limacina. Experientia 1977, 33, 1273-1274. [CrossRef]

396. Spinella, A.; Gavagnin, M.; Crispino, A.; Cimino, G. 4-acetylaplykurodin B and aplykurodinone B, two ichthyotoxic degraded sterols from the Mediterranean mollusk Aplysia fasciata. J. Nat. Prod. 1992, 5, 989-993. [CrossRef]

397. Ortega, M.J.; Zubía, E.; Salvá, J. 3-epi-aplykurodinone B, a new degraded sterol from Aplysia fasciata. J. Nat. Prod. 1997, 60, 488-489. [CrossRef]

398. Miyamoto, T.; Higuchi, R.; Komori, T. Isolation and structures of aplykurodins A and B, two new isoprenoids from the marine mollusk Aplysia kurodai. Tetrahedron Lett. 1986, 27, 1153-1156. [CrossRef]

399. Miyamoto, T.; Ebisawa, Y.; Higuchi, R. Aplyparvunin, a bioactive acetogenin from the sea hare Aplysia parvula. Tetrahedron Lett. 1995, 36, 6073-6074. [CrossRef]

400. McPhail, K.L.; Davies-Coleman, M.T. (3Z)-Bromofucin from a South African sea hare. Nat. Prod. Res. 2005, 19, 449-452. [CrossRef] [PubMed]

401. Midland, S.L.; Wing, R.M.; Sims, J.J. New crenulides from the sea hare Aplysia vaccaria. J. Org. Chem. 1983, 48, 1906-1909. [CrossRef]

402. Sun, H.H.; McEnroe, F.J.; Fenical, W. Acetoxycrenulide, a new bicyclic cyclopropane-containing diterpenoid from the brown seaweed Dictyota crenulata. J. Org. Chem. 1983, 48, 1903-1906. [CrossRef]

403. Spinella, A.; Zubía, E.; Martînez, E.; Ortea, J.; Cimino, G. Structure and stereochemistry of aplyolides A- E, lactonized dihydroxy fatty acids from the skin of the marine mollusk Aplysia depilans. J. Org. Chem. 1997, 62, 5471-5475. [CrossRef]

404. Gerwick, W.H.; Fenical, W.; Fritsch, N.; Clardy, J. Stypotriol and stypoldione; ichthyotoxins of mixed biogenesis from the marine alga Stypopodium zonale. Tetrahedron Lett. 1979, 2, 145-148. [CrossRef]

405. Kuniyoshi, M.; Yamada, K.; Higa, T. A biologically active diphenyl ether from the green alga Cladophora fascicularis. Experientia 1985, 41, 523-524. [CrossRef]

406. Doty, M.S.; Aguilar-Santos, G. Transfer of toxic algal substances in marine food chains. Pac. Sci. 1970, 24, 351-355.

407. Gavagnin, M.; Marín, A.; Castelluccio, F.; Villani, G.; Cimino, G. Defensive relationships between Caulerpa prolifera and its shelled sacoglossan predators. J. Exp. Mar. Biol. Ecol. 1994, 175, 197-210. [CrossRef]

408. Cimino, G.; Crispino, A.; Di Marzo, V.; Gavagnin, M.; Ros, J.D. Oxytoxins, bioactive molecules produced by the marine opisthobranch mollusc Oxynoe olivacea from a diet-derived precursor. Experientia 1990, 46, 767-770. [CrossRef]

409. Fontana, A.; Ciavatta, M.L.; Mollo, E.; Naik, C.D.; Wahidulla, S.; D’Sousa, L.; Cimino, G. Volvatellin, cauerpenyne-related product from the sacoglossan Volvatella sp. J. Nat. Prod. 1999, 62, 931-933. [CrossRef] [PubMed] 
410. Jensen, K.R. Evolution of the sacoglossa (Mollusca, Opisthobranchia) and the ecological associations with their food plants. Evol. Ecol. 1997, 11, 301-335. [CrossRef]

411. Ciavatta, M.L.; López Gresa, M.P.; Gavagnin, M.; Manzo, E.; Mollo, E.; D’Souza, L.; Cimino, G. New caulerpenyne-derived metabolites of an Elysia sacoglossan from the south Indian coast. Molecules 2006, 11, 808-816. [CrossRef] [PubMed]

412. Carbone, M.; Muniain, C.; Castelluccio, F.; Iannicelli, O.; Gavagnin, M. First chemical study of the sacoglossan Elysia patagonica: Isolation of a $\gamma$-pyrone propionate hydroperoxide. Biochem. System. Ecol. 2013, 49, 172-175. [CrossRef]

413. Gosliner, T.M. The genus Thuridilla (Opisthobranchia: Elysiidae) from thetropical indo-pacific, with a revision of the phylogeny of the elysiidae. Calif. Acad. Sci. 1995, 59, 1-54.

414. Dawe, R.D.; Wright, J.L.C. The major polypropionate metabolites from the sacoglossan mollusc Elysia chlorotica. Tetrahedron Lett. 1986, 27, 2559-2562. [CrossRef]

415. Ireland, C.D.; Faulkner, J.; Solheim, B.A.; Clardy, J. Tridachione, a propionate-derived metabolite of the opisthobranch mollusc Tridachiella diomedea. J. Am. Chem. Soc. 1978, 100, 1002-1003. [CrossRef]

416. Ireland, C.; Faulkner, J. The metabolites of the marine molluscs Tridachiella diomedea and Tridachia crispata. Tetrahedron 1981, 37, 233-240. [CrossRef]

417. Ksebati, M.B.; Schmitz, F.J. Tridachiapyrones: Propionate-derived metabolites from the sacoglossan mollusc Tridachia crispata. J. Org. Chem. 1985, 50, 5637-5642. [CrossRef]

418. Cueto, M.; D'Croz, L.; Maté, J.L.; San-Martín, A.; Darias, J. Elysiapyrones from Elysia diomedea. Do such metabolites evidence an enzymatically assisted electrocyclization cascade for the biosynthesis of their bicyclo[4.2.0]octane core? Org. Lett. 2005, 7, 415-418. [CrossRef] [PubMed]

419. Díaz-Marrero, A.R.; Cueto, M.; D'Croz, L.; Darias, J. Validating and endoperoxide as a key intermediate in the biosynthesis of elysiapyrones. Org. Lett. 2008, 10, 3057-3060. [CrossRef] [PubMed]

420. De Petrocellis, L.; Orlando, P.; Gavagnin, M.; Ventriglia, M.; Cimino, G.; Di Marzo, V. Novel diterpenoid diacylglycerols from marine molluscs: Potent morphogens and protein kinase $\mathrm{C}$ activators. Experientia 1996, 52, 874-877. [CrossRef] [PubMed]

421. Hochlowski, J.E.; Faulkner, D.J.; Bass, L.S.; Clardy, J. Metabolites of the dorid nudibranch Chromodoris sedna. J. Org. Chem. 1983, 48, 1738-1740. [CrossRef]

422. Fusetani, N.; Nagata, H.; Hirota, H.; Tsuyuki, T. Astrogorgiadiol and astrogorgin, inhibitors of cell division in fertilized starfish eggs, from a gorgonian Astrogorgia sp. Tetrahedron Lett. 1989, 30, 7079-7082. [CrossRef]

423. Ochi, M.; Yamada, K.; Shirase, K.; Kotsuki, H. Calicophirins A and B, two new insect growth inhibitory diterpenoids from a gorgonian coral Calicogorgia sp. Heterocycles (Sendai) 1991, 32, 19-21. [CrossRef]

424. Carmely, S.; Ilan, M.; Kashman, Y. 2-Amino Imidazole Alkaloids from the Marine Sponge Leucetta chagosensis. Tetrahedron 1989, 45, 2193-2200. [CrossRef]

425. Mai, T.; Tintillier, F.; Lucasson, A.; Moriou, C.; Bonno, E.; Petek, S.; Magré, K.; Al Mourabit, A.; Saulnier, D.; Debitus, C. Quorum sensing inhibitors from Leucetta chagosensis Dendy, 1863. Lett. Appl. Microbiol. 2015, 61, 311-317. [CrossRef]

426. Alvi, K.A.; Crews, P.; Loughhead, D.G. Structures and total synthesis of 2-aminoimidazoles from a Notodoris nudibranch. J. Nat. Prod. 1991, 54, 1509-1515. [CrossRef]

427. König, G.M.; Wright, A.D.; Franzblau, S.G. Assessment of antimycobacterial activity of a series of mainly marine derived natural products. Planta Med. 2000, 66, 337-342. [CrossRef]

428. Slattery, M.; Hamann, M.T.; McClintock, J.B.; Perry, T.L.; Puglisi, M.P.; Yoshida, W.Y. Ecological roles for water-borne metabolites from Antarctic soft corals. Mar. Ecol. Progr. Ser. 1997, 161, 133-144. [CrossRef]

429. Kladi, M.; Ntountaniotis, D.; Zervou, M.; Vagias, C.; Ioannou, E.; Roussis, V. Glandulaurencianols A-C, brominated diterpenes from the red alga, Laurencia glandulifera and the sea hare, Aplysia punctata. Tetrahedron Lett. 2014, 55, 2835-2837. [CrossRef]

430. Findlay, J.A.; Li, G. Novel terpenoids from the sea hare Aplysia punctata. Can. J. Chem. 2002, 80, $1697-1707$. [CrossRef]

431. Caccamese, S.; Toscano, R.M.; Cerrini, S.; Gavuzzo, E. Laurencianol, a new halogenated diterpenoid from the marine alga Laurencia obtusa. Tetrahedron Lett. 1982, 23, 114-116. [CrossRef]

432. Kobayashi, M.; Kanda, F.; Kamiya, H. Occurrence of pyropheophorbides a and b in the viscera of the sea hare Aplysia juliana. Nippon Suisan Gakk. 1991, 57, 1983. [CrossRef] 
433. Atta-ur-Rahman, K.A.; Abbas, S.A.; Sultana, T.; Shameel, M. A diterpenoid lactone from Aplysia juliana. J. Nat. Prod. 1991, 54, 886-888. [CrossRef]

434. Benkendorff, K.; Davis, A.R.; Rogers, C.N.; Bremner, J.B. Free fatty acids and sterols in the benthic spawn of aquatic molluscs, and their associated antimicrobial properties. J. Exp. Mar. Biol. Ecol. 2005, 316, 29-44. [CrossRef]

435. Kisugi, J.; Ohye, H.; Kamiya, H.; Yamazaki, M. Biopolymers from marine invertebrates. XIII. Characterization of an antibacterial protein, dolabellanin A, from the albumen gland of the sea hare, Dolabella auricularia. Chem. Pharm. Bull. 1992, 40, 1537-1539. [CrossRef]

436. Fusetani, N. Biofouling and antifouling. Nat. Prod. Rep. 2004, 21, 94-104. [CrossRef]

437. Nishikawa, K.; Nakahara, H.; Shirokura, Y.; Nogata, Y.; Yoshimura, E.; Umezawa, T.; Okino, T.; Matsuda, F. Total synthesis of 10-isocyano-4-cadinene and its stereoisomers and evaluations of antifouling activities. J. Org. Chem. 2011, 76, 6558-6573. [CrossRef]

438. Tanaka, J.; Higa, T. Two new cytotoxic carbonimidic dichlorides from the nudibranch Reticulidia fungia. J. Nat. Prod. 1999, 62, 1339-1340. [CrossRef] [PubMed]

439. Targett, N.M.; Bishop, S.S.; McConnell, O.J.; Yoder, J.A. Antifouling agents against the benthic marine diatom, Navicula salinicola Homarine from the gorgonians Leptogorgia virgulata and L. setacea and analogs. J. Chem. Ecol. 1983, 9, 817-829. [CrossRef] [PubMed]

440. Klein, D. A Proposed Definition of Mental Illness. Critical Issues in Psychiatric Diagnosis. Ph.D. Thesis, New York University, New York, NY, USA, 1978.

441. Berking, S. Is homarine a morphogen in the marine hydroid Hydractinia? Roux's Arch. Dev. Biol. 1986, 195, 33-38. [CrossRef] [PubMed]

442. Berking, S. Homarine ( $\mathrm{N}$-methylpicolinic acid) and trigonelline (N-methylnicotinic acid) appear to be involved in pattern control in a marine hydroid. Development 1987, 99, 211-220.

443. Ortlepp, S.; Pedpradap, S.; Dobretsov, S.; Proksch, P. Antifouling activity of sponge-derived polybrominated diphenyl ethers and synthetic analogues. Biofouling 2008, 24, 201-208. [CrossRef]

444. Spinella, A.; Alvarez, L.; Passeggio, A.; Cimino, G. New3-alkylpyridines from 3 Mediterranean cephalaspidean mollusks; structure, ecological role and taxonomic relevance. Tetrahedron 1993, 49, 1307-1314. [CrossRef]

445. Blihoghe, D.; Manzo, E.; Villela, A.; Cutignano, A.; Picariello, G.; Faimali, M.; Fontana, A. Evaluation of the antifouling properties of 3-alyklpyridine compounds. Biofouling 2011, 27, 99-109. [CrossRef]

446. Cutignano, A.; Tramice, A.; De Caro, S.; Villani, G.; Cimino, G.; Fontana, A. Biogenesis of 3-alkylpyridine alkaloids in the marine mollusc Haminoea orbignyana. Angew. Chem. Int. Ed. 2003, 42, 2633-2636. [CrossRef]

447. Koehler, E. 'Trailing' Behaviour in Risbecia tryoni. Sea Slug Forum; Australian Museum: Sydney, Australia, 1999; Available online: http://www.seaslugforum.net/find/760 (accessed on 20 November 2020).

448. Fenical, W.; Sleeper, H.L.; Paul, V.J.; Stallard, M.O.; Sun, H.H. Defensive chemistry of Navanax and related opisthobranch molluscs. Pure Appl. Chem. 1979, 51, 1865-1874. [CrossRef]

449. Cimino, G.; Passeggio, A.; Sodano, G.; Spinella, A.; Villani, G. Alarm pheromones from the Mediterranean opisthobranch Haminoea navicula. Experientia 1991, 47, 61-63. [CrossRef]

450. Cutignano, A.; Cimino, G.; Giordano, A.; d'Ippolito, G.; Fontana, A. Polyketide origin of 3-alkylpyridines in the marine mollusc Haminoea orbignyana. Tetrahedron Lett. 2004, 45, 2627-2629. [CrossRef]

451. Spinella, A.; Álvarez, L.A.; Cimino, G. Alkylphenols from the cephalaspidean mollusc Haminoea callidegenita. Tetrahedron Lett. 1998, 39, 2005-2008. [CrossRef]

452. Domènech, A.; Avila, C.; Ballesteros, M. Opisthobranch molluscs from the subtidal trawling grounds off Blanes (Girona, northeast Spain). J. Mar. Biolog. Assoc. 2006, 86, 383-389. [CrossRef]

453. Eilertsen, M.H.; Malaquias, M.A.E. Speciation in the dark: Diversification and biogeography of the deep-sea gastropod genus Scaphander in the Atlantic Ocean. J. Biogeogr. 2015, 42, 843-855. [CrossRef] [PubMed]

454. Cutignano, A.; Avila, C.; Rosica, A.; Romano, G.; Laratta, B.; Domenech-Coll, A.; Cimino, G.; Mollo, E.; Fontana, A. Biosynthesis and cellular localization of functional polyketides in the gastropod mollusc Scaphander lignarius. Chembiochem. 2012, 13, 1759-1766. [CrossRef] [PubMed]

455. Cutignano, A.; Avila, C.; Domenech-Coll, A.; d'Ippolito, G.; Cimino, G.; Fontana, A. First biosynthetic evidence on the phenyl-containing polyketides of the marine mollusc Scaphander lignarius. Organic Lett. 2008, 10, 2963-2966. [CrossRef]

456. Della Sala, G.; Cutignano, A.; Fontana, A.; Spinella, A.; Calabrese, G.; Domènech, A.; D'Ippolito, G.; Monica, C.D.; Cimino, G. Towards the biosynthesis of the aromatic products of the Mediterranean mollusc Scaphander lignarius: Isolation and synthesis of analogues of lignarenones. Tetrahedron 2007, 63, 7256-7263. [CrossRef] 
457. Kamio, M.; Kicklighter, C.E.; Nguyen, L.; Germann, M.W.; Derby, C.D. Isolation and structural elucidation of novel mycosporine-like amino acids as alarm cues in the defensive ink secretion of the sea hare Aplysia californica. Helv. Chim. Acta 2011, 94, 1012-1018. [CrossRef]

458. Kicklighter, C.E.; Kamio, M.; Nguyen, L.; Germann, M.W.; Derby, C.D. Mycosporine-like amino acids are multifunctional molecules in sea hares and their marine community. Proc. Nat. Acad. Sci. USA 2011, 108, 11494-11499. [CrossRef]

459. Núñez-Pons, L.; Avila, C.; Romano, G.; Verde, C.; Giordano, D. UV-protective compounds in marine organisms from the Southern Ocean. Mar. Drugs 2018, 16, 336. [CrossRef]

460. Czeczuga, B. Investigations of carotenoids in some animals of the Adriatic Sea-VI Representatives of sponges, annelids, molluscs and echinodermates. Comp. Biochem. Physiol. B Comp. Biochem. 1984, 78, 259-264. [CrossRef]

461. Whitehead, K.; Karentz, D.; Hedges, J. Mycosporine-like amino acids (MAAs) in phytoplankton, a herbivorous pteropod (Limacina helicina), and its pteropod predator (Clione antarctica) in McMurdo Bay, Antarctica. Mar. Biol. 2001, 139, 1013-1019.

462. Gavagnin, M.; Carbone, M.; Ciavatta, M.L.; Mollo, E. Natural products from marine Heterobranchs: An overview of recent results. Chem. J. Mold. 2019, 14, 9-31. [CrossRef]

463. Cutignano, A.; Cimino, G.; Villani, G.; Fontana, A. Shaping the polypropionate biosynthesis in the solar-powered mollusc Elysia viridis. ChemBioChem. 2009, 10, 315-322. [CrossRef]

464. Gavagnin, M.; Mollo, E.; Cimino, G. Is phototridachiahydropyrone a true natural product? Rev. Bras. Pharmacogn. 2015, 25, 588-591. [CrossRef]

465. Gavagnin, M.; Marín, A.; Mollo, E.; Crispino, A.; Villani, G.; Cimino, G. Secondary metabolites from Mediterranean Elysioidea: Origin and biological role. Comp. Biochem. Physiol. B Comp. Biochem. 1994, 108, 107-115. [CrossRef]

466. Ireland, C.; Scheuer, P.J. Photosynthetic marine molluscs: In vivo $14 \mathrm{C}$ incorporation into metabolites of the sacoglossan Placobranchus ocellatus. Science 1979, 205, 922-923. [CrossRef]

467. Powell, K.J.; Richens, J.L.; Bramble, J.P.; Han, L.C.; Sharma, P.; O'Shea, P.; Moses, J.E. Photochemical activity of membrane-localised polyketide derived marine natural products. Tetrahedron 2017, 74, 1191-1198. [CrossRef]

468. Manzo, E.; Ciavatta, M.L.; Gavagnin, M.; Mollo, E.; Wahidulla, S.; Cimino, G. New $\gamma$-pyrone propionates from the Indian Ocean sacoglossan Placobranchus ocellatus. Tetrahedron Lett. 2005, 46, 465-468. [CrossRef]

469. Fu, X.; Hong, E.P.; Schmitz, F.J. New polypropionate pyrones from the Philippine sacoglossan mollusc Placobranchus ocellatus. Tetrahedron 2000, 56, 8989-8993. [CrossRef]

470. Avila, C. The growth of Peltodoris atromaculata Bergh, 1880 (Gastropoda: Nudibranchia) in the laboratory. J. Molluscan Stud. 1996, 62, 151-157. [CrossRef]

471. Di Marzo, V.; Minardi, C.; Vardaro, R.R.; Mollo, E.; Cimino, G. Prostaglandin F-1, 15-lactone fatty acyl esters: A prostaglandin lactone pathway branch developed during the reproduction and early larval stages of a marine mollusc. Comp. Biochem. Physiol. B Biochem. 1992, 101, 99-104. [CrossRef]

472. Marin, A.; Di Marzo, V.; Cimino, G. A histological and chemical study of the cerata of the opisthobranch mollusc Tethys fimbria. Mar. Biol. 1991, 111, 353-358. [CrossRef]

473. Vardaro, R.R.; Di Marzo, V.; Marín, A.; Cimino, G. A- and g-Pyrone-polypropionates from the Mediterranean ascoglossan mollusc Ercolania funerea. Tetrahedron 1992, 48, 9561-9566. [CrossRef]

474. Di Marzo, V.; Marín, A.; Vardaro, R.R.; De Petrocellis, L.; Villani, G.; Cimino, G. Histological and biochemical bases of defense mechanisms in four species of Polybranchoidea ascoglossan molluscs. Mar. Biol. 1993, 117, 367-380. [CrossRef]

475. Ciavatta, M.L.; Manzo, E.; Nuzzo, G.; Villani, G.; Cimino, G.; Cervera, J.L.; Malaquias, M.A.E.; Gavagnin, M. Aplysiopsenes: An additional example of marine polyketides with a mixed acetate/propionate pathway. Tetrahedron Lett. 2009, 50, 527-529. [CrossRef]

476. Ungur, N.; Gavagnin, M.; Fontana, A.; Cimino, G. Synthetic studies on natural diterpenoid glyceryl esters. Tetrahedron 2000, 14, 2503-2512. [CrossRef]

477. Zhang, W.; Gavagnin, M.; Guo, Y.-W.; Mollo, E.; Cimino, G. Chemical studies on the South China Sea nudibranch Dermatobranchus ornatus and its suggested prey gorgonian Muricella sp. Chin. J. Org. Chem. 2006, $26,1667-1672$.

478. Newman, D.J.; Cragg, G.M. Natural products as sources of new drugs over the nearly four decades from 01/1981 to 09/2019. J. Nat. Prod. 2020, 83, 770-803. [CrossRef] 
479. Ciavatta, M.L.; Lefranc, F.; Carbone, M.; Mollo, E.; Gavagnin, M.; Betancourt, T.; Dasari, R.; Kornienko, A.; Kiss, R. Marine mollusk-derived agents with antiproliferative activity as promising anticancer agents to overcome chemotherapy resistance. Med. Res. Rev. 2017, 37, 702-801. [CrossRef]

480. Newman, D.J.; Cragg, G.M. Natural products as sources of new drugs over the last 25 years. J. Nat. Prod. 2007, 70, 461-477. [CrossRef] [PubMed]

481. Vinothkumar, S.; Parameswaran, P.S. Recent advances in marine drug research. Biotechnol. Adv. 2013, 31, 1826-1845. [CrossRef] [PubMed]

482. Nobili, S.; Lippi, D.; Witort, E.; Donnini, M.; Bausi, L.; Mini, E.; Capaccioli, S. Natural compounds for cancer treatment and prevention. Pharmacol. Res. 2009, 59, 365-378. [CrossRef] [PubMed]

483. Bray, F.; Ferlay, J.; Soerjomataram, I.; Siegel, R.L.; Torre, L.A.; Jemal, A. Global cancer statistics 2018: GLOBOCAN estimates of incidence and mortality worldwide for 36 cancers in 185 countries. CA A Cancer J. Clin. 2018, 68, 394-424. [CrossRef] [PubMed]

484. Howitz, K.T.; Sinclair, D.A. Xenohormesis: Sensing the chemical cues of other species. Cell 2008, 133, 387-391. [CrossRef] [PubMed]

485. Ang, K.K.H.; Holmes, M.J.; Higa, T.; Hamann, M.T.; Kara, U.A.K. In vivo antimalarial activity of the beta-carboline alkaloid manzamine A. Antimicrob. Agents Chemother. 2000, 44, 1645-1649. [CrossRef] [PubMed]

486. De Petrocellis, L.; Di Marzo, V.; Arca, B.; Gavagnin, M.; Minei, R.; Cimino, G. The effect of diterpenoidic diacylglycerols on tentacle regeneration in Hydra vulgaris. Comp. Biochem. Physiol. C Comp. Pharmacol. 1991, 100C, 603-607. [CrossRef]

487. Alvi, K.A.; Peters, B.M.; Lisa, H.M.; Phillip, C. 2-Aminoimidazoles and their zinc complexes from Indo-Pacific Leucetta sponges and Notodoris nudibranchs. Tetrahedron 1993, 49, 329-336. [CrossRef]

488. Carroll, A.R.; Bowden, B.F.; Coll, J.C. New imidazole alkaloids from the sponge Leucetta sp. and the associated predatory nudibranch Notodoris gardineri. Aust. J. Chem. 1993, 46, 1229-1234. [CrossRef]

489. Copp, B.R.; Fairchild, C.R.; Cornell, L.; Casazza, A.M.; Robinson, S.; Ireland, C.M. Naamidine A is an antagonist of the epidermal growth factor receptor and an in vivo active antitumor agent. J. Med. Chem. 1998, 41, 3909-3911. [CrossRef]

490. LaBarbera, D.V.; Modzelewska, K.; Glazar, A.I.; Gray, P.D.; Kaur, M.; Liu, T.; Grossman, D.; Harper, M.K.; Kuwada, S.K.; Moghal, N.; et al. The marine alkaloid Naamidine A promotes caspase-dependent apoptosis in tumor cells. Anticancer Drugs 2009, 20, 425-436. [CrossRef] [PubMed]

491. Graziani, E.I.; Allen, T.M.; Andersen, R.J. Lovenone, a cytotoxic degraded triterpenoid isolated from skin extracts of the North Sea dorid nudibranch Adalaria loveni. Tetrahedron Lett. 1995, 36, 1763-1766. [CrossRef]

492. Trindade-Silva, A.E.; Lim-Fong, G.E.; Sharp, K.H.; Haygood, M.G. Bryostatins: Biological context and biotechnological prospects. Curr. Opin. Biotechnol. 2010, 21, 834-842. [CrossRef] [PubMed]

493. Davidson, S.K. The Biology of the Bryostatins in the Marine Bryozoan Bugula neritina. Ph.D. Thesis, University of California, San Diego, CA, USA, 1999.

494. Lim, G.E. Bugula (Bryozoa) and Their Bacterial Symbionts: A Study in Symbiosis, Molecular Phylogenetics and Secondary Metabolism. Ph.D. Thesis, University of California, San Diego, CA, USA, 2004.

495. Sudek, S.; Lopanik, N.B.; Waggoner, L.E.; Hildebrand, M.; Anderson, C.; Liu, H.; Patel, A.; Sherman, D.H.; Haygood, M.G. Identification of the putative bryostatin polyketide synthase gene cluster from Candidatus Endobugula sertula, the uncultivated microbial symbiont of the marine bryozoan Bugula neritina. J. Nat. Prod. 2007, 70, 67-74. [CrossRef] [PubMed]

496. Zonder, J.A.; Shields, A.F.; Zalupski, M.; Chaplen, R.; Heilbrun, L.K.; Arlauskas, P.; Philip, P.A. A phase II trial of bryostatin 1 in the treatment of metastatic colorectal cancer. Clin. Cancer Res. 2001, 7, 38-42. [PubMed]

497. Mayer, A.M.S.; Glaser, K.B.; Cuevas, C.; Jacobs, R.S.; Kem, W.; Little, R.D.; McIntosh, J.M.; Newman, D.J.; Potts, B.C.; Shuster, D.E. The odyssey of marine pharmaceuticals: A current pipeline perspective. Trends Pharmacol. Sci. 2010, 31, 255-265. [CrossRef] [PubMed]

498. Maki, A.; Diwakaran, H.; Redman, B.; Al-Asfar, S.; Pettit, G.R.; Mohammad, R.M.; Al-Katib, A. The bcl-2 and p53 oncoproteins can be modulated by bryostatin 1 and dolastatins in human diffuse large cell lymphoma. Anticancer Drugs 1995, 6, 392-397. [CrossRef]

499. Skropeta, D.; Pastro, N.; Zivanovic, A. Kinase inhibitors from marine sponges. Mar. Drugs 2011, 9, $2131-2154$. [CrossRef] 
500. Kortmansky, J.; Schwartz, G.K. Bryostatin-1: A novel PKC inhibitor in clinical development. Cancer Investig. 2003, 21, 924-936. [CrossRef]

501. Kinnel, R.B.; Scheuer, P.J. 11-hydroxystaurosporine: A highly cytotoxic, powerful protein kinase C inhibitor from a tunicate. J. Org. Chem. 1992, 57, 6327-6329. [CrossRef]

502. Sekar, M.; Poomalai, S.; Gunasekaran, M.; Mani, P.; Krishnamurthy, A. Bioactive compounds from marine yeast inhibits lung cancer. J. Appl. Pharm. Sci. 2015, 5, 7-15.

503. Wall, N.R.; Mohammad, R.M.; Reddy, K.B.; Al-Katib, A.M. Bryostatin 1 induces ubiquitination and proteasome degradation of Bcl-2 in the human acute lymphoblastic leukemia cell line, Reh. Int. J. Mol. Med. 2000, 5, 165-236. [CrossRef] [PubMed]

504. Manzo, E.; Carbone, M.; Mollo, E.; Irace, C.; Di Pascale, A.; Li, Y.; Ciavatta, M.L.; Cimino, G.; Guo, Y.-W.; Gavagnin, M. Structure and synthesis of a unique isonitrile lipid isolated from the marine mollusk Actinocyclus papillatus. Org. Lett. 2011, 13, 1897-1899. [CrossRef] [PubMed]

505. Carbone, M.; Ciavatta, M.L.; Mathieu, V.; Ingels, A.; Kiss, R.; Pascale, P.; Mollo, E.; Ungur, N.; Guo, Y.-W.; Gavagnin, M. Marine terpenoid diacylguanidines: Structure, synthesis, and biological evaluation of naturally occurring actinofide and synthetic analogues. J. Nat. Prod. 2017, 80, 1339-1346. [CrossRef]

506. Parikh, M.; Riess, J.; Lara, P.N., Jr. New and emerging developments in extensive-stage small cell lung cancer therapeutics. Curr. Opin. Oncol. 2016, 28, 97-103. [CrossRef]

507. Stupp, R.; Hegi, M.E.; Mason, W.P.; Van Den Bent, M.J.; Taphoorn, M.J.; Janzer, R.C.; Ludwin, S.K.; Allgeier, A.; Fisher, B.; Belanger, K.; et al. Effects of radiotherapy with concomitant and adjuvant temozolomide versus radiotherapy alone on survival in glioblastoma in a randomised phase III study: 5-year analysis of the EORTC-NCIC trial. Lancet Oncol. 2009, 10, 459-466. [CrossRef]

508. Perret, G.Y.; Uzzan, B. An anticancer strategic dilemma: To kill or to contain. The choice of the pharmaceutical industry in 2009. Fund. Clin. Pharmaccol. 2011, 25, 283-295. [CrossRef]

509. Montagnac, A.; Martin, M.T.; Debitus, C.; Pais, M. Drimane sesquiterpenes from the sponge Dysidea fusca. J. Nat. Prod. 1996, 59, 866-868. [CrossRef]

510. Jaisamut, S. Terpenoids from the Nudibranch Phyllidia coelestis Bergh. Ph.D. Thesis, Prince of Songkla University, Hat Yai, Thailand, 2014.

511. Wratten, S.J.; Faulkner, D.J. Minor carbonimidic dichlorides from the marine sponge Pseudaxinyssa pitys. Tetrahedron Lett. 1978, 19, 1395-1398. [CrossRef]

512. Wratten, S.J.; John, D.; Van Engen, D.; Clardy, J. A vinyl carbonimidic dichloride from the marine sponge Pseudaxinyssa pitys. Tetrahedron Lett. 1978, 19, 1391-1394. [CrossRef]

513. Daoust, J.; Fontana, A.; Merchant, C.E.; De Voogd, N.J.; Patrick, B.O.; Kieffer, T.J.; Andersen, R.J. Ansellone A, a sesterterpenoid isolated from the nudibranch Cadlina luteromarginata and the sponge Phorbas sp., activates the cAMP signaling pathway. Org. Lett. 2010, 12, 3208-3211. [CrossRef] [PubMed]

514. Shirley, H.J.; Jamieson, M.L.; Brimble, M.A.; Bray, C.D. A new family of sesterterpenoids isolated around the Pacific Rim. Nat. Prod. Rep. 2018, 35, 210-219. [CrossRef] [PubMed]

515. El Sayed, K.A.; Youssef, D.T.A.; Marchetti, D. Bioactive natural and semisynthetic latrunculins. J. Nat. Prod. 2006, 69, 219-223. [CrossRef] [PubMed]

516. Spector, I.; Shochet, N.R.; Blasberger, D.; Kashman, Y. Latrunculins; novel marine macrolides that disrupt microfilament organization and affect cell growth: I. Comparison with cytochalasin D. Cell Motil. Cytoskelet. 1989, 13, 127-144. [CrossRef] [PubMed]

517. Spector, I.; Shochet, N.R.; Kashman, Y.; Groweiss, A. Latrunculins: Novel marine toxins that disrupt microfilament organization in cultured cells. Science 1983, 219, 493-495. [CrossRef] [PubMed]

518. Sayed, K.A.; Khanfar, M.A.; Shallal, H.M.; Muralidharan, A.; Awate, B.; Youssef, D.T.; Liu, Y.; Zhou, Y.D.; Nagle, D.G.; Shah, G. Latrunculin A and its C-17-O-carbamates inhibit prostate tumor cell invasion and HIF-1 activation in breast tumor cells. J. Nat. Prod. 2008, 71, 396-402. [CrossRef] [PubMed]

519. Longley, R.E.; McConnell, O.J.; Essich, E.; Harmody, D. Evaluation of marine sponge metabolites for cytotoxicity and signal transduction activity. J. Nat. Prod. 1993, 56, 915-920. [CrossRef]

520. Konishi, H.; Kikuchi, S.; Ochiai, T.; Ikoma, H.; Kubota, T.; Ichikawa, D.; Fujiwara, H.; Okamoto, K.; Sakakura, C.; Sonoyama, T.; et al. Latrunculin a has a strong anticancer effect in a peritoneal dissemination model of human gastric cancer in mice. Anticancer Res. 2009, 29, 2091-2097. 
521. Prota, A.E.; Bargsten, K.; Northcote, P.T.; Marsh, M.; Altmann, K.H.; Miller, J.H.; Diaz, J.F.; Steinmetz, M.O. Structural basis of microtubule stabilization by laulimalide and peloruside A. Angew. Chem. Int. Ed. 2014, 5, 1621-1625. [CrossRef]

522. Churchill, C.D.; Klobukowski, M.; Tuszynski, J.A. The unique binding mode of laulimalide to two tubulin protofilaments. Chem. Biol. Drug Des. 2015, 86, 190-199. [CrossRef]

523. Mooberry, S.L.; Randall-Hlubek, D.A.; Leal, R.M.; Hegde, S.G.; Hubbard, R.D.; Zhang, L.; Wender, P.A. Microtubule-stabilizing agents based on designed laulimalide analogues. Proc. Natl. Acad. Sci. USA 2004, 101, 8803-8808. [CrossRef] [PubMed]

524. Churchill, C.D.M.; Klobukowski, M.; Tuszynski, J.A. Analysis of the binding mode of laulimalide to microtubules: Establishing a laulimalide-tubulin pharmacophore. J. Biomol. Struct. Dyn. 2016, 34, 1455-1469. [CrossRef] [PubMed]

525. Liu, J.; Towle, M.J.; Cheng, H.; Saxton, P.; Reardon, C.; Wu, J.; Murphy, E.A.; Kuznetsov, G.; Johannes, C.W.; Tremblay, M.R.; et al. In vitro and in vivo anticancer activities of synthetic (-)-laulimalide, a marine natural product microtubule stabilizing agent. Anticancer Res. 2007, 27, 1509-1518. [PubMed]

526. Mooberry, S.L.; Tien, G.; Hernandez, A.H.; Plubrukarn, A.; Davidson, B.S. Laulimalide and isolaulimalide, new paclitaxel-like microtubule-stabilizing agents. Cancer Res. 1999, 59, 653-660. [PubMed]

527. Rohena, C.C.; Peng, J.; Johnson, T.A.; Crews, P.; Mooberry, S.L. Chemically diverse microtubule stabilizing agents initiate distinct mitotic defects and dysregulated expression of key mitotic kinases. Biochem. Pharmacol. 2013, 85, 1104-1114. [CrossRef] [PubMed]

528. Pryor, D.E.; O’Brate, A.; Bilcer, G.; Díaz, J.F.; Wang, Y.; Wang, Y.; Kabaki, M.; Jung, M.K.; Andreu, J.M.; Ghosh, A.K.; et al. The microtubule stabilizing agent laulimalide does not bind in the taxoid site, kills cells resistant to paclitaxel and epothilones, and may not require its epoxide moiety for activity. Biochemistry 2002, 41, 9109-9115. [CrossRef]

529. Kanakkanthara, A.; Northcote, P.T.; Miller, J.H. $\beta I I-$ tubulin and $\beta$ III-tubulin mediate sensitivity to peloruside A and laulimalide, but not paclitaxel or vinblastine, in human ovarian carcinoma cells. Mol. Cancer Ther. 2012, 11, 393-404. [CrossRef]

530. Kanakkanthara, A.; Rawson, P.; Northcote, P.T.; Miller, J.H. Acquired resistance to peloruside A and laulimalide is associated with downregulation of vimentin in human ovarian carcinoma cells. Pharm. Res. 2012, 29, 3022-3032. [CrossRef]

531. Evidente, A.; Kornienko, A.; Lefranc, F.; Cimmino, A.; Dasari, R.; Evidente, M.; Mathieu, V.; Kiss, R. Sesterterpenoids with anticancer activity. Curr. Med. Chem. 2015, 22, 3502-3522. [CrossRef]

532. Forster, L.C.; Pierens, G.K.; White, A.M.; Cheney, K.L.; Dewapriya, P.; Capon, R.J.; Garson, M.J. Cytotoxic spiroepoxide lactone and its putative biosynthetic precursor from Goniobranchus splendidus. ACS Omega 2017, 2, 2672-2677. [CrossRef]

533. Rueda, A.; Losada, A.; Fernandez, R.; Cabanas, C.; Garcia-Fernandez, L.F.; Reyes, F.; Cuevas, C. Gracilins G-I, cytotoxic bisnorditerpenes from Spongionella pulchella, and the anti-adhesive properties of gracilin B. Lett. Drug. Des. Discov. 2006, 3, 753-760. [CrossRef]

534. Sanchez, J.A.; Alfonso, A.; Leiros, M.; Alonso, E.; Rateb, M.E.; Jaspars, M.; Houssen, W.E.; Ebel, R.; Tabudravu, J.; Botana, L.M. Identification of Spongionella compounds as cyclosporine A mimics. Pharmacol. Res. 2016, 107, 407-414. [CrossRef] [PubMed]

535. Kohmoto, S.; McConnell, O.J.; Wrigth, A.; Cross, S. Isospongiadiol, a cytotoxic and antiviral diterpene from a Caribbean deep water marine sponge, Spongia sp. Chem. Lett. 1987, 16, 1687-1690. [CrossRef]

536. Fontana, A.; Mollo, E.; Ricciardi, D.; Fakhr, I.; Cimino, G. Chemical studies of Egyptian opisthobranchs: Spongian diterpenoids from Glossodoris atromarginata. J. Nat. Prod. 1997, 60, 444-448. [CrossRef]

537. Cambie, R.C.; Craw, P.A.; Stone, M.J.; Bergquist, P.R. Chemistry of sponges, IV. Spongian diterpenes from Hyatella intestinalis. J. Nat. Prod. 1988, 51, 293-297. [CrossRef]

538. Agrawal, M. Isolation and Structural Elucidation of Cytotoxic Agents from Marine Invertebrates and Plants Sourced from the Great Barrier Reef, Australia. Ph.D. Thesis, James Cook University, Townsville, Australia, 2007.

539. Yong, K.W.; Garson, M.J.; Bernhardt, P.V. Absolute structures and conformations of the spongian diterpenes spongia-13(16), 14-dien-3-one, epispongiadiol and spongiadiol. Acta Crystallogr. Sect. C Cryst. Struct. Commun. 2009, 65, 167-170. [CrossRef] [PubMed] 
540. Wonganuchitmeta, S.; Yuenyongsawad, S.; Keawpradub, N.; Plubrukarn, A. Antitubercular sesterterpenes from the Thai sponge Brachiaster sp. J. Nat. Prod. 2004, 67, 1767-1770. [CrossRef]

541. Kazlauskas, R.; Murphy, P.T.; Quinn, R.J.; Wells, R.J. Heteronemin, a new scalarin type sesterterpene from the sponge Heteronema erecta. Tetrahedron Lett. 1976, 17, 2631-2634. [CrossRef]

542. Kopf, S.; Viola, K.; Atanasov, A.G.; Jarukamjorn, K.; Rarova, L.; Kretschy, N.; Teichmann, M.; Vonach, C.; Saiko, P.; Giessrigl, B.; et al. In vitro characterisation of the anti-intravasative properties of the marine product heteronemin. Arch. Toxicol. 2013, 87, 1851-1861. [CrossRef]

543. Schnermann, M.J.; Beaudry, C.M.; Egorova, A.V.; Polishchuk, R.S.; Suetterlin, C.; Overman, L.E. Golgi-modifying properties of macfarlandin $\mathrm{E}$ and the synthesis and evaluation of its 2,7-dioxabicyclo[3.2.1] octan-3-one core. Proc. Natl. Acad. Sci. USA 2010, 107, 6158-6163. [CrossRef]

544. Chattopadhyay, S.K.; Pattenden, G. Total synthesis of ulapualide A, a novel tris-oxazole containing macrolide from the marine nudibranch Hexabranchus sanguineus. Tetrahedron Lett. 1998, 39, 6095-6098. [CrossRef]

545. Vincent, E.; Saxton, J.; Baker-Glenn, C.; Moal, I.; Hirst, J.D.; Pattenden, G.; Shaw, P.E. Effects of ulapualide A and synthetic macrolide analogues on actin dynamics and gene regulation. Cell Mol. Life Sci. 2007, 64, 487-497. [CrossRef] [PubMed]

546. Parrish, S.M.; Yoshida, W.; Yang, B.; Williams, P.G. Ulapualides C-E Isolated from a Hawaiian Hexabranchus sanguineus Egg Mass. J. Nat. Prod. 2017, 80, 726-730. [CrossRef] [PubMed]

547. Matsunaga, S.; Fusetani, N.; Hashimoto, K. Kabiramide C, a novel antifungal macrolide from nudibranch eggmasses. J. Am. Chem. Soc. 1986, 108, 847-849. [CrossRef]

548. Sirirak, T.; Kittiwisut, S.; Janma, C.; Yuenyongsawad, S.; Suwanborirux, K.; Plubrukarn, A. Kabiramides J and K, trisoxazole macrolides from the sponge Pachastrissa nux. J. Nat. Prod. 2011, 74, 1288-1292. [CrossRef]

549. Tanaka, J.; Yan, Y.; Choi, J.; Bai, J.; Klenchin, V.A.; Rayment, I.; Marriott, G. Biomolecular mimicry in the actin cytoskeleton: Mechanisms underlying the cytotoxicity of kabiramide $\mathrm{C}$ and related macrolides. Proc. Natl. Acad. Sci. USA 2003, 100, 13851-13856. [CrossRef]

550. Braet, F.; Spector, I.; Shochet, N.; Crews, P.; Higa, T.; Menu, E.; De Zanger, R.; Wisse, E. The new anti-actin agent dihydrohalichondramide reveals fenestrae-forming centers in hepatic endothelial cells. BMC Cell Biol. 2002, 3, 1-14. [CrossRef]

551. Shin, Y.; Kim, G.D.; Jeon, J.E.; Shin, J.; Lee, S.K. Antimetastatic effect of halichondramide, a trisoxazole macrolide from the marine sponge Chondrosia corticata, on human prostate cancer cells via modulation of epithelial-to-mesenchymal transition. Mar. Drugs 2013, 11, 2472-2485. [CrossRef]

552. Bae, S.Y.; Kim, G.D.; Jeon, J.E.; Shin, J.; Lee, S.K. Anti-proliferative effect of (19Z)-halichondramide, a novel marine macrolide isolated from the sponge Chondrosia corticata, is associated with G2/M cell cycle arrest and suppression of mTOR signaling in human lung cancer cells. Toxicol. In Vitro 2013, 27, 694-699. [CrossRef]

553. Fontana, A.; Cavaliere, P.; Wahidulla, S.; Naik, C.G.; Cimino, G. A new antitumor isoquinoline alkaloid from the marine nudibranch Jorunna funebris. Tetrahedron 2000, 56, 7305-7308. [CrossRef]

554. Oku, N.; Matsunaga, S.; van Soest, R.W.; Fusetani, N. Renieramycin J, a highly cytotoxic tetrahydroisoquinoline alkaloid, from a marine sponge Neopetrosia sp. J. Nat. Prod. 2003, 66, 1136-1139. [CrossRef] [PubMed]

555. Newman, D.J.; Cragg, G.M. Drugs and drug candidates from marine sources: An assessment of the current "State of Play". Planta Med. 2016, 82, 775-789. [CrossRef] [PubMed]

556. Petek, B.J.; Jones, R.L. PM00104 (Zalypsis@): A marine derived alkylating agent. Molecules 2014, 19, 12328-12335. [CrossRef] [PubMed]

557. Cimino, G.; Ciavatta, M.L.; Fontana, A.; Gavagnin, M. Metabolites of marine opisthobranchs: Chemistry and biological activity. In Bioactive Compounds from Natural Sources; Isolation, Characterization and Biological Properties; Tringali, C., Ed.; Taylor and Francis: London, UK, 2001; pp. 579-637.

558. Malve, H. Exploring the ocean for new drug developments: Marine pharmacology. J. Pharm. Bioallied Sci. 2016, 8, 83-91. [CrossRef]

559. Cuevas, C.; Perez, M.; Francesch, A.; Fernandez, C.; Chicharro, J.L.; Gallego, P.; Zarzuelo, M.; de la Calle, F.; Manzanares, I. Hemisynthetic method and intermediates thereof. PCT Application WO 2000069862 A2, 23 November 2000.

560. Charupant, K.; Suwanborirux, K.; Amnuoypol, S.; Saito, E.; Kubo, A.; Saito, N. Jorunnamycins A-C, new stabilized renieramycin-type bistetrahydroisoquinolines isolated from the Thai nudibranch Jorunna funebris. Chem. Pharm. Bull. 2007, 55, 81-86. [CrossRef] 
561. Charupant, K.; Daikuhara, N.; Saito, E.; Amnuoypol, S.; Suwanborirux, K.; Owa, T.; Saito, N. Chemistry of renieramycins. Part 8: Synthesis and cytotoxicity evaluation of renieramycin M-jorunnamycin a analogues. Bioorg. Med. Chem. 2009, 17, 4548-4558. [CrossRef]

562. McPherson, J.R.; Ong, C.K.; Ng, C.C.Y.; Rajasegaran, V.; Heng, H.L.; Yu, W.S.S.; Tan, B.K.T.; Madhukumar, P.; Teo, M.C.C.; Ngeow, J.; et al. Whole-exome sequencing of breast cancer, malignant peripheral nerve sheath tumor and neurofibroma from a patient with neurofibromatosis type 1. Cancer Med. 2015, 4, 1871-1878. [CrossRef]

563. Storm, E.E.; Durinck, S.; e Melo, F.D.S.; Tremayne, J.; Kljavin, N.; Tan, C.; Ye, X.; Chiu, C.; Pham, T.; Hongo, J.A.; et al. Targeting PTPRK-RSPO3 colon tumours promotes differentiation and loss of stem-cell function. Nature 2016, 529, 97-100. [CrossRef]

564. He, W.F.; Li, Y.; Feng, M.T.; Gavagnin, M.; Mollo, E.; Mao, S.C.; Guo, Y.W. New isoquinolinequinone alkaloids from the South China Sea nudibranch Jorunna funebris and its possible sponge-prey Xestospongia sp. Fitoterapia 2014, 96, 109-114. [CrossRef]

565. Huang, R.Y.; Chen, W.T.; Kurtán, T.; Mándi, A.; Ding, J.; Li, J.; Guo, Y.W. Bioactive isoquinolinequinone alkaloids from the South China Sea nudibranch Jorunna funebris and its sponge-prey Xestospongia sp. Fut. Med. Chem. 2016, 8, 17-27. [CrossRef]

566. Castiello, D.; Cimino, G.; De Rosa, S.; De Stefano, S.; Sodano, G. High molecular weight polyacetylenes from the nudibranch Peltodoris atromaculata and the sponge Petrosia ficiformis. Tetrahedron Lett. 1980, 21, 5047-5050. [CrossRef]

567. Gemballa, S.; Schermutzki, F. Cytotoxic haplosclerid sponges preferred: A field study on the diet of the dotted sea slug Peltodoris atromaculata (Doridoidea: Nudibranchia). Mar. Biol. 2004, 144, 1213-1222. [CrossRef]

568. Ciavatta, M.L.; Nuzzo, G.; Takada, K.; Mathieu, V.; Kiss, R.; Villani, G.; Gavagnin, M. Sequestered fulvinol-related polyacetylenes in Peltodoris atromaculata. J. Nat. Prod. 2014, 77, 1678-1684. [CrossRef] [PubMed]

569. Castiello, D.; Cimino, G. de Rosa, S.; de Stefano, S.; Izzo, G.; Sodano, G. In Colloq. Int. CNRS 1979, $291,413$.

570. Ueoka, R.; Ise, Y.; Matsunaga, S. Cytotoxic polyacetylenes related to petroformyne- 1 from the marine sponge Petrosia sp. Tetrahedron 2009, 65, 5204-5208. [CrossRef]

571. Ortega, M.G.; Zubia, E.; Carballo, J.L.; Salvá, J. Fulvinol, a new long-chain diacetylenic metabolite from the sponge Reniera fulva. J. Nat. Prod. 1996, 59, 1069-1071. [CrossRef]

572. Rapson, T.D. Bioactive 4-Methoxypyrrolic Natural Products from Two South African Marine Invertebrates. Master's Sc. Thesis, Rhodes University, Rhodes, South Africa, 2004.

573. Berlinck, R.G.; Hajdu, E.; da Rocha, R.M.; de Oliveira, J.H.; Hernández, I.L.; Seleghim, M.H.; Granato, A.C.; de Almeida, E.V.; Nuñez, C.V.; Muricy, G.; et al. Challenges and rewards of research in marine natural products chemistry in Brazil. J. Nat. Prod. 2004, 67, 510-522. [CrossRef]

574. Cavalcanti, B.C.; Júnior, H.V.; Seleghim, M.H.; Berlinck, R.G.; Cunha, G.M.; Moraes, M.O.; Pessoa, C. Cytotoxic and genotoxic effects of tambjamine $\mathrm{D}$, an alkaloid isolated from the nudibranch Tambja eliora, on Chinese hamster lung fibroblasts. Chem. Biol. Interact. 2008, 174, 155-162. [CrossRef]

575. Pinkerton, D.M.; Banwell, M.G.; Garson, M.J.; Kumar, N.; de Moraes, M.O.; Cavalcanti, B.C.; Barros, F.W.A.; Pessoa, C. Antimicrobial and cytotoxic activities of synthetically derived tambjamines C and E-J, BE-18591, and a related alkaloid from the marine bacterium Pseudoalteromonas tunicata. Chem. Biodivers. 2010, 7, 1311-1324. [CrossRef]

576. Melvin, M.S.; Ferguson, D.C.; Lindquist, N.; Manderville, R.A. DNA binding by 4-methoxypyrrolic natural products. Preference for intercalation at AT sites by tambjamine E and prodigiosin. J. Org. Chem. 1999, 64, 6861-6869. [CrossRef]

577. Aldrich, L.N.; Stoops, S.L.; Crews, B.C.; Marnett, L.J.; Lindsley, C.W. Total synthesis and biological evaluation of tambjamine K and a library of unnatural analogs. Bioorg. Med. Chem. Lett. 2010, 20, 5207-5211. [CrossRef] [PubMed]

578. Kazlauskas, R.; Marwood, J.F.; Murphy, P.T.; Wells, R.J. A blue pigment from a compound ascidian. Aust. J. Chem. 1982, 35, 215-217. [CrossRef]

579. Melvin, M.S.; Wooton, K.E.; Rich, C.C.; Saluta, G.R.; Kucera, G.L.; Lindquist, N.; Manderville, R.A. Copper-nuclease efficiency correlates with cytotoxicity for the 4-methoxypyrrolic natural products. J. Inorg. Biochem. 2001, 87, 129-135. [CrossRef] 
580. Matsunaga, S.; Fusetani, N.; Hashimoto, K. Bioactive marine metabolites. VIII. Isolation of an antimicrobial blue pigment from the bryozoan Bugula dentata. Experientia 1986, 42, 84. [CrossRef]

581. Hernández, P.I.; Moreno, D.; Javier, A.A.; Torroba, T.; Pérez-Tomás, R.; Quesada, R. Tambjamine alkaloids and related synthetic analogs: Efficient transmembrane anion transporters. ChemComm. 2012, 48, 1556-1558. [CrossRef]

582. Xu, W.Q.; Song, L.J.; Liu, Q.; Zhao, L.; Zheng, L.; Yan, Z.W.; Fu, G.H. Expression of anion exchanger 1 is associated with tumor progress in human gastric cancer. J. Cancer Res. Clinical Oncol. 2009, 135, 1323-1330. [CrossRef]

583. Liedauer, R.; Svoboda, M.; Wlcek, K.; Arrich, F.; Jäger, W.; Toma, C.; Thalhammer, T. Different expression patterns of organic anion transporting polypeptides in osteosarcomas, bone metastases and aneurysmal bone cysts. Oncol. Rep. 2009, 22, 1485-1492.

584. Buxhofer-Ausch, V.; Secky, L.; Wlcek, K.; Svoboda, M.; Kounnis, V.; Briasoulis, E.; Tzakos, A.G.; Jaeger, W.; Thalhammer, T. Tumor-specific expression of organic anion-transporting polypeptides: Transporters as novel targets for cancer therapy. J. Drug Deliv. 2013, 2013, 1-12. [CrossRef]

585. AbuAli, G.; Grimm, S. Isolation and characterization of the anticancer gene organic cation transporter like-3 (ORCTL3). In Anticancer Genes; Springer: London, UK, 2014; pp. 213-227.

586. Liu, T.; Li, Q. Organic anion-transporting polypeptides: A novel approach for cancer therapy. J. Drug. Target. 2014, 22, 14-22. [CrossRef]

587. Baker, B.; Scheuer, P. The punaglandins: 10-chloroprostanoids from the octocoral Telesto riisei. J. Nat. Prod. 1994, 57, 1346-1353. [CrossRef]

588. Pika, J.; Faulkner, D.J. Four sesquiterpenes from the South African nudibranch Leminda millecra. Tetrahedron 1994, 50, 3065-3070. [CrossRef]

589. McPhail, K.L.; Davies-Coleman, M.T.; Starmer, J. Sequestered chemistry of the arminacean nudibranch Leminda millecra in Algoa Bay, South Africa. J. Nat. Prod. 2001, 64, 1183-1190. [CrossRef] [PubMed]

590. Whibley, C.E.; McPhail, K.L.; Keyzers, R.A.; Maritz, M.F.; Leaner, V.D. : Birrer, M.J.; Davies-Coleman, M.T.; Hendricks, D.T. Reactive oxygen species mediated apoptosis of esophageal cancer cells induced by marine triprenyl toluquinones and toluhydroquinones. Mol. Cancer Ther. 2007, 6, 2535-2543. [CrossRef] [PubMed]

591. Kasheverov, I.E.; Shelukhina, I.V.; Kudryavtsev, D.S.; Makarieva, T.N.; Spirova, E.N.; Guzii, A.G.; Stonik, V.A.; Tsetlin, V.I. 6-Bromohypaphorine from marine nudibranch mollusk Hermissenda crassicornis is an agonist of human $\alpha 7$ nicotinic acetylcholine receptor. Mar. Drugs 2015, 13, 1255-1266. [CrossRef]

592. Carbone, M.; Li, Y.; Irace, C.; Mollo, E.; Castelluccio, F.; Di Pascale, A.; Cimino, G.; Santamaria, R.; Guo, Y.W.; Gavagnin, M. Structure and cytotoxicity of phidianidines A and B: First finding of 1, 2, 4-oxadiazole system in a marine natural product. Organic Lett. 2011, 13, 2516-2519. [CrossRef]

593. Brogan, J.T.; Stoops, S.L.; Lindsley, C.W. Total synthesis and biological evaluation of phidianidines A and B uncovers unique pharmacological profiles at CNS targets. ACS Chem. Neurosci. 2012, 3, 658-664. [CrossRef]

594. Lin, H.Y.; Snider, B.B. Synthesis of phidianidines A and B. J. Org. Chem. 2012, 77, 4832-4836. [CrossRef]

595. Manzo, E.; Pagano, D.; Carbone, M.; Ciavatta, M.L.; Gavagnin, M. Synthesis of phidianidine B, a highly cytotoxic 1, 2, 4-oxadiazole marine metabolite. Arkivoc 2012, 9, 220-228. [CrossRef]

596. Buchanan, J.C.; Petersen, B.P.; Chamberland, S. Concise total synthesis of phidianidine A and B. Tetrahedron Lett. 2013, 54, 6002-6004. [CrossRef]

597. Maftei, C.V.; Fodor, E.; Jones, P.G.; Franz, M.H.; Kelter, G.; Fiebig, H.; Neda, I. Synthesis and characterization of novel bioactive 1, 2, 4-oxadiazole natural product analogs bearing the N-phenylmaleimide and N-phenylsuccinimide moieties. Beilstein J. Org. Chem. 2013, 9, 2202-2215. [CrossRef]

598. Jiang, C.S.; Fu, Y.; Zhang, L.; Gong, J.X.; Wang, Z.Z.; Xiao, W.; Zhang, H.Y.; Guo, Y.W. Synthesis and biological evaluation of novel marine-derived indole-based 1, 2, 4-oxadiazoles derivatives as multifunctional neuroprotective agents. Bioorg. Med. Chem. Lett. 2015, 25, 216-220. [CrossRef] [PubMed]

599. Zhang, L.; Jiang, C.S.; Gao, L.X.; Gong, J.X.; Wang, Z.H.; Li, J.Y.; Li, J.; Li, X.W.; Guo, Y.W. Design, synthesis and in vitro activity of phidianidine B derivatives as novel PTP1B inhibitors with specific selectivity. Bioorg. Med. Chem. Lett. 2016, 26, 778-781. [CrossRef] [PubMed]

600. Khan, I.; Ibrar, A.; Abbas, N. Oxadiazoles as privileged motifs for promising anticancer leads: Recent advances and future prospects. Archiv. Pharm. Chem. Life Sci. 2014, 347, 1-20. [CrossRef] [PubMed] 
601. Ding, D.; Boudreau, M.A.; Leemans, E.; Spink, E.; Yamaguchi, T.; Testero, S.A.; O'Daniel, P.I.; Lastochkin, E.; Chang, M.; Mobashery, S. Exploration of the structure-activity relationship of 1,2,4-oxadiazole antibiotics. Bioorg. Med. Chem. Lett. 2015, 25, 4854-4857. [CrossRef] [PubMed]

602. Lukin, A.; Karapetian, R.; Ivanenkov, Y.; Krasavin, M. Privileged 1,2,4-oxadiazoles in anticancer drug design: Novel 5-aryloxymethyl-1,2,4-oxadiazole leads for prostate cancer therapy. Lett. Drug Des. Discov. 2016, 13, 198-204. [CrossRef]

603. Pitasse-Santos, P.; Sueth-Santiago, V.; Lima, M.E.F. 1,2,4- and 1,3,4-oxadiazoles as scaffolds in the development of antiparasitic agents. J. Brazil Chem. Soc. 2018, 29, 435-456. [CrossRef]

604. Chawla, G. 1,2,4-Oxadiazole as a privileged scaffold for anti-inflammatory and analgesic activities: A review. Mini-Rev. Med. Chem. 2018, 18, 1536-1547. [CrossRef]

605. Manzo, E.; Pagano, D.; Ciavatta, M.L.; Carbone, M.; Gavagnin, M. 1, 2, 4-Oxadiazol Derivatives, Process for Their Preparation and Use Thereof as Intermediates in the Preparation of Indolic Alkaloids. U.S. Patent 20150051405A1, 19 February 2015.

606. Carroll, A.R.; Scheuer, P.J. Kuanoniamines A, B, C, and D: Pentacyclic alkaloids from a tunicate and its prosobranch mollusk predator Chelynotus semperi. J. Org. Chem. 1990, 55, 4426-4431. [CrossRef]

607. Singleton, P.A.; Moss, J.; Karp, D.D.; Atkins, J.T.; Janku, F. The mu opioid receptor: A new target for cancer therapy? Cancer 2015, 121, 2681-2688. [CrossRef]

608. Vitale, R.M.; Gatti, M.; Carbone, M.; Barbieri, F.; Felicità, V.; Gavagnin, M.; Florio, T.; Amodeo, P. Minimalist hybrid ligand/receptor-based pharmacophore model for CXCR4 applied to a small-library of marine natural products led to the identification of phidianidine A as a new CXCR4 ligand exhibiting antagonist activity. ACS Chem. Biol. 2013, 8, 2762-2770. [CrossRef]

609. Barbieri, F.; Thellung, S.; Wurth, R.; Gatto, F.; Corsaro, A.; Villa, V.; Nizzari, M.; Albertelli, M.; Ferone, D.; Florio, T. Emerging targets in pituitary adenomas: Role of the CXCL12/CXCR4-R7 system. Int. J. Endocrinol. 2014, 2014, 753524. [CrossRef] [PubMed]

610. Fu, X.; Palomar, A.J.; Hong, E.P.; Schmitz, F.J.; Valeriote, F.A. Cytotoxic lissoclimide-type diterpenes from the molluscs Pleurobranchus albiguttatus and Pleurobranchus forskalii. J. Nat. Prod. 2004, 67, 1415-1418. [CrossRef] [PubMed]

611. Wesson, K.J.; Hamann, M.T. Keenamide A, a bioactive cyclic peptide from the marine mollusk Pleurobranchus forskalii. J. Nat. Prod. 1996, 59, 629-631. [CrossRef] [PubMed]

612. Tan, K.C.; Wakimoto, T.; Takada, K.; Ohtsuki, T.; Uchiyama, N.; Goda, Y.; Abe, I. Cycloforskamide, a cytotoxic macrocyclic peptide from the sea slug Pleurobranchus forskalii. J. Nat. Prod. 2013, 76, 1388-1391. [CrossRef]

613. Shoemaker, R.H. The NCI60 human tumour cell line anticancer drug screen. Nat. Rev. Cancer 2006, 6, 813-823. [CrossRef]

614. Darro, F.; Decaestecker, C.; Gaussin, J.F.; Mortier, S.; Van Ginckel, R.; Kiss, R. Are syngeneic mouse tumor models still valuable experimental models in the field of anti-cancer drug discovery? Int. J. Oncol. 2005, 27, 607-616.

615. Wakimoto, T.; Tan, K.C.; Abe, I. Ergot Alkaloid from the Sea Slug Pleurobranchus forskalii. Toxicon 2013, 72, 1-4. [CrossRef]

616. Mulac, D.; Humpf, H.-U. Cytotoxicity and accumulation of ergot alkaloids in human primary cells. Toxicology 2011, 282, 112-121. [CrossRef]

617. Boyd, M.R.; Paull, K.D. Some practical considerations and applications of the National Cancer Institute in vitro anticancer drug discovery screen. Drug. Dev. Res. 1995, 34, 91-109. [CrossRef]

618. Robert, F.; Gao, H.Q.; Donia, M.; Merrick, W.C.; Hamann, M.T.; Pelletier, J. Chlorolissoclimides: New inhibitors of eukaryotic protein synthesis. RNA 2006, 12, 717-725. [CrossRef]

619. Malochet-Grivois, C.; Roussakis, C.; Robillard, N.; Biard, J.F.; Riou, D.; Debitus, C.; Verbist, J.F. Effects in vitro of two marine substances, chlorolissoclimide and dichlorolissoclimide, on a non-small-cell bronchopulmonary carcinoma line (NSCLC-N6). Anticancer Drug Des. 1992, 7, 493-505. [PubMed]

620. Uddin, M.J.; Kokubo, S.; Suenaga, K.; Ueda, K.; Uemura, D. Haterumaimides AE, five new dichlorolissoclimide-type diterpenoids from an ascidian, Lissoclinum sp. Heterocycles 2001, 54, 1039-1047.

621. Uddin, M.J.; Kokubo, S.; Ueda, K.; Suenaga, K.; Uemura, D. Haterumaimides F- I, four new cytotoxic diterpene alkaloids from an ascidian Lissoclinum species. J. Nat. Prod. 2001, 64, 1169-1173. [CrossRef] [PubMed] 
622. Uddin, M.J.; Kokubo, S.; Ueda, K.; Suenaga, K.; Uemura, D. Haterumaimides J and K, potent cytotoxic diterpene alkaloids from the ascidian Lissoclinum species. Chem. Lett. 2002, 31, 1028-1029. [CrossRef]

623. Uddin, J.; Ueda, K.; Siwu, E.R.; Kita, M.; Uemura, D. Cytotoxic labdane alkaloids from an ascidian Lissoclinum sp.: Isolation, structure elucidation, and structure-activity relationship. Bioorg. Med. Chem. 2006, 14, 6954-6961. [CrossRef] [PubMed]

624. González, M.A.; Romero, D.; Zapata, B.; Betancur-Galvis, L. First synthesis of lissoclimide-type alkaloids. Lett. Org. Chem. 2009, 6, 289-292. [CrossRef]

625. Thoms, C.; Ebel, R.; Proksch, P. Sequestration and possible role of dietary alkaloids in the sponge-feeding mollusk Tylodina perversa. In Molluscs; Springer: Berlin/Heidelberg, Germany, 2006; pp. 261-275.

626. Kimura, J.; Takada, Y.; Inayoshi, T.; Nakao, Y.; Goetz, G.; Yoshida, W.Y.; Scheuer, P.J. Kulokekahilide-1, a cytotoxic depsipeptide from the cephalaspidean mollusk Philinopsis speciosa. J. Org. Chem. 2002, 67, 1760-1767. [CrossRef]

627. Nakao, Y.; Yoshida, W.Y.; Takada, Y.; Kimura, J.; Yang, L.; Mooberry, S.L.; Scheuer, P.J. Kulokekahilide-2, a cytotoxic depsipeptide from a cephalaspidean mollusk Philinopsis speciosa. J. Nat. Prod. 2004, 67, 1332-1340. [CrossRef]

628. Umehara, M.; Negishi, T.; Tashiro, T.; Nakao, Y.; Kimura, J. Structure-related cytotoxic activity from kulokekahilide-2, a cyclodepsipeptide of Hawaiian marine mollusk. Bioorg. Med. Chem. Lett. 2012, 22, 7422-7425. [CrossRef]

629. Takada, Y.; Umehara, M.; Katsumata, R.; Nakao, Y.; Kimura, J. The total synthesis and structure-activity relationships of a highly cytotoxic depsipeptide kulokekahilide-2 and its analogs. Tetrahedron 2012, 68, 659-669. [CrossRef]

630. Vasskog, T.; Andersen, J.H.; Hansen, E.; Svenson, J. Characterization and cytotoxicity studies of the rare 21: 4 n-7 acid and other polyunsaturated fatty acids from the marine opisthobranch Scaphander lignarius, isolated using bioassay guided fractionation. Mar. Drugs 2012, 10, 2676-2690. [CrossRef] [PubMed]

631. Wessels, M.; König, G.M.; Wright, A.D. New Natural Product Isolation and Comparison of the Secondary Metabolite Content of Three Distinct Samples of the Sea Hare Aplysia dactylomela from Tenerife. J. Nat. Prod. 2000, 63, 920-928. [CrossRef] [PubMed]

632. Sims, J.J.; Lin, G.H.; Wing, R.M. Marine natural products X elatol, a halogenated sesquiterpene alcohol from the red alga Laurencia elata. Tetrahedron Lett. 1974, 15, 3487-3490. [CrossRef]

633. Lang, K.L.; Silva, I.T.; Zimmermann, L.A.; Lhullier, C.; Mañalich Arana, M.V.; Palermo, J.A.; Falkenberg, M.; Simões, C.M.; Schenkel, E.P.; Durán, F.J. Cytotoxic activity of semi-synthetic derivatives of elatol and isoobtusol. Mar. Drugs 2012, 10, 2254-2264. [CrossRef] [PubMed]

634. Gonzalez, A.G.; Darias, J.; Diaz, A.; Fourneron, J.D.; Martin, J.D.; Perez, C. Evidence for the biogenesis of halogenated chamigrenes from the red alga Laurencia obtusa. Tetrahedron Lett 1976, 17, 3051-3054. [CrossRef]

635. Dias, T.; Brito, I.; Moujir, L.; Paiz, N.; Darias, J.; Cueto, M. Cytotoxic Sesquiterpenes from Aplysia dactylomela. J. Nat. Prod. 2005, 68, 1677-1679. [CrossRef]

636. Campos, A.; Souza, C.B.; Lhullier, C.; Falkenberg, M.; Schenkel, E.P.; Ribeiro-do-Valle, R.M.; Siqueira, J.M. Anti-tumour effects of elatol, a marine derivative compound obtained from red algae Laurencia microcladia. J. Pharm. Pharmacol. 2012, 64, 1146-1154. [CrossRef]

637. Van Goietsenoven, G.; Hutton, J.; Becker, J.P.; Lallemand, B.; Robert, F.; Lefranc, F.; Pirker, C.; Vandenbussche, G.; Van Antwerpen, P.; Evidente, A.; et al. Targeting of eEF1A with Amaryllidaceae isocarbostyrils as a strategy to combat melanomas. FASEB J. 2010, 24, 4575-4584. [CrossRef]

638. Mathieu, V.; Le Mercier, M.; De Neve, N.; Sauvage, S.; Gras, T.; Roland, I.; Lefranc, F.; Kiss, R. Galectin-1 knockdown increases sensitivity to temozolomide in a B16F10 mouse metastatic melanoma model. J. Invest. Dermatol. 2007, 127, 2399-2410. [CrossRef]

639. Schmitz, F.J.; Michaud, D.P.; Schmidt, P.G. Marine natural products: Parguerol, deoxyparguerol, and isoparguerol. New brominated diterpenes with modified pimarane skeletons from the sea hare Aplysia dactylomela. J. Am. Chem. Soc. 1982, 104, 6415-6423. [CrossRef]

640. Awad, N.E. Bioactive brominated diterpenes from the marine red alga Jania rubens (L.) Lamx. Phytother. Res. 2004, 18, 275-279. [CrossRef] [PubMed]

641. Vera, B.; Rodríguez, A.D.; Avilés, E.; Ishikawa, Y. Aplysqualenols A and B: Squalene-derived polyethers with antitumoral and antiviral activity from the caribbean sea slug Aplysia dactylomela. Eur. J. Org. Chem. 2009, 31, 5327-5336. [CrossRef] [PubMed] 
642. Vera, B.; Rodríguez, A.D.; La Clair, J.J. Aplysqualenol A binds to the light chain of dynein type 1 (DYNLL1). Angew. Chem. 2011, 123, 8284-8288. [CrossRef]

643. Zhu, G.; Yang, F.; Balachandran, R.; Höök, P.; Vallee, R.B.; Curran, D.P.; Day, B.W. Synthesis and biological evaluation of purealin and analogues as cytoplasmic dynein heavy chain inhibitors. J. Med. Chem. 2006, 49, 2063-2076. [CrossRef]

644. Alberti, C. Cytoskeleton structure and dynamic behaviour: Quick excursus from basic molecular mechanisms to some implications in cancer chemotherapy. Eur. Rev. Med. Pharmacol. Sci. 2009, 13, 13-21.

645. Wong, D.M.; Li, L.; Jurado, S.; King, A.; Bamford, R.; Wall, M.; Walia, M.K.; Kelly, G.L.; Walkley, C.R.; Tarlinton, D.M.; et al. The transcription factor ASCIZ and its target DYNLL1 are essential for the development and expansion of MYC-driven B cell lymphoma. Cell Rep. 2016, 14, 1488-1499. [CrossRef]

646. Manzo, E.; Gavagnin, M.; Bifulco, G.; Cimino, P.; Di Micco, S.; Ciavatta, M.L.; Guo, Y.-W.; Cimino, G. Aplysiols $\mathrm{A}$ and $\mathrm{B}$, squalene-derived polyethers from the mantle of the sea hare Aplysia dactylomela. Tetrahedron 2007, 63, 9970-9978. [CrossRef]

647. Blunt, J.W.; Hartshorn, M.P.; McLennan, T.J.; Munro, M.H.G.; Robinson, W.T.; Yorke, S.C. Thyrsiferol: A squalene-derived metabolite of Laurencia thyrsifera. Tetrahedron Lett. 1978, 19, 69-72. [CrossRef]

648. Mahdi, F.; Falkenberg, M.; Ioannou, E.; Roussis, V.; Zhou, Y.D.; Nagle, D.G. Thyrsiferol inhibits mitochondrial respiration and HIF-1 activation. Phytochem. Lett. 2011, 4, 75-78. [CrossRef]

649. Fernández, J.; Souto, M.L.; Norte, M. Evaluation of the cytotoxic activity of polyethers isolated from Laurencia. Bioorg. Med. Chem. 1998, 6, 2237-2243. [CrossRef]

650. Jiménez, C.; Quiñoá, E.; Castedo, L.; Riguera, R. Epidioxy sterols from the tunicates Dendrodoa grossularia and Ascidiella aspersa and the gastropoda Aplysia depilans and Aplysia punctata. J. Nat. Prod. 1986, 49, 905-909. [CrossRef]

651. Mun, B.; Wang, W.; Kim, H.; Hahn, D.; Yang, I.; Won, D.H.; Kim, E.H.; Lee, J.; Han, C.; Kim, H.; et al. Cytotoxic $5 \alpha, 8 \alpha$-epidioxy sterols from the marine sponge Monanchora sp. Arch. Pharm. Res. 2015, 38, $18-25$. [CrossRef] [PubMed]

652. Yamada, K.; Ojika, M.; Ishigaki, T.; Yoshida, Y.; Ekimoto, H.; Arakawa, M. Aplyronine A, a potent antitumor substance, and the congeners aplyronines B and C isolated from the sea hare Aplysia kurodai. J. Am. Chem. Soc. 1993, 115, 11020-11021. [CrossRef]

653. Ojika, M.; Kigoshi, H.; Suenaga, K.; Imamura, Y.; Yoshikawa, K.; Ishigaki, T.; Sakakura, A.; Mutou, T.; Yamada, K. Aplyronines D-H from the sea hare Aplysia kurodai: Isolation, structures, and cytotoxicity. Tetrahedron 2012, 68, 982-987. [CrossRef]

654. Kuroda, T.; Kigoshi, H. Aplaminal: A novel cytotoxic aminal isolated from the sea hare Aplysia kurodai. Organic Lett. 2008, 10, 489-491. [CrossRef]

655. Kigoshi, H.; Suenaga, K.; Takagi, M.; Akao, A.; Kanematsu, K.; Kamei, N.; Okugawa, Y.; Yamada, K. Cytotoxicity and actin-depolymerizing activity of aplyronine $\mathrm{A}$, a potent antitumor macrolide of marine origin, and its analogs. Tetrahedron 2002, 58, 1075-1102. [CrossRef]

656. Ojika, M.; Kigoshi, H.; Yoshida, Y.; Ishigaki, T.; Nisiwaki, M.; Tsukada, I.; Arakawa, M.; Ekimoto, H.; Yamada, K. Aplyronine A, a potent antitumor macrolide of marine origin, and the congeners aplyronines B and C: Isolation, structures, and bioactivities. Tetrahedron 2007, 63, 3138-3167. [CrossRef]

657. Yamada, K.; Ojika, M.; Kigoshi, H.; Suenaga, K. Aplyronine A, a potent antitumour macrolide of marine origin, and the congeners aplyronines B-H: Chemistry and biology. Nat. Prod. Rep. 2009, 26, 27-43. [CrossRef]

658. Kita, M.; Kigoshi, H. Marine natural products that interfere with multiple cytoskeletal protein interactions. Nat. Prod. Rep. 2015, 32, 534-542. [CrossRef]

659. Ohno, O.; Morita, M.; Kitamura, K.; Teruya, T.; Yoneda, K.; Kita, M.; Kigoshi, H.; Suenaga, K. Apoptosis-inducing activity of the actin-depolymerizing agent aplyronine A and its side-chain derivatives. Bioorg. Med. Chem. Lett. 2013, 23, 1467-1471. [CrossRef]

660. Hirata, K.; Muraoka, S.; Suenaga, K.; Kuroda, T.; Kato, K.; Tanaka, H.; Yamamoto, M.; Takata, M.; Yamada, K.; Kigoshi, H. Structure basis for antitumor effect of aplyronine A. J. Mol. Biol. 2006, 356, 945-954. [CrossRef] [PubMed]

661. Kita, M.; Hirayama, Y.; Sugiyama, M.; Kigoshi, H. Development of highly cytotoxic and actin-depolymerizing biotin derivatives of aplyronine A. Angew. Chem. Int. Ed. 2011, 50, 9871-9874. [CrossRef] [PubMed] 
662. Kita, M.; Hirayama, Y.; Yoneda, K.; Yamagishi, K.; Chinen, T.; Usui, T.; Sumiya, E.; Uesugi, M.; Kigoshi, H. Inhibition of microtubule assembly by a complex of actin and antitumor macrolide aplyronine A. J. Am. Chem. Soc. 2013, 135, 18089-18095. [CrossRef] [PubMed]

663. Hong, W.P.; Noshi, M.N.; El-Awa, A.; Fuchs, P.L. Synthesis of the C1-C20 and C15-C27 segments of aplyronine A. Org. Lett. 2011, 13, 6342-6345. [CrossRef] [PubMed]

664. Paterson, I.; Fink, S.J.; Lee, L.Y.; Atkinson, S.J.; Blakey, S.B. Total synthesis of aplyronine C. Org. Lett. 2013, 15, 3118-3121. [CrossRef]

665. Anžiček, N.; Williams, S.; Housden, M.P.; Paterson, I. Toward aplyronine payloads for antibody-drug conjugates: Total synthesis of aplyronines A and D. Org. Biomol. Chem. 2018, 16, 1343-1350. [CrossRef]

666. Newman, D.J.; Cragg, G.M. Current status of marine-derived compounds as warheads in anti-tumor drug candidates. Mar. Drugs 2017, 15, 99. [CrossRef]

667. Kigoshi, H.; Imamura, Y.; Yoshikawa, K.; Yamada, K. Three new cytotoxic alkaloids, aplaminone, neoaplaminone and neoaplaminone sulfate from the marine mollusc Aplysia kurodai. Tetrahedron Lett. 1990, 31, 4911-4914. [CrossRef]

668. Kusumi, T.; Uchida, H.; Inouye, Y.; Ishitsuka, M.; Yamamoto, H.; Kakisawa, H. Novel cytotoxic monoterpenes having a halogenated tetrahydropyran from Aplysia kurodai. J. Org. Chem. 1987, 52, 4597-4600. [CrossRef]

669. Miyamoto, T.; Higuchi, R.; Marubayashi, N.; Komori, T. Two new polyhalogenated monoterpenes from the sea hare Aplysia kurodai. Liebigs Ann. Chem. 1988, 12, 1191-1193. [CrossRef]

670. Katayama, A.; Ina, K.; Nozaki, H.; Nakayama, M. Structural elucidation of kurodainol, a novel halogenated monoterpene from sea hare (Aplysia kurodai). Agr. Biol. Chem. 1982, 46, 859-860. [CrossRef]

671. Yamamura, S.; Hirata, Y. A naturally-occurring bromo-compound, aplysin-20 from Aplysia kurodai. Bull. Chem. Soc. Jpn. 1971, 44, 2560-2562. [CrossRef]

672. Yamamura, S.; Terada, Y. Isoaplysin-20, a natural bromine-containing diterpene, from Aplysia kurodai. Tetrahedron Lett. 1977, 25, 2171-2172. [CrossRef]

673. Ojika, M.; Yoshida, Y.; Okumura, M.; Ieda, S.; Yamada, K. Aplysiadiol, a new brominated diterpene from the marine mollusc Aplysia kurodai. J. Nat. Prod. 1990, 53, 1619-1622. [CrossRef]

674. Ojika, M.; Kigoshi, H.; Yoshikawa, K.; Nakayama, Y.; Yamada, K. A new bromo diterpene, epi-aplysin-20, and ent-isoconcinndiol from the marine mollusc Aplysia kurodai. Bull. Chem. Soc. Jpn. 1992, 65, 2300-2302. [CrossRef]

675. Ojika, M.; Yoshida, Y.; Nakayama, Y.; Yamada, K. Aplydilactone, a novel fatty acid metabolite from the marine mollusc Aplysia kurodai. Tetrahedron Lett. 1990, 31, 4907-4910. [CrossRef]

676. Ojika, M.; Yoshida, T.; Yamada, K. Aplysepine, a novel 1,4-benzodiazepine alkaloid from the sea hare Aplysia kurodai. Tetrahedron Lett. 1993, 34, 5307-5308. [CrossRef]

677. Iijima, R.; Kisugi, J.; Yamazaki, M. Antifungal activity of aplysianin E, a cytotoxic protein of sea hare (Aplysia kurodai) eggs. Dev. Comp. Immunol. 1995, 19, 13-19.

678. Iijima, R.; Kisugi, J.; Yamazaki, M. A novel antimicrobial peptide from the sea hare Dolabella auricularia. Dev. Comp. Immunol. 2003, 27, 305-311. [CrossRef]

679. Kaviarasan, T.; Siva, S.R.; Yogamoorthi, A. Antimicrobial secondary metabolites from marine gastropod egg capsules and egg masses. Asian Pac. J. Trop Biomed. 2012, 2, 916-922. [CrossRef]

680. Yamamura, S.; Hirata, Y. Structures of aplysin and aplysinol, naturally occurring bromo-compounds. Tetrahedron 1963, 19, 1485-1496. [CrossRef]

681. Ryu, G.S.; Park, S.H.; Choi, B.W.; Lee, N.H.; Hwang, H.J.; Ryu, S.Y.; Lee, B.H. Cytotoxic activities of brominated sesquiterpenes from the red alga Laurencia okamurae. Nat. Prod. Sci. 2002, 8, 103-107.

682. Liu, J.; Ma, L.; Wu, N.; Liu, G.; Zheng, L.; Lin, X. Aplysin sensitizes cancer cells to TRAIL by suppressing P38 MAPK/survivin pathway. Mar. Drugs 2014, 12, 5072-5088. [CrossRef] [PubMed]

683. Gong, A.J.; Gong, L.L.; Yao, W.C.; Ge, N.; Lu, L.X.; Liang, H. Aplysin induces apoptosis in glioma cells through HSP90/AKT pathway. Exp. Biol. Med. 2015, 240, 639-644. [CrossRef]

684. Hegazy, M.E.F.; Moustfa, A.Y.; Mohamed, A.E.H.H.; Alhammady, M.A.; Elbehairi, S.E.I.; Ohta, S.; Paré, P.W. New cytotoxic halogenated sesquiterpenes from the Egyptian sea hare, Aplysia oculifera. Tetrahedron Lett. 2014, 55, 1711-1714. [CrossRef]

685. Ortega, M.J.; Zubía, E.; Salvá, J. New polyhalogenated monoterpenes from the sea hare Aplysia punctata. J. Nat. Prod. 1997, 60, 482-484. [CrossRef] 
686. Pennings, S.C.; Paul, V.J.; Dunbar, D.C.; Hamann, M.T.; Lumbang, W.; Novack, B.; Jacobs, R.S. Unpalatable compounds in the marine gastropod Dolabella auricularia: Distribution and effect of diet. J. Chem. Ecol. 1999, 25, 735-755. [CrossRef]

687. Suenaga, K.; Shibata, T.; Takada, N.; Kigoshi, H.; Yamada, K. Aurilol, a cytotoxic bromotriterpene isolated from the sea hare Dolabella auricularia. J. Nat. Prod. 1998, 61, 515-518. [CrossRef]

688. Sone, H.; Kigoshi, H.; Yamada, K. Aurisides A and B, cytotoxic macrolide glycosides from the Japanese sea hare Dolabella auricularia. J. Org. Chem. 1996, 61, 8956-8960. [CrossRef]

689. Paterson, I.; Florence, G.J.; Heimann, A.C.; Mackay, A.C. Stereocontrolled total synthesis of (-)-aurisides A and B. Angew. Chem. Int. Ed. 2005, 44, 1130-1133. [CrossRef]

690. Tello-Aburto, R.; Olivo, H.F. A formal synthesis of the auriside aglycon. Organic Lett. 2008, 10, $2191-2194$. [CrossRef] [PubMed]

691. Ojika, M.; Nemoto, T.; Yamada, K. Doliculols A and B, the non-halogenated C15 acetogenins with cyclic ether from the sea hare Dolabella auricularia. Tetrahedron Lett 1993, 34, 3461-3462. [CrossRef]

692. Ojika, M.; Nagoya, T.; Yamada, K. Dolabelides A and B, cytotoxic 22-membered macrolides isolated from the sea hare Dolabella auricularia. Tetrahedron Lett. 1995, 36, 7491-7494. [CrossRef]

693. Suenaga, K.; Nagoya, T.; Shibata, T.; Kigoshi, H.; Yamada, K. Dolabelides C and D, cytotoxic macrolides isolated from the sea hare Dolabella auricularia. J. Nat. Prod. 1997, 60, 155-157. [CrossRef]

694. Yamada, K.; Ojika, M.; Kigoshi, H.; Suenaga, K. Cytotoxic substances from two species of Japanese sea hares: Chemistry and bioactivity. Proc. Japan Acad. Ser. B Phys. Biol. Sci. 2010, 86, 176-189. [CrossRef]

695. Sone, H.; Kondo, T.; Kiryu, M.; Ishiwata, H.; Ojika, M.; Yamada, K. Dolabellin, a cytotoxic bisthiazole metabolite from the sea hare Dolabella auricularia: Structural determination and synthesis. J. Org. Chem. 1995, 60, 4774-4781. [CrossRef]

696. Suenaga, K.; Kigoshi, H.; Yamada, K. Auripyrones A and B, cytotoxic polypropionates from the sea hare Dolabella auricularia: Isolation and structures. Tetrahedron Lett. 1996, 37, 5151-5154. [CrossRef]

697. Lister, T.; Perkins, M.V. Total synthesis of auripyrone A. Angew. Chem. Int. Ed. 2006, 45, $2560-2564$. [CrossRef]

698. Jung, M.E.; Chaumontet, M.; Salehi-Rad, R. Total synthesis of auripyrone B using a non-aldol aldolcuprate opening process. Org. Lett. 2010, 12, 2872-2875. [CrossRef]

699. Jung, M.E.; Salehi-Rad, R. Total synthesis of auripyrone A using a tandem non-aldol aldol/Paterson aldol process as a key step. Angew. Chem. Int. Ed. 2009, 48, 8766-8769. [CrossRef]

700. Hayakawa, I.; Takemura, T.; Fukasawa, E.; Ebihara, Y.; Sato, N.; Nakamura, T.; Suenaga, K.; Kigoshi, H. Total synthesis of auripyrones A and B and determination of the absolute configuration of auripyrone B. Angew. Chem. Int. Ed. 2010, 49, 2401-2405. [CrossRef] [PubMed]

701. Park, P.K.; O'Malley, S.J.; Schmidt, D.R.; Leighton, J.L. Total synthesis of dolabelide D. J. Am. Chem. Soc. 2006, 128, 2796-2797. [CrossRef] [PubMed]

702. Hanson, P.R.; Chegondi, R.; Nguyen, J.; Thomas, C.D.; Waetzig, J.D.; Whitehead, A. Total synthesis of dolabelide C: A phosphate-mediated approach. J. Org. Chem. 2011, 76, 4358-4370. [CrossRef] [PubMed]

703. Suenaga, K.; Mutou, T.; Shibata, T.; Itoh, T.; Kigoshi, H.; Yamada, K. Isolation and stereostructure of aurilide, a novel cyclodepsipeptide from the Japanese sea hare Dolabella auricularia. Tetrahedron Lett. 1996, 37, 6771-6774. [CrossRef]

704. Han, B.; Gross, H.; Goeger, D.E.; Mooberry, S.L.; Gerwick, W.H. Aurilides B and C, cancer cell toxins from a Papua New Guinea collection of the marine cyanobacterium Lyngbya majuscula. J. Nat. Prod. 2006, 69, 572-575. [CrossRef]

705. Suenaga, K.; Mutou, T.; Shibata, T.; Itoh, T.; Fujita, T.; Takada, N.; Hayamizu, K.; Takagi, M.; Irifune, T.; Kigoshi, H.; et al. Aurilide, a cytotoxic depsipeptide from the sea hare Dolabella auricularia: Isolation, structure determination, synthesis, and biological activity. Tetrahedron 2004, 60, 8509-8527. [CrossRef]

706. Hollingshead, M.G.; Alley, M.C.; Camalier, R.F.; Abbott, B.J.; Mayo, J.G.; Malspeis, L.; Grever, M.R. In vivo cultivation of tumor cells in hollow fibers. Life Sci. 1995, 57, 131-141. [CrossRef]

707. Sato, S.I.; Murata, A.; Orihara, T.; Shirakawa, T.; Suenaga, K.; Kigoshi, H.; Uesugi, M. Marine natural product aurilide activates the OPA1-mediated apoptosis by binding to prohibitin. Chem. Biol. 2011, 18, 131-139. [CrossRef] 
708. Ishiwata, H.; Nemoto, T.; Ojika, M.; Yamada, K. Isolation and stereostructure of doliculide, a cytotoxic cyclodepsipeptide from the Japanese sea hare Dolabella auricularia. J. Org. Chem. 1994, 59, 4710-4711. [CrossRef]

709. Bai, R.; Covell, D.G.; Liu, C.; Ghosh, A.K.; Hamel, E. (-)-Doliculide, a new macrocyclic depsipeptide enhancer of actin assembly. J. Biol. Chem. 2002, 277, 32165-32171. [CrossRef]

710. Ishiwata, H.; Sone, H.; Kigoshi, H.; Yamada, K. Enantioselective total synthesis of doliculide, a potent cytotoxic cyclodepsipeptide of marine origin and structure-cytotoxicity relationships of synthetic doliculide congeners. Tetrahedron 1994, 50, 12853-12882. [CrossRef]

711. Ghosh, A.K.; Liu, C. Total synthesis of antitumor depsipeptide (-)-doliculide. Org. Lett. 2001, 3, $635-638$. [CrossRef] [PubMed]

712. Matcha, K.; Madduri, A.V.; Roy, S.; Ziegler, S.; Waldmann, H.; Hirsch, A.K.; Minnaard, A.J. Total synthesis of (-)-Doliculide, structure-activity relationship studies and its binding to F-actin. Chem. Bio. Chem. 2012, 13, 2537-2548. [CrossRef] [PubMed]

713. Foerster, F.; Braig, S.; Chen, T.; Altmann, K.H.; Vollmar, A.M. Pharmacological characterization of actin-binding (-)-Doliculide. Bioorg. Med. Chem. 2014, 22, 5117-5122. [CrossRef] [PubMed]

714. Harrigan, G.G.; Luesch, H.; Yoshida, W.Y.; Moore, R.E.; Nagle, D.G.; Paul, V.J.; Mooberry, S.L.; Corbett, T.H.; Valeriote, F.A. Symplostatin 1: A Dolastatin 10 analogue from the marine cyanobacterium Symploca hydnoides. J. Nat. Prod. 1998, 61, 1075-1077. [CrossRef]

715. Luesch, H.; Harrigan, G.G.; Goetz, G.; Horgen, F.D. The cyanobacterial origin of potent anticancer agents originally isolated from sea hares. Curr. Med. Chem. 2002, 9, 1791-1806. [CrossRef]

716. Engene, N.; Tronholm, A.; Salvador-Reyes, L.A.; Luesch, H.; Paul, V.J. Caldora penicillata gen. nov., comb. nov. (Cyanobacteria), a pantropical marine species with biomedical relevance. J. Phycol. 2015, 51, 670-681. [CrossRef]

717. Maderna, A.; Leverett, C.A. Recent advances in the development of new auristatins: Structural modifications and application in antibody drug conjugates. Mol. Pharm. 2015, 12, 1798-1812. [CrossRef]

718. Pettit, G.R.; Kamano, Y.; Brown, P.; Gust, D.; Inoue, M.; Herald, C.L. Structure of the cyclic peptide dolastatin 3 from Dolabella auricularia. J. Am. Chem. Soc. 1982, 104, 905-907. [CrossRef]

719. Pettit, G.R.; Kamano, Y.; Herald, C.L.; Fujii, Y.; Kizu, H.; Boyd, M.R.; Boettner, F.E.; Doubek, D.L.; Schmidt, J.M.; Chapuis, J.-C.; et al. Isolation of dolastatins 10-15 from the marine mollusc Dolabella auricularia. Tetrahedron 1993, 49, 9151-9170. [CrossRef]

720. Yamada, K.; Kigoshi, H. Bioactive compounds from the sea hares of two genera: Aplysia and Dolabella. Bull. Chem. Soc. Jpn. 1997, 70, 1479-1489. [CrossRef]

721. Sone, H.; Nemoto, T.; Ishiwata, H.; Ojika, M.; Yamada, K. Isolation, structure, and synthesis of dolastatin D, a cytotoxic cyclic depsipeptide from the sea hare Dolabella auricularia. Tetrahedron Lett. 1993, 34, 8449-8452. [CrossRef]

722. Sone, H.; Nemoto, T.; Ojika, M.; Yamada, K. Isolation, structure, and synthesis of dolastatin C, a cytotoxic cyclic depsipeptide from the sea hare Dolabella auricularia. Tetrahedron Lett. 1993, 34, 8445-8448. [CrossRef]

723. Sone, H.; Shibata, T.; Fujita, T.; Ojika, M.; Yamada, K. Dolastatin H and isodolastatin H, potent cytotoxic peptides from the sea hare Dolabella auricularia: Isolation, stereostructures, and synthesis. J. Am. Chem. Soc. 1996, 118, 1874-1880. [CrossRef]

724. Mutou, T.; Kondo, T.; Ojika, M.; Yamada, K. Isolation and stereostructures of dolastatin G and nordolastatin G, cytotoxic 35-membered cyclodepsipeptides from the Japanese sea hare Dolabella auricularia. J. Org. Chem. 1996, 61, 6340-6345. [CrossRef]

725. Luesch, H.; Yoshida, W.Y.; Moore, R.E.; Paul, V.J. Lyngbyastatin 2 and norlyngbyastatin 2, analogues of dolastatin $\mathrm{G}$ and nordolastatin $\mathrm{G}$ from the marine cyanobacterium Lyngbya majuscula. J. Nat. Prod. 1999, 62, 1702-1706. [CrossRef]

726. Newman, D.J. The "utility" of highly toxic marine-sourced compounds. Mar. Drugs 2019, 17, 324. [CrossRef]

727. Pettit, G.R.; Kamano, Y.; Holzapfel, C.W.; Van Zyl, W.J.; Tuinman, A.A.; Herald, C.L.; Baczynskyj, L.; Schmidt, J.M. Antineoplastic agents. 150. The structure and synthesis of dolastatin 3. J. Am. Chem. Soc. 1987, 109, 7581-7582. [CrossRef]

728. Mitchell, S.S.; Faulkner, D.J.; Rubins, K.; Bushman, F.D. Dolastatin 3 and two novel cyclic peptides from a Palauan collection of Lyngbya majuscula. J. Nat. Prod. 2000, 63, 279-282. [CrossRef] 
729. Pettit, G.R.; Kamano, Y.; Herald, C.L.; Tuinman, A.A.; Boettner, F.E.; Kizu, H.; Schmidt, J.M.; Baczynskyj, L.; Tomer, K.B.; Bontems, R.J. The isolation and structure of a remarkable marine animal antineoplastic constituent: Dolastatin 10. J. Am. Chem. Soc. 1987, 109, 6883-6885. [CrossRef]

730. Pettit, G.R.; Singh, S.B.; Hogan, F.; Lloyd-Williams, P.; Herald, D.L.; Burkett, D.D.; Clewlow, P.J. The absolute configuration and synthesis of natural (-)-dolastatin 10. J. Am. Chem. Soc. 1989, 111, 5463-5466. [CrossRef]

731. Singh, R.; Sharma, M.; Joshi, P.; Rawat, D.S. Clinical status of anti-cancer agents derived from marine sources. Anticancer Agents Med. Chem. 2008, 8, 603-617. [CrossRef] [PubMed]

732. Poncet, J. The dolastatins, a family of promising antineoplastic agents. Cur. Pharm. Des. 1999, 5, $139-162$.

733. Bai, R.; Pettit, G.R.; Hamel, E. Dolastatin 10, a powerful cytostatic peptide derived from a marine animal. Inhibition of tubulin polymerization mediated through the vinca alkaloid binding domain. Biochem. Pharmacol. 1990, 39, 1941-1949. [CrossRef]

734. Pathak, S.; Multani, A.S.; Ozen, M.; Richardson, M.A.; Newman, R.A. Dolastatin-10 induces polyploidy, telomeric associations and apoptosis in a murine melanoma cell line. Oncol. Rep. 1998, 5, 373-379. [CrossRef]

735. Mooberry, S.L.; Leal, R.M.; Tinley, T.L.; Luesch, H.; Moore, R.E.; Corbett, T.H. The molecular pharmacology of symplostatin 1: A new antimitotic dolastatin 10 analog. Int. J. Cancer 2003, 104, 512-521. [CrossRef]

736. Kalemkerian, G.P.; Ou, X.; Adil, M.R.; Rosati, R.; Khoulani, M.M.; Madan, S.K.; Pettit, G.R. Activity of dolastatin 10 against small-cell lung cancer in vitro and in vivo: Induction of apoptosis and bcl-2 modification. Cancer Chemother. Pharmacol. 1999, 43, 507-515. [CrossRef]

737. Mohammad, R.M.; Pettit, G.R.; Almatchy, V.P.; Wall, N.; Varterasian, M.; Al-Katib, A. Synergistic interaction of selected marine animal anticancer drugs against human diffuse large cell lymphoma. Anticancer Drugs 1998, 9, 149-156. [CrossRef]

738. Aherne, G.W.; Hardcastle, A.; Valenti, M.; Bryant, A.; Rogers, P.; Pettit, G.R.; Srirangam, J.K.; Kelland, L.R. Antitumour evaluation of dolastatins 10 and 15 and their measurement in plasma by radioimmunoassay. Cancer Chemother. Pharmacol. 1996, 38, 225-232. [CrossRef]

739. Watanabe, J.; Natsume, T.; Fujio, N.; Miyasaka, K.; Kobayashi, M. Induction of apoptosis in human cancer cells by TZT-1027, an antimicrotubule agent. Apoptosis 2000, 5, 345-353. [CrossRef]

740. Verdier-Pinard, P.; Kepler, J.A.; Pettit, G.R.; Hamel, E. Sustained intracellular retention of dolastatin 10 causes its potent antimitotic activity. Mol. Pharmacol. 2000, 57, 180-187. [PubMed]

741. Doronina, S.O.; Toki, B.E.; Torgov, M.Y.; Mendelsohn, B.A.; Cerveny, C.G.; Chace, D.F.; DeBlanc, R.L.; Gearing, R.P.; Bovee, T.D.; Siegall, C.B.; et al. Development of potent monoclonal antibody auristatin conjugates for cancer therapy. Nature Biotech. 2003, 21, 778-784. [CrossRef] [PubMed]

742. Steinmetz, M.O.; Prota, A.E. Microtubule-targeting agents: Strategies to hijack the cytoskeleton. Trends Cell Biol. 2018, 28, 776-792. [CrossRef] [PubMed]

743. Johansson, M.P.; Maaheimo, H.; Ekholm, F.S. New insight on the structural features of the cytotoxic auristatins MMAE and MMAF revealed by combined NMR spectroscopy and quantum chemical modelling. Sci. Rep. 2017, 7, 1-10. [CrossRef] [PubMed]

744. Flahive, E.; Srirangam, J. The Dolastatins. In Anticancer Agents from Natural Products, 2nd ed.; Cragg, G.M., Kingston, D.G.I., Newman, D.J., Eds.; Taylor and Francis: Boca Raton, FL, USA, 2011; pp. 263-290.

745. Salvador-Reyes, L.A.; Luesch, H. Biological targets and mechanisms of action of natural products from marine cyanobacteria. Nat. Prod. Rep. 2015, 32, 478-503. [CrossRef] [PubMed]

746. Pettit, G.R.; Barkoczy, J.; Kantoci, D. Human Cancer Inhibitory Pentapeptide Amides. US Patent 5410024, 25 April 1995.

747. Watanabe, J.; Minami, M.; Kobayashi, M. Antitumor activity of TZT-1027 (Soblidotin). Anticancer Res. 2006, 26, 1973-1981.

748. Natsume, T.; Watanabe, J.; Ogawa, K.; Yasumura, K.; Kobayashi, M. Tumor-specific antivascular effect of TZT-1027 (Soblidotin) elucidated by magnetic resonance imaging and confocal laser scanning microscopy. Cancer Sci. 2007, 98, 598-604. [CrossRef]

749. Martins, A.; Vieira, H.; Gaspar, H.; Santos, S. Marketed marine natural products in the pharmaceutical and cosmeceutical industries: Tips for success. Mar. Drugs 2014, 12, 1066-1101. [CrossRef]

750. Pettit, G.R.; Kamano, Y.; Kizu, H.; Dufresne, C.; Herald, C.L.; Bontems, R.J.; Schmidt, J.M.; Boettner, F.E.; Nieman, R.A. Isolation and structure of the cell growth inhibitory depsipeptides dolastatins 11 and 12. Heterocycles 1989, 28, 553-558. [CrossRef] 
751. Pettit, G.R.; Kamano, Y.; Herald, C.L.; Dufresne, C.; Cerny, R.L.; Herald, D.L.; Schmidt, J.M.; Kizu, H. Isolation and structure of the cytostatic depsipeptide dolastatin 13 from the sea hare Dolabella auricularia. J. Am. Chem. Soc. 1989, 111, 5015-5017. [CrossRef]

752. Pettit, G.R.; Kamano, Y.; Herald, C.L.; Dufresne, C.; Bates, R.B.; Schmidt, J.M.; Cerny, R.L.; Kizu, H. Antineoplastic agents. 190. Isolation and structure of the cyclodepsipeptide dolastatin 14. J. Org. Chem. 1990, 55, 2989-2990. [CrossRef]

753. Harrigan, G.G.; Yoshida, W.Y.; Moore, R.E.; Nagle, D.G.; Park, P.U.; Biggs, J.; Paul, V.J.; Mooberry, S.L.; Corbett, T.H.; Valeriote, F.A. Isolation, structure determination, and biological activity of dolastatin 12 and lyngbyastatin 1 from Lyngbya majuscula/Schizothrix calcicola cyanobacterial assemblages. J. Nat. Prod. 1998, 61, 1221-1225. [CrossRef] [PubMed]

754. Ali, M.A.; Bates, R.B.; Crane, Z.D.; Dicus, C.W.; Gramme, M.R.; Hamel, E.; Marcischak, J.; Martinez, D.S.; McClure, K.J.; Nakkiew, P.; et al. Dolastatin 11 conformations, analogues and pharmacophore. Bioorg. Med. Chem. 2005, 13, 4138-4152. [CrossRef] [PubMed]

755. Thornburg, C.C.; Thimmaiah, M.; Shaala, L.A.; Hau, A.M.; Malmo, J.M.; Ishmael, J.E.; Youssef, D.T.; McPhail, K.L. Cyclic depsipeptides, grassypeptolides D and E and ibu-epidemethoxylyngbyastatin 3, from a Red Sea Leptolyngbya cyanobacterium. J. Nat. Prod. 2011, 74, 1677-1685. [CrossRef] [PubMed]

756. Pettit, G.R.; Kamano, Y.; Dufresne, C.; Cerny, R.L.; Herald, C.L.; Schmidt, J.M. Isolation and structure of the cytostatic linear depsipeptide dolastatin 15. J. Org. Chem. 1989, 54, 6005-6006. [CrossRef]

757. Pettit, G.R.; Herald, D.L.; Singh, S.B.; Thornton, T.J.; Mullaney, J.T. Antineoplastic agents. 220. Synthesis of natural (-)-dolastatin 15. J. Am. Chem. Soc. 1991, 113, 6692-6693. [CrossRef]

758. Akaji, K.; Hayashi, Y.; Kiso, Y.; Kuriyama, N. Convergent synthesis of dolastatin 15 by solid phase coupling of an N-methylamino acid. J. Org. Chem. 1999, 64, 405-411. [CrossRef]

759. Yokosaka, A.; Izawa, A.; Sakai, C.; Sakurada, E.; Morita, Y.; Nishio, Y. Synthesis and evaluation of novel dolastatin 10 derivatives for versatile conjugations. Bioorg. Med. Chem. 2018, 26, 1643-1652. [CrossRef]

760. Newman, D.J.; Cragg, G.M. Advanced preclinical and clinical trials of natural products and related compounds from marine sources. Curr. Med. Chem. 2004, 11, 1693-1713. [CrossRef]

761. Miller, J.H.; Field, J.J.; Kanakkanthara, A.; Owen, J.G.; Singh, A.J.; Northcote, P.T. Marine invertebrate natural products that target microtubules. J. Nat. Prod. 2018, 81, 691-702. [CrossRef]

762. Bai, R.; Friedman, S.J.; Pettit, G.R.; Hamel, E. Dolastatin 15, a potent antimitotic depsipeptide derived from Dolabella auricularia: Interaction with tubulin and effects on cellular microtubules. Biochem. Pharmacol. 1992, 43, 2637-2645. [CrossRef]

763. Ali, M.A.; Rosati, R.; Pettit, G.; Kalemkerian, G.P. Dolastatin 15 induces apoptosis and BCL-2 phosphorylation in small cell lung cancer cell lines. Anticancer Res. 1998, 18, 1021-1026. [PubMed]

764. Sato, M.; Sagawa, M.; Nakazato, T.; Ikeda, Y.; Kizaki, M. A natural peptide, dolastatin 15, induces G2/M cell cycle arrest and apoptosis of human multiple myeloma cells. Int. J. Oncol. 2007, 30, 1453-1459. [CrossRef] [PubMed]

765. Beckwith, M.; Urba, W.J.; Longo, D.L. Growth inhibition of human lymphoma cell lines by the marine products, dolastatins 10 and 15. JNCI J. Nat. Cancer Ins. 1993, 85, 483-488. [CrossRef]

766. Bai, R.; Edler, M.C.; Bonate, P.L.; Copeland, T.D.; Pettit, G.R.; Luduena, R.F.; Hamel, E. Intracellular activation and deactivation of tasidotin, an analog of dolastatin 15: Correlation with cytotoxicity. Mol. Pharmacol. 2009, 75, 218-226. [CrossRef]

767. Ray, A.; Okouneva, T.; Manna, T.; Miller, H.P.; Schmid, S.; Arthaud, L.; Luduena, R.; Jordan, M.A.; Wilson, L. Mechanism of action of the microtubule-targeted antimitotic depsipeptide tasidotin (formerly ILX651) and its major metabolite tasidotin C-carboxylate. Cancer Res. 2007, 67, 3767-3776. [CrossRef]

768. Garg, V.; Zhang, W.; Gidwani, P.; Kim, M.; Kolb, E.A. Preclinical analysis of tasidotin HCl in Ewing's sarcoma, rhabdomyosarcoma, synovial sarcoma, and osteosarcoma. Clin. Cancer Res. 2007, 13, 5446-5454. [CrossRef]

769. Salvador, L.A.; Biggs, J.S.; Paul, V.J.; Luesch, H. Veraguamides A- G, cyclic hexadepsipeptides from a dolastatin 16-producing cyanobacterium Symploca cf. hydnoides from Guam. J. Nat. Prod. 2011, 74, 917-927. [CrossRef]

770. Pettit, G.R.; Xu, J.P.; Hogan, F.; Williams, M.D.; Doubek, D.L.; Schmidt, J.M.; Cerny, R.L.; Boyd, M.R. Isolation and structure of the human cancer cell growth inhibitory cyclodepsipeptide dolastatin 16. J. Nat. Prod. 1997, 60, 752-754. [CrossRef] 
771. Nogle, L.M.; Gerwick, W.H. Isolation of four new cyclic depsipeptides, antanapeptins A- D, and dolastatin 16 from a Madagascan collection of Lyngbya majuscula. J. Nat. Prod. 2002, 65, 21-24. [CrossRef]

772. Monks, A.; Scudiero, D.; Skehan, P.; Shoemaker, R.; Paull, K.; Vistica, D.; Hose, C.; Langley, J.; Cronise, P.; Vaigro-Wolff, A.; et al. Feasibility of a high-flux anticancer drug screen using a diverse panel of cultured human tumor cell lines. JNCI J. Natl. Cancer I. 1991, 83, 757-766. [CrossRef] [PubMed]

773. Pettit, G.R.; Xu, J.P.; Hogan, F.; Cerny, R.L. Isolation and structure of dolastatin 17. Heterocycles 1998, 47, 491-496. [CrossRef]

774. Kobayashi, S.; Kobayashi, J.; Yazaki, R.; Ueno, M. Toward the total synthesis of onchidin, a cytotoxic cyclic depsipeptide from a mollusc. Chem. Asian J. 2007, 2, 135-144. [CrossRef] [PubMed]

775. Pettit, G.R.; Xu, J.P.; Williams, M.D.; Hogan, F.; Schmidt, J.M.; Cerny, R.L. Antineoplastic agents 370. Isolation and structure of dolastatin 18. Bioorg. Chem. Med. Lett. 1997, 7, 827-832. [CrossRef]

776. Pettit, G.R.; Xu, J.P.; Doubek, D.L.; Chapuis, J.C.; Schmidt, J.M. Antineoplastic Agents. 510. Isolation and structure of dolastatin 19 from the Gulf of California sea hare Dolabella auricularia. J. Nat. Prod. 2004, 67, 1252-1255. [CrossRef]

777. Moore, R.E. Toxins, anticancer agents, and tumor promoters from marine prokaryotes. Pure Appl. Chem. 1982, 54, 1919-1934. [CrossRef]

778. Watson, M. Midgut gland toxins of Hawaiian sea hares. I. Isolation and preliminary toxicological observations. Toxicon 1973, 11, 259-267. [CrossRef]

779. Watson, M.; Rayner, M.D. Midgut gland toxins of Hawaiian sea hares. II. A preliminary pharmacological study. Toxicon 1973, 11, 269-276. [CrossRef]

780. Ashida, Y.; Yanagita, R.C.; Takahashi, C.; Kawanami, Y.; Irie, K. Binding mode prediction of aplysiatoxin, a potent agonist of protein kinase $C$, through molecular simulation and structure-activity study on simplified analogs of the receptor-recognition domain. Bioorg. Med. Chem. 2016, 24, 4218-4227. [CrossRef]

781. Cardellina, J.H.; Marner, F.J.; Moore, R.E. Seaweed dermatitis: Structure of Lyngbyatoxin A. Science 1979, 204, 193-195. [CrossRef]

782. Cardellina, J.H.; Marner, F.J.; Moore, R.E. Malyngamide A, a novel chlorinated metabolite of the marine cyanophyte Lyngbya majuscula. J. Am. Chem. Soc. 1979, 101, 240-242. [CrossRef]

783. Capper, A.; Tibbetts, I.R.; O'Neil, J.M.; Shaw, G.R. The fate of Lyngbya majuscula toxins in three potential consumers. J. Chem. Ecol. 2005, 31, 1595-1606. [CrossRef] [PubMed]

784. Suntornchashwej, S.; Chaichit, N.; Isobe, M.; Suwanborirux, K. Hectochlorin and morpholine derivatives from the Thai sea hare, Bursatella leachii. J. Nat. Prod. 2005, 68, 951-955. [CrossRef] [PubMed]

785. Marquez, B.L.; Watts, K.S.; Yokochi, A.; Roberts, M.A.; Verdier-Pinard, P.; Jimenez, J.I.; Hamel, E.; Scheuer, P.J.; Gerwick, W.H. Structure and absolute stereochemistry of hectochlorin, a potent stimulator of actin assembly. J. Nat. Prod. 2002, 65, 866-871. [CrossRef] [PubMed]

786. Appleton, D.R.; Sewell, M.A.; Berridge, M.V.; Copp, B.R. A new biologically active malyngamide from a New Zealand collection of the sea hare Bursatella leachii. J. Nat. Prod. 2002, 65, 630-631. [CrossRef]

787. Suntornchashwej, S.; Suwanborirux, K.; Koga, K.; Isobe, M. Malyngamide X: The first (7R)-lyngbic acid that connects to a new tripeptide backbone from the Thai sea hare Bursatella leachii. Chem. Asian J. 2007, 2, 114-122. [CrossRef]

788. Fischel, J.L.; Lemee, R.; Formento, P.; Caldani, C.; Moll, J.L.; Pesando, D.; Meinesz, A.; Grelier, P.; Pietra, P.; Guerriero, A. Cell growth inhibitory effects of caulerpenyne, a sesquiterpenoid from the marine algae Caulerpa taxifolia. Anticancer Res. 1995, 15, 2155-2160.

789. Cavas, L.; Baskin, Y.; Yurdakoc, K.; Olgun, N. Antiproliferative and newly contributed apoptotic activities from an invasive marine alga: Caulerpa racemosa var. cylindracea. J. Exp. Mar. Biol. Ecol. 2006, 339, 111-119. [CrossRef]

790. Barbier, P.; Guise, S.; Huitorel, P.; Amade, P.; Pesando, D.; Briand, C.; Peyrot, V. Caulerpenyne from Caulerpa taxifolia has an antiproliferative activity on tumor cell line SK-N-SH and modifies the microtubule network. Life Sci. 2001, 70, 415-429. [CrossRef]

791. Parent-Massin, D.; Fournier, V.; Amade, P.; Lemee, R.; Durand-Clement, M.; Delescluse, C.; Pesando, D. Evaluation of the toxicological risk to humans of caulerpenyne using human hematopoietic progenitors, melanocytes, and keratinocytes in culture. J. Toxicol. Environ. Health 1996, 47, 47-59. [CrossRef] 
792. Bourdron, J.; Barbier, P.; Allegro, D.; Villard, C.; Lafitte, D.; Commeiras, L.; Parrain, J.L.; Peyrot, V. Caulerpenyne binding to tubulin: Structural modifications by a non conventional pharmacological agent. Med. Chem. 2009, 5, 182-190. [CrossRef] [PubMed]

793. Pesando, D.; Pesci-Bardon, C.; Huitorel, P.; Girard, J.P. Caulerpenyne blocks MBP kinase activation controlling mitosis in sea urchin eggs. Eur. J. Cell. Biol. 1999, 78, 903-910. [CrossRef]

794. Gao, J.; Hamann, M.T. Chemistry and biology of kahalalides. Chem. Rev. 2011, 111, 3208-3235. [CrossRef] [PubMed]

795. Ciavatta, M.L.; Devi, P.; Carbone, M.; Mathieu, V.; Kiss, R.; Casapullo, A.; Gavagnin, M. Kahalalide F analogues from the mucous secretion of Indian sacoglossan mollusc Elysia ornata. Tetrahedron 2016, 72, 625-631. [CrossRef]

796. Ashour, M.; Edrada, R.; Ebel, R.; Wray, V.; Wätjen, W.; Padmakumar, K.; Müller, W.E.G.; Lin, W.H.; Proksch, P. Kahalalide derivatives fromthe Indian dacoglossan mollusk Elysia grandifolia. J. Nat. Prod. 2006, 69, 1547-1553. [CrossRef]

797. Hamann, M.T.; Scheuer, P.J. Kahalalide F: A bioactive depsipeptide from the sacoglossan mollusk Elysia rufescens and the green alga Bryopsis sp. J. Am. Chem. Soc. 1993, 115, 5825-5826. [CrossRef]

798. Kan, Y.; Fujita, T.; Sakamoto, B.; Hokama, Y.; Nagai, H. A new cyclic depsipeptide from the Hawaiian green alga Bryopsis species. J. Nat. Prod. 1999, 62, 1169-1172. [CrossRef]

799. Suárez, Y.; González, L.; Cuadrado, A.; Berciano, M.; Lafarga, M.; Muñoz, A. Kahalalide F, a new marine-derived compound, induces oncosis in human prostate and breast cancer cells. Mol. Cancer Ther. 2003, 2, 863-872.

800. Janmaat, M.L.; Rodriguez, J.A.; Jimeno, J.; Kruyt, F.A.E.; Giaccone, G. Kahalalide F induces necrosis-like cell death that involves depletion of ErbB3 and inhibition of Akt signaling. Mol. Pharmacol. 2005, 68, 502-510. [CrossRef]

801. Pardo, B.; Paz-Ares, L.; Tabernero, J.; Ciruelos, E.; García, M.; Salazar, R.; López, A.; Blanco, M.; Nieto, A.; Jimeno, J.; et al. Phase I clinical and pharmacokinetic study of kahalalide F administered weekly as a 1-hour infusion to patients with advanced solid tumors. Clin. Cancer Res. 2008, 14, 1116-1123. [CrossRef]

802. Rademaker-Lakhai, J.M.; Horenblas, S.; Meinhardt, W.; Stokvis, E.; de Reijke, T.M.; Jimeno, J.M.; Lopez-Lazaro, L.; Martin, J.A.L.; Beijnen, J.H.; Schellens, J.H. Phase I clinical and pharmacokinetic study of kahalalide F in patients with advanced androgen refractory prostate cancer. Clin. Cancer Res. 2005, 11, 1854-1862. [CrossRef] [PubMed]

803. Sewell, J.M.; Mayer, I.; Langdon, S.P.; Smyth, J.F.; Jodrell, D.I.; Guichard, S.M. The mechanism of action of Kahalalide F: Variable cell permeability in human hepatoma cell lines. Eur. J. Cancer 2005, 41, 1637-1644. [CrossRef] [PubMed]

804. Miguel-Lillo, B.; Valenzuela, B.; Peris-Ribera, J.E.; Soto-Matos, A.; Pérez-Ruixo, J.J. Population pharmacokinetics of kahalalide F in advanced cancer patients. Cancer Chemother. Pharmacol. 2015, 76, 365-374. [CrossRef] [PubMed]

805. Martín-Algarra, S.; Espinosa, E.; Rubió, J.; López, J.J.L.; Manzano, J.L.; Carrión, L.A.; Plazaola, A.; Tanovic, A.; Paz-Ares, L. Phase II study of weekly Kahalalide F in patients with advanced malignant melanoma. Eur. J. Cancer 2009, 45, 732-735. [CrossRef]

806. Wang, B.; Waters, A.L.; Valeriote, F.A.; Hamann, M.T. An efficient and cost-effective approach to Kahalalide F $\mathrm{N}$-terminal modifications using a nuisance algal bloom of Bryopsis pennata. Biochim. Biophys. Acta (BBA) Gen. Subj. 2015, 1850, 1849-1854. [CrossRef]

807. Shilabin, A.G.; Hamann, M.T. In vitro and in vivo evaluation of select kahalalide F analogs with antitumor and antifungal activities. Bioorg. Med. Chem. 2011, 19, 6628-6632. [CrossRef]

808. Davis, J.; Fricke, W.F.; Hamann, M.T.; Esquenazi, E.; Dorrestein, P.C.; Hill, R.T. Characterization of the bacterial community of the chemically defended hawaiian sacoglossan Elysia rufescens. Appl. Environ. Microbiol. 2013, 79, 7073-7081. [CrossRef]

809. Ling, Y.H.; Miguel, A.; Zou, Y.; Yuan, Z.; Lu, B.; José, J.; Ana, M.C.; Perez-Soler, R. PM02734 (elisidepsin) induces caspase-independent cell death associated with features of autophagy, inhibition of the Akt/mTOR signaling pathway, and activation of death-associated protein kinase. Clin. Cancer Res. 2011, 17, 5353-5366. [CrossRef] 
810. Serova, M.; de Gramont, A.; Bieche, I.; Riveiro, M.E.; Galmarini, C.M.; Aracil, M.; Jimeno, J.; Faivre, S.; Raymond, E. Predictive factors of sensitivity to elisidepsin, a novel Kahalalide F-derived marine compound. Mar. Drugs 2013, 11, 944-959. [CrossRef]

811. Goldwasser, F.; Faivre, S.; Alexandre, J.; Coronado, C.; Fernandez-Garcia, E.M.; Kahatt, C.M.; Paramio, P.G.; Dios, J.L.; Miguel-Lillo, B.; Raymond, E. Phase I study of elisidepsin (IrvalecR) in combination with carboplatin or gemcitabine in patients with advancedmalignancies. Invest. New Drugs 2014, 32, 500-509. [CrossRef]

812. Ratain, M.J.; Geary, D.; Undevia, S.D.; Coronado, C.; Alfaro, V.; Iglesias, J.L.; Schilsky, R.L.; Miguel-Lillo, B. First-in-human, phase I study of elisidepsin (PM02734) administered as a 30-min or as a 3-hour intravenous infusion every three weeks in patients with advanced solid tumors. Invest. New Drugs 2015, 33, 901-910. [CrossRef] [PubMed]

813. Herrero, A.B.; Astudillo, A.M.; Balboa, M.A.; Cuevas, C.; Balsinde, J.; Moreno, S. Levels of SCS7/FA2H-mediated fatty acid 2-hydroxylation determine the sensitivity of cells to antitumor PM02734. Cancer Res. 2008, 68, 9779-9787. [CrossRef] [PubMed]

814. Váradi, T.; Roszik, J.; Lisboa, D.; Vereb, G.; Molina-Guijarro, J.M.; Galmarini, C.M.; Szöllősi, J.; Nagy, P. ErbB protein modifications are secondary to severe cell membrane alterations induced by elisidepsin treatment. Eur. J. Pharmacol. 2011, 667, 91-99. [CrossRef] [PubMed]

815. Molina-Guijarro, J.M.; García, C.; Macías, Á.; García-Fernández, L.F.; Moreno, C.; Reyes, F.; Martínez-Leal, J.F.; Fernández, R.; Martínez, V.; Valenzuela, C.; et al. Elisidepsin interacts directly with glycosylceramides in the plasma membrane of tumor cells to induce necrotic cell death. PLoS ONE 2015, 10, e0140782. [CrossRef]

816. Salazar, R.; Jones, R.J.; Oaknin, A.; Crawford, D.; Cuadra, C.; Hopkins, C.; Gil, M.; Coronado, C.; Soto-Matos, A.; Cullell-Young, M.; et al. A phase I and pharmacokinetic study of elisidepsin (PM02734) in patients with advanced solid tumors. Cancer Chemother. Pharmacol. 2012, 70, 673-681. [CrossRef] [PubMed]

817. Petty, R.; Anthoney, A.; Metges, J.P.; Alsina, M.; Gonçalves, A.; Brown, J.; Montagut, C.; Gunzer, K.; Laus, G.; Dios, J.L.I.; et al. Phase Ib/II study of elisidepsin in metastatic or advanced gastroesophageal cancer (IMAGE trial). Cancer Chemother. Pharmacol. 2016, 77, 819-827. [CrossRef]

818. Ciavatta, M.L.; Villani, G.; Trivellone, E.; Cimino, G. Two new labdane aldehydes from the skin of the notaspidean Pleurobranchaea meckelii. Tetrahedron Lett. 1995, 36, 8673-8676. [CrossRef]

819. Díaz-Marrero, A.R.; Dorta, E.; Cueto, M.; Rovirosa, J.; San Martín, A.; Loyola, L.A.; Darias, J. New polyhydroxylated steroids from the marine pulmonate Trimusculus peruvianus. Arkivoc J. Org. Chem. 2003, 10, 107-117. [CrossRef]

820. Rodriguez, J.; Riguera, R.; Debitus, C. The natural polypropionate-derived esters of the mollusk Onchidium sp. J. Org. Chem. 1992, 57, 4624-4632. [CrossRef]

821. Zhou, Z.F.; Li, X.L.; Yao, L.G.; Li, J.; Gavagnin, M.; Guo, Y.W. Marine bis- $\gamma$-pyrone polypropionates of onchidione family and their effects on the XBP1 gene expression. Bioorg. Med. Chem. Lett. 2018, 28, 1093-1096. [CrossRef]

822. Ireland, C.M.; Biskupiak, J.E.; Hite, G.J.; Rapposch, M.; Scheuer, P.J.; Ruble, J.R. Ilikonapyrone esters, likely defense allomones of the mollusk Onchidium verruculatum. J. Org. Chem. 1984, 49, 559-561. [CrossRef]

823. Arimoto, H.; Cheng, J.-F.; Nishiyama, S.; Yamamura, S. Synthetic studies on fully substituted $\gamma$-pyrone-containing natural products: The absolute configurations of ilikonapyrone and peroniatriols I and II. Tetrahedron Lett. 1993, 34, 5781-5784. [CrossRef]

824. Maschek, J.A. Chemical Investigation of the Antarctic Marine Invertebrates Austrodoris kerguelenensis \& Dendrilla membranosa and the Antarctic Red Alga Gigartina skottsbergii. Ph.D. Thesis, University of South Florida, Tampa, FL, USA, 2011.

825. Morgan, J.B.; Mahdi, F.; Liu, Y.; Coothankandaswamy, V.; Jekabsons, M.B.; Johnson, T.A.; Sashidhara, K.V.; Crews, P.; Nagle, D.G.; Zhou, Y.D. The marine sponge metabolite mycothiazole: A novel prototype mitochondrial complex I inhibitor. Bioorg. Med. Chem. 2010, 18, 5988-5994. [CrossRef] [PubMed]

826. Meyer, K.J.; Singh, A.J.; Cameron, A.; Tan, A.S.; Leahy, D.C.; O'Sullivan, D.; Joshi, P.; La Flamme, A.C.; Northcote, P.T.; Berridge, M.V.; et al. Mitochondrial genome-knockout cells demonstrate a dual mechanism of action for the electron transport complex I inhibitor mycothiazole. Mar. Drugs 2012, 10, 900-917. [CrossRef] [PubMed] 
827. Hamann, M.T.; Scheuer, P.J.; Kelly-Borges, M. Biogenetically diverse, bioactive constituents of a sponge, order Verongida: Bromotyramines and sesquiterpene-shikimate derived metabolites. J. Org. Chem. 1993, 58, 6565-6569. [CrossRef]

828. Kazlauskas, R.; Murphy, P.T.; Wells, R.J.; Noack, K.; Oberhansli, W.E.; Schonholzer, P. A new series of diterpenes from Australian Spongia species. Australian J. Chem. 1979, 32, 867-880. [CrossRef]

829. Pettit, G.R.; Herald, C.L.; Allen, M.S.; Von Dreele, R.B.; Vanell, L.D.; Kao, J.P.; Blake, W. Antineoplastic agents. 48. The isolation and structure of aplysistatin. J. Am. Chem. Soc. 1977, 99, 262-263. [CrossRef]

830. Fischbach, M.A.; Walsh, C.T. Antibiotics for emerging pathogens. Science 2009, 325, 1089-1093. [CrossRef]

831. Kubo, I.; Taniguchi, M. Polygodial, an antifungal potentiator. J. Nat. Prod. 1988, 51, 22-29. [CrossRef]

832. Benkendorff, K.; Davis, A.R.; Bremner, J.B. Chemical defense in the egg masses of benthic invertebrates: An assessment of antibacterial activity in 39 mollusks and 4 polychaetes. J. Invertebr. Pathol. 2001, 78, 109-118. [CrossRef]

833. El Sayed, K.A.; Bartyzel, P.; Shen, X.; Perry, T.L.; Zjawiony, J.K.; Hamann, M.T. Marine natural products as anti-tuberculosis agents. Tetrahedron 2000, 56, 949-953. [CrossRef]

834. Singh, E.K.; Ramsey, D.M.; McAlpine, S.R. Total synthesis of trans,trans-sanguinamide B and conformational isomers. Organic Lett. 2012, 14, 1198-1201. [CrossRef] [PubMed]

835. Wahyudi, H.; Tantisantisom, W.; Liu, X.; Ramsey, D.M.; Singh, E.K.; McAlpine, S.R. Synthesis, structure-activity analysis, and Biological Evaluation of Sanguinamide B Analogues. J. Org. Chem. 2012, 77, 10596-10616. [CrossRef] [PubMed]

836. Doralyn S., D.; Evan W., R.; Arthur S., E.; Tadeusz F., M. Structure Elucidation at the Nanomole Scale. 1. Trisoxazole Macrolides and Thiazole-Containing Cyclic Peptides from the Nudibranch Hexabranchus sanguineus. J. Nat. Prod. 2009, 72, 732-738.

837. Zhang, W.; Gavagnin, M.; Guo, Y.W.; Mollo, E.; Ghiselin, M.T.; Cimino, G. Terpenoid metabolites of the nudibranch Hexabranchus sanguineus from the South China Sea. Tetrahedron 2007, 63, 4725-4729. [CrossRef]

838. Guo, Y.; Gavagnin, M.; Mollo, E.; Trivellone, E.; Cimino, G.; Fakhr, I. Structure of the pigment of the Red Sea nudibranch Hexabranchus sanguineus. Tetrahedron Lett. 1998, 39, 2635-2638. [CrossRef]

839. He, H.; Faulkner, D.J. Renieramycins E and F from the sponge Reniera sp. Reassignment of the stereochemistry of the renieramycins. J. Org. Chem. 1989, 54, 5822-5824. [CrossRef]

840. Reddy, K.V.; Mohanraju, R.; Murthy, K.N.; Ramesh, C.; Karthick, P. Antimicrobial properties of nudibranchs tissues extracts from South Andaman, India. J. Coast. Life Med. 2015, 3, 582-584.

841. Fahey, S.J.; Carroll, A.R. Natural products isolated from species of Halgerda Bergh, 1880 (Mollusca: Nudibranchia) and their ecological and evolutionary implications. J. Chem. Ecol. 2007, 33, 1226-1234. [CrossRef]

842. Ishibashi, M.; Yamaguchi, Y.; Hirano, Y.J. Bioactive natural products from nudibranchs. In Biomaterials from Aquatic and Terrestrial Organisms; Fingerman, M., Nagabhushanam, R., Eds.; Science Publishers: Enfield, NH, USA, 2006; pp. 513-535.

843. Ramya, M.S.; Sivasubramanian, K.; Ravichandran, S.; Anbuchezhian, R. Screening of antimicrobial compound from the sea slug Armina babai. Bangladesh J. Pharmacol. 2014, 9, 268-274. [CrossRef]

844. Shin, J.; Seo, Y. Isolation of new ceramides from the gorgonian Acabaria undulata. J. Nat. Prod. 1995, 58, 948-953. [CrossRef]

845. Hay, M.E.; Pawlik, J.R.; Duffy, J.E.; Fenical, W. Seaweed-herbivore-predator interactions: Host-plant specialization reduces predation on small herbivores. Oecologia 1989, 81, 418-427. [CrossRef] [PubMed]

846. Paul, V.J.; Fenical, W. Chemical defense in tropical green algae, order Caulerpales. Mar. Ecol. Prog. Ser. 1986, 34, 157-169. [CrossRef]

847. Wright, A.D.; König, G.M.; Angerhofer, C.K.; Greenidge, P.; Linden, A.; Desqueyroux-Faundez, R. Antimalarial activity: The search for marine-derived natural products with selective antimalarial activity. J. Nat. Prod. 1996, 59, 710-716. [CrossRef] [PubMed]

848. Angerhofer, C.K.; Pezzuto, J.M.; König, G.M.; Wright, A.D.; Sticher, O. Antimalarial activity of sesquiterpenes from the marine sponge Acanthella klethra. J. Nat. Prod. 1992, 55, 1787-1789. [CrossRef] [PubMed]

849. Wright, A.D.; Wang, H.; Gurrath, M.; König, G.M.; Kocak, G.; Neumann, G.; Loria, P.; Foley, M.; Tilley, L. Inhibition of heme detoxification processes underlies the antimalarial activity of terpene isonitrile compounds from marine sponges. J. Med. Chem. 2001, 44, 873-885. [CrossRef] 
850. White, A.M.; Dao, K.; Vrubliauskas, D.; Könst, Z.A.; Pierens, G.K.; Mándi, A.; Andrews, K.T.; Skinner-Adams, T.S.; Clarke, M.E.; Narbutas, P.T.; et al. Catalyst-controlled stereoselective synthesis secures the structure of the antimalarial isocyanoterpene pustulosaisonitrile-1. J. Org. Chem. 2017, 82, 13313-13323. [CrossRef]

851. Yang, S.S.; Cragg, G.M.; Newman, D.J.; Bader, J.P. Natural product-based anti-HIV drug discovery and development facilitated by the NCI developmental therapeutics program. J. Nat. Prod. 2001, 64, 265-277. [CrossRef]

852. Newman, D.J.; Cragg, G.M.; Snader, K.M. The influence of natural products upon drug discovery. Nat. Prod. Rep. 2000, 17, 175-285. [CrossRef]

853. Gochfeld, D.J.; El Sayed, K.A.; Yousaf, M.; Hu, J.; Bartyzel, P.; Dunbar, D.C.; Wilkins, S.P.; Zjawiony, J.K.; Schinazi, R.F.; Schlueter-Wirtz, S.; et al. Marine natural products as lead anti-HIV agents. Mini-Rev. Med. Chem. 2003, 3, 401-424. [CrossRef]

854. Mitjà, O.; Clotet, B. Use of antiviral drugs to reduce COVID-19 transmission. Lancet Glob. Health 2020, 8, e639-e640. [CrossRef]

855. Wang, M.; Tietjen, I.; Chen, M.; Williams, D.E.; Daoust, J.; Brockman, M.A.; Andersen, R.J. Sesterterpenoids isolated from the sponge Phorbas sp. activate latent HIV-1 provirus expression. J. Org. Chem. 2016, 81, 11324-11334. [CrossRef] [PubMed]

856. Jacobs, R.S.; Bober, M.A.; Pinto, I.; Williams, A.B.; Jacobson, P.B.; de Carvalho, M.S. Pharmacological studies of marine novel marine metabolites. In Advances in Marine Biotechnology; Attaway, D.H., Zaborsky, O.R., Eds.; Plenum Press: New York, NY, USA, 1993; Volume 1, pp. 77-99.

857. Cimino, G.; De Stefano, S.; Minale, L. Scalaradial, a third sesterterpene with the tetracarbocyclic skeleton of scalarin, from the sponge Cacospongia mollior. Experientia 1974, 30, 846-847.

858. De Carvalho, M.S.; Jacobs, R.S. Two-step inactivation of bee venom phospholipase A2 by scalaradial. Biochem. Pharm. 1991, 42, 1621-1626. [CrossRef]

859. Oliveira, A.P.; Lobo-da-Cunha, A.; Taveira, M.; Ferreira, M.; Valentão, P.; Andrade, P.B. Digestive gland from Aplysia depilans Gmelin: Leads for inflammation treatment. Molecules 2015, 20, 15766-15780. [CrossRef]

860. Jiménez-Romero, C.; Mayer, A.M.; Rodriguez, A.D. Dactyloditerpenol acetate, a new prenylbisabolane-type diterpene from Aplysia dactylomela with significant in vitro anti-neuroinflammatory activity. Bioorg. Med. Chem. Lett. 2014, 24, 344-348. [CrossRef]

861. Mohammed, K.A.; Hossain, C.F.; Zhang, L.; Bruick, R.K.; Zhou, Y.D.; Nagle, D.G. Laurenditerpenol, a new diterpene from the tropical marine alga Laurencia intricata that potently inhibits HIF-1 mediated hypoxic signaling in breast tumor cells. J. Nat. Prod. 2004, 67, 2002-2007. [CrossRef]

862. Choi, D.Y.; Choi, H. Natural products from marine organisms with neuroprotective activity in the experimental models of Alzheimer's disease, Parkinson's disease and ischemic brain stroke: Their molecular targets and action mechanisms. Arch. Pharm. Res. 2015, 38, 139-170. [CrossRef]

863. Leiros, M.; Alonso, E.; Rateb, M.E.; Houssen, W.E.; Ebel, R.; Jaspars, M.; Alfonso, A.; Botana, L.M. Gracilins: Spongionella-derived promising compounds for Alzheimer disease. Neuropharmacol. 2015, 93, 285-293. [CrossRef]

864. Llorach-Pares, L.; Rodriguez-Urgelles, E.; Nonell-Canals, A.; Alberch, J.; Avila, C.; Sanchez-Martinez, M.; Giralt, A. Meridianins and Lignarenone B as Potential GSK3 $\beta$ Inhibitors and Inductors of Structural Neuronal Plasticity. Biomolecules 2020, 10, 639. [CrossRef]

865. Meijer, L.; Flajolet, M.; Greengard, P. Pharmacological inhibitors of glycogen synthase kinase 3. Trends Pharmacol. Sci. 2004, 25, 471-480. [CrossRef] [PubMed]

866. Sun, M.K.; Alkon, D.L. Bryostatin-1: Pharmacology and Therapeutic Potential as a CNS Drug. CNS Drug Rev. 2006, 12, 1-8. [CrossRef] [PubMed]

867. Cimino, G.; Spinella, A.; Sodano, G. Potential alarm pheromones from the Mediterranean opisthobranch Scaphander lignarius. Tetrahedron Lett. 1989, 30, 5003-5004. [CrossRef]

868. Davis, W.J.; Mpitsos, G.J. Behavioral choice and habituation in the marine mollusk Pleurobranchaea californica MacFarland (Gastropoda, Opisthobranchia). Z. Vgl. Physiol. 1971, 75, 207-232.

869. McNabb, P.; Selwood, A.I.; Munday, R.; Wood, S.A.; Taylor, D.I.; MacKenzie, L.A.; van Ginkel, R.; Rhodes, L.L.; Cornelisen, C.; Heasman, K.; et al. Detection of tetrodotoxin from the grey side-gilled sea slug Pleurobranchaea maculata, and associated dog neurotoxicosis on beaches adjacent to the Hauraki Gulf, Auckland, New Zealand. Toxicon 2010, 56, 466-473. [CrossRef] 
870. Salvitti, L.R.; Wood, S.A.; Winsor, L.; Cary, S.C. Intracellular immunohistochemical detection of tetrodotoxin in Pleurobranchaea maculata (Gastropoda) and Stylochoplana sp. (Turbellaria). Mar. Drugs 2015, 13, 756-769. [CrossRef]

871. Chau, R.; Kalaitzis, J.A.; Neilan, B.A. On the origins and biosynthesis of tetrodotoxin. Aquat. Toxicol. 2011, 104, 61-72. [CrossRef]

872. Salvitti, L.R.; Wood, S.A.; Fairweather, R.; Cary, S.C. In situ accumulation of tetrodotoxin in non-toxic Pleurobranchaea maculata (Opisthobranchia). Aquat. Sci. 2016, 79, 1-10. [CrossRef]

873. Böhringer, N.; Fisch, K.M.; Schillo, D.; Bara, R.; Hertzer, C.; Grein, F.; Eisenbarth, J.-H.; Kaligis, F.; Schneider, T.; Wägele, H.; et al. Antimicrobial potential of bacteria associated with marine sea slugs from North Sulawesi, Indonesia. Front. Microbiol. 2017, 8, 1092. [CrossRef]

874. Fisch, K.M.; Schäberle, T.F. Toolbox for antibiotics discovery from microorganisms. Arch. Pharm. 2016, 349, 683-691. [CrossRef]

875. Newman, D.J. Developing natural product drugs: Supply problems and how they have been overcome. Pharmacol. Ther. 2016, 162, 1-9. [CrossRef] [PubMed]

876. Hosta, L.; Pla-Roca, M.; Arbiol, J.; López-Iglesias, C.; Samitier, J.; Cruz, L.J.; Kogan, M.J.; Albericio, F. Conjugation of Kahalalide $\mathrm{F}$ with gold nanoparticles to enhance in vitro antitumoral activity. Bioconjugate Chem. 2009, 20, 138-146. [CrossRef] [PubMed]

Publisher's Note: MDPI stays neutral with regard to jurisdictional claims in published maps and institutional affiliations. 